\title{
Corrosion Performance of Candidate Materials for Canadian Gen IV Supercritical Water Cooled Reactor
}

by

\section{Rainier Garcia Sanchez}

A thesis submitted to the Faculty of Graduate and Postdoctoral Affairs in partial fulfillment of the requirements for the degree of

\author{
Master of Applied Science \\ in \\ Mechanical Engineering \\ Carleton University \\ Ottawa, Ontario
}


Corrosion Performance of Candidate Materials for Canadian Gen IV Supercritical Water Cooled Reactor

by

\section{Rainier Garcia Sanchez}

A thesis submitted to the Faculty of Graduate and Postdoctoral Affairs in partial fulfillment of the requirements for the degree of

\section{Master of Applied Science}

in

Mechanical Engineering

Professor Xiao Huang, Thesis Supervisor

Professor Metin I. Yaras, Chair, Department of Mechanical and Aerospace Engineering 


\section{Abstract}

Nuclear power plants have been an important source of energy in many countries for the last fifty years. The Canadian supercritical water cooled reactors (SCWR), among the Generation IV reactors, are currently being designed in Canada and many other countries. It presents challenges for many scientists and engineers due to the harsh environment in which the reactor must operate and the lack of knowledge of material's performance in this corrosive conditions of high temperature and pressure. This thesis entails the corrosion testing of four candidate materials, two nickel based alloys (IN 625 and A-286) and two stainless steels (AISI 304 and AISI 310), and microstructure evaluation of samples after being exposed to supercritical water (SCW), subcritical water (SubCW), and superheated steam.

Samples were ground to 600 grit finish and placed in an autoclave and a superheated steam rig to a maximum of three thousand hours and one thousand hours respectively. Procedures, based on the manufacturer's manuals, were created for the setup and operation of all the equipment. The temperature of all three tests was set to $625^{\circ} \mathrm{C}$ with a pressure of $29 \mathrm{MPa}$ (SCW), $8 \mathrm{MPa}$ (subcritical water) or ambient (superheated steam). The surface morphology and composition were analyzed using scanning electron microscope (SEM) imaging and energydispersive X-ray spectroscopy (EDS).

Results from this study show a poor corrosion performance, in terms of surface oxide formation and weight change, for A-286 and AISI 304 in all conditions due to their low chromium content. AISI 310 and IN 625, with higher chromium content, exhibit an excellent corrosion resistance in almost all conditions, except for the superheated steam test where oxide spallation may have 
taken place. The excellent performance (in terms of minimum weight change) of these two materials makes them promising candidate materials for further evaluation in long tests. A general observation obtained thus far suggests that supercritical water yields a lower corrosion than the subcritical water. The superheated steam and the supercritical water tests are not analogous. The results obtained will be useful in future research of test protocol and development of alloys that could be used as reactor fuel cladding and other components transporting fluid in the SCWR. 


\section{Acknowledgements}

This thesis project has been an important challenge in all aspects. Without the help and guidance of many people it wouldn't have been possible to accomplish. First, I would like to thank my supervisor Dr. Xiao Huang for trusting me in this project and for her help, support and guidance through the entire process.

I would like to thank Fred Barrett for his help and teaching in the use and setup of the all equipment. I would also like to thank Dr. Jianqun Wang for helping in achieving the best possible results in the SEM and EDS analysis. A special thank you to all the machine shop's personnel that helped out in the cutting and drilling of samples.

A special thank to my wife: Adianés Garcia, for her help and support during the last two years. I would like to thank my family for their enormous sacrifice and support throughout my entire academic career. Finally, I would like to thank God for filling me with his patience and understanding, for always being my best friend. 


\section{Table of Contents}

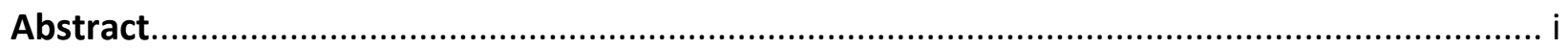

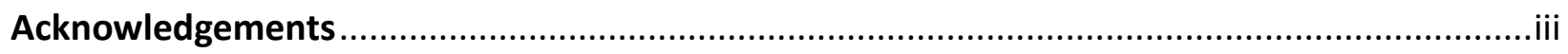

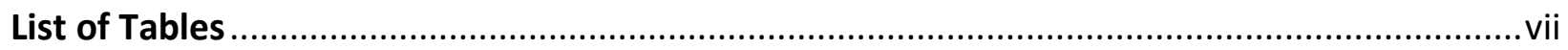

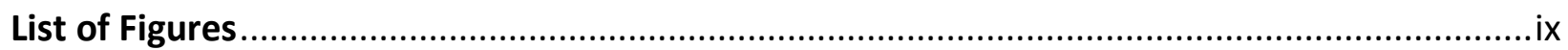

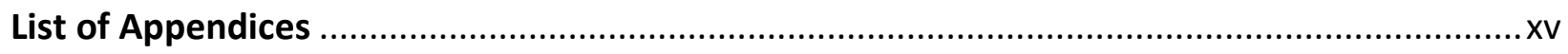

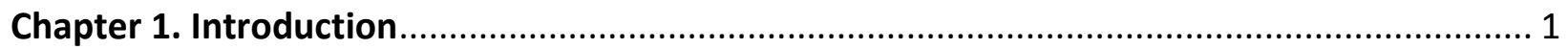

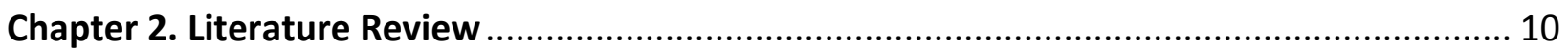

2.1 Nuclear Reactor for Power Generation............................................................. 10

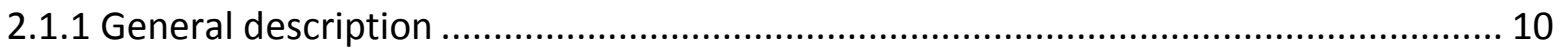

2.1.2 CANDU I and CANDU II operating principle....................................................... 11

2.2 Oxidation and Corrosion in Supercritical Water .......................................................... 13

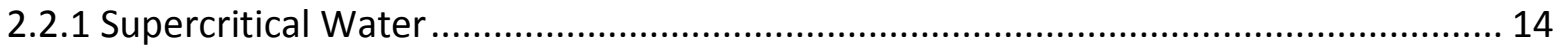

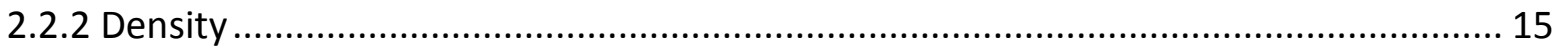

2.2.3 Polarity, Dielectric Constant and Hydrogen Bonding ........................................... 16

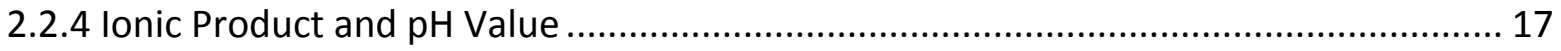

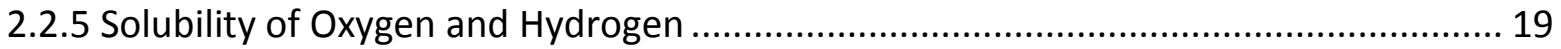

2.3 Types of Corrosion and Parameters Influencing Corrosion ........................................ 19

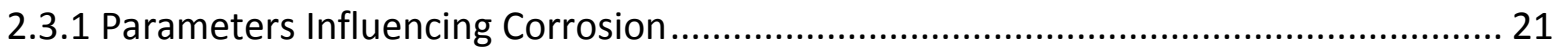

2.4 Oxidation and Corrosion in Superheated Steam ....................................................... 30

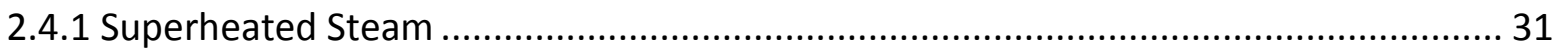

2.4.2 Alloying Addition and Their Roles in Oxidation and Corrosion Prevention ................ 31

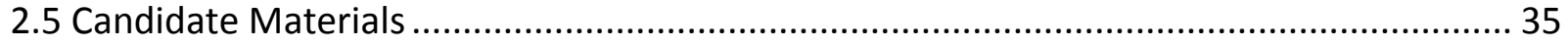

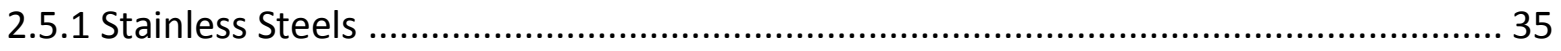




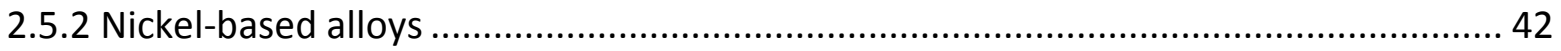

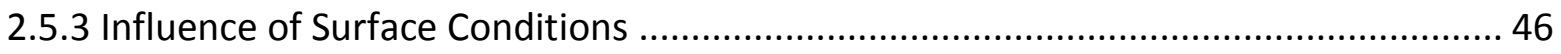

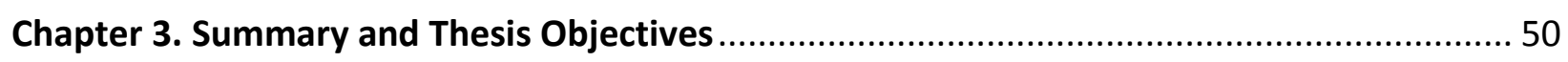

Chapter 4. Materials and Experimental Procedures .............................................................. 52

4.1 Materials and Composition ...................................................................................... 52

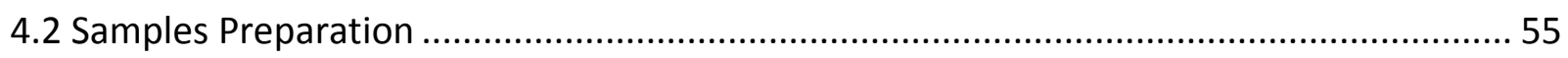

4.3 Testing in Supercritical and Subcritical Water Autoclave ............................................... 56

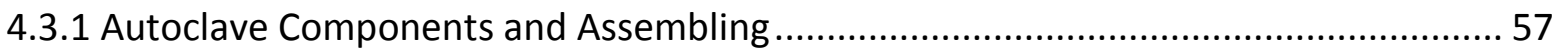

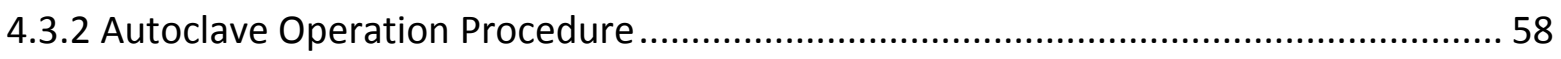

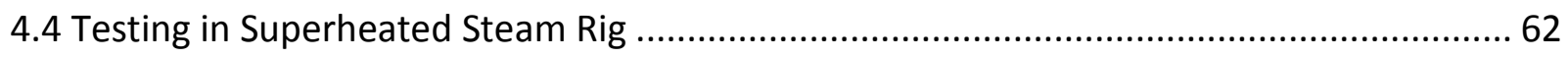

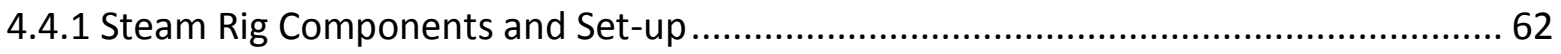

4.4.2 Superheated Steam Rig Operation Procedure ……………………………............... 67

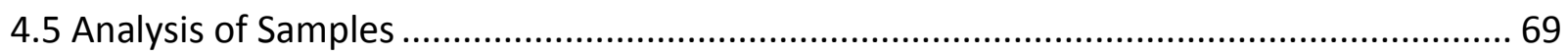

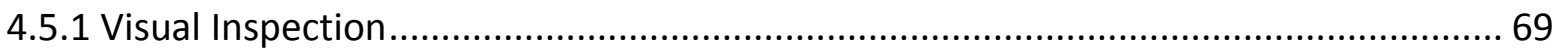

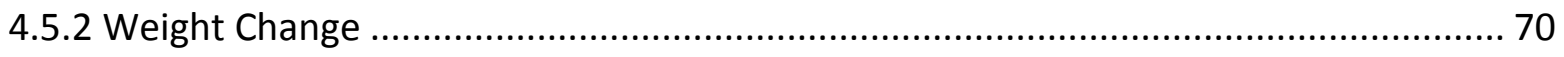

4.5.3 Scanning Electron Microscope (SEM) and Energy Dispersive X-Ray Spectrometry (EDS)

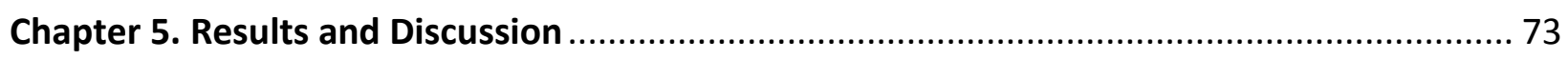

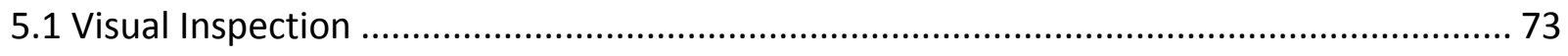

5.1.1 Effects of Testing Duration and Pressure in Sub- and Supercritical Samples .............. 74

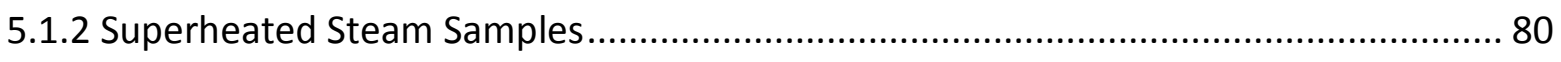

5.1.3 Effects of Substrate Material................................................................................... 82

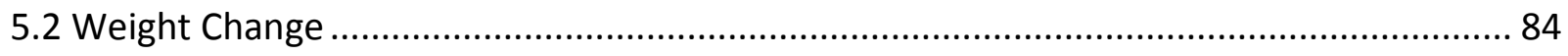

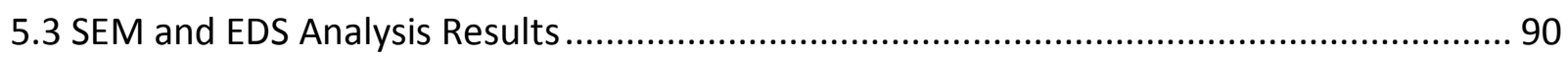




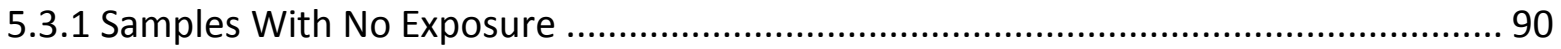

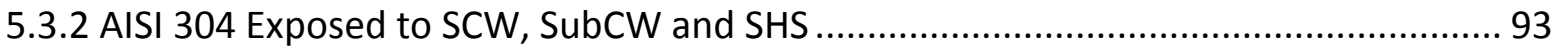

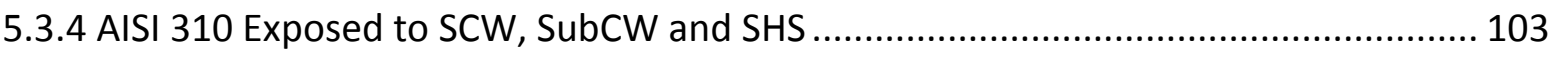

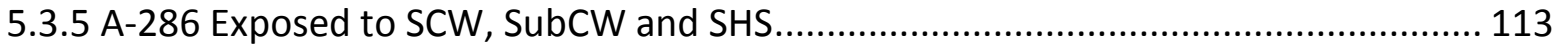

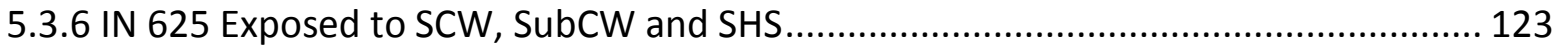

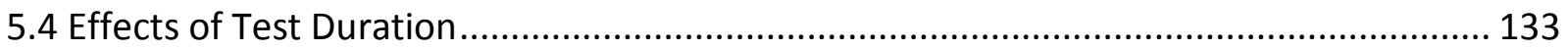

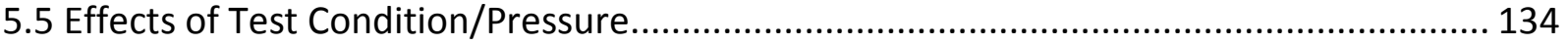

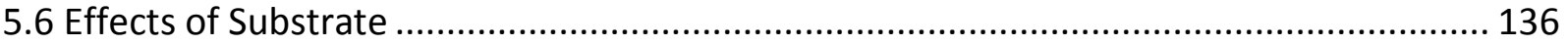

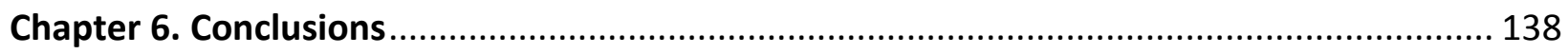

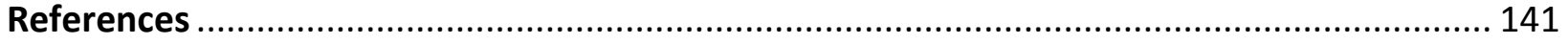

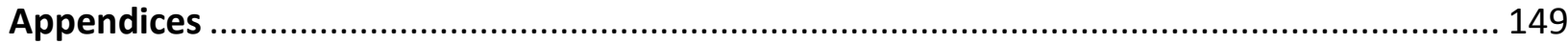




\section{List of Tables}

Table 1. Some details about Gen IV systems [5] .......................................................... 3

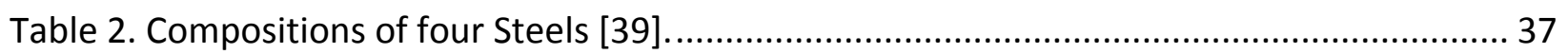

Table 3. Compositions of Selected Ni-based Alloys and Stainless Steels [43].......................... 45

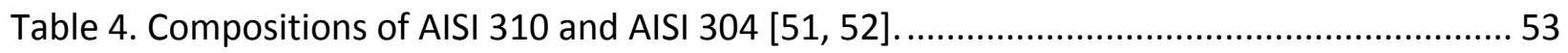

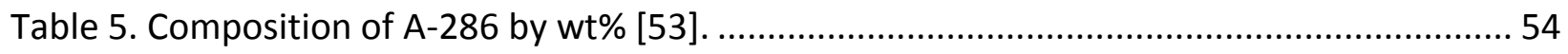

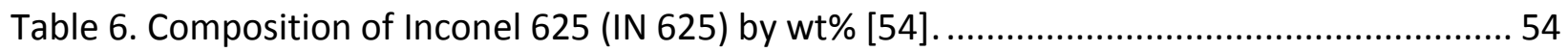

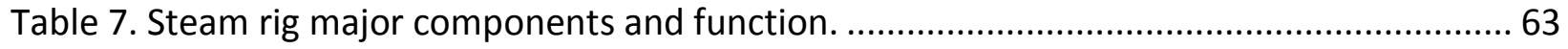

Table 8. Samples' surface appearance before any type of exposure.................................... 74

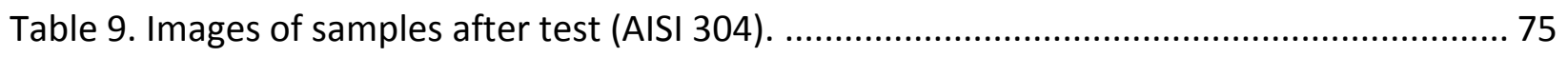

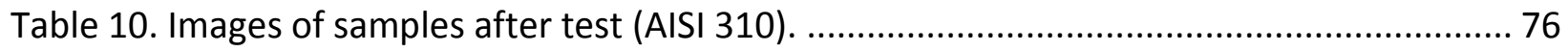

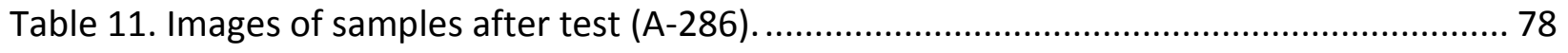

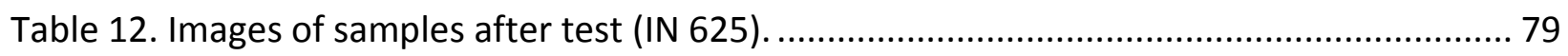

Table 13. Images of samples after superheated steam test................................................ 81

Table 14. Images of samples tested in supercritical water for 3000 hours.............................. 82

Table 15. Images of samples tested in subcritical water for 3000 hours.............................. 83

Table 16. Images of samples tested in superheated steam for 1000 hours. ............................. 84

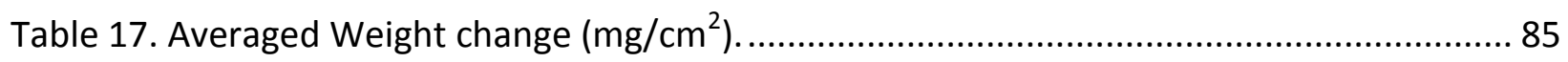

Table 18. Averaged weight change in superheated steam samples $\left(\mathrm{mg} / \mathrm{cm}^{2}\right)$.................... 87

Table 19. Maximum specified and EDS chemical compositions for untested materials............. 93

Table 20. EDS chemical composition of AISI 304 exposed to SCW......................................... 97

Table 21. EDS chemical composition of AISI 304 exposed to SubCW. ................................. 101 
Table 22. EDS chemical composition of AISI 304 exposed to superheated steam.................. 103

Table 23. EDS chemical composition of AISI 310 exposed to SCW...................................... 106

Table 24. EDS chemical composition of AISI 310 exposed to SubCW. .................................. 110

Table 25. EDS chemical composition of AISI 310 exposed to superheated steam.................. 113

Table 26. EDS chemical composition of A-286 exposed to supercritical water. ..................... 117

Table 27. EDS chemical composition of A-286 exposed to subcritical water......................... 120

Table 28. EDS chemical composition of A-286 exposed to superheated steam..................... 123

Table 29. EDS chemical composition of IN 625 exposed to supercritical water. ..................... 127

Table 30. EDS chemical composition of IN 625 exposed to subcritical water........................ 130

Table 31. EDS chemical composition of IN 625 exposed to superheated steam. ................... 133 


\section{List of Figures}

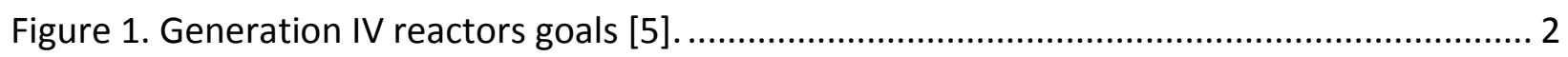

Figure 2. Supercritical water cooled reactor - a simplified schematic diagram [4]...................... 5

Figure 3. Pressure-temperature diagram of water for typical operating conditions of SCWRs,

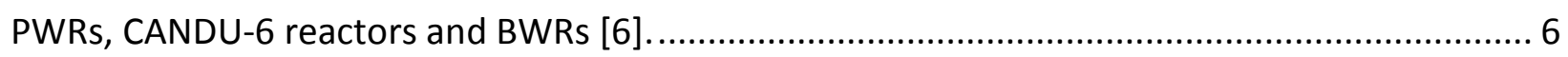

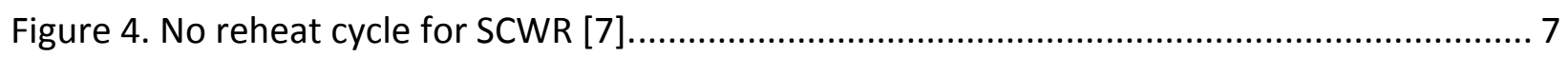

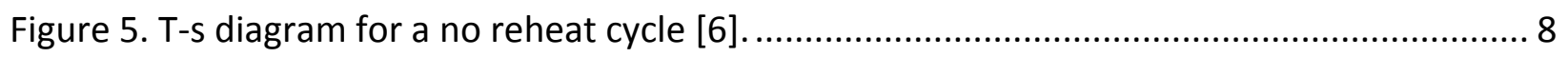

Figure 6. Schematic diagram of a nuclear power plant using a CANDU reactor [10]................. 12

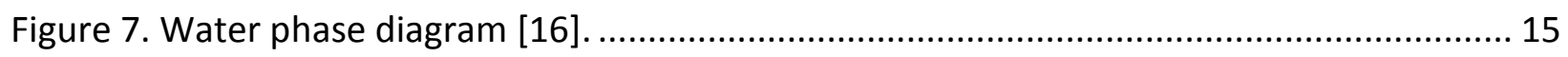

Figure 8. Water physical properties variation with temperature at pressure value of $25 \mathrm{MPa}$

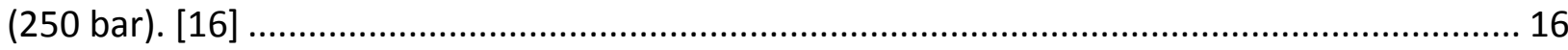

Figure 9. Hydrogen bonding in water at ambient temperature [17] .................................... 17

Figure 10. lonic product of high-temperatures water vs. different pressures [18] .................... 18

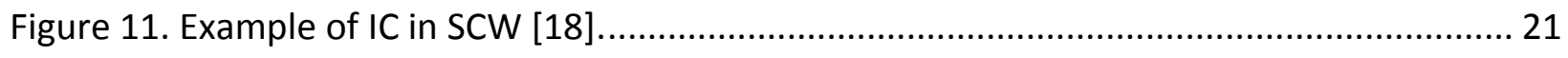

Figure 12. A general Pourbaix diagram for alloys oxide layers [18] ........................................... 23

Figure 13. Pourbaix diagram of the $\mathrm{Fe}-\mathrm{H}_{2} \mathrm{O}$ system at $400^{\circ} \mathrm{C}, 25 \mathrm{MPa}$, and $10^{-12}$ molar [29] ..... 24

Figure 14. Pourbaix diagram of the $\mathrm{Ni}-\mathrm{H}_{2} \mathrm{O}$ system at $400^{\circ} \mathrm{C}, 25 \mathrm{MPa}$, and $10^{-8}$ molar [29]....... 25

Figure 15. Pourbaix diagram of the $\mathrm{Cr}-\mathrm{H}_{2} \mathrm{O}$ system at $400^{\circ} \mathrm{C}, 25 \mathrm{MPa}$, and $10^{-8}$ molar [29]........ 25

Figure 16. Schematic diagram of forming soluble chromates in acidic and alkaline solution [19].

Figure 17. Interdependences of the corrosion factors in high-temperature water solutions [19]. 
Figure 18. Experimental corrosion rates of general corrosion for two values of pressure caused by $\mathrm{HCl}$ solution [18]. 29

Figure 19. Density range of high corrosion at different temperatures [18]...... 30

Figure 20. Metal loss rate as a function of chromium content for selected materials under

simulated fireside corrosion conditions [33]. 34

Figure 21. Effect of increasing the Si content in $9 \mathrm{Cr}-1$ Mo Steel [33]. 35

Figure 22. SEM image of the cross-section of oxide formed on Alloy $800 \mathrm{H}$ exposed to SCW at $500^{\circ} \mathrm{C}[41]$ 36

Figure 23. Loss of weight after descaling at various temperature and pressure of a) A: SUS

347HTB, B: 17- 14CuMo b) C: 20Cr-25Ni, D: 22Cr-35Ni [39]. 38

Figure 24. Surface oxide morphology in stainless steel $304 \mathrm{NG}$ after exposure to SCW at $650^{\circ} \mathrm{C}$ for $1000 h$ [41]. 39

Figure 25. Effects of $\mathrm{Cr}$ content and grain size of austenitic stainless steel on steam oxidation [33]. 40

Figure 26. Corrosion of stainless steels a) in static oxygenated steam at $600^{\circ} \mathrm{C}$, b) in flowing steam at $650^{\circ} \mathrm{C}$, and steam velocity of $61 \mathrm{~m} / \mathrm{s}[43]$ 41

Figure 27. Oxides formed on AISI 304L surface during steam exposure: (a) polished and exposed

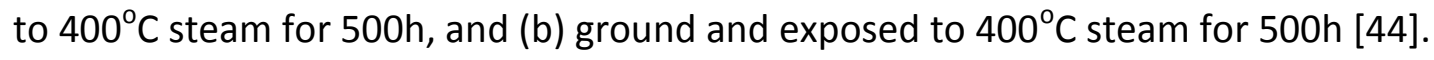
42 Figure 28. Weight gain as a function of exposure time for IN 625 in low oxygen concentration water $(0.02-0.025 \mathrm{ppm})$ at $360^{\circ} \mathrm{C}, 500^{\circ} \mathrm{C}$, and $600^{\circ} \mathrm{C}[40]$ 43 Figure 29 (a) Grain boundary region lacking of $\mathrm{Ni}(\mathrm{b})$ Inner layer with $\mathrm{Cr}$ depletion [40]. 44 Figure 30. Corrosion of nickel alloys in flowing steam at $650^{\circ} \mathrm{C}$ and $61 \mathrm{~m} / \mathrm{s}$ velocity [43]. 45 
Figure 31. Corrosion of AISI 304 in autoclaves: (a) (left) $300^{\circ} \mathrm{C}$ in autoclave (b) (right) Flowing

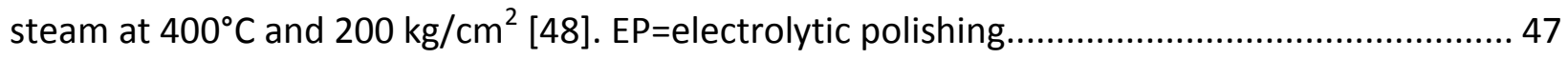

Figure 32. Total corrosion of AISI 304 in 1000 hr in superheated steam (autoclaves) [48]........ 48

Figure 33. Position of holes for samples of each material, from left to right: A-286, IN 625, AISI

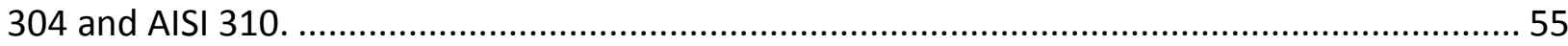

Figure 34. a) Autoclave with closure assembly. b) Metal stand with ceramic rods inserted....... 58

Figure 35. a) Diagram indicating components of self-sealer. b) Autoclave self-sealer closure

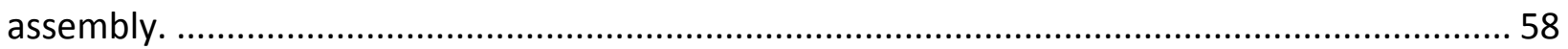

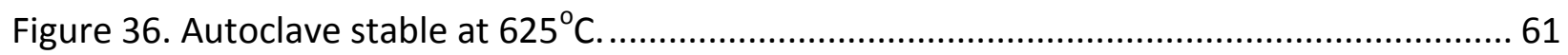

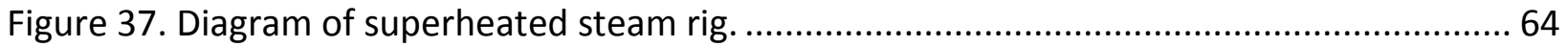

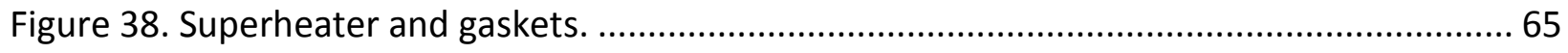

Figure 39. Superheater steam sample stand with ceramic rods. ....................................... 66

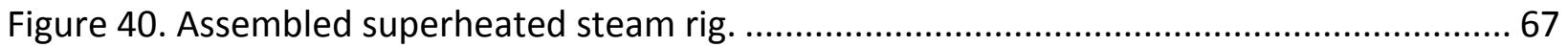

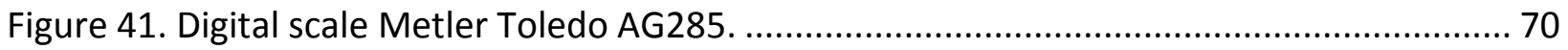

Figure 42. Line graph of $\mathrm{mg} / \mathrm{cm}^{2}$ vs. time for supercritical $\left(625^{\circ} \mathrm{C}, 29 \mathrm{MPa}\right)$ and subcritical

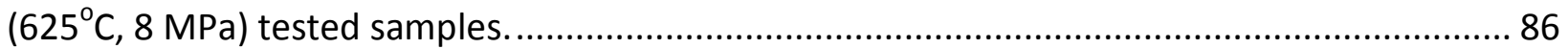

Figure 43. Weight gain of samples exposed to superheated steam $\left(625^{\circ} \mathrm{C}, 0.1 \mathrm{MPa}\right) \ldots \ldots \ldots \ldots . . . . .88$

Figure 44. Bar graph of weight change $\mathrm{mg} / \mathrm{cm}^{2}$ vs. test condition for all samples tested for 1000

hours.

Figure 45. SEM images (BSE left, SE right) of unexposed AISI 304 at $1 \mathrm{kx}$ (top) and 5kx (bottom). 
Figure 46. SEM images (BSE left, SE right) of unexposed AISI 310 at $1 \mathrm{kx}$ (top) and 5kx (bottom).

Figure 47. SEM images (BSE left, SE right) of unexposed A-286 at $1 \mathrm{kx}$ (top) and 5kx (bottom). . 92

Figure 48. SEM images (BSE left, SE right) of unexposed IN 625 at $1 \mathrm{kx}$ (top) and 5kx (bottom). 92

Figure 49. SEM surface images of AISI 304 exposed to SCW $\left(625^{\circ} \mathrm{C}, 29 \mathrm{MPa}\right)$ for $1000 \mathrm{~h} . . . \ldots \ldots . . .94$

Figure 50. SEM surface images of AISI 304 exposed to SCW $\left(625^{\circ} \mathrm{C}, 29 \mathrm{MPa}\right)$ for $2000 \mathrm{~h} . . . \ldots \ldots . . .95$

Figure 51. SEM surface images of AISI 304 exposed to SCW $\left(625^{\circ} \mathrm{C}, 29 \mathrm{MPa}\right)$ for $3000 \mathrm{~h} . . . \ldots \ldots . . . .96$

Figure 52. SEM surface images of AISI 304 exposed to SubCW $\left(625^{\circ} \mathrm{C}, 8 \mathrm{MPa}\right)$ for $1000 \mathrm{~h} . \ldots \ldots . .98$

Figure 53. SEM surface images of AISI 304 exposed to SubCW $\left(625^{\circ} \mathrm{C}, 8 \mathrm{MPa}\right)$ for $2000 \mathrm{~h} . \ldots . . . .99$

Figure 54. SEM surface images of AISI 304 exposed to SubCW $\left(625^{\circ} \mathrm{C}, 8 \mathrm{MPa}\right)$ for $3000 \mathrm{~h} . \ldots . . .100$

Figure 55. SEM surface images of AISI 304 exposed to superheated steam $\left(625^{\circ} \mathrm{C}, 0.1 \mathrm{MPa}\right)$ for

350h. 101

Figure 56. SEM surface images of AISI 304 exposed to superheated steam $\left(625^{\circ} \mathrm{C}, 0.1 \mathrm{MPa}\right)$ for

700h. 102

Figure 57. SEM surface images of AISI 304 exposed to superheated steam $\left(625^{\circ} \mathrm{C}, 0.1 \mathrm{MPa}\right)$ for

1000h. 103

Figure 58. SEM surface images of AISI 310 exposed to SCW $\left(625^{\circ} \mathrm{C}, 29 \mathrm{MPa}\right)$ for $1000 \mathrm{~h} . . . \ldots . . .104$

Figure 59. SEM surface images of AISI 310 exposed to SCW $\left(625^{\circ} \mathrm{C}, 29 \mathrm{MPa}\right)$ for $2000 \mathrm{~h} . . . \ldots . . .105$

Figure 60. SEM surface images of AISI 310 exposed to SCW $\left(625^{\circ} \mathrm{C}, 29 \mathrm{MPa}\right)$ for $3000 \mathrm{~h} . . . \ldots . . . .106$

Figure 61. SEM surface images of AISI 310 exposed to SubCW (625 $\mathrm{C}, 8 \mathrm{MPa})$ for $1000 \mathrm{~h} . \ldots . . .107$

Figure 62. SEM surface images of AISI 310 exposed to SubCW $\left(625^{\circ} \mathrm{C}, 8 \mathrm{MPa}\right)$ for $2000 \mathrm{~h} . \ldots . . .108$

Figure 63. SEM surface images of AISI 310 exposed to SubCW $\left(625^{\circ} \mathrm{C}, 8 \mathrm{MPa}\right)$ for $3000 \mathrm{~h} . \ldots . . .109$ 
Figure 64. SEM surface images of AISI 310 exposed to superheated steam $\left(625^{\circ} \mathrm{C}, 0.1 \mathrm{MPa}\right)$ for $350 h$. 111

Figure 65. SEM surface images of AISI 310 exposed to superheated steam $\left(625^{\circ} \mathrm{C}, 0.1 \mathrm{MPa}\right)$ for

700h. 111

Figure 66. SEM surface images of AISI 310 exposed to superheated steam $\left(625^{\circ} \mathrm{C}, 0.1 \mathrm{MPa}\right)$ for 1000h. 112

Figure 67. SEM surface images of A-286 exposed to SCW $\left(625^{\circ} \mathrm{C}, 29 \mathrm{MPa}\right)$ for $1000 \mathrm{~h}$. 114

Figure 68. SEM surface images of A-286 exposed to SCW $\left(625^{\circ} \mathrm{C}, 29 \mathrm{MPa}\right)$ for $2000 \mathrm{~h}$. 114

Figure 69. SEM surface images of A-286 exposed to SCW $\left(625^{\circ} \mathrm{C}, 29 \mathrm{MPa}\right)$ for $3000 \mathrm{~h}$. 116

Figure 70. SEM surface images of A-286 exposed to SubCW (625 $\mathrm{C}, 8 \mathrm{MPa})$ for $1000 \mathrm{~h}$. 118

Figure 71. SEM surface images of A-286 exposed to SubCW (625 $\mathrm{C}, 8 \mathrm{MPa})$ for $2000 \mathrm{~h}$. 118

Figure 72. SEM surface images of A-286 exposed to SubCW $\left(625^{\circ} \mathrm{C}, 8 \mathrm{MPa}\right)$ for $3000 \mathrm{~h}$. 119

Figure 73. SEM surface images of A-286 exposed to superheated steam $\left(625^{\circ} \mathrm{C}, 0.1 \mathrm{MPa}\right)$ for 350h.

Figure 74. SEM surface images of A-286 exposed to superheated steam $\left(625^{\circ} \mathrm{C}, 0.1 \mathrm{MPa}\right)$ for 700h. 122

Figure 75. SEM surface images of A-286 exposed to superheated steam ( $\left.625^{\circ} \mathrm{C}, 0.1 \mathrm{MPa}\right)$ for 1000h. 122

Figure 76. SEM surface images of IN 625 exposed to SCW $\left(625^{\circ} \mathrm{C}, 29 \mathrm{MPa}\right)$ for $1000 \mathrm{~h}$. 124

Figure 77. SEM surface images of IN 625 exposed to SCW $\left(625^{\circ} \mathrm{C}, 29 \mathrm{MPa}\right)$ for $2000 \mathrm{~h}$. 125

Figure 78. SEM surface images of IN 625 exposed to SCW $\left(625^{\circ} \mathrm{C}, 29 \mathrm{MPa}\right)$ for $3000 \mathrm{~h}$. 126

Figure 79. SEM surface images of IN 625 exposed to SubCW $\left(625^{\circ} \mathrm{C}, 8 \mathrm{MPa}\right)$ for $1000 \mathrm{~h}$. 128 
Figure 80. SEM surface images of IN 625 exposed to SubCW $\left(625^{\circ} \mathrm{C}, 8 \mathrm{MPa}\right)$ for $2000 \mathrm{~h}$.

Figure 81. SEM surface images of IN 625 exposed to SubCW $\left(625^{\circ} \mathrm{C}, 8 \mathrm{MPa}\right)$ for $3000 \mathrm{~h} . \ldots \ldots \ldots 129$ Figure 82. SEM surface images of IN 625 exposed to superheated steam $\left(625^{\circ} \mathrm{C}, 0.1 \mathrm{MPa}\right)$ for 350h.

Figure 83. SEM surface images of IN 625 exposed to superheated steam $\left(625^{\circ} \mathrm{C}, 0.1 \mathrm{MPa}\right)$ for 700h. 131

Figure 84. SEM surface images of IN 625 exposed to superheated steam $\left(625^{\circ} \mathrm{C}, 0.1 \mathrm{MPa}\right)$ for 1000h. 


\section{List of Appendices}

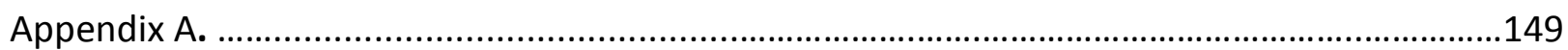

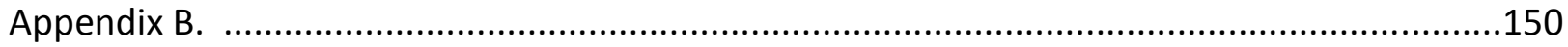

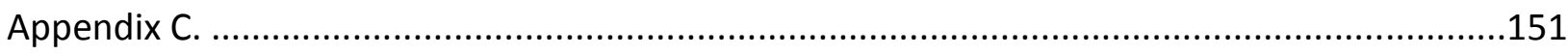




\section{Chapter 1. Introduction}

As a result of our need for improved quality of life, energy demand has been on the rise in the past few decades. With even greater demand in the years to come, we will face many challenges such as environmental concerns and energy resources. Among the variety of means used to produce electric energy, none of them are considered to be ideal. They have advantages and disadvantages, mainly associated with the capacity of meeting huge demands, the by-products generated by heat producing reaction, geographical issues, and wastes from the whole energy producing process that need to be managed.

Nuclear power plant has the ability to provide low greenhouse gas emissions and is able to meet increasing energy demand as a result of accelerated growth of world's population and industrialization. Nuclear energy is also an important alternative to overcome the rising fossil fuel cost in the last years. Many countries are using this type of energy production this days, with the overall nuclear power worldwide represents $13.4 \%$ of the total electricity generated by all means in 2009 [1]. Of the countries where nuclear energy is used as a partial source of electricity, France takes the lead, with $76 \%$ of the total electricity produced by nuclear plants. The United States are reported to have the highest installed nuclear capacity (101 GW) in 2010 $[2,3]$. These numbers will increase despite many nuclear plants being shut down or reaching their lifetime. In addition, many countries are in the process to construct more new nuclear reactors; this will increase more significantly in future years once the more efficient next generations of nuclear reactors, particularly Gen IV, are in the market. 
With the purpose of consolidating the design effort internationally and taking the lead in the development of future nuclear energy systems the Generation IV International Forum (GIF) was created. This forum was formed by nine of the developed countries (including Canada) in the world; they were also the bigger producers of nuclear energy for domestic and industrial use [4]. The goals of the new reactor designs were clearly defined into four main categories: sustainability, safety and reliability, economics and proliferation resistance and physical protection [5]. More detailed explanation is provided in Figure 1.

\section{Generation IV Goals}

\section{Sustainability}

1. Generate energy sustainably, and promote long-term availability of nuclear fuel

2. Minimize nuclear waste and reduce the long term stewardship burden

\section{Safety \& Reliability}

3. Excel in safety and reliability

4. Have a very low likelihood and degree of reactor core damage

5. Eliminate the need for offsite emergency response

\section{Economics}

6. Have a life cycle cost advantage over other energy sources

7. Have a level of financial risk comparable to other energy projects

\section{Proliferation Resistance \& Physical Protection}

8. Be a very unattractive route for diversion or theft of weapons-usable materials, and provide increased physical protection against acts of terrorism

Figure 1. Generation IV reactors goals [5].

Out of the work developed by the GIF since its inception, six designs are considered to be the most promising ones for Gen IV reactors. These are: Gas-Cooled Fast Reactor (GFR), LeadCooled Fast Reactor (LFR), Molten Salt Reactor (MSR), Sodium-Cooled Fast Reactor (SFR), 
Supercritical-Water Reactor (SCWR) and Very-High-Temperature Reactor (VHTR). As their names suggest, the main differences between all of these reactors are the type of coolant and moderator used as well as the temperature region in which they operate. Table 1 provides more details about these systems.

Table 1. Some details about Gen IV systems [5].

\begin{tabular}{|c|c|c|c|c|c|c|}
\hline System & $\begin{array}{l}\text { Neutron } \\
\text { Spectrum }\end{array}$ & $\begin{array}{l}\text { Fuel } \\
\text { Cycle }\end{array}$ & Coolant & $\begin{array}{l}\text { Size } \\
\text { (MWe) }\end{array}$ & Applications & R\&D Needed \\
\hline $\begin{array}{l}\text { Supercritical-Water } \\
\text { Reactor (SCWR) }\end{array}$ & Thermal, Fast & $\begin{array}{l}\text { Open, } \\
\text { Closed }\end{array}$ & Water & 1500 & Electricity & $\begin{array}{l}\text { Materials, Thermal- } \\
\text { hydraulics }\end{array}$ \\
\hline $\begin{array}{l}\text { Lead Cooled Fast } \\
\text { Reactor (LCFR) }\end{array}$ & Fast & Closed & $\begin{array}{l}\text { Lead- } \\
\text { Bismuth }\end{array}$ & $\begin{array}{l}50-150 \\
300-600 \\
1200\end{array}$ & $\begin{array}{l}\text { Electricity, Hydrogen } \\
\text { Production }\end{array}$ & Fuels, Materials \\
\hline $\begin{array}{l}\text { Molten Salt Reactor } \\
\text { (MSR) }\end{array}$ & Epithermal & Closed & $\begin{array}{l}\text { Fluoride } \\
\text { salts }\end{array}$ & 1000 & $\begin{array}{ll}\text { Electricity, } & \text { Hydrogen } \\
\text { Production, } & \text { Actinide } \\
\text { Management } & \end{array}$ & $\begin{array}{l}\text { Fuel Treatment, } \\
\text { Materials, } \\
\text { Reliability }\end{array}$ \\
\hline $\begin{array}{l}\text { Very-High- } \\
\text { Temperature Reactor } \\
\text { (VHTR) }\end{array}$ & Thermal & Open & Helium & 250 & $\begin{array}{l}\text { Electricity, Hydrogen, } \\
\text { Process Heat }\end{array}$ & $\begin{array}{l}\text { Fuel, Materials, } \mathrm{H}_{2} \\
\text { production }\end{array}$ \\
\hline $\begin{array}{lr}\text { Gas-Cooled } & \text { Fast } \\
\text { Reactor (GFR) } & \end{array}$ & Fast & Closed & Helium & $\begin{array}{l}200- \\
1200\end{array}$ & $\begin{array}{l}\text { Electricity, Hydrogen, } \\
\text { Actinide Management }\end{array}$ & $\begin{array}{l}\text { Fuels, Materials, } \\
\text { Thermal-hydraulics }\end{array}$ \\
\hline $\begin{array}{l}\text { Sodium Cooled Fast } \\
\text { Reactor (SFR) }\end{array}$ & Fast & Closed & Sodium & $\begin{array}{l}300- \\
1500\end{array}$ & $\begin{array}{l}\text { Electricity, Actinide } \\
\text { Management }\end{array}$ & $\begin{array}{l}\text { Advanced Recycle } \\
\text { Options, Fuels }\end{array}$ \\
\hline
\end{tabular}

Canada has been an active member of the GIF since the beginning. A national program for Generation IV Energy Technologies was established in 2006 by National Resources Canada (NRCan) to support the collaboration in research and development internationally and within 
the country for the development of the Gen IV technology. In 2010 Canada was assigned to work in two of the six candidate systems: SCWR and VHTR. The SCWR is an evolution of the existing CANDU nuclear systems used in Canada. The knowledge and experience accumulated in 40 years of designing and operating CANDU reactors in Canada will be a great asset in the development of the SCWR technology. The main focus of the Gen IV R\&D program currently is on thermohydraulics, safety, materials and chemistry.

The SCWR is a high pressure high temperature system that employs water, above supercritical point, as a coolant (a term used in nuclear industry to represent working fluid in a thermodynamic system). The current design of the SCWR allows for a simplified plant, as shown in a schematic diagram (Figure 2). Here a single turbine represents both the high pressure and low pressure turbines as a whole. The design of SCWRs with single-phase coolant (SCW working fluid) is regarded as the most promising advanced nuclear systems because of their high thermodynamic efficiency [i.e., about $45 \%$ vs. $33 \%$ of current light water reactors (LWRs)] and considerable plant simplification. The high operating pressure and temperature thermodynamic conditions ( $>374^{\circ} \mathrm{C}$ and $22 \mathrm{MPa}$ ) utilized in SCWRs ensure this superior thermal efficiency by reducing the containment volume and eliminating the need for recirculation and other hardware such as jet pumps, pressurizers, steam generators, steam separators and dryers. 


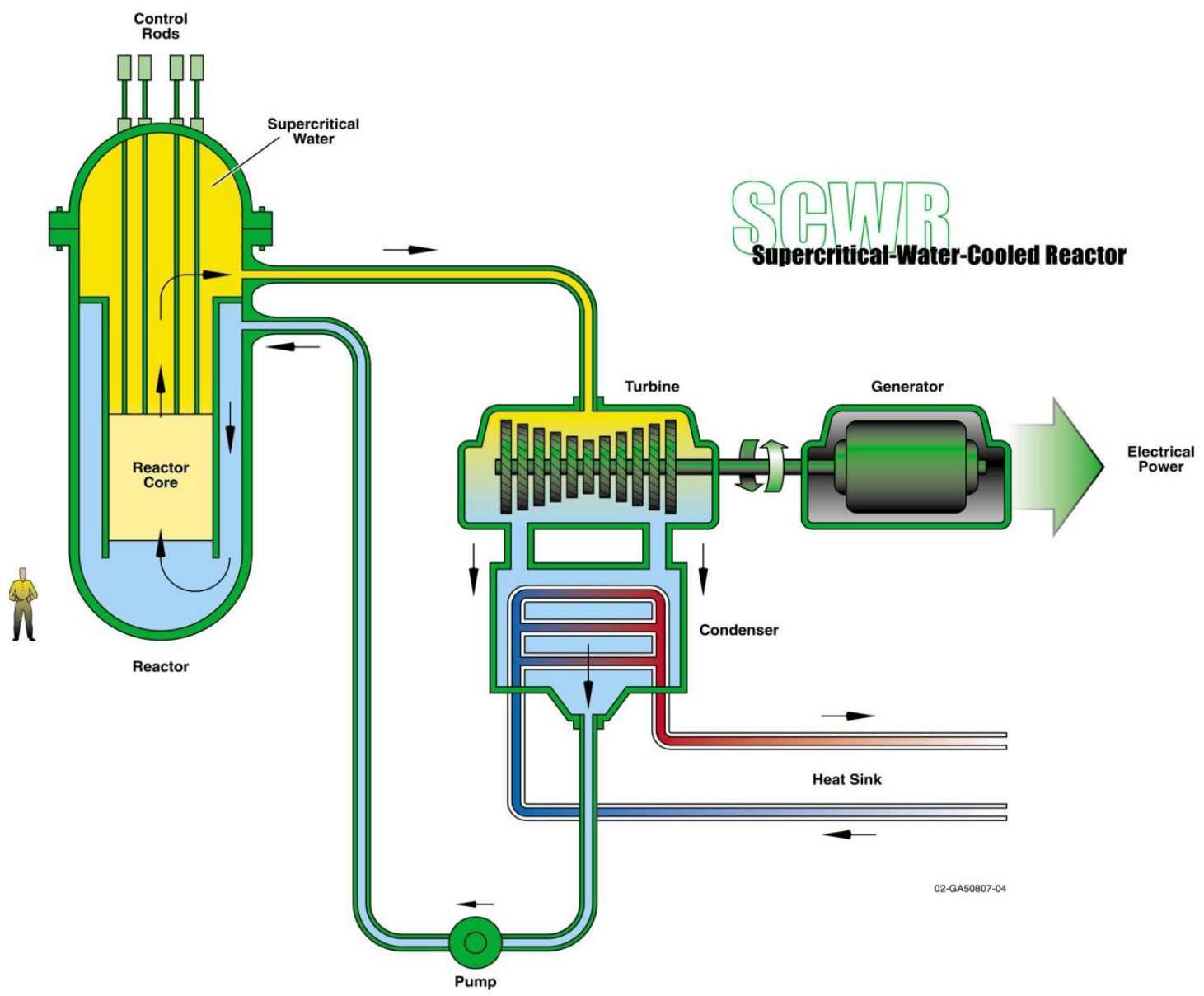

Figure 2. Supercritical water cooled reactor - a simplified schematic diagram [4].

The majority of nuclear reactors employ water as working fluid. A comparison of both temperature and pressure of working fluid among some of the reactors used nowadays, such as Boiling Water Reactor (BWR), Pressurized Water Reactor (PWR), CANDU-6 (CANDU generation II) and the two main Gen IV SCW reactor designs (US and CANDU), is shown in Figure 3.

The SCWR designs include a large pressure vessel similar to conventional Light Water Reactors (LWRs) or a distributed pressure tubes system similar to conventional Heavy Water Reactors (HWRs) of the CANDU type [6]. The second type of design is considered more flexible in many aspects and safer due to the lower risk involves in using tubes to carry SCW fluid rather than 
employing a large vessel [6]. As can be seen in Figure 3, the temperature of the fluid in this type of reactor can be as high as $625^{\circ} \mathrm{C}$ in the outlet of the reactor and approximate $325^{\circ} \mathrm{C}$ in the inlet of the reactor.

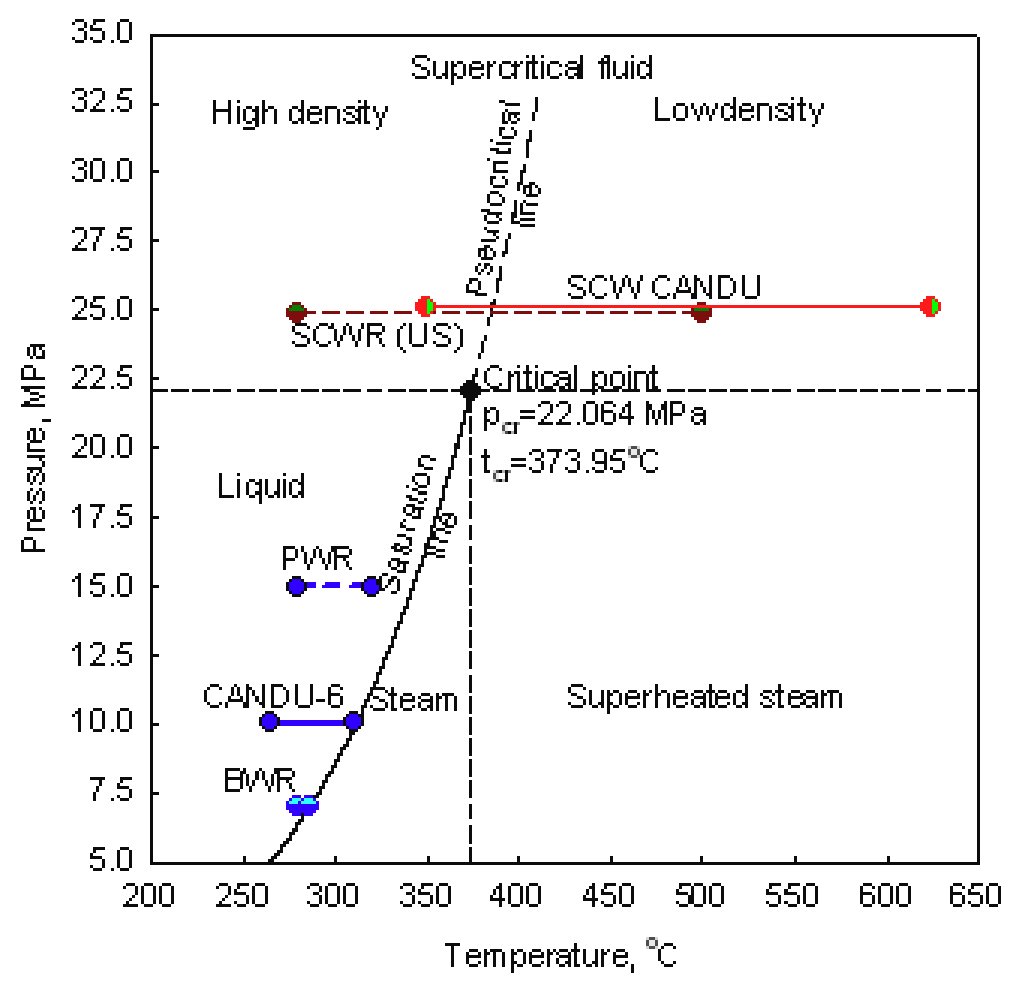

Figure 3. Pressure-temperature diagram of water for typical operating conditions of SCWRs, PWRs, CANDU-6 reactors and BWRs [6].

To maximize the thermodynamic efficiency of reactors, many designs were studied. One of the most promising and simpler cycles studied is the no reheat single cycle. The main difference of this cycle with some other cycles is the absence of reheating of the steam between each turbine stage. A schematic diagram of this cycle is shown in Figure 4.

To obtain a fluid temperature close to $350^{\circ} \mathrm{C}$ before entering the reactor, a series of low (LP HTR) and high pressure feedwater heaters (HP HTR) are used to increase the temperature of 
the fluid (some time with temperature as low as $40^{\circ} \mathrm{C}$ after existing the last low pressure turbine stage). This heating step increases the thermodynamic efficiency of the whole cycle.

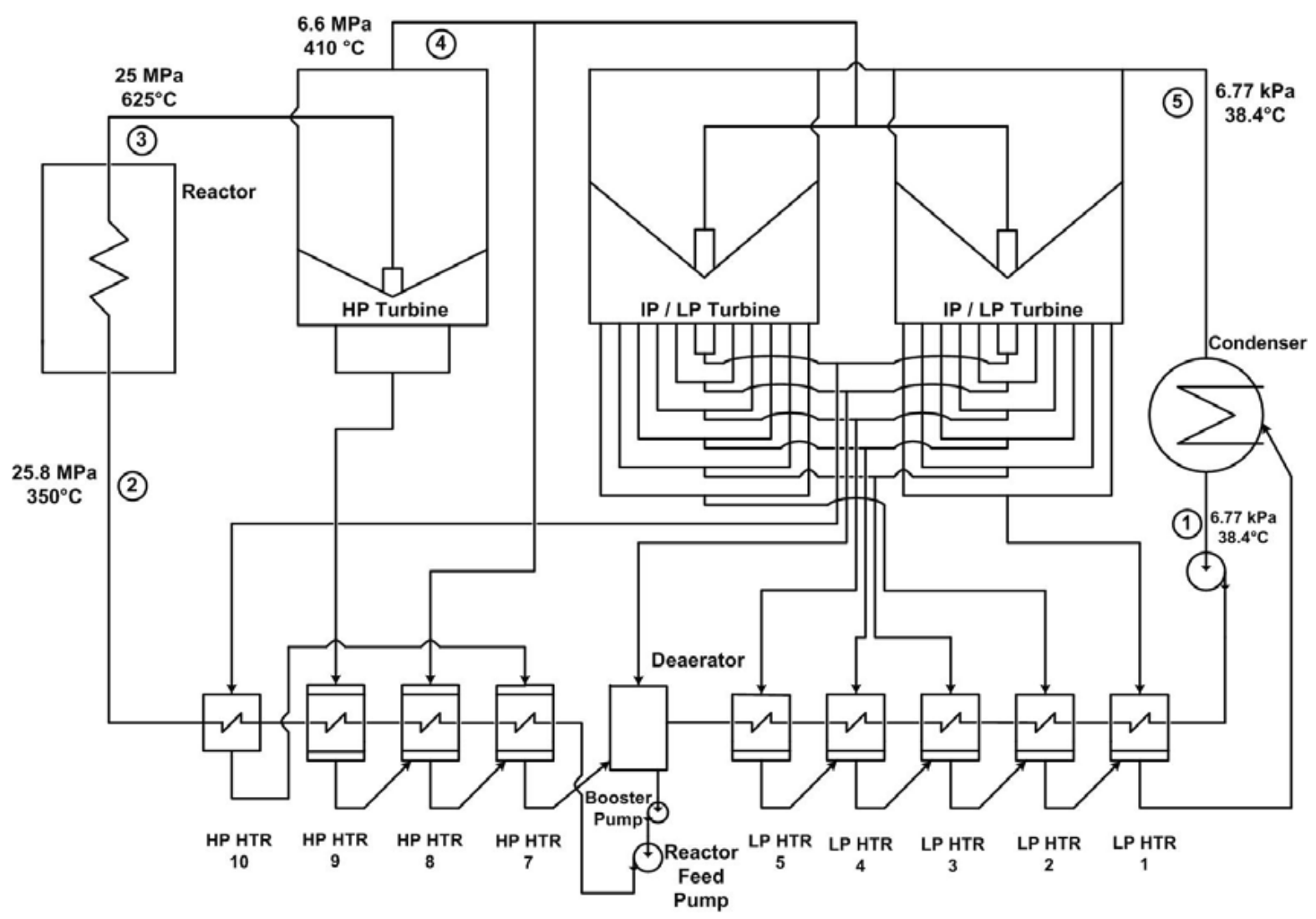

Figure 4. No reheat cycle for SCWR [7].

The T-s diagram corresponding to the cycle shown in Figure 4 can be seen in Figure 5 . The supercritical water exits the reactor at $625^{\circ} \mathrm{C}$ and $25 \mathrm{MPa}$ and expands in the HP turbine; heat extraction takes place at this stage. After leaving the HP turbine, it goes through two LP turbines where further expansion and heat extraction of the feedwater take place, and an output temperature of approximate $40^{\circ} \mathrm{C}$ characterizes the steam when it leaves the last stage of $L P$ turbine. 


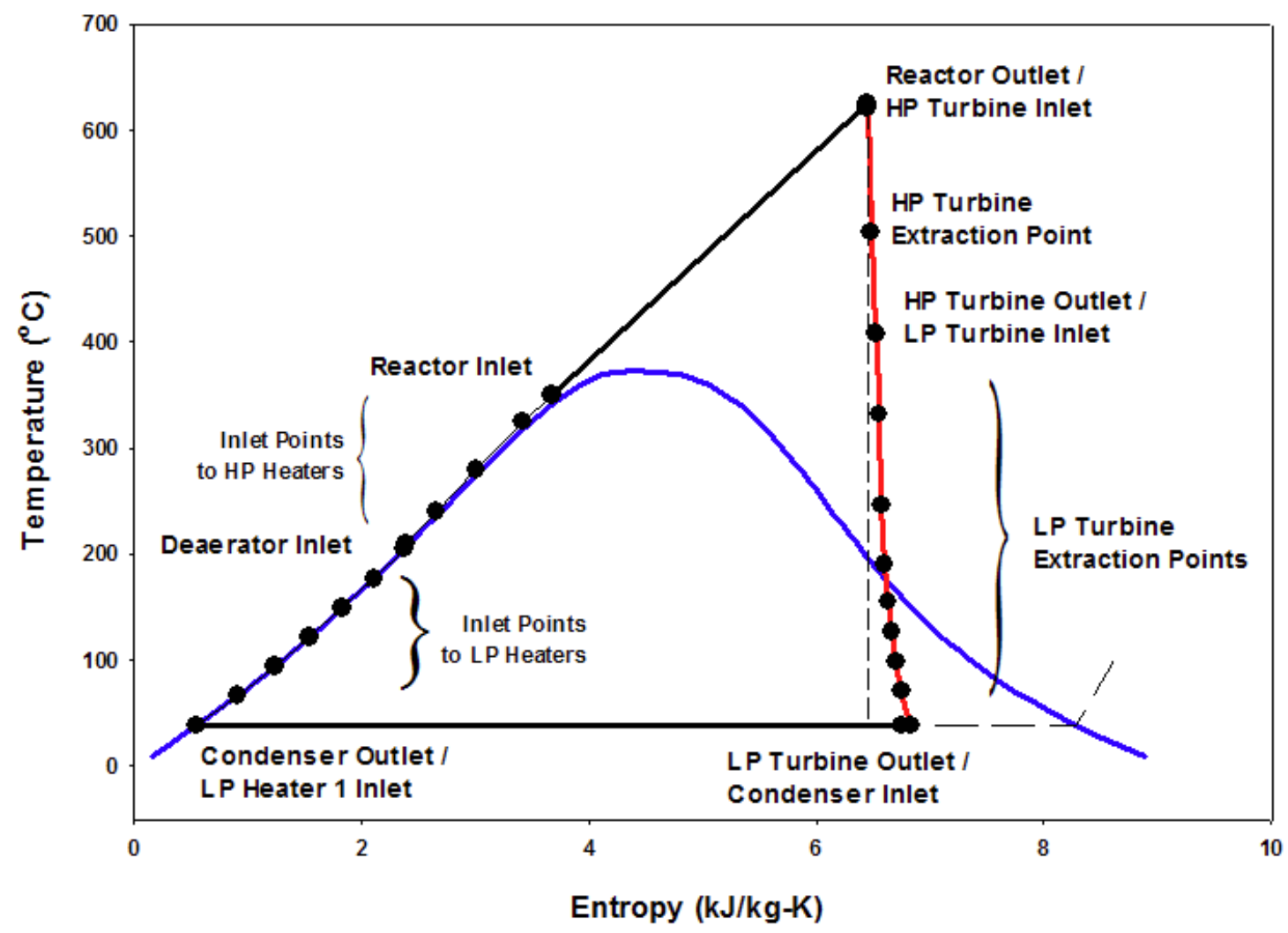

Figure 5. T-s diagram for a no reheat cycle [6].

The saturated steam flows into a condenser where it is condensed under constant pressure and temperature. A condensate extraction pump forces the condensate through a LP HTR (constant pressure) to a deaerator; the working fluid leaves this point as a saturated liquid [6]. Subsequently, a reactor feed pump raises the fluid pressure to the $25 \mathrm{MPa}$, required for the reactor inlet, and several HP HTRs raise the fluid temperature to $325^{\circ} \mathrm{C}$. The heat generated inside the reactor, as a result of the fission reaction, increases the fluid temperature to over $625^{\circ} \mathrm{C}$ under constant pressure of $25 \mathrm{MPa}$, and the above mentioned cycle repeats.

The operation temperatures inside the reactor range from $510^{\circ} \mathrm{C}$ to $625^{\circ} \mathrm{C}$ [5], with localized areas reaching $850^{\circ} \mathrm{C}$. This elevated temperature regime together with high pressures $(>22.1$ $\mathrm{MPa}$ ) limits the type of materials that can withstand this environment. The selection of 
materials is also difficult due to the non-existing information available in the literature about the behaviour of materials in these extreme conditions.

Under supercritical water conditions the main concerns regarding the selection of the appropriate materials are the prevention of stress corrosion cracking and the resistance to corrosion at high temperatures and pressure, and under the neutron radiation for materials used in the reactor core. Some of the candidate materials that can be used are stainless steels and high nickel-chromium alloys, some of them will be studied in detail in this thesis.

Besides the performance evaluation of candidate materials in SCW environments, another key objective of this thesis is to study and determine the behaviour of these materials under superheated steam conditions. This is important because currently there is no existing pressurized test rig than can reach temperatures beyond $650^{\circ} \mathrm{C}$; superheated steam (not pressurized) has been proposed as a surrogate to test candidate materials at temperatures above this threshold. This study will compare materials tested at the same temperature but under different pressure settings. Furthermore, the use of superheated steam in steam turbines has the benefit of increasing efficiency due to the thermal properties of superheated steam and cycle design. 


\section{Chapter 2. Literature Review}

In this chapter, a general review of the behaviour and properties of engineering materials in supercritical water and superheated steam will be presented. The main focus will be on the corrosion mechanisms and performance of materials in these environments. More specifically, a review of the available literature for several high nickel chromium alloys and stainless steels with regard to their corrosion and oxidation behaviour will be presented.

\subsection{Nuclear Reactor for Power Generation}

A nuclear reactor initiates and controls a sustained chain reaction that releases high amount of energy due to the fission of atoms (fission reactor). The fission process consists in the splitting of the nucleus of an atom into lower atomic number atoms due to a nuclear reaction or radioactive decay. The most common nuclear reaction used in nuclear reactors for power generation is the fission of Uranium-235 by a neutron into two other lighter elements and three new neutrons which are the responsible for maintaining the chain reaction. The high amount of energy released is used as the heat source in power plants to produce electricity.

\subsubsection{General description}

There is a variety of nuclear reactor designs for power generation. The main differences between designs are: the type of coolant used (boiling or pressurized light water, heavy water or carbon dioxide), and the type of moderator used, most common ones are: light water, heavy water or graphite. Regardless of the type of reactor, all nuclear power plants have common components in the reactor side: fuel rods, control rods to regulate the chain reaction, reactor 
vessel, a moderator for the chain reaction and the coolant substance that will extract the heat from the reactor core to the heat exchangers.

The conventional side of all nuclear generation plants is almost the same in all cases and so it is the principle for power generation in all of them. Light clean water will enter the steam generator where it will be transformed to steam with the heat obtained from the nuclear core. This high kinetic energy steam will be transform to the turbine inlets where it pushes against the blades of the turbine, causing the turbine, and therefore, the attached rotor of the electrical generator, to spin and produce electricity by a magnetic field variation principle. This is a quick and very simplified description of a nuclear plant functioning, this is high complicated system with a lot more components that the ones mentioned here. They are also specific and expensive designed parts that have required large study in all engineering aspects including the materials field for several years.

\subsubsection{CANDU I and CANDU II operating principle}

One of the reactors used in power generation is the CANada Deuterium Uranium (CANDU), which is the first and only type of heavy water moderated reactor in the industry, besides it is the most efficient of all reactors in the use of Uranium [8]. CANDU have evolved from experimental and limited power designs to single units of $600 \mathrm{MWe}$ and $900 \mathrm{MWe}$ in current use around the world [9]. Efforts in the development of new generation designs are being made. The first and second generation of CANDU reactors have similar operation principles. Figure 6 shows a general diagram of the main components in a CANDU reactor based nuclear power plant (note this diagram does not show the water pumps at the outlet of the condenser 
to pump water back to the steam generator and at the outlet of the steam generator in the heavy water loop to pump the heavy water back to the calandria).

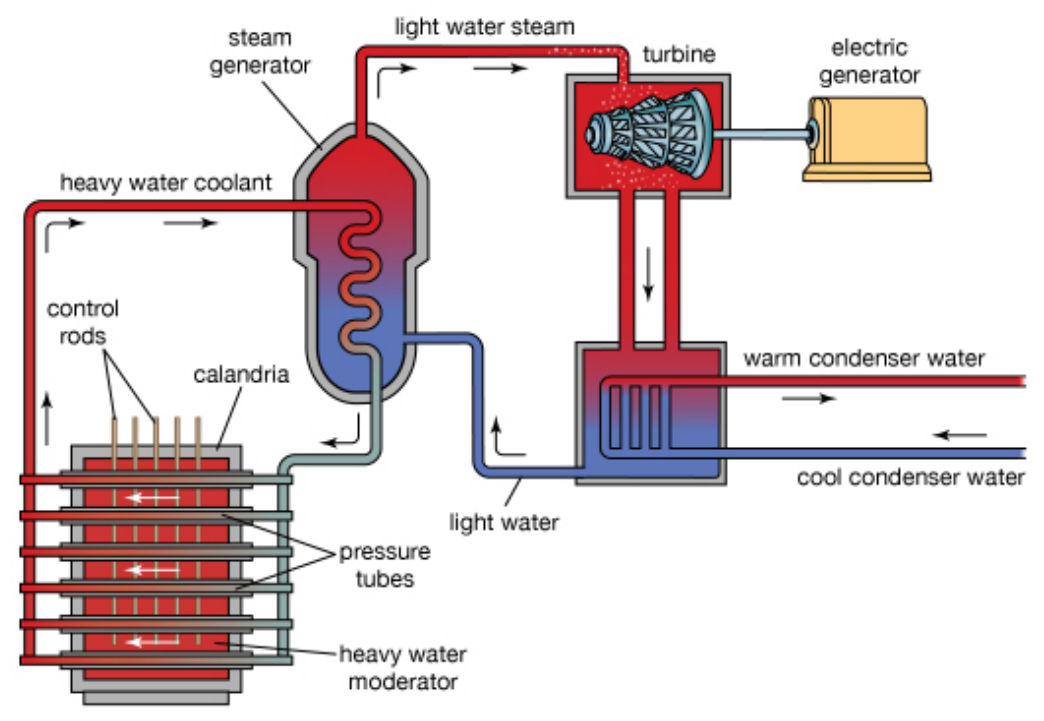

Figure 6. Schematic diagram of a nuclear power plant using a CANDU reactor [10].

The CANDU reactor uses unenriched uranium dioxide as fuel, which is held in zirconium alloy cans loaded into horizontal zirconium alloy tubes inside the pressure tubes (Figure 6). The fuel is cooled by pumping high heavy water through the tubes and then to a steam generator to raise steam from light water. By immersing the zirconium alloy tubes in the calandria (unpressurized vessel) containing more heavy water, the additional moderation action over the chain reaction is achieved. To control and regulate the reaction in the reactor core, cadmium control rods are inserted in the calandria vessel. The whole reactor and the steam generator are contained inside a concrete reinforced building named the reactor building. The harsh environment causing high oxidation and corrosion in all nuclear reactors and other nuclear power plant components, limits the options of materials that can be used. These limitations are bigger for the newer generations of reactors and plants that are being designed. 


\subsection{Oxidation and Corrosion in Supercritical Water}

In order to analyze the mechanism of corrosion and oxidation in supercritical water, it is important to know the properties of SCW and understand different factors that will affect materials' mechanical and chemical properties under these conditions. The harshness of this pressurized high-temperature environment often leads to accelerated degradation of materials. A key parameter in defining the corrosion behavior in an SCWR will be an enhanced understanding of the chemistry of supercritical water. The marked change in the density of SCW through the critical point noted above is accompanied by dramatic changes in chemical properties. For example, the ionization constant reduces from $10^{-14}$ to $10^{-23}$; hydrogen bonding is greatly reduced or non-existent depending on the pressure; and, the dielectric constant is reduced by more than an order of magnitude. These changes mean that the ionic solubility, $\mathrm{pH}$, and corrosion potential will be distinctly different at the core inlet compared to the outlet.

These complications are further exacerbated by in-core radiolysis, which is the dissociation of water molecules by ionizing radiation [11]. The radiolysis process in the nuclear reactor is influenced by the type and amount of radiation present, the temperature and the pressure in the reactor core, and the properties of the water used as coolant (working fluid) or moderator [12]. The water radiolysis in today's reactors is mainly due to alpha and fast neutron particles; some products from these reactions, such as $\mathrm{H}^{+}, \mathrm{OH}^{-}, \mathrm{H}_{2} \mathrm{O}_{2}$, and $\mathrm{O}_{2}$, contribute to the formation of oxidizing environment that leads to an increased corrosion rate of the reactor components. Stress corrosion cracking and cracking of Inconel superalloys and austenitic steels become susceptible in this environment $[12,13,14]$. The radiation in the reactor core, especially by the neutron particles, is one of the factors that change the properties of solid metal components of 
the reactor. Neutron radiation produces dislocation loops and void in the crystal lattices, causing a decrease in the fracture toughness of materials [15].

To understand the corrosion potential in an SCWR core and to effectively control corrosion rates will require knowledge of the corrosion potential of each of the stable and reactiveintermediate species present in-core. The radiolytic yields and recombination rates in SCW are currently unknown, and preliminary studies suggest a markedly different behavior at SCW conditions compared to what would have been predicted from simplistic extrapolations of the behavior encountered in conventional water-cooled reactors [14]. In the following sections, the properties of water under different conditions are summarized.

\subsubsection{Supercritical Water}

A supercritical fluid is defined as a substance that exists in a temperature and pressure above its thermodynamic critical point. Above this point it is not possible to distinguish between two or more fluid phases. This point is well defined for each fluid and plays important roles in many thermodynamic systems. In the case of pure substances the supercritical point situates at the limit of the vapor-liquid equilibrium where the density of the two phases merges [16]. Above the supercritical point there is no phase transformation and the substance is not liquid or gas anymore, it is considered a homogeneous supercritical fluid. Water is considered a supercritical fluid when its temperature and pressure are above $374^{\circ} \mathrm{C}$ and $22.1 \mathrm{MPa}$ respectively. In Figure 7 the phase diagram of water can be observed, it shows also the supercritical water region. 


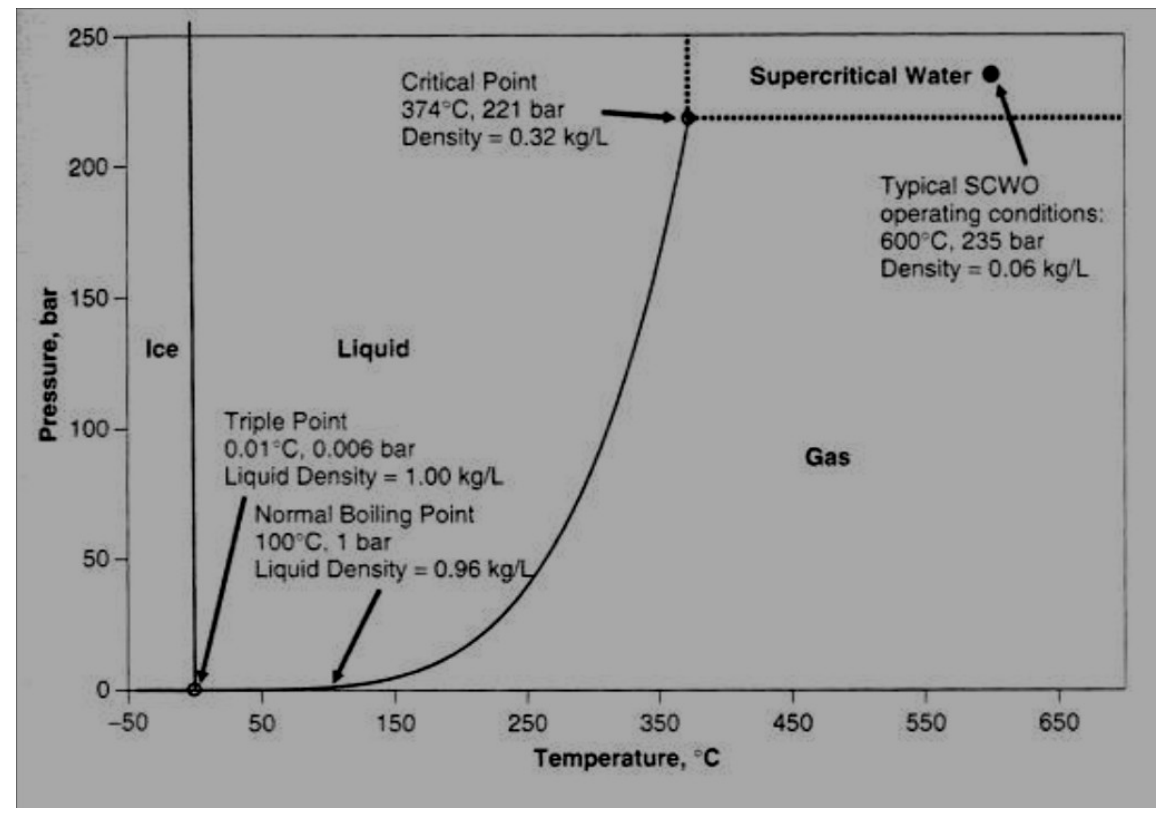

Figure 7. Water phase diagram [16].

\subsubsection{Density}

In the neighbourhood of the supercritical point, the changes in the water's physical properties are very dramatic with small changes in pressure or temperature. These properties can be closer to the liquid properties or to the gas properties or a mixture of both. Density of supercritical water decreases abruptly when increasing the temperature above the supercritical point at a certain pressure; these changes are smaller at higher temperatures. The decrease in density in the supercritical region can be observed in Figure 8 , a diagram under a specific value of pressure of $25 \mathrm{MPa}$ (250 bar).

Density is just one of the physical properties that are affected by changes in temperature or pressure in this region. Figure 8 also shows how the ion product and dielectric constant decrease dramatically when increasing the temperature above the critical point at a supercritical pressure. 


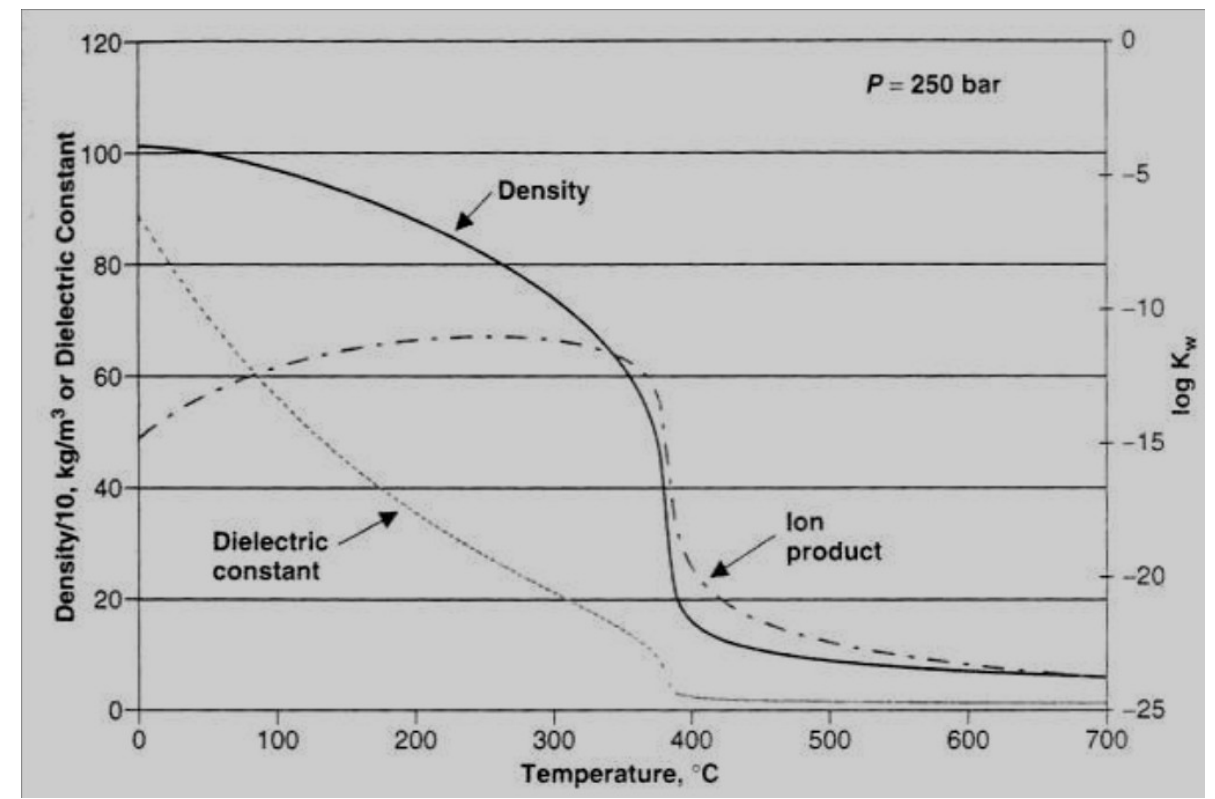

Figure 8. Water physical properties variation with temperature at pressure value of $25 \mathrm{MPa}$ (250 bar). [16]

\subsubsection{Polarity, Dielectric Constant and Hydrogen Bonding}

Water $\left(\mathrm{H}_{2} \mathrm{O}\right)$ is a polar molecule as the result of a more electronegative oxygen atom than the 2 atoms of hydrogen to which it is bonded [17]. Due to the high electronegativity of oxygen, electrons are strongly attracted by the oxygen atom that gives it a negative charge; this also creates an electron deficiency in the hydrogen atoms which give them a slight positive charge [16]. This difference in the distribution of charges is responsible for the polarity of water molecules and it is the basis for forming hydrogen bonding [16]. Dielectric constant of water quantifies the water molecule's polarity.

Hydrogen bonding is formed due to electrostatic attraction between the positive charged hydrogen atoms of one molecule and the negative charged oxygen atom of the neighbouring molecule, shown in Figure 9 [17]. This weak interaction, together with the polarity of the water 
molecule, is responsible for many of the properties of the water [16], with solvent properties as one of the most important ones for our interests.

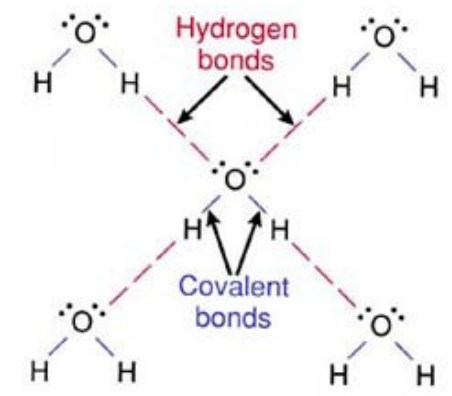

Hydrogen bonding in water.

Figure 9. Hydrogen bonding in water at ambient temperature [17].

At ambient temperature water is a good solvent for many polar substances, but not for nonpolar substances [16]. When temperature and pressure reach high values like that in supercritical water conditions, the hydrogen bonding tends to get weaker due to the decrease in density and the weak interaction between molecules. Dielectric constant also decreases with the temperature increase; this results in behaviour of SCW as a non-polar solvent with low solvency for ionic compounds, but high for non-polar organic substances such as salts and gases $[18,19]$. Low density SCW has high diffusivity and excellent transport properties; this is also applicable to steam $[16,18,20]$.

\subsubsection{Ionic Product and pH Value}

The ionic product of water $\mathrm{K}_{\mathrm{w}}$ is dependant of the product of the concentrations of $\mathrm{H}^{+}$and $\mathrm{OH}^{-}$ ions that form as a result of the ionization due to electric fluctuations between neighboring molecules [21]. This ionization is given by a simple equilibrium equation [18]: 


$$
\mathrm{H}_{2} \mathrm{O}=\mathrm{H}^{+}+\mathrm{OH}^{-} \quad \text { Equation. (1) }
$$

The $\mathrm{pH}$ value of water is determined by the concentration of hydrogen ions. At ambient temperature the production of $\mathrm{H}^{+}$and $\mathrm{OH}^{-}$due to ionization takes place at the same rate, which makes the $\mathrm{pH}$ value neutral $(\mathrm{pH}=7)[18]$.

The ionic product, as well as density and dielectric constant, decrease with the increase of temperature over the supercritical point at a constant supercritical pressure value (Figure 8) [19]. However, as can be seen in Figure 10, the ionic product, and similarly the density and dielectric constant, increase with the pressure at various temperatures. The values of ionic product at certain pressures are higher than that at ambient temperatures [18]. The variation of temperature or pressure can favour the equilibrium equation (Eq.(1)) in one way or the other. This will change the $\mathrm{pH}$ value and render the water either as acid or alkaline [18].

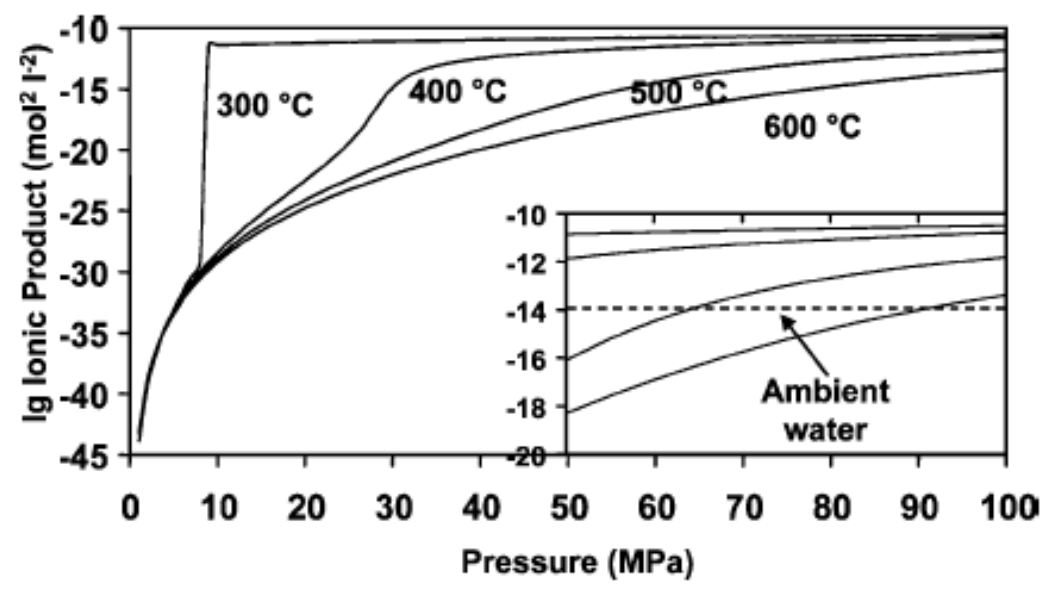

Figure 10. Ionic product of high-temperatures water vs. different pressures [18]. 


\subsubsection{Solubility of Oxygen and Hydrogen}

Non-polar gases, including oxygen and hydrogen, have a low solubility in water at room temperature. The increase in pressure results in an increased solubility of these gases in water. The same way, increasing the temperature to supercritical conditions will drastically increase their solubility in water [22]. The increase of oxygen and hydrogen concentrations in supercritical water will cause an accelerated corrosion process in metals that will have certain consequences for applications where the changes in temperature and pressure may release the dissolved oxygen and hydrogen to the environment [19].

\subsection{Types of Corrosion and Parameters Influencing Corrosion}

The main corrosion mechanism observed at high temperature will be discussed below. The corrosion at high temperature is the direct reaction of a metal or its protecting oxide with aggressive gases [19]. The formation of a protective oxide layer (dense, stable and free of defects) on the metal surface helps to control the further propagation of corrosion, and with this, the useful life of the metal part can be extended. Failing to establish this layer will cause the uncontrolled propagation of different types of corrosion due to environmental attack. The main factors causing various types of corrosion will also be reviewed.

\section{General Corrosion}

General corrosion is the most common type of corrosion and can be located on the entire surface area of a metal as it is caused by a general instability of the surface film. Chemical or electrochemical reactions will cause the deterioration of the entire exposed surface of the metal [23]. In this case, none of the alloy components can form a protective layer on the 
surface. It usually starts in the weakest points of the metal like grain boundaries or highly stressed area [24]. Pitting corrosion can often turn into general corrosion [23].

\section{Pitting Corrosion}

Pitting corrosion is a kind of localized corrosion. Aggressive anions such as chloride or bromide exist in this environment. They attack and destroy the oxide protective film in localized areas, mainly grain boundaries or around inclusions in the metal, causing the appearance of small pits at the beginning of the process [25]. The increase in concentration of the anions also leads to a strong acidification of the solution inside the pits, as the corrosion progresses [26]. The increase in temperature accelerates the attach, that's the reason higher temperatures pitting corrosion occurs more readily [25]. It has a non-predictive nature which makes this type of corrosion insidious.

\section{Intergranular Corrosion (IC)}

Although not as common as other kinds of corrosion, IC can lead to the more dangerous stress corrosion induced cracking. Grain boundaries and surrounding areas have different chemical properties when compared to that within the grains. Metal phases such as carbides and nitrides can also be formed in the boundary regions. During the IC, grain boundaries or neighboring areas are attacked by different corrosion mechanisms. It can be observed under a wide range of environmental conditions and for many engineering materials [27]. An example of IC in nickelbase alloy 625 in SCW is shown in Figure 11. 


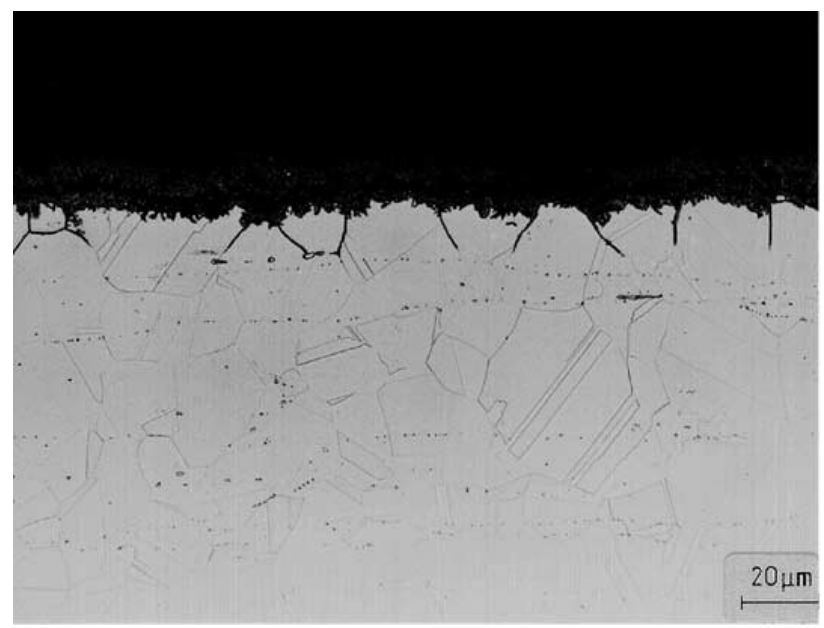

Figure 11. Example of IC in SCW [18].

\section{Stress Corrosion Cracking (SCC)}

SCC is a type of corrosion that occurs under the combination of stress, material chemistry and environment. Since laboratory test conditions may not simulate the actual working environment of the materials, this mode of corrosion, if not realized, can cause catastrophic failures because of its nature [18]. Any changes to the chemical environment or stress condition can lead to unpredicted failures. At high temperatures it has been observed either water with high concentrations of hydrogen or oxygen accelerates SCC. It can be inter-granular or transgranular depending where in the grain structure the crack takes place [28].

\subsubsection{Parameters Influencing Corrosion}

The factors that control different kinds of corrosion seen above are very important when selecting materials for next generation SCW reactors. The following sections will analyze the most important environmental parameters.

\section{Temperature and Pressure}


As discussed in previous sections, the variation in temperature and pressure will affect water physical properties such as density, ion product and dielectric constant. All these changes that take place near supercritical region will have an influence on the surface oxide layer or the base material itself. According to previous research, the increase of temperature to supercritical region $\left(500^{\circ} \mathrm{C}\right)$ will slow down the corrosion process, when comparing it to water at subcritical temperature $\left(300^{\circ} \mathrm{C}\right)[18]$. This is a direct result of the decreased density, ionic product and dielectric constant of the fluid. An increase in pressure at supercritical temperatures will produce an increase in all of the physical properties of water mentioned above [19], they will in turn contribute to a higher dissolution rate of the metal protective oxide layer hence increased corrosion rate of the base material. Finally, the increase in temperature will accelerate many chemical reactions and elemental diffusion rates, thus has an effect on corrosion/oxidation rate of substrate materials [19].

\section{Water Density, $\mathrm{pH}$ and Oxide Solubility}

The changes in water properties at high temperatures, produce variations in the solvent character of water that goes from a high polar solvent at high pressure (high density), being able to dissolve even non-polar gases and organic compounds, to non-polar solvent at low pressure (low density) $[16,19]$. The $\mathrm{pH}$ value plays an important role in the solvent properties of water as well.

If the solubility of oxides that are part of the oxide protective layer in a fluid is high, the rate of corrosion in the metal will increase quickly [19]. Pourbaix diagrams are maps that display the thermodynamic stability of metals, metals oxide and dissolution of components at a given 
temperature, pressure and ionic concentration [29]. In the example shown in Figure 12, the relationship between electrochemical potential and $\mathrm{pH}$ values provides regions with minimized corrosion [29]. In each diagram, the region of least corrosion resides where the passive state prevails. A variation in $\mathrm{pH}$ or electrochemical potential outside the stability region will lead to an unstable condition in which the corrosion processes will be faster; for a chemical dissolution, it could lead to acidic or an alkaline dissolution depending upon $\mathrm{pH}$ values. $\mathrm{Cr}_{2} \mathrm{O}_{3}$ has a Pourbaix diagram similar to the one shown in Figure 12 [19].

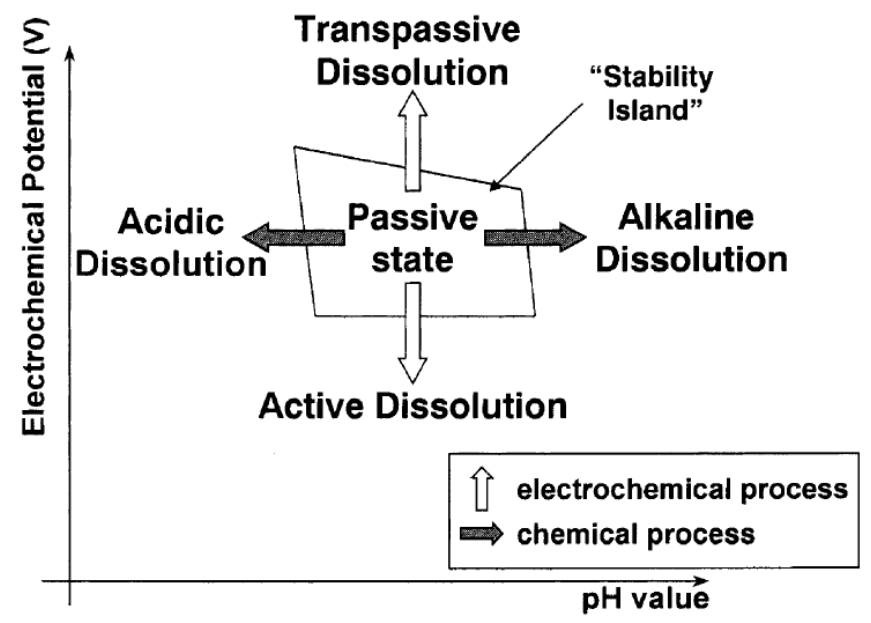

Figure 12. A general Pourbaix diagram for alloys oxide layers [18].

The increase in the production of ions shown in the water stability equation (Eq. (1)) due to a temperature increase will affect the $\mathrm{pH}$ values. A higher (more alkaline) or lower value (more acidic) of $\mathrm{pH}$ will produce oxide (formed on metal surface) dissolution at a constant electrochemical potential. Most engineering metals/surface oxides are affected by either alkaline or acidic dissolutions; chromium containing alloys have shown better stability and least corrosion among various metals tested in these acidic, neutral of alkaline conditions [18]. 
There are three important elements that are part of many alloys being considered to be used in the next generation of reactors: $\mathrm{Fe}, \mathrm{Ni}$ and $\mathrm{Cr}$ [29]. Pourbaix diagrams built at $25 \mathrm{MPa}$ for temperatures of $350^{\circ} \mathrm{C}$ (subcritical) and $400^{\circ} \mathrm{C}$ (supercritical) for these three materials in water, show important differences. For the Iron-Water system (Figure 13), regions of immunity and passivity higher $\mathrm{pH}$ values regardless of potential are noticed in the supercritical conditions. This is different in subcritical conditions: when approaching values of supercritical temperature, the immunity region is separated from the passivity areas by corrosion regions [29].

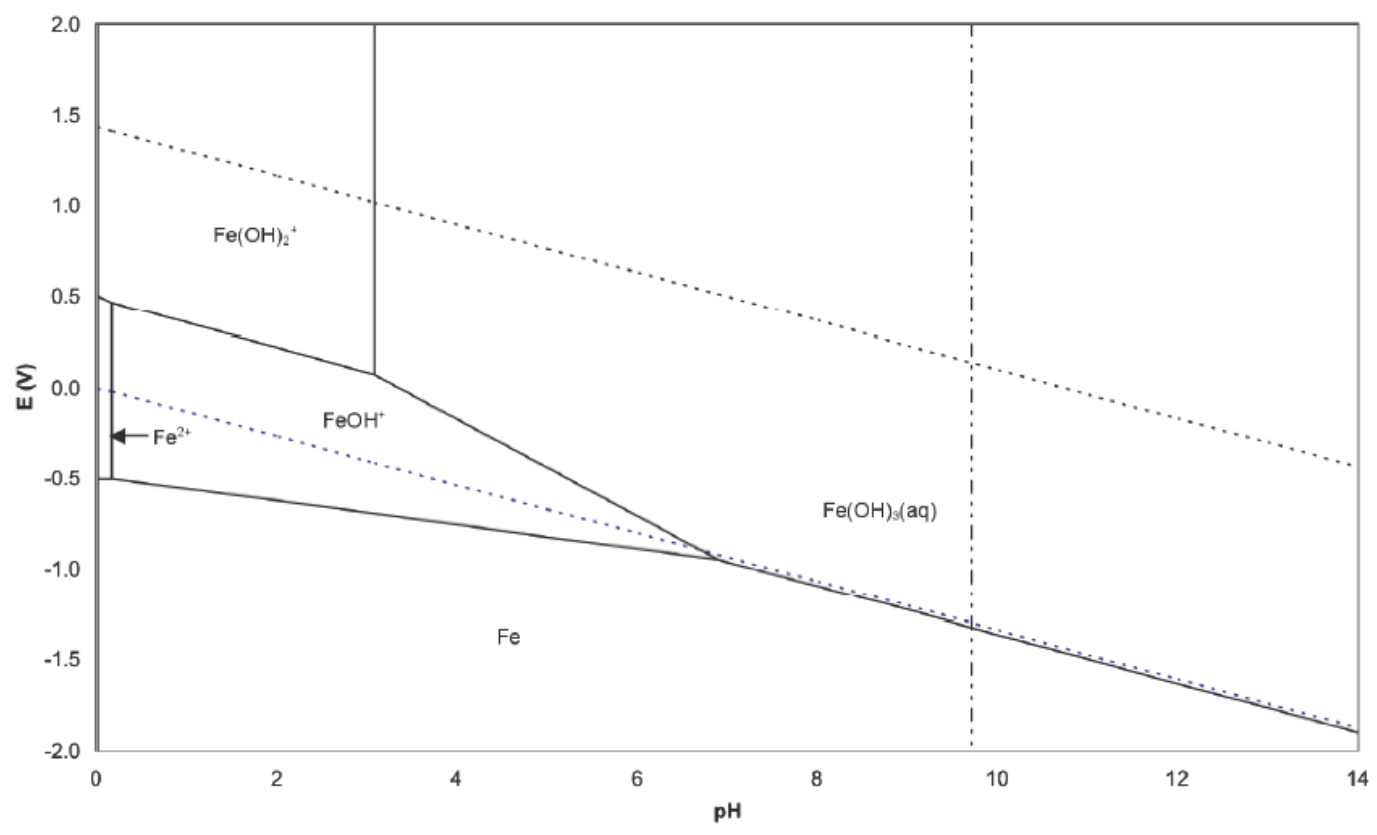

Figure 13. Pourbaix diagram of the $\mathrm{Fe}-\mathrm{H}_{2} \mathrm{O}$ system at $400^{\circ} \mathrm{C}, 25 \mathrm{MPa}$, and $10^{-12}$ molar [29].

For Nickel, stability is observed at supercritical condition (Figure 14); just a small corrosion is noted when the acid levels are very high. In subcritical temperature, passivation regions are present when $\mathrm{pH}$ is close to neutral [29]. 


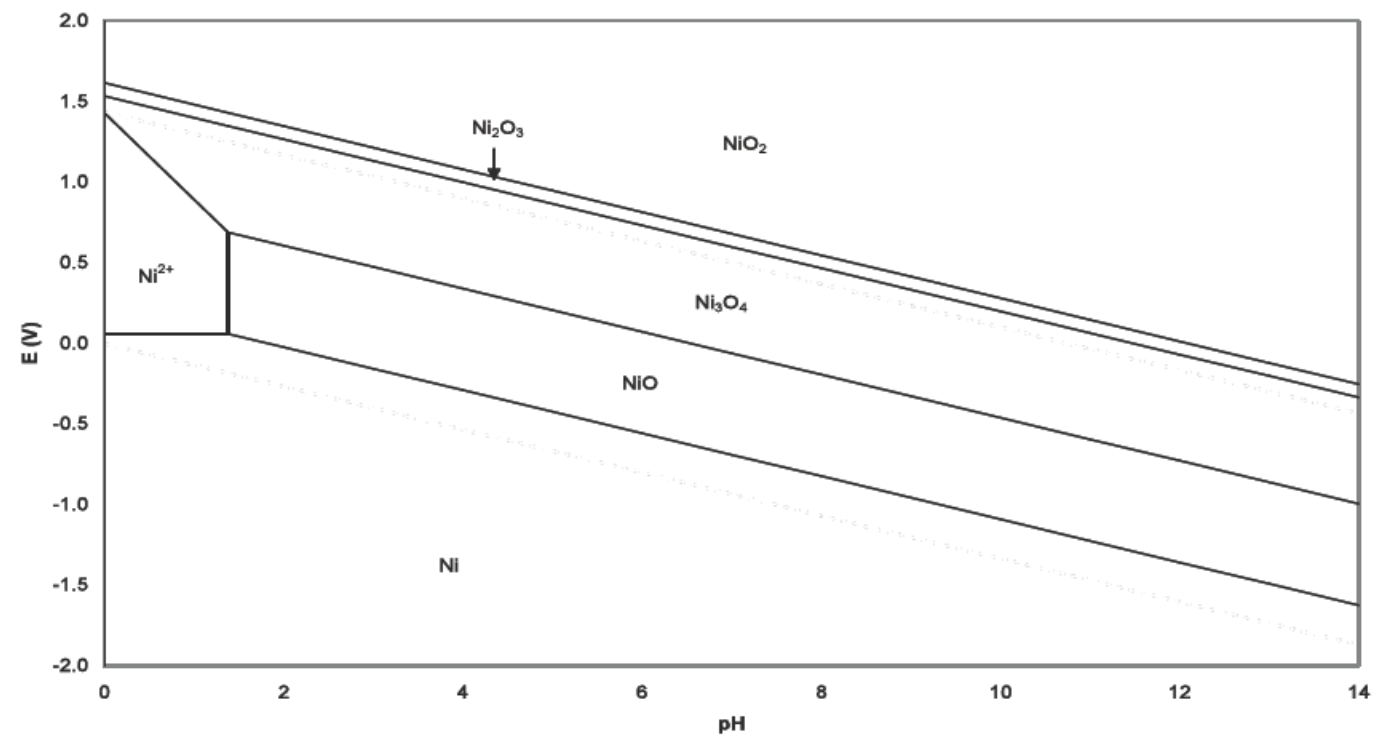

Figure 14. Pourbaix diagram of the $\mathrm{Ni}-\mathrm{H}_{2} \mathrm{O}$ system at $400^{\circ} \mathrm{C}, 25 \mathrm{MPa}$, and $10^{-8}$ molar [29].

Chromium shows large passive regions composed as a result of the formation of chromite in subcritical conditions and a combination of chromite and chromium oxide in supercritical conditions (Figure 15) [29].

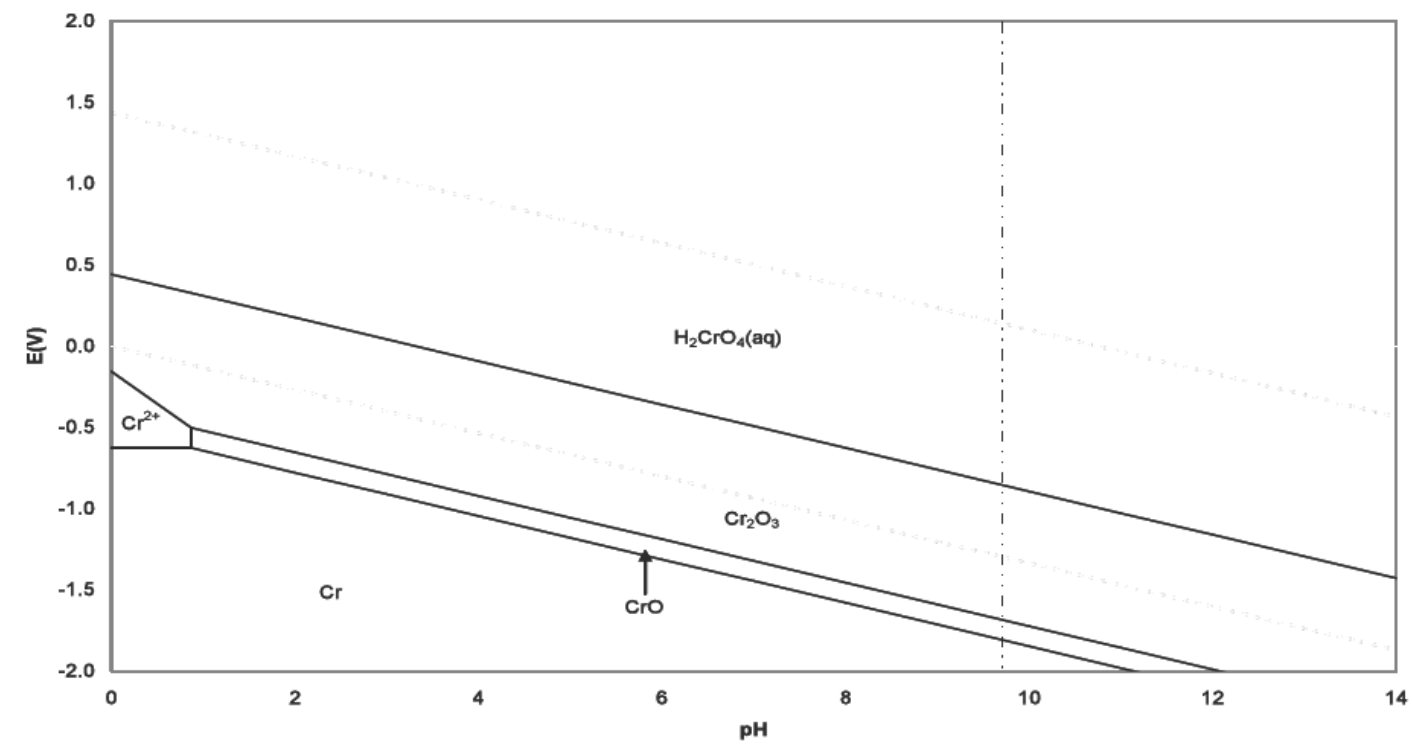

Figure 15. Pourbaix diagram of the $\mathrm{Cr}-\mathrm{H}_{2} \mathrm{O}$ system at $400^{\circ} \mathrm{C}, 25 \mathrm{MPa}$, and $10^{-8}$ molar [29]. 


\section{Dissolved Oxygen and Electrochemical Potential}

The increase of temperature favors the solubility of non-polar gases like oxygen, hydrogen and nitrogen in water. The solubility of these gases in water at supercritical temperature and pressure is remarkably high [30]. The higher the amount of dissolved oxygen that is present in water the more damaging the corrosion and oxidation processes will be.

The other type of dissolution that takes place at high temperature is the electrochemical dissolution, which is directly affected by the electrochemical potential and temperature. This is a process that takes place at a constant $\mathrm{pH}$ value. The reactions are considered as oxidation and they are greatly affected by variations in the electrochemical potential (or solubility of oxygen in the medium). For the formation of a stable oxide film (passive state), a certain value of electrochemical potential is needed; under or above this number, transpassive dissolution or an active dissolution (Figure 12) will occur [18]. As shown in Figure 16, $\mathrm{Cr}_{2} \mathrm{O}_{3}$ will move into transpassive state/dissolution (soluble $\mathrm{Cr}^{6+}$ ) when the electrochemical potential or solubility of oxygen is high. On the other extreme, $\mathrm{Cr}_{2} \mathrm{O}_{3}$ may dissolve (in the form of $\mathrm{Cr}^{2+}$ ) in alkaline medium when the electrochemical potential is low. Nickel-based alloys have shown a strong corrosion resistance in this type of high oxidizing environments due to the formation of $\mathrm{NiO}$ [18]. 


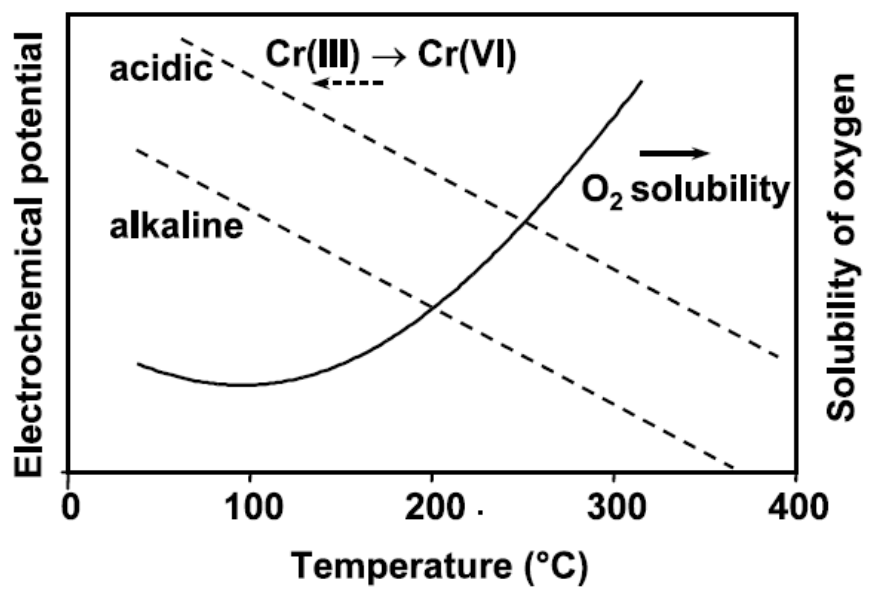

Figure 16. Schematic diagram of forming soluble chromates in acidic and alkaline solution [19].

In the most commonly used reactor materials (stainless steels and nickel-based alloys), chromium is added as oxide former to provide a protective surface layers [18]. In acidic solutions the formation of $\mathrm{Cr}$ (III) compounds leads a protective layer on the metal. When the electrochemical potential falls below where $\mathrm{Cr}$ (III) is stable, $\mathrm{Cr}(\mathrm{II})$ is formed, and active dissolution takes place at this state [18]. When the electrochemical potential goes above the stable value, the oxide layer loses its protective function and is dissolved via a transpassive dissolution process. Higher temperature accelerates the oxidation process and also changes the oxygen activity in the medium, thus chromium can fail to provide protection to the substrate alloy and bulk metal oxidation will take place [20].

\section{Material Properties}

Addition of effective alloying elements is a very important factor in the mitigation of corrosion. As mentioned before, the presence of chromium helps to improve general corrosion resistance; it is useful in both mild acidic and oxidizing solutions and also improves pitting corrosion 
resistance of the alloy $[18,29]$. However, this protective nature is reduced at high temperatures. To enable an alloy to form a stable oxide layer, Niobium, Tantalum, Aluminum, Zirconium and Yttrium have been added to provide high temperature oxidation solutions [18]. Nickel is a suitable alloying element for both alkaline and neutral solutions at high temperature where its oxide forms a stable protective layer [18, 29].

Heat treatment has a direct effect on the grain boundaries chemistry, hence intergranular corrosion [18]. Surface conditioning is another important measure used to control the corrosion. It is known that polished surfaces are more corrosion resistance than non-polished ones, but once the corrosion progresses the corrosion rates may become higher [31]. More details about the effects of surface finish will be presented in future sections.

\section{Relation between Parameters}

The correlation between all parameters affecting corrosion is explained in Figure 17. All of them are dependent on the water properties, which are controlled by the pressure and temperature; these properties are mutually dependant. Previous research shows that the corrosion is low in low density solutions; it is the opposite for high density SCW in which corrosion is quiet high due to the higher extent of dissociation of acids, salts and bases and the increased solubility of salts $[18,19]$. 


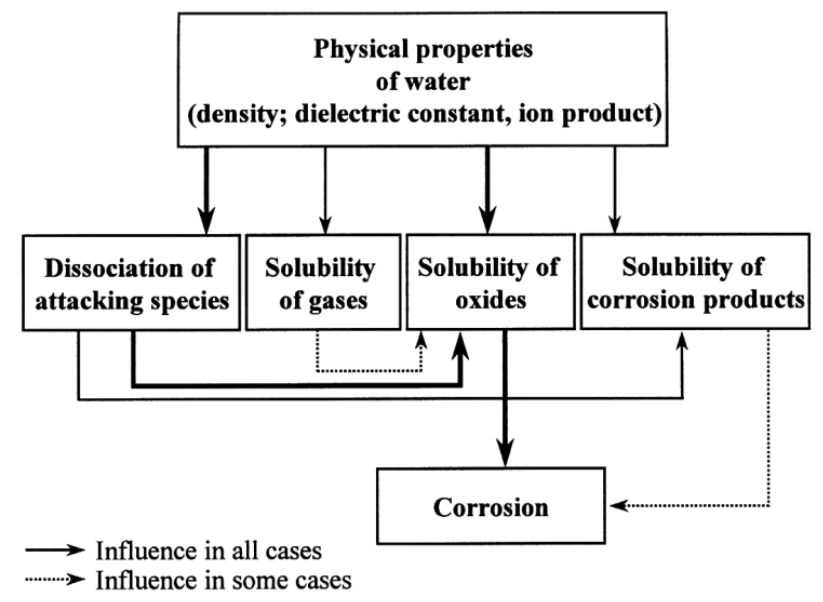

Figure 17. Interdependences of the corrosion factors in high-temperature water solutions [19].

Figure 18 shows the effects of high density SCW (higher pressure) on the corrosion processes in the case of $\mathrm{HCl}$ solution. The dissociation of acids, salts and bases and the solubility of salts increase with the density, and consequently accelerate the corrosion process. The protective oxide layers form on metal surface react with the solution and yield primary corrosion products in the form of salts.

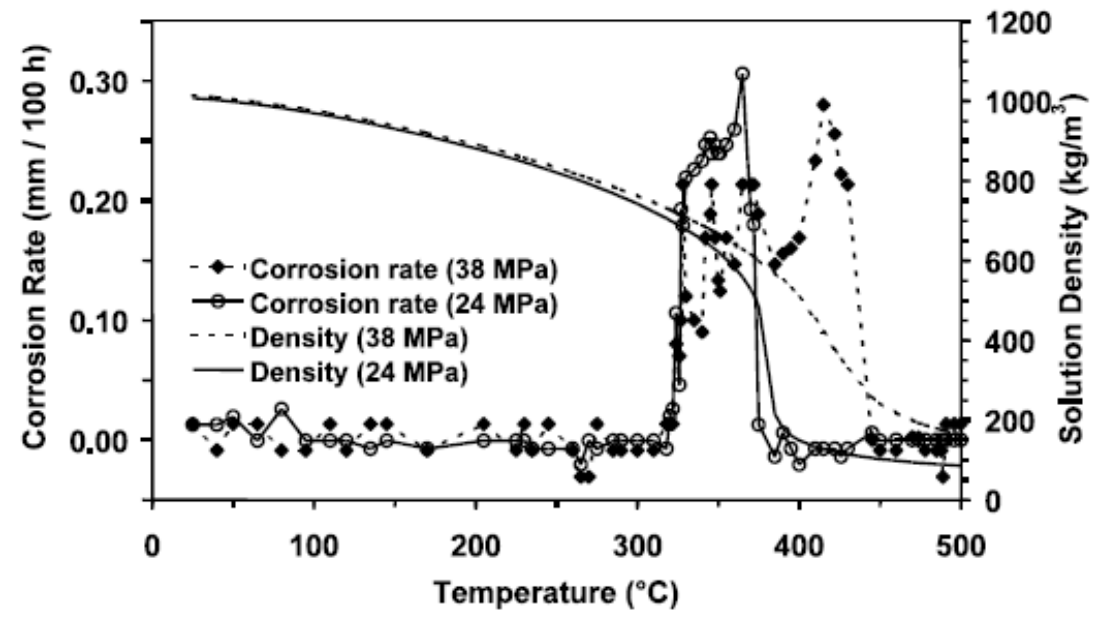

Figure 18. Experimental corrosion rates of general corrosion for two values of pressure caused by $\mathrm{HCl}$ solution

[18]. 
The occurrence of high corrosion rates at certain temperature-pressure regimes is shown in Figure 19. Corrosion is considered high when densities are above $200-300 \mathrm{~kg} / \mathrm{m}^{3}$. At low temperatures, $300^{\circ} \mathrm{C}$ for example, a high corrosion rate is observed when the pressure is over $10 \mathrm{MPa}$. At higher temperatures, for example $600^{\circ} \mathrm{C}$, high corrosion rates occur under high densities created by a pressure of $65 \mathrm{MPa}$ or more.

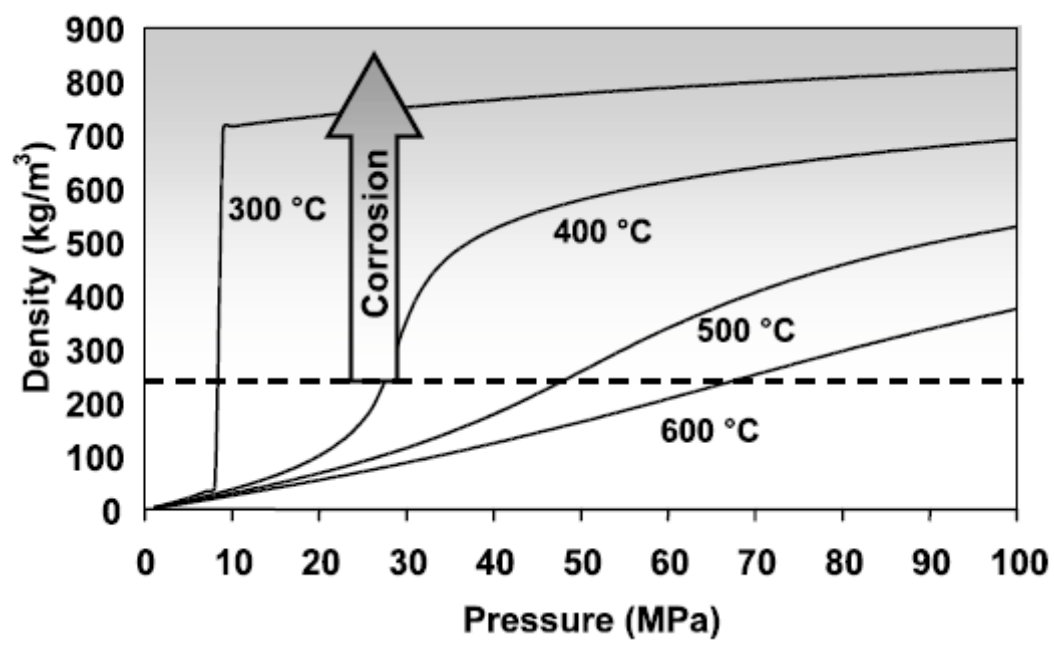

Figure 19. Density range of high corrosion at different temperatures [18].

\subsection{Oxidation and Corrosion in Superheated Steam}

In all power plants, for the power generating cycle to function the basic design must include components such as boilers/steam generators, tubes transporting the steam and turbines driven by high temperature steam. The nature of this steam can be saturated after it is produced in the boilers, or superheated when it is exposed to higher temperatures at the superheaters after leaving the boilers; the heating temperature depends upon the type of power plant and its design. The knowledge of high temperature steam properties and the main 
mechanism of oxidation and corrosion characteristics of this environment are vital for the design of next generation of nuclear plants.

\subsubsection{Superheated Steam}

When steam reaches the temperature that is higher than its saturation temperature under a defined pressure, it is named superheated steam [32]. This temperature will be above $600^{\circ} \mathrm{C}$ for the Gen IV reactors, which is extremely high in comparison to that in conventional steam power plants. Besides this high temperature, high pressure is another parameter involved in the process. The use of the superheated steam will bring noticeable benefits among which the increase in thermodynamic efficiency of the cycle is the most important one [32]. It is also vital to know that, due to its nature, superheated steam and water vapour can't co-exist. A further addition of water to the superheated steam will cause the evaporation of the water and transform the mixture to saturated steam. Saturated steam also appears when the temperature drops to just above the saturation temperature. This transformation with superheated steam will remove the process of condensation and the presence of water; and with this, a reduced occurrence of steam plant failures such as water erosion in pipes and turbine blades. However, due to the elevated temperature the materials to be used in the superheated power plants will be exposed to oxidation, creep or thermal fatigue [33]; they have to be chosen with good mechanical properties and also good oxidation resistance.

\subsubsection{Alloying Addition and Their Roles in Oxidation and Corrosion Prevention}

The absence of liquid water and the behaviour of superheated steam (like a gas) will reduce oxidation and corrosion, but general corrosion and stress corrosion cracking are still present in 
the materials used in these conditions. The two corrosion processes mentioned have already been explained in previous sections. The most commonly used methods to minimize them will be briefly discussed below.

The oxidation of alloys is a complicated process that involves the formation of more than one oxide. The element to first get oxidized will form the outer oxide layer; this is called selective oxidation. This process must be understood in order to select alloying additions that will help to increase the stability of the alloy under various conditions, each element performing a specific function [34]. The addition of alloying elements needs to be as low as possible in order to avoid detrimental effects on the mechanical and other properties of the metal, hence its performance in service. High temperature steam oxidation resistance can be improved by modifying the inherent nature of the protective oxide scale; this is commonly done by the addition of controlled amount of chromium for iron based alloys, and the addition of silicon for stainless steels [33, 34].

The addition of chromium has provided effective means in the control of oxidation/corrosion processes. Carbon steels form a scale consisting of one or more layers of wustite (FeO), hematite $\left(\mathrm{Fe}_{2} \mathrm{O}_{3}\right)$ and magnetite $\left(\mathrm{Fe}_{3} \mathrm{O}_{4}\right)$, under specific oxidation parameters [33]. The addition of chromium to the alloys at first changes the scale such that the inner layer is an ironchromium spinel $(\mathrm{Fe}, \mathrm{Cr})_{3} \mathrm{O}_{4}$ (instead of magnetite in plain carbon steels) in low alloy ferritic (up to $3 \% \mathrm{Cr})$ or martensitic $(9-12 \% \mathrm{Cr})$ steels [33]. The formation of chromia $\left(\mathrm{Cr}_{2} \mathrm{O}_{3}\right)$ will take place with an increased addition of chromium [33]. Solberg et al. [35] demonstrated a consistent decrease in metal loss with increasing chromium content (shown by up to 6 times lower 
penetration/inches of corrosion between the lower and higher $\mathrm{Cr}$ content alloy, giving up to $20 \%$ wt decrease in metal loss) in short-term laboratory tests at $593{ }^{\circ} \mathrm{C}$. This effect has been also demonstrated in service exposures of 36000 hours [33].

Others studies have shown that the level of benefit arising from increased chromium content is not constant but dependent on the water content of the oxidizing steam atmosphere [33]; the higher the moisture content results in higher corrosion rates. For alloys with $\mathrm{Cr}$ content higher than $12 \%$ the benefits in steam oxidation resistance have been observed. In a study by Tavast [36], it was concluded as a general rule that when the $\mathrm{Cr}$ content is over $25 \%$, a continuous chromia layer can be rapidly established at the metal-metal oxide interface, slowing down the diffusion of iron to form magnetite at the gas-metal interface. This suggests the existence of a limit to the maximum amount of $\mathrm{Cr}$ that is beneficial in terms of scale adherence [33]. Figure 20 shows how the loss of metal decreases with the increase of $\mathrm{Cr}$ content until it starts to approach a limit of a minimum value, suggesting that there is limit for achieving the best effect of $\mathrm{Cr}$ addition. 


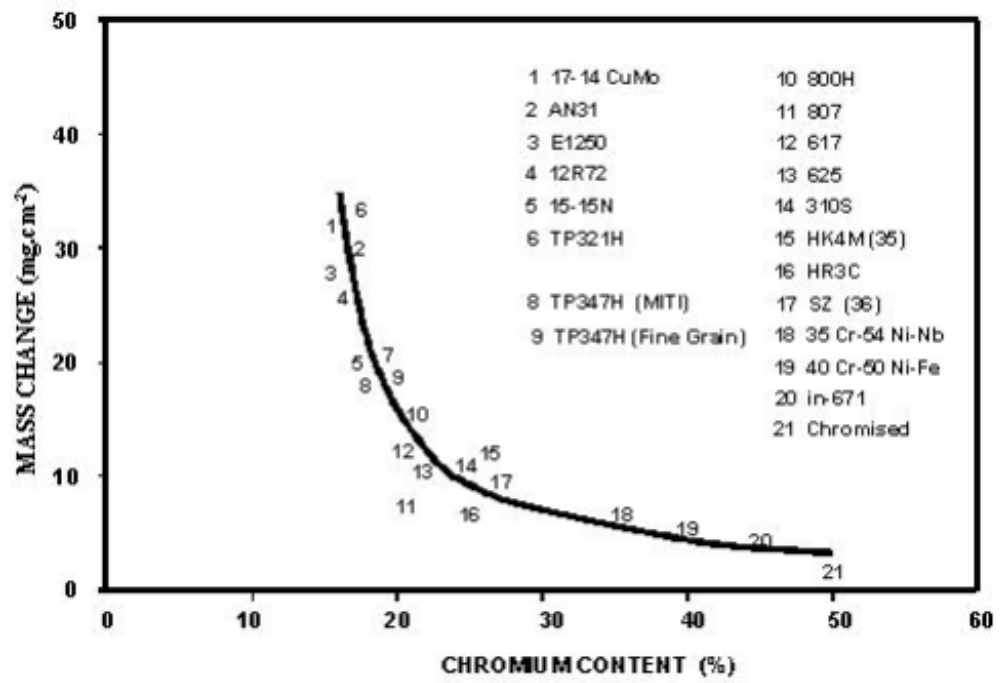

Figure 20. Metal loss rate as a function of chromium content for selected materials under simulated fireside corrosion conditions [33].

The addition of silicon is known to be beneficial for enhancing oxidation resistance of stainless steels used in high temperature steam [33]; the lower silicon content alloys experience higher corrosion rates [34]. Investigations by Griess and Maxwell [37] with alloys of different silicon concentrations revealed that the mass gains were generally lower for higher silicon content alloys, when being exposed to superheated steam at temperatures of $482^{\circ} \mathrm{C}$ and $538^{\circ} \mathrm{C}$. Figure 21 shows the results for $9 \mathrm{Cr}-1$ Mo steel with Si addition. 


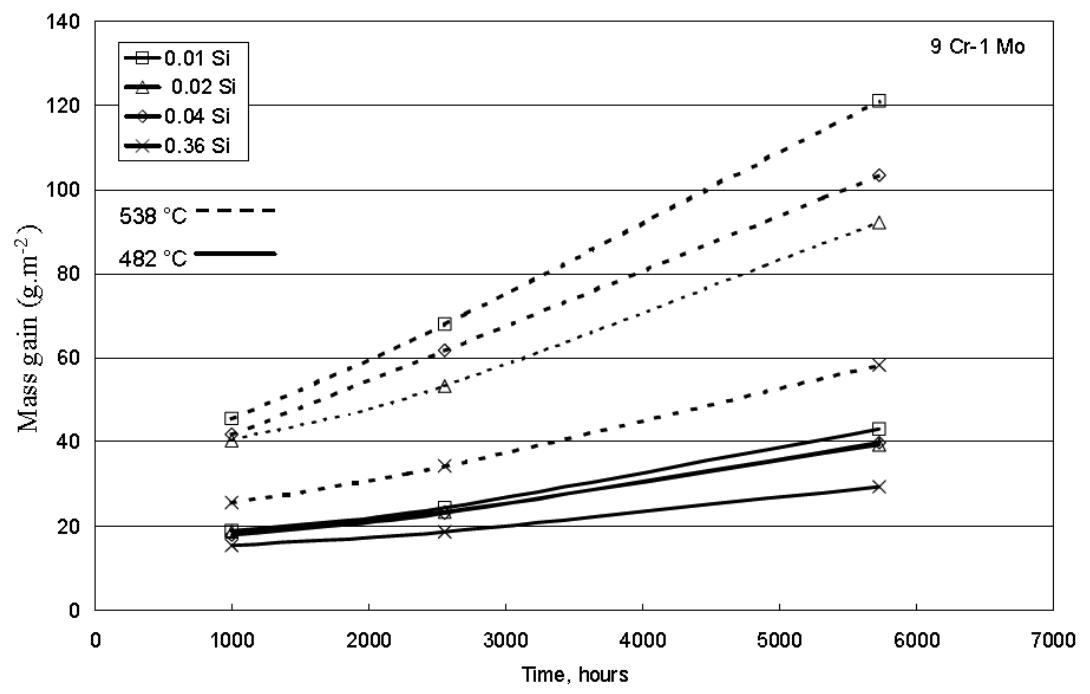

Figure 21. Effect of increasing the Si content in $9 \mathrm{Cr}-1$ Mo Steel [33].

\subsection{Candidate Materials}

In the following section, the most promising materials for supercritical water reactors will be analyzed. The mechanical properties and corrosion resistance displayed by stainless steels and high-nickel based alloys make them viable options for high temperature and pressure components as wells as for applications where superheated steam is used.

\subsubsection{Stainless Steels}

Stainless steels are widely used in industry because of their corrosion resistance; this resistance is due mainly to the high $\mathrm{Cr}$ content of alloys ( $>11 \mathrm{wt} \% \mathrm{Cr}$ ) and the formation of Chromia surface protective layer [38]. Between the three types of stainless steels, ferritic, martensitic and austenitic which are classified according to the predominant constituent of the phase structure, the austenitic steels are the most resistant to corrosion at high temperatures. They have higher $\mathrm{Cr}$ content compared to other two types, and $\mathrm{Ni}$ is also added. The temperature 
limit in oxidizing environments for these materials to maintain their oxidation resistance and mechanical properties is as high as $1000^{\circ} \mathrm{C}[38]$.

\section{Oxidation and Corrosion in Supercritical and Subcritical Water}

Austenitic stainless steels have been used in applications subjected to varying temperatures and high temperature gradients [33]. They are characterized by high coefficients of expansion which contribute to oxide scale spallation due to thermal stresses (generated during start up (heating) or shutdown (cooling) of the reactor or due to oxide growth (volume change) at operating temperature), leading to weight losses after exposure to harsh conditions [33, 39]. In austenitic stainless steels the protective oxide is generally consisted of a two or a three oxide layer structure [40]. The outer layer is composed of magnetite with an inner layer of high amount of chromium forming either a layer of corundum structure type $(\mathrm{Cr}, \mathrm{M})_{2} \mathrm{O}_{3}$ or a spinel type $(\mathrm{Cr}, \mathrm{M})_{3} \mathrm{O}_{4}$ chromium-containing oxide $[40,41]$. Figure 22 shows the layered structure on austenitic stainless steel $800 \mathrm{H}$; in this case the outer layer is composed of both hematite and magnetite [40].

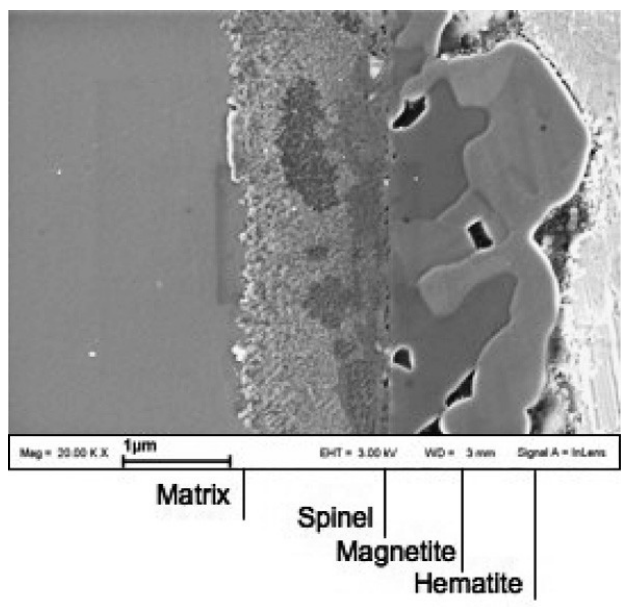

Figure 22. SEM image of the cross-section of oxide formed on Alloy $800 \mathrm{H}$ exposed to SCW at $500^{\circ} \mathrm{C}[41]$. 
At high temperatures, the difference between the corrosion (material removal) and the surface deposition of the dissolved and vaporized substances results in weight change of materials [41]. Usually there is weight gain in the samples after exposure in SCW. The weight gain and oxidation rates, according to Was et al. [40], are higher with the increase in temperature, pressure and oxygen content in water for almost all the alloys studied. All of these alloys also show evidence of the presence of stress corrosion cracking, mainly intergranular. A general decrease in the maximum stress to failure with temperature and pressure was observed, but the strain to failure does not show a clear trend [40].

Previous studies by Otoguro at al. [39] showed the behaviour of austenitic stainless in supercritical water and subcritical conditions (supercritical temperatures but subcritical pressures). It was considered that the resistance to oxidation should be measured by loss in weight after descaling of the tested steels. Figure 23 shows the influence of pressure and high temperatures on the weight loss of four different steels with compositions shown in Table 2; the higher pressure and temperature resulted in greater lose in weight. The scale on the materials was thicker at higher temperatures. Also observed was that steels with $\mathrm{Ni}$ addition were more oxidation resistance even though it had less $\mathrm{Cr}$ concentration; $\mathrm{Ni}$ was believed to have prevented the growth of the scale layer.

Table 2. Compositions of four Steels [39].

\begin{tabular}{|c|c|c|c|c|c|c|c|c|c|}
\hline & $\mathbf{C}$ & $\mathbf{N i}$ & $\mathbf{C r}$ & $\mathbf{M o}$ & $\mathbf{T i}$ & $\mathbf{N b}$ & $\mathbf{B}$ & $\mathbf{N}$ & $\mathbf{C u}$ \\
\hline Steel A & 0.07 & 11.3 & 17.8 & - & - & 0.72 & - & 0.01 & - \\
\hline Steel B & 0.11 & 14.5 & 15.9 & 2.50 & 0.24 & 0.43 & - & 0.01 & 3.1 \\
\hline Steel C & 0.07 & 25.2 & 20.1 & 1.56 & 0.06 & 0.27 & 0.004 & 0.18 & - \\
\hline Steel D & 0.08 & 33.7 & 22.1 & 1.46 & 0.12 & 0.19 & 0.005 & 0.03 & - \\
\hline
\end{tabular}




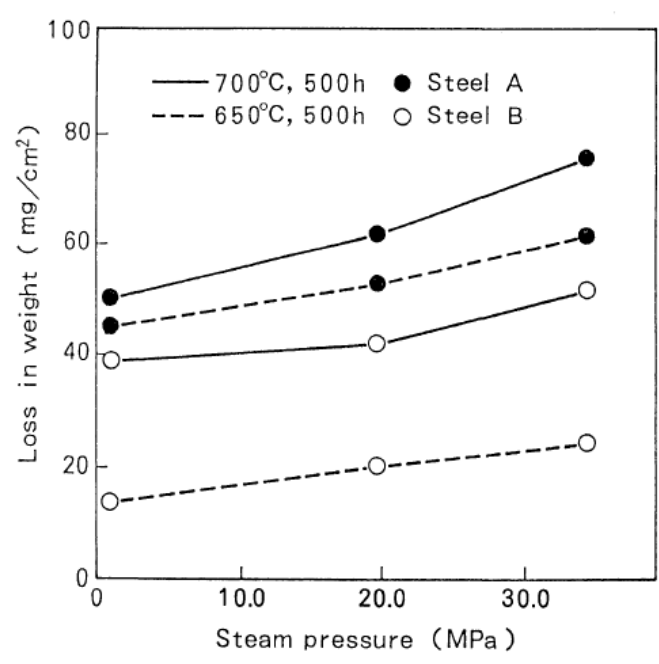

(a)

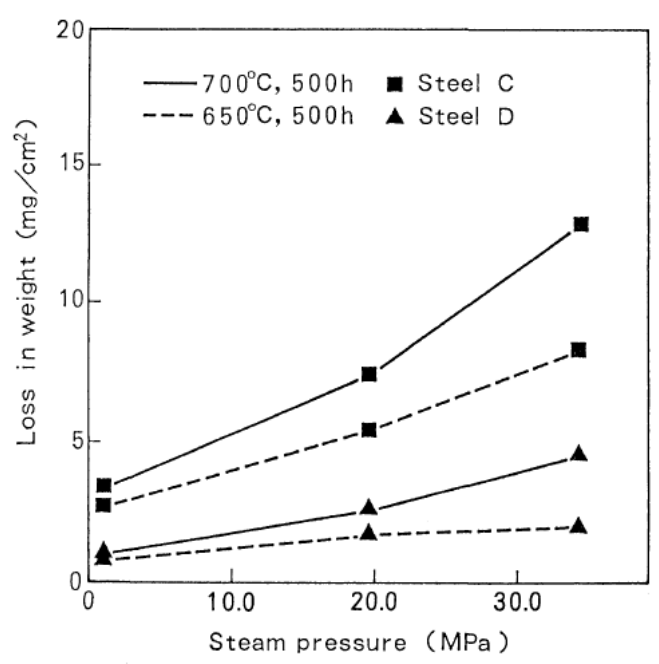

(b)

Figure 23. Loss of weight after descaling at various temperature and pressure of a) A: SUS 347HTB, B: 17-

$14 \mathrm{CuMo}$ b) C: $20 \mathrm{Cr}-25 \mathrm{Ni}, \mathrm{D:}$ 22Cr-35Ni [39].

Studies conducted by Zhang et al. [41] show that austenitic stainless steel 304NG (0Cr19Ni10) has weight gain similar to that of nickel base alloys, but the corrosion rates are considerably increased when temperatures are higher than $600^{\circ} \mathrm{C}$. Figure 24 shows the morphology of the oxide found on the surface of 304NG alloy. A kind of nodular corrosion morphology is observed at the surface. As a result of the loss and supply of $\mathrm{Cr}$ to the surface, oxide islands appear and corrosion pit grow from the interior [41]. 


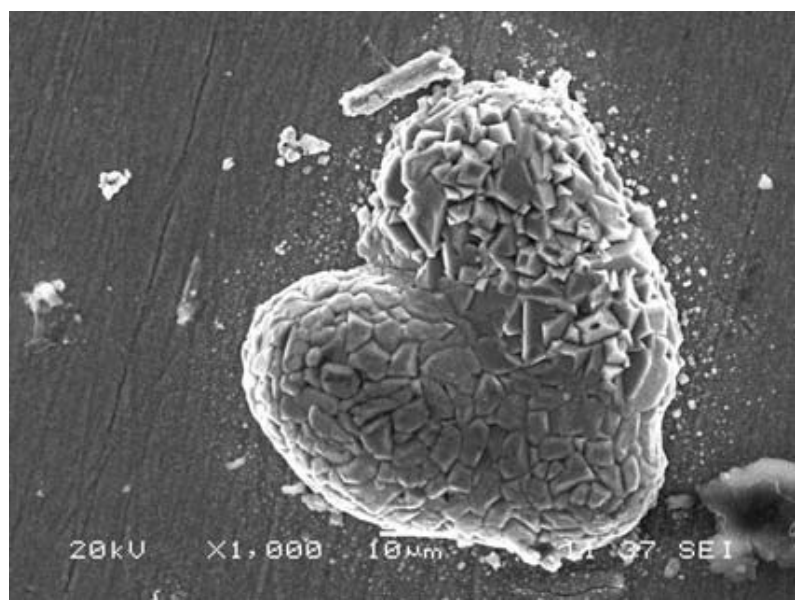

Figure 24. Surface oxide morphology in stainless steel $304 \mathrm{NG}$ after exposure to $\mathrm{SCW}$ at $650^{\circ} \mathrm{C}$ for $1000 \mathrm{~h}$ [41].

\section{Oxidation and Corrosion in Superheated Steam}

Otoguro et al. [39] determined that the resistance to steam oxidation was influenced by the steam pressure, temperature, and $\mathrm{Cr}$ and Ni content. Montgomery et al. [42] concluded that an increase in pressure would cause a decrease in the integrity of the oxidation layer, increasing the oxidation rate; this behavior was also observed by Otoguro et al [39]. As mentioned in the previous section, steels containing high level of $\mathrm{Cr}$ normally have better corrosion resistance and Figure 25 shows the influence of chromium content and grain size on the weight loss of austenitic steel AISI 347. In addition to Cr content, grain size and surface preparation are the two other factors that will be further analyzed in following section. An improvement in steam oxidation is also observed with increasing in $\mathrm{Ni}$ content due to the formation of $\mathrm{Ni}$-enriched surface oxide layer [39]. 


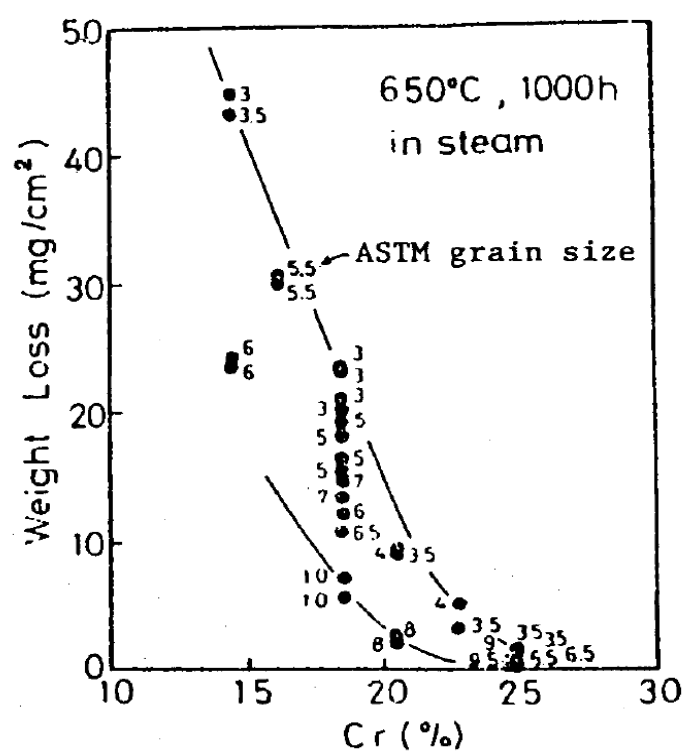

Figure 25. Effects of $\mathrm{Cr}$ content and grain size of austenitic stainless steel on steam oxidation [33].

Results obtained by Ruther and Greenberg [43] from the study of stainless steel AISI 304 suggest that the corrosion rates drastically increase in oxygenated static steam when temperature is incremented from $540^{\circ} \mathrm{C}$ to $650^{\circ} \mathrm{C}$. In dynamic tests, with superheated steam at certain velocities the corrosion rates increased up to $50 \%$. Figure $26 \mathrm{a}$ and $\mathrm{b}$ show the weight loss for stainless steels at static and dynamic conditions in superheated steam and with different surface preparations. It is noticed that the corrosion rates increase in both cases with the exposure time, the increase being greater for the dynamic condition. 


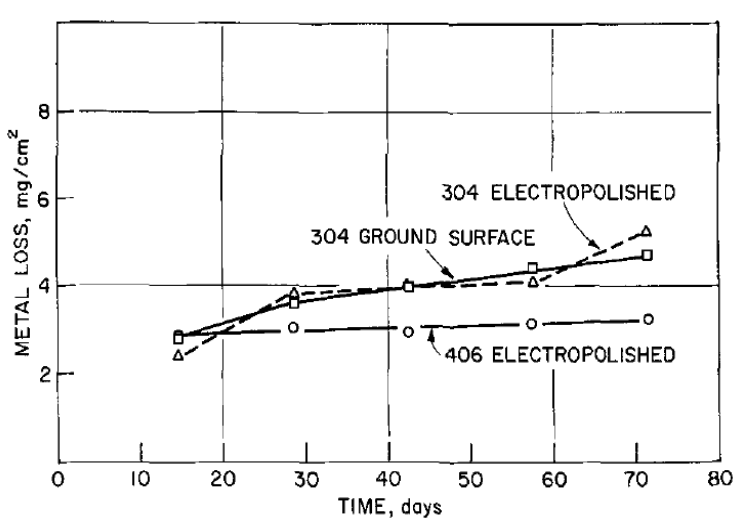

(a)

Figure 26. Corrosion of stainless steels a) in static oxygenated steam at $600^{\circ} \mathrm{C}, \mathrm{b}$ ) in flowing steam at $650^{\circ} \mathrm{C}$, and steam velocity of $61 \mathrm{~m} / \mathrm{s}$ [43].

Cisse et al. [44] found that AISI 304L samples, when being exposed to $400^{\circ} \mathrm{C}$ steam for 500 hours, had a double oxide layer developed on the surface. It was composed of an interfacial oxide layer rich in chromium and an outer layer of large magnetite crystals and smaller spinels enriched in iron and chromium [44]. Figure 27 shows schemes of these layers. The presence of chromium in the inner layer after exposure allowed this oxide layer to protect the steel from further corrosion. The thickness of the oxide layer increased as iron diffuses to the outer layer and oxygen diffuses inwards through the oxide layer. $\mathrm{Cr}$ and $\mathrm{Ni}$ enrichment at the metal oxide interface helped protect the base material [44]. The base material under the oxide layer was also found to be recrystallized, with fine elongated nanograins [44]. The thickness of the oxide layer was found to be inversely proportional to the recrystallized layer; the thicker was the oxide layer, the thinner the recrystallized one [44]. 
(a)

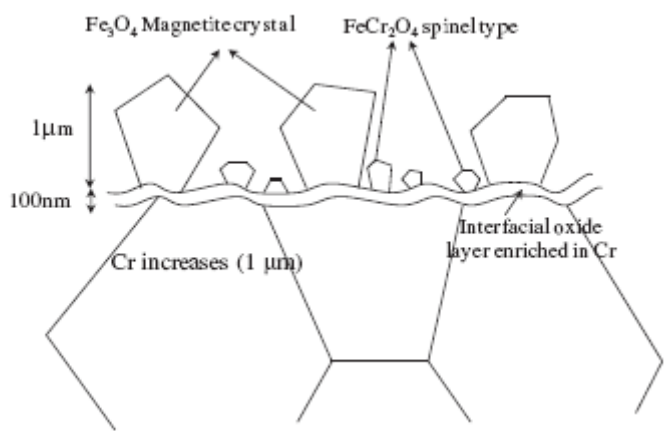

(b)

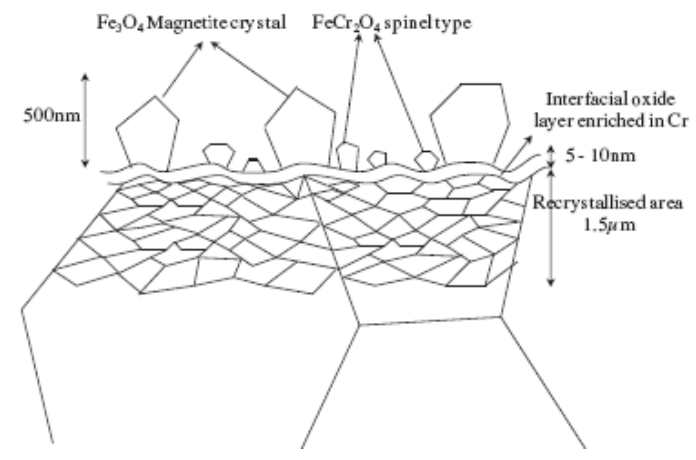

Figure 27. Oxides formed on AISI 304L surface during steam exposure: (a) polished and exposed to $400^{\circ} \mathrm{C}$ steam for $500 \mathrm{~h}$, and (b) ground and exposed to $400^{\circ} \mathrm{C}$ steam for $500 \mathrm{~h}[44]$.

\subsubsection{Nickel-Based Alloys}

Nickel-based alloys are characterized by high temperature strength and toughness. Ni-based components are thus largely used to withstand harsh environments, such as gas turbines, nuclear power plants and chemical processes. At high temperatures they exhibit good creep resistance, high surface stability and excellent oxidation and corrosion resistance [45].

\section{Oxidation and Corrosion in Supercritical and Subcritical Water}

Fujisawa et al. [46] have found that some nickel-based alloys, including the Alloy 625 (IN 625), have lower corrosion rates than the stainless steel type 316 when being exposed to both reducing and oxidizing SCW. Zhang et al. [41] reported that a variety of nickel-based alloys, after being exposed to SCW at $550^{\circ} \mathrm{C}$ and $25 \mathrm{MPa}$ for 1000 hours, had just a slight weight gain.

Weight gain in Ni-based alloys is smaller when compared to ferritic-martensitic steels and austenitic steels [40]; for Alloy 625 it reached up to three times lower of the weight gain than stainless steel 316 [40]. Figure 28 shows the weight gain for Alloy 625 under one subcritical and two supercritical temperatures for various exposure times. Weight gain for Alloy 625 at 
subcritical temperature of $360^{\circ} \mathrm{C}$ is higher than the weight gain at supercritical temperature; the effect of a higher water density (under subcritical condition) could be the reason for the increased weight gain [40]. The oxide layer was found to be very thin and the presence of pitting was also noticed on the Ni-based alloy surface.

In a study by Kritzer at al. [47] of the same alloy (IN 625), it was determined that NiO protected the alloy in a wide range of temperatures due to the thermodynamic stability of the oxide, but this protective effect was found to be decreased when the temperature was increased. For subcritical temperature of $150^{\circ} \mathrm{C}$, intergranular attack with a penetration depth of $20 \mu \mathrm{m}$ was observed in the alloy. For supercritical temperatures the critical range for higher corrosion rates was determined to be between $420^{\circ} \mathrm{C}$ and $500^{\circ} \mathrm{C}$; pitting corrosion was also noted in the alloy at high temperature [47].

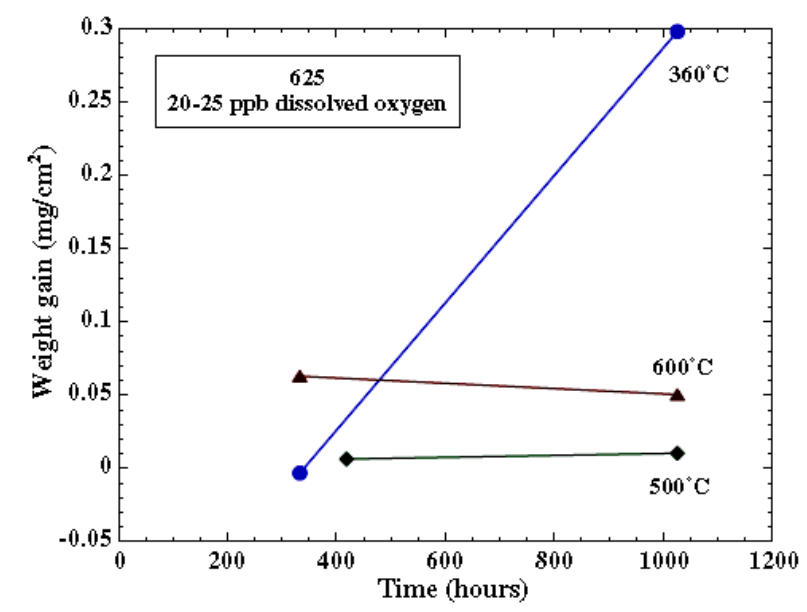

Figure 28. Weight gain as a function of exposure time for IN 625 in low oxygen concentration water (0.02$0.025 \mathrm{ppm})$ at $360^{\circ} \mathrm{C}, 500^{\circ} \mathrm{C}$, and $600^{\circ} \mathrm{C}[40]$ 
Was et al. [40] observed that on the oxide surface, oxygen and chromium were enriched at grain boundaries and there was a lack of nickel (Figure 29). While in the layer just beneath the surface oxide the chromium was depleted at grain boundaries where a small enrichment of nickel was found. The grain boundaries are the primary route for delivering chromium to the surface, leading to $\mathrm{Cr}$-rich oxides preferentially forming above the grain boundaries and $\mathrm{Cr}$ deficient grain boundaries at the metal surface [40].

(a)

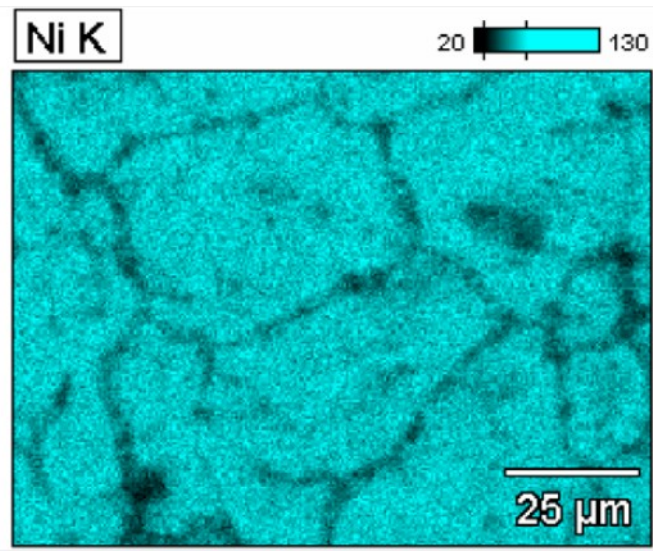

(b)

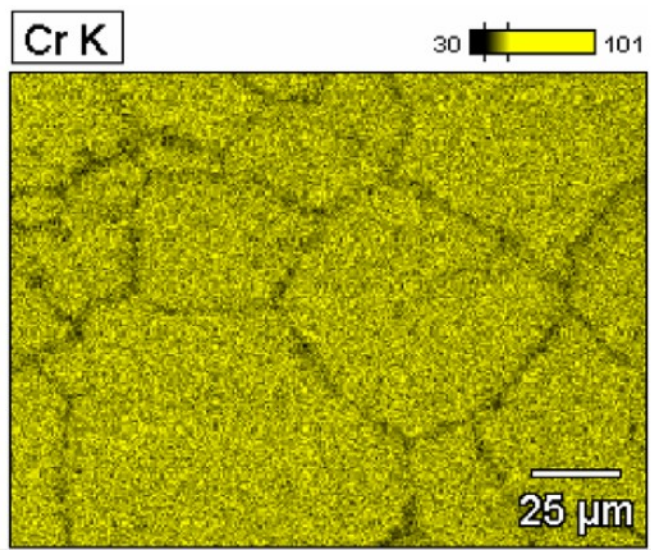

Figure 29 (a) Grain boundary region lacking of $\mathrm{Ni}$ (b) Inner layer with Cr depletion [40].

\section{Oxidation and Corrosion in Superheated Steam}

Early studies by Ruther and Greenberg [43] in superheated steam conditions, nickel based alloys, Inconel 600, 625, X750, Rene'41 and Incoloy 800 (compositions shown in Table 3), showed a higher corrosion resistance than that of stainless steel 304 in short static and dynamic tests. IN 625, along with the other nickel alloys, exhibited an increased weight loss (after descaling) with increased exposure time; however, this weight loss in IN 625, Rene'41 and Incoloy 800 was lower than that in stainless steel 406 after long exposure time [43]. Figure 30 shows the higher corrosion resistance of IN 625, Rene'41 and Incoloy 800 with respect to 304 
and 406 stainless steel. The corrosion resistance of Inconel 600 and X750 was considered poor in comparison with the other alloys in extended testing [43].

Table 3. Compositions of Selected Ni-based Alloys and Stainless Steels [43].

\begin{tabular}{|c|c|c|c|c|c|c|c|c|c|c|c|}
\hline Alloy & Al & Cr & C & Fe & Mo & Mn & Ni & P & Si & S & Other(s) \\
\hline IN 625 & 0.17 & 22.0 & 0.03 & 1.86 & 8.75 & 0.12 & 62.3 & - & 0.25 & 0.007 & $\begin{array}{l}\mathrm{Nb}+\mathrm{Ta}(4.24), \\
\mathrm{Ti}(0.23)\end{array}$ \\
\hline Incol.800 & - & 20.0 & 0.04 & 45.2 & - & 0.85 & 33.0 & - & 0.4 & 0.007 & $\mathrm{Cu}(0.41)$ \\
\hline IN X750 & 0.74 & 15.13 & 0.04 & 6.87 & - & 0.45 & 72.5 & - & 0.25 & 0.007 & $\begin{array}{l}\mathrm{Cb}+\mathrm{Ta}(0.98), \\
\mathrm{Ti}(2.62)\end{array}$ \\
\hline Rene' 41 & 1.52 & 19.05 & 0.07 & 0.3 & 9.83 & - & $\mathrm{R}$ & - & 0.5 & 0.005 & $\begin{array}{l}\mathrm{Ti}(3.21), \mathrm{Co} \\
(10.95)\end{array}$ \\
\hline IN 600 & - & 16.3 & 0.04 & 7.24 & - & 0.17 & 75.9 & - & 0.29 & 0.007 & - \\
\hline $\mathbf{4 0 6}$ & 4.48 & 13.1 & 0.11 & $\mathrm{R}$ & - & 0.44 & 0.36 & 0.019 & 0.46 & 0.007 & - \\
\hline $\mathbf{3 0 4}$ & - & 18.2 & 0.07 & $\mathrm{R}$ & - & 1.68 & 8.76 & 0.026 & 0.85 & 0.01 & - \\
\hline
\end{tabular}

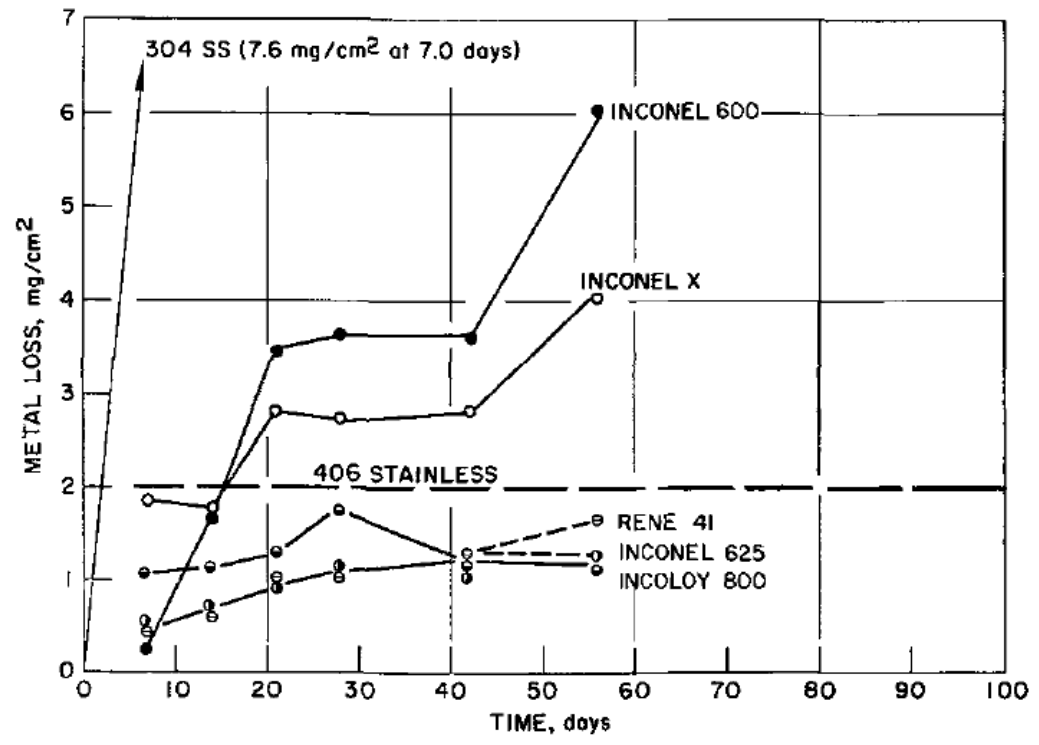

Figure 30. Corrosion of nickel alloys in flowing steam at $650^{\circ} \mathrm{C}$ and $61 \mathrm{~m} / \mathrm{s}$ velocity [43]. 


\subsubsection{Influence of Surface Conditions}

It has been determined that the characteristics of the surface finish of metals influencing corrosion are: roughness, the presence of an oxide (thin film), the mechanical (residual stresses) characteristics, and physical characteristics (contamination, asperities) at microscopic level [48]. The oxide presence has been discussed in previous sections and may offer protection to the substrate metals. The roughness or surface finish and the near surface structural characteristics will be briefly discussed below.

The effect of surface finish on the corrosion behaviour in stainless steels at high temperature steam was studied by Warzee et al. [48]. The work showed that for temperatures between 250 and $300^{\circ} \mathrm{C}$ the surface condition didn't have a marked effect on the corrosion rates of stainless steels. It was recommended that machine finishing or pickling in acid may improve the corrosion resistance in these conditions [48]. In Figure 31, the corrosion rates of stainless 304 with different surface finishes are provided for two conditions: pressurized water at $300^{\circ} \mathrm{C}$ and steam at $400^{\circ} \mathrm{C}$. It can be noted that higher metal loses occurs when the sample is polished to 600 grit in the first test (Figure 31), while the metal suffers the most losses if the surface is electro-polished for the steam at $400^{\circ} \mathrm{C}$ test (Figure 31 ). 


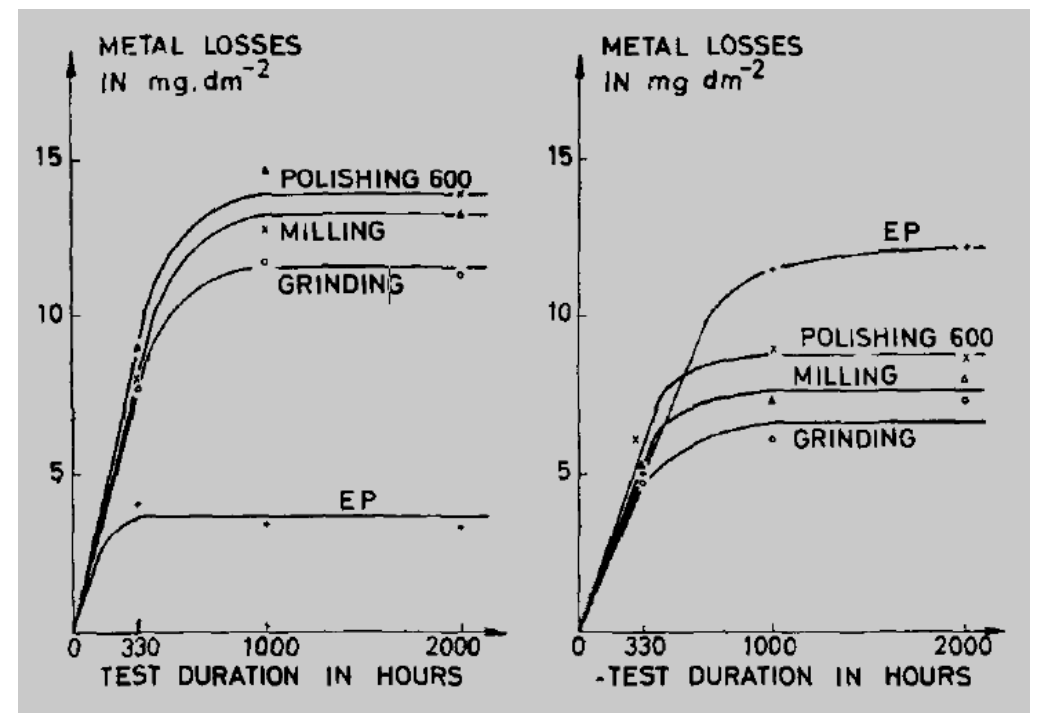

Figure 31. Corrosion of AISI 304 in autoclaves: (a) (left) $300^{\circ} \mathrm{C}$ in autoclave (b) (right) Flowing steam at $400^{\circ} \mathrm{C}$ and $200 \mathrm{~kg} / \mathrm{cm}^{2}$ [48]. EP=electrolytic polishing.

According to Warzee et al. [48] the corrosion of stainless steel in superheated steam is highly influenced by the surface condition, with the surface cold work being the most important of all factors. Samples with a greater degree of surface cold work showed a considerable reduced corrosion rate at $500^{\circ} \mathrm{C}$, this can be a consequence of an enriched $\mathrm{Cr}$ on the surface after the process of cold work and exposure to heat; this increased $\mathrm{Cr}$ present on the surface provided a better corrosion resistance to the alloy(s) [48]. Modifying the grain size is another method to improve the corrosion resistance of alloys. Higher grain boundary density (i.e., smaller grain sizes) facilitates $\mathrm{Cr}$ ions to diffuse faster into the surface regions [49] where it reacts with oxygen forming $\mathrm{Cr}_{2} \mathrm{O}_{3}$ protective layer. The effect of surface condition will change with temperature. Figure 32 shows the corrosion rates change of mechanically treated and electropolished samples as a function of temperature. It can be noted that the surface condition effects are not significant below $350^{\circ} \mathrm{C}$ [48]. These effects increase notably with high 
temperature; by the time a $600^{\circ} \mathrm{C}$ is reached, as also shown in Figure 32 , the mechanical treated surface sample has a metal loss 50 times lower than the electro-polished one.

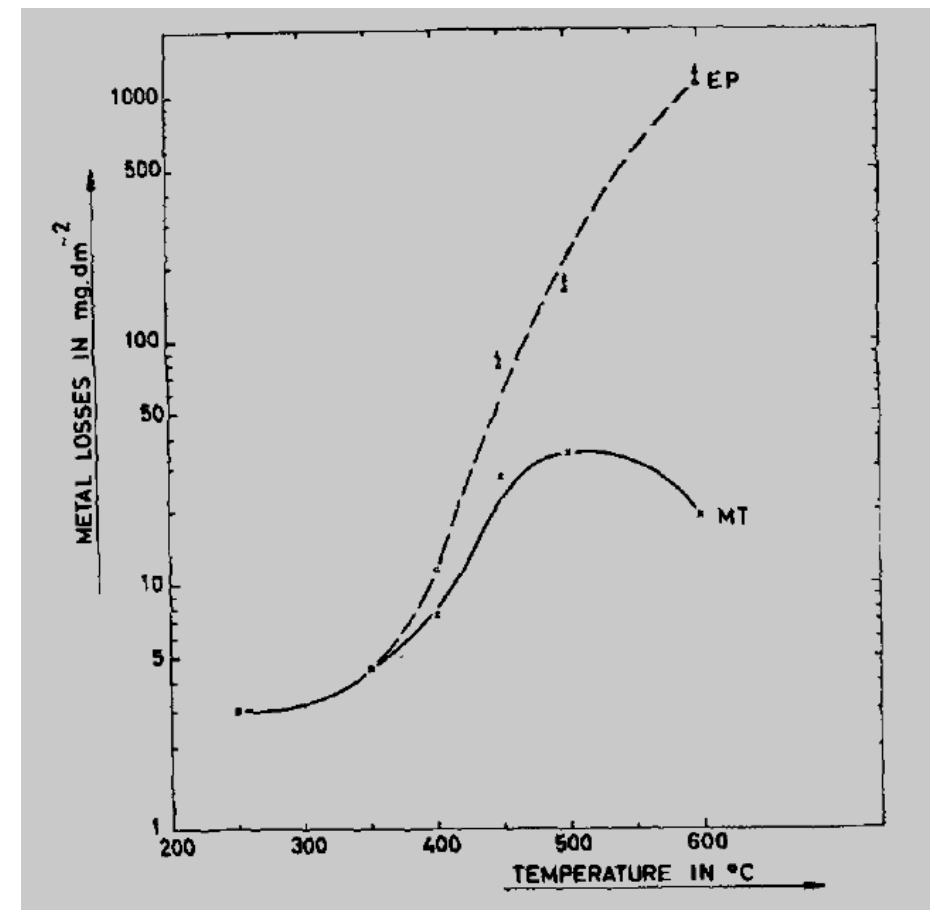

Figure 32. Total corrosion of AISI $304 \mathrm{in} 1000 \mathrm{hr}$ in superheated steam (autoclaves) [48].

Similarly, Ruther and Greenberg [43] also claimed that surfaces cold work improved the corrosion resistance of AISI 304 stainless steel. A sample with 50\% cold work showed less corrosion than the sample in the initial condition when tested in superheated steam at $650^{\circ} \mathrm{C}$. Stainless steel samples that were electro-polished suffered a higher degree of corrosion in superheated steam. In the same study it was found that samples of nickel-based alloys (Inconol 800, Inconel 600 and X750) displayed more corrosion dependence on surface finish in steam with low oxygen content [43].

Shot peening is cold working technique used to increase oxidation resistance of stainless steels in supercritical water [50]. This surface modification allows for faster diffusion of chromium to 
the surface to produce the protective oxide scale of $\mathrm{Cr}_{2} \mathrm{O}_{3}$, the same way as that occurs in the grain size refinement. Tan et al. [50] demonstrated that alloy $800 \mathrm{H}$ with improved oxidation resistance in supercritical water after shot peening. 


\section{Chapter 3. Summary and Thesis Objectives}

After consulting the literature, a lack of information about samples exposed to subcritical conditions of high temperature and subcritical pressure was noted. There was also a shortage or almost no information concerning materials exposed to temperatures higher than $650^{\circ} \mathrm{C}$.

Based on the literature review presented above, most alloys suffered from some form of corrosion/oxidation in corrosive supercritical/subcritical water or superheated steam. So far, there is no single alloy that currently has shown satisfactory performance to enable it to be used for fuel cladding or components transporting fluid in the Gen IV SCWR where a temperature as high as $800^{\circ} \mathrm{C}$ is predicted. Performance is defined by either scale thickness increase per year, metal loss (after descaling) per year or the occurrence of large cracks. To further complicate the design process, there has not been any test conducted at temperatures near $800^{\circ} \mathrm{C}$. And no known test facility exists to test materials in supercritical water at temperatures above $650^{\circ} \mathrm{C}$ and $30 \mathrm{MPa}$, the use of superheated steam as an equivalent fluid for corrosion testing has been proposed. As part of this thesis work, the effects of pressure on the corrosion behavior of four candidate materials will be studied.

To recommend potential materials for Gen IV SCWR application, stainless steels (304 and 310) and nickel-based and nickel-iron-based superalloys (IN 625 and A-286) are selected for this research as they have the optimal balance of structural strength and corrosion resistance needed for high temperature power plant applications. Samples of each material are exposed to subcritical and supercritical water and also to superheated steam to study effects of the environment on the material's corrosion behavior. By testing in all three conditions (with 
constant temperature), a comparison of the influence of pressure on corrosion behavior of iron based, nickel based, and iron-nickel based alloys can be carried out. 


\section{Chapter 4. Materials and Experimental Procedures}

This chapter will detail the fours alloys chosen for this study and also the facility and experimental procedures used. The alloy selected for these comparative studies are: one nickel-based alloy - IN 625, an iron and nickel based alloy - A-286, and two austenitic stainless steels - AISI 304 and AISI 310. The three conditions used to test these candidate materials are: subcritical water, supercritical water and superheated steam (SHS).

\subsection{Materials and Composition}

Stainless steel grade 304 (AISI) is also an austenitic steel but with a lower $\mathrm{Cr}$ and $\mathrm{Ni}$ concentration than AISI 310. It is one the most versatile and commonly used stainless steel. It has excellent welding and forming properties, a corrosion resistance (not as good as AISI 310), and good oxidation resistance at atmospheric and hot environments. It is susceptible to stress corrosion cracking in aqueous corrosive solutions [51]. It is widely used in food processing equipment, arquitecture, chemical containers, heat exchangers and woven or welded screens for mining, quarrying and water filtration [51]. This alloy is selected for this research as a baseline for comparison. Its composition is provided in Table 4.

Stainless steel grade 310 (AISI) is an austenitic steel with high amount of $\mathrm{Ni}$ and $\mathrm{Cr}$. Its properties include good weldability, excellent resistance to oxidation and corrosion at high temperatures, moderate strength and ductility [52]. It is mainly used in furnaces, oil burners, heat treatment baskets, and heat exchangers in power plants [52]. Its composition by wt\% of element can be seen in Table 4. 
Table 4. Compositions of AISI 310 and AISI 304 [51, 52].

\begin{tabular}{|l|c|c|c|c|}
\hline \multirow{2}{*}{ Element } & \multicolumn{2}{|c|}{ AISI 310 } & \multicolumn{2}{c|}{ AISI 304} \\
\cline { 2 - 5 } & Minimum (\%) & Maximum (\%) & $\begin{array}{c}\text { Minimum } \\
\text { (\%) }\end{array}$ & $\begin{array}{c}\text { Maximum } \\
\text { (\%) }\end{array}$ \\
\hline Iron (Fe) & Remainder & Remainder & Remainder & Remainder \\
\hline Chromium (Cr) & 24.0 & 26.0 & 18.0 & 20.0 \\
\hline Nickel (Ni) & 19.0 & 22.0 & 8.0 & 10.5 \\
\hline Manganese (Mn) & - & 2.00 & - & 2.00 \\
\hline Silicon (Si) & - & 1.50 & - & 0.75 \\
\hline Carbon (C) & - & 0.25 & - & 0.08 \\
\hline Sulfur (S) & - & 0.030 & - & 0.030 \\
\hline Phosphorus (P) & - & 0.045 & - & 0.045 \\
\hline Nitrogen (N) & & & - & 0.10 \\
\hline
\end{tabular}

A-286 is an iron and Ni-based superalloy with moderate Cr content. This alloy is age hardenable and commonly used in applications where a high strength level in very low and high temperatures is required [53]. It also has a relatively high corrosion resistance under continues service. Its aqueous corrosion resistance is comparable to 316/L stainless steel [53]. It has been used to manufacture jet engine components, high temperature fasteners and for moderate corrosion applications in aqueous solutions [53]. Its chemical composition is shown in Table 5.

Inconel 625 is a nickel-based alloy that has $\mathrm{Cr}$ as second main component. The properties of this alloy include good mechanical strength at extremely low and high temperatures, excellent corrosion/oxidation resistance at high temperature, and good resistance to acids. This material is widely used in marine, aerospace and nuclear industries [54]. The material has been acquired from Dynamic Metals; its chemical composition is given in Table 6. 
Table 5. Composition of A-286 by wt\% [53].

\begin{tabular}{|l|c|c|}
\hline \multicolumn{1}{|c|}{ Element } & Minimum (\%) & $\begin{array}{c}\text { Maximum } \\
\text { (\%) }\end{array}$ \\
\hline Chromium (Cr) & 13.5 & 16.0 \\
\hline Nickel (Ni) & 24 & 27 \\
\hline Molybdenum (Mo) & 1.00 & 1.50 \\
\hline Cobalt (Co) & - & 1.00 \\
\hline Vanadium (V) & 0.10 & 0.50 \\
\hline Aluminum (Al) & - & 0.35 \\
\hline Titanium (Ti) & 1.90 & 2.35 \\
\hline Boron (B) & 0.003 & 0.010 \\
\hline Carbon (C) & - & 0.08 \\
\hline Iron (Fe) & Remainder & Remainder \\
\hline Manganese (Mn) & - & 2.00 \\
\hline Silicon (Si) & - & 1.00 \\
\hline Phosphorus (P) & - & 0.025 \\
\hline Sulfur (S) & - & 0.025 \\
\hline
\end{tabular}

Table 6. Composition of Inconel 625 (IN 625) by wt\% [54].

\begin{tabular}{|l|c|c|}
\hline \multicolumn{1}{|c|}{ Element } & Minimum (\%) & $\begin{array}{c}\text { Maximum } \\
\text { (\%) }\end{array}$ \\
\hline Nickel (Ni) & Remainder & Remainder \\
\hline Chromium (Cr) & 20 & 23 \\
\hline Iron (Fe) & - & 5 \\
\hline Molybdenum (Mo) & 8 & 10 \\
\hline $\begin{array}{l}\text { Niobium+Tantalum } \\
\text { (Nb+Ta) }\end{array}$ & 3.15 & 4.15 \\
\hline Carbon (C) & - & 0.10 \\
\hline Manganese (Mn) & - & 0.50 \\
\hline Silicon (Si) & - & 0.50 \\
\hline Phosphorus (P) & - & 0.015 \\
\hline Sulfur (S) & - & 0.015 \\
\hline Aluminum (Al) & - & 0.40 \\
\hline Titanium (Ti) & - & 0.40 \\
\hline Cobalt (Co) & - & 1.00 \\
\hline
\end{tabular}




\subsection{Samples Preparation}

IN 625, A-286 and AISI 304 were supplied in sheet form of $1.5 \mathrm{~mm}$ in thickness. AISI 310 was supplied by the manufacturer in cylindrical bars with a diameter of $12.5 \mathrm{~mm}$. A total of three samples of each material for each of the three tests were prepared. That makes a total of 12 samples for each test condition and 36 samples made for the entire research portfolio. All the steps related to the preparation process are explained below:

Cutting: AISI 310 samples were cut from a bar stock with a diamond cutter in precision saw (Buehler Isomet 1000) to $0.5 \mathrm{~cm}$ thick cylinders.

Shearing: A-286, IN 625 and AISI 304 were sheared to $2.0 \mathrm{~cm} \times 2.0 \mathrm{~cm}( \pm 0.2 \mathrm{~cm})$ squares.

Drilling: A press driller was used to drill holes of $1 / 8^{\prime \prime}(3.175 \mathrm{~mm})$ with carbide drill bits in different positions depending upon the type of material (Figure 33); this allowed for easy identification of the samples throughout the test. The holes also permitted the hanging of the samples in both autoclave (SCW and subcritical water tests) and the steam rig (superheated steam test).
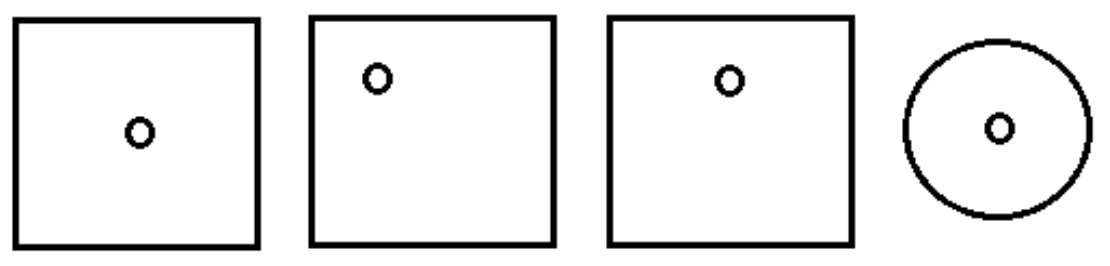

Figure 33. Position of holes for samples of each material, from left to right: A-286, IN 625, AISI 304 and AISI 310. 
Grinding: Samples were ground manually to 600 grit; grinding process was done progressively from 240, 320, 400 and ending at 600 grit. A special carbide grid paper for metallography was used in the grinding process.

Cleaning: Samples were cleaned in an ultrasonic bath (Branson 2510). First cleaning was done in water and detergent ( $1 \mathrm{drop} / 50 \mathrm{~mL}$ of water) for $45 \mathrm{~min}$ and the second cleaning was done with acetone for 15 min before fan drying.

Handling: Samples were handled with tweezers in every step after ultrasonic cleaning to avoid contamination.

Baking: Samples were baked at $200^{\circ} \mathrm{C}$ for two hours to remove all presence of moisture in a furnace (Cole-Parmer StableTemp furnace).

Weighing after cleaning: Samples were weighed three times using a Mettler Toledo AG285 scale to an accuracy of $10^{-5} \mathrm{~g}$ before being tested.

Dimensioning: All samples dimensions were taken with a caliper and recorded.

Resting: Samples were placed in covered containers and left to rest for at least 48 hours before SCW, subcritical or steam test.

Weighing after each test: Samples were weighed again 3 times after being tested.

\subsection{Testing in Supercritical and Subcritical Water Autoclave}

Testing for supercritical and subcritical water conditions was done in an autoclave. The autoclave was manufactured by Parker-Autoclave Engineers; its limits for temperature and 
pressure according to the manufacturer are $650^{\circ} \mathrm{C}$ and $38 \mathrm{MPa}$ respectively. The procedures followed for both conditions were the same, except the final achieved pressure in the autoclave. This was a direct result of the volume of water injected into the autoclave before assembling the system and turning the heating elements on. Both tests were set to the same temperature of $625^{\circ} \mathrm{C}$, but in a subcritical condition a pressure of $8 \mathrm{MPa}$ was achieved, and in the other test the supercritical value of pressure was $28 \mathrm{MPa}$.

\subsubsection{Autoclave Components and Assembling}

The assembly of the autoclave system was done following the manufacturer's manual. The autoclave was mounted in a steel structure for secondary containment; it was protected with steel plates in three sides for safety reasons. Emergency pressure release valve was also part of the system and the outlet was directly straight vertical towards the ceiling. For better detail of the system refer to Figure 34a. For hanging the samples inside the autoclave, an Inconel 625 stand was manufactured with $1 / 8^{\prime \prime}$ holes drilled for the insertion of ceramic rods to which the samples are to be hung (Figure 34b). The diagram of self-sealing pressure vessel closure assembly, provided by the manufacturer, is shown in Figure 35a. Figure 35b shows the selfsealer assembly after being cleaned with all its components in position. Copper-based sealant was used in the assembly but every effort was made to apply minimum amount of sealant to avoid the contamination of test samples. 

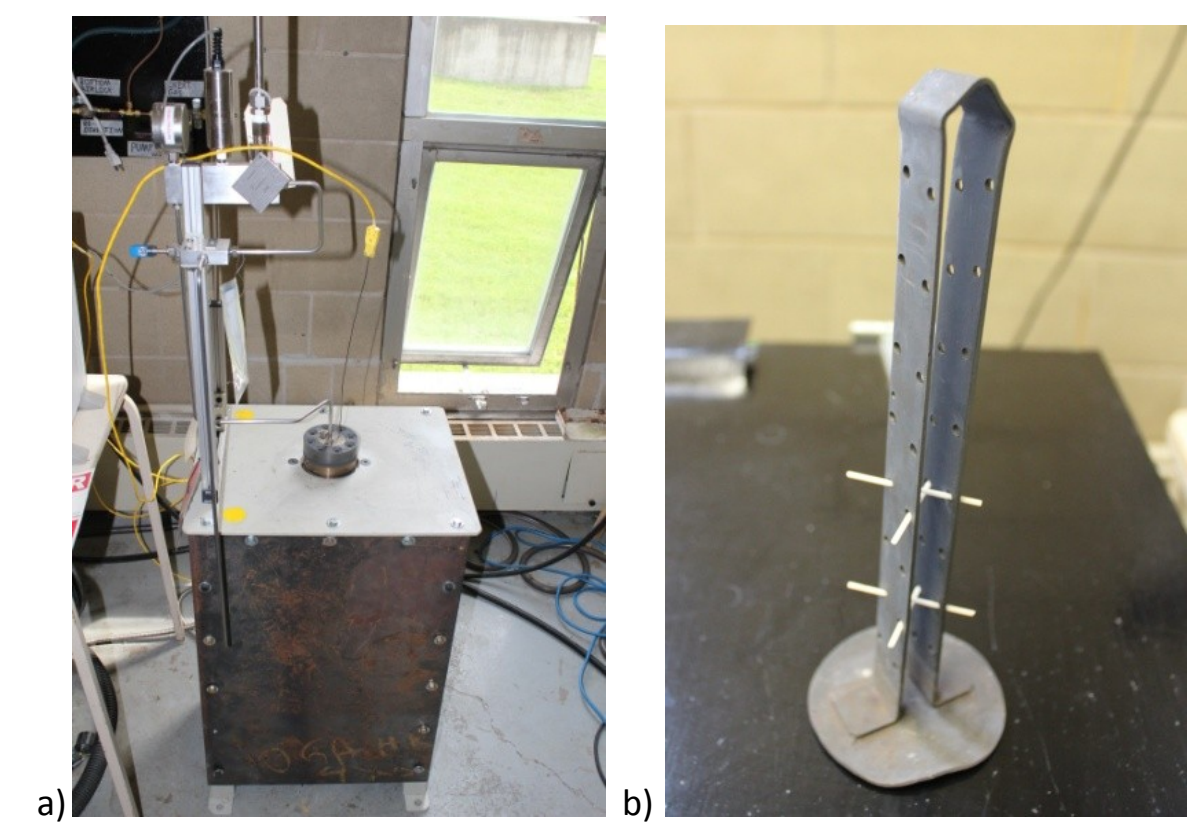

Figure 34. a) Autoclave with closure assembly. b) Metal stand with ceramic rods inserted.
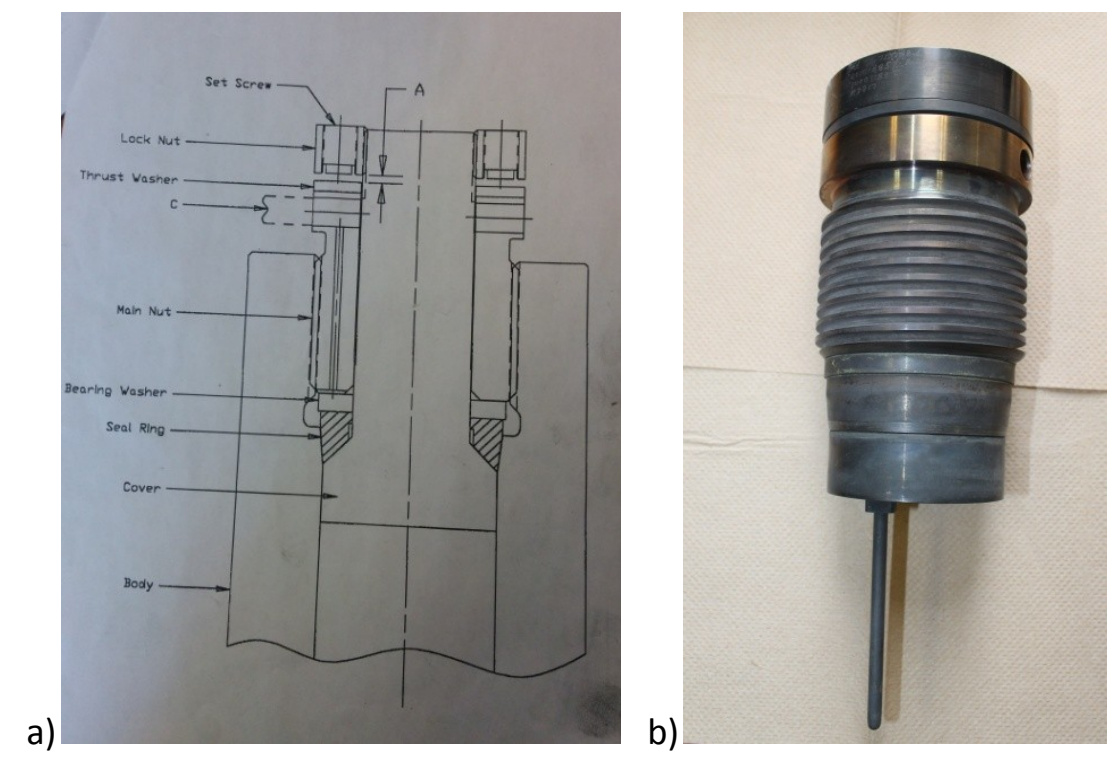

Figure 35. a) Diagram indicating components of self-sealer. b) Autoclave self-sealer closure assembly.

\subsubsection{Autoclave Operation Procedure}

The set up for autoclave for supercritical and subcritical water testing was carried out following the manufacturer's procedure. Some steps and modifications were added that allowed for 
better optimization of the process and performance. The actual procedure is detailed as follows:

1- After removing the soft rags protecting the base of the autoclave vessel (done at all times when disassembled), the threaded locations are wiped with a clean rag to remove any grease/water and further cleaned up with a vacuum to remove dry contaminants.

2- Clean all parts of the self-sealer closure assembly with a small clean brush and new rags to remove any excess of sealer lubricant from previous test or any other contamination.

3- Apply the copper lubricant to the main external threads, the bottom bearing surface of the main nut, the internal threads, the top of the seal ring, the lock nut on the internal threads, the set screw threads, the bottom of the set screws, and the sealing surfaces of the seal ring.

4- Assemble the seal ring, bearing washer, main nut, thrust washer, and lock nut onto the cover. Thread the set screws fully into the lock knot, make sure they are flush with the bottom surface of the lock nut. Then the lock nut is threaded onto the cover until the total gap between parts reaches approximately $1 / 16^{\prime \prime}$.

5- Carefully lower the samples hanging in the metal stand into the vessel opening.

6- Add distilled water to the vessel using a syringe (the water has to be tested for $\mathrm{pH}$ and oxygen concentration before being added to the vessel). To achieve $28 \mathrm{MPa}$ of pressure at $625^{\circ} \mathrm{C}$, a total amount of $105 \mathrm{~mL}$ of water was added; for a pressure of $8 \mathrm{MPa}$ at the same temperature, the volume of water added was equal to $31 \mathrm{~mL}$.

7- Lower the cover into the vessel while threading the main nut in place. The cover should not move during the installation process to avoid interference with the sample stand. 
8- Once the main nut is engaged, a tommy bar is inserted into it and tightened a quarter turn using a mallet to create the initial seal between the seal ring and the vessel body.

9- Tighten the set screws using a hex wrench by using an alternating cross pattern to evenly torque the screws. Using a torque wrench and the same pattern, the screws are tightened to $10 \mathrm{ft}$-lbs, then $20 \mathrm{ft}-\mathrm{lbs}$, then $30 \mathrm{ft}$-lbs gradually. After finishing this, the screws have to be tightened to $30 \mathrm{ft}-\mathrm{lbs}$ a second time.

10- Slide the thermocouple into the cavity on the top of the cover, ensuring no plastic part of the thermocouple is touching the top surface of the autoclave.

11- Fasten the piping to the pressure gauge and blow-off valve to the cover, ensuring the emergency valve is tightened clockwise.

12- Ensuring the front "Heater" breaker is in the 'OFF' position. Power the autoclave controller by turning the breaker 'ON' in the back of the unit.

13- The "Process temperature" setting on the controller has to be in $0.0^{\circ} \mathrm{C}$ to ensure the controller fuse does not blow when the autoclave controller is powered on.

14- Powered the heater with the "Heater" breaker, keeping in mind not to touch the "Mixer" breaker beside it.

15- Raise the "Process Temperature" gradually $\left(100^{\circ} \mathrm{C}\right.$ at a time) to the desired test temperature. To reach a stable $625^{\circ} \mathrm{C}$, approximately five hours are required. The "Process Pressure" should be monitored to ensure the pressure does not spike above 5546 psi.

Figure 36 shows a view of the system after it has reached stable condition at $625^{\circ} \mathrm{C}$. Pressure and temperature were check on daily basics and no changes were observed in 3000 hours of test for supercritical and subcritical conditions. 


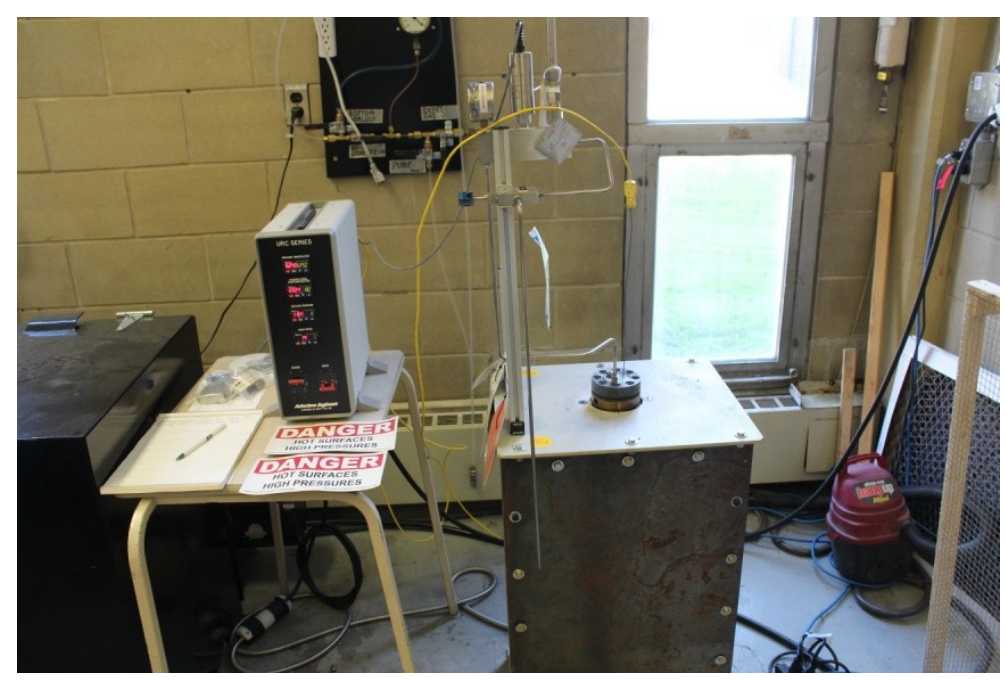

Figure 36. Autoclave stable at $625^{\circ} \mathrm{C}$.

Following the specific amount of hours for every test, samples were brought out of the autoclave for cleaning and weighing. The procedure for the disassembly of the system is as follows:

1- In the autoclave controller box turn off the "Heater" breaker.

2- Ensure that the temperature start to descend. The complete cooling process takes approximately from 24 to 32 hours, depending on room temperature. Before continuing with the next step, ensure that that the temperature indicator in the controller is close to room temperature.

3- Open the emergency pressure valve to relieve any excess pressure.

4- Remove all connections from the cover: the thermocouple and the piping to the pressure gauge and emergency valve.

5- Loosen all set screws from the lock nut by using a torque wrench and doing an alternating cross pattern. 
6- Insert a tommy bar into the main nut. Tap the bar to loosen the main nut approximately half a turn; ensuring that the cover does not rotate with the main nut.

7- Evenly tighten any two opposing set screws to pull free the seal ring that should be wedged into the body.

8- Lift the cover and unthread the main nut in order to remove the closure; ensuring the cover does not rotate while unthreading the main nut.

9- Bring the stand with samples out of the vessel. Dry and clean the vessel interior and threads as well as the closure assembly. Ensure to cover the vessel opening, until the next operation to avoid contamination.

\subsection{Testing in Superheated Steam Rig}

A custom steam rig was used for the superheated steam testing. The system was already setup from previous research works, but some modifications/corrections were implemented due to a failure. The steam generator and the superheater units unit were manufactured by Micropyretics Heaters International (MHI). The description of the system, parts and its setup are described below.

\subsubsection{Steam Rig Components and Set-up}

The list of the equipment and the custom build components that form the steam rig are shown in Table 7. 
Table 7. Steam rig major components and function.

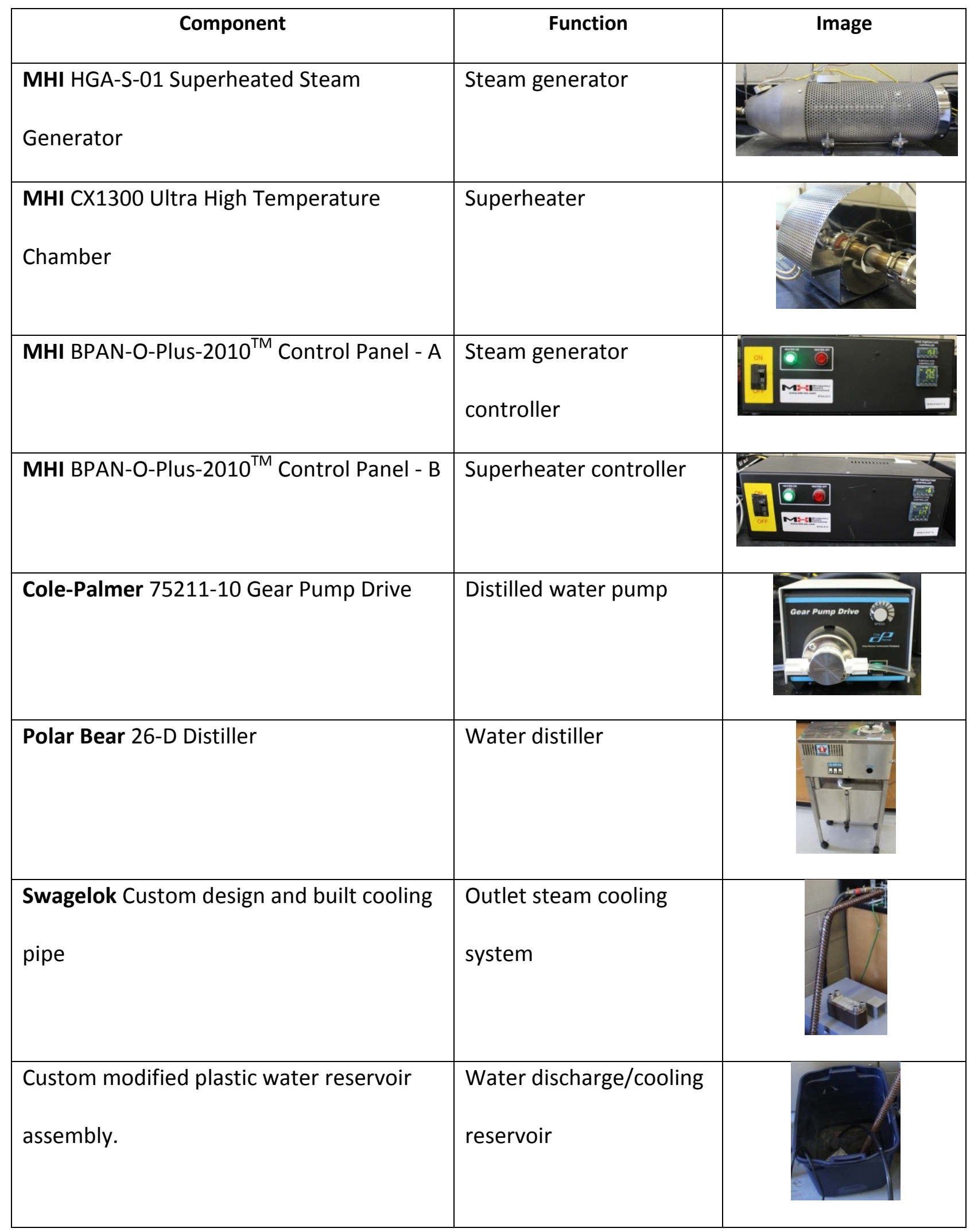


For a better understanding of the system, Figure 37 shows a diagram of the components of the superheated steam rig and their connections.

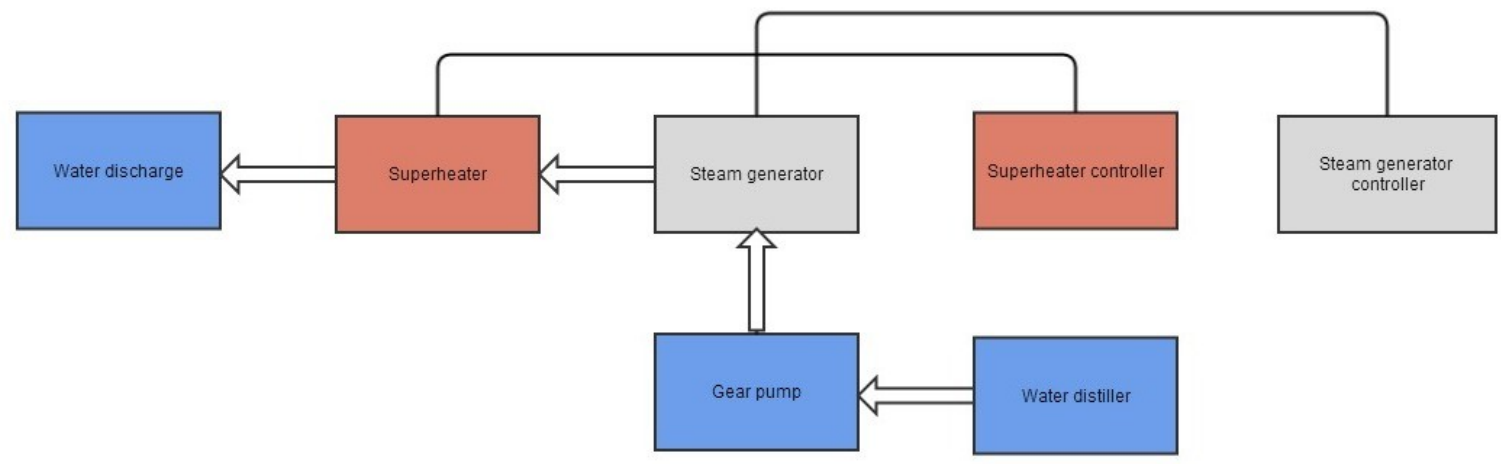

Figure 37. Diagram of superheated steam rig.

The water for the gear pump comes from a water distiller. The use of distilled water is recommended by the steam generator manufacturer to maximize its useful life. The water distiller receives water automatically from the tap when the level is low. It has a capacity of generating $1.1 \mathrm{~L}$ of distilled water per hour. To ensure that the distiller provides sufficient water supply to the gear pump, the heaters for the distillation process automatically turns on and off depending of the water level in the distillation reservoir.

The gear pump acquired from Cole-Parmer proves to be much reliable than the peristaltic pump provided with the system by $\mathrm{MHI}$ as it allows longer testing time without failure. All the flex tubing for interconnections was provided by $\mathrm{MHI}$ and Cole-Parmer. The steam generator is rated to produce a superheated steam with peak temperature of $450^{\circ} \mathrm{C}$ in the outlet; although it is recommended by the manufacturer to stay below $300^{\circ} \mathrm{C}$ for the longer use. The steam leaves the steam generator and continues its flow to the superheater where it reaches the final 
desired temperature of the test. The superheater is rated to a maximum temperature of $1300^{\circ} \mathrm{C}$; for the current test it was setup to $625^{\circ} \mathrm{C}$. The steam flows inside a $1.5^{\prime \prime}$ diameter and 18" long stainless steel 316 tube costumed built for the system. The alumina tube provided by the manufacturer didn't stand the temperature gradients and suffered from cracking. The connection of this stainless tube to the steam generator outlet and the discharge cooling piping presented some challenges. In the end, a silicon gasket was used in the inlet side of the superheater. A graphite gasket acquired from Hydro Silica Equipment Ltd., which is rated to $625^{\circ} \mathrm{C}$ and more, was used in the superheater outlet side. Figure 38 shows a view of the superheater and the two gaskets: the orange gasket on the right side is the silicon one, the black color gasket on the left side is made of graphite.

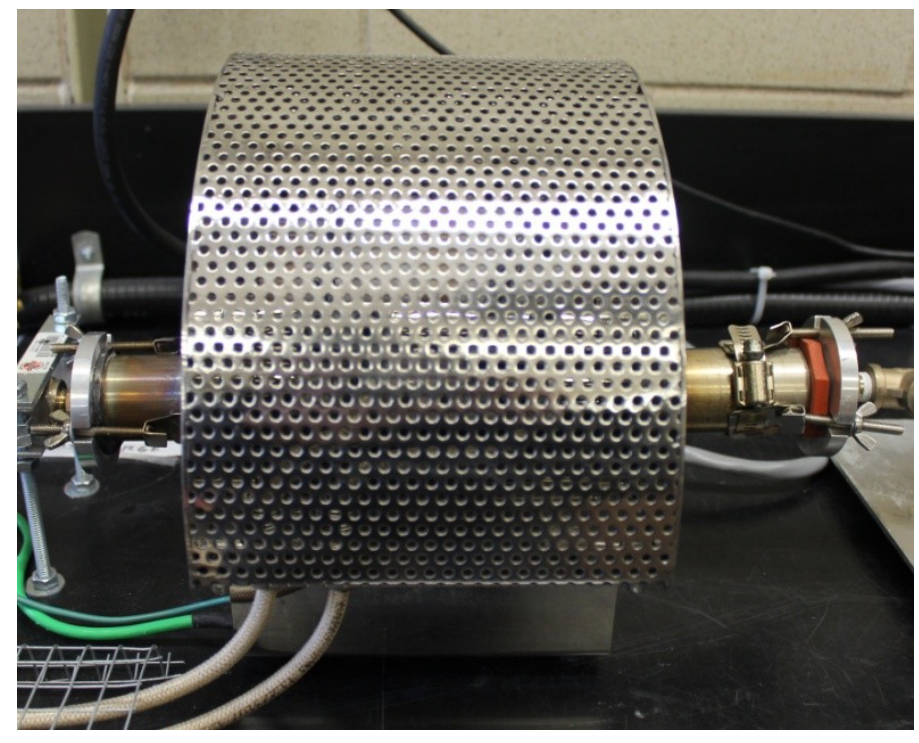

Figure 38. Superheater and gaskets.

The samples were hanged on ceramic rods positioned in 1/16" holes drilled into a $1 \mathrm{~mm}$ thick Inconel 625 costumed designed stand. The stand has a rectangular shape with two sides measuring $18 \mathrm{~mm}$ deep. The bottom of the stand measures $25 \mathrm{~mm}$ wide and $280 \mathrm{~mm}$ long. 
This stand was placed inside the stainless steel tubing inside the superheater. A view of the stand with the ceramic rods placed in the holes can be seen in Figure 39. The positioning of the samples in this custom designed stand allowed for a uniform exposure of all sides to the superheated steam flow.

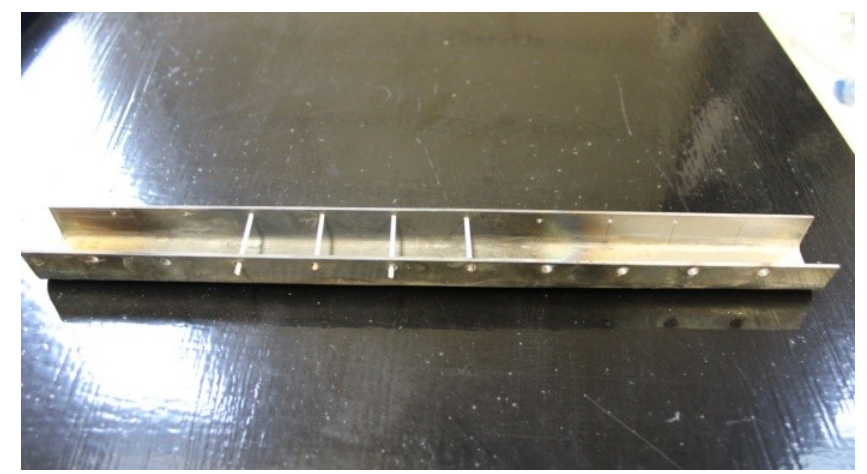

Figure 39. Superheater steam sample stand with ceramic rods.

The discharge cooling system was custom designed from previous research and built by Swagelok. It consists of a $1 / 4$ " dia. copper tubing wrapped around a pipe of stainless steel tube of $2 "$ in diameter. The stainless tube is fitted and fasten in the superheater outlet; it directs the exhaust steam from the superheater to the water reservoir. The copper tubing is connected to a supply with flowing cold water to condensate the exhaust steam and also provide cooler water to the reservoir. An open loop cycle was used; the water in the reservoir is pumped to a drainage with a regular yard pump that is activated automatically by a float valve.

Figure 40 shows a picture of all steam rig components assembled together and ready to be powered on. The system worked at steady temperature for both the steam generator and for the superheater in the entire 1000 hours of testing time. No emergency stops or equipment failures took place during the test. 


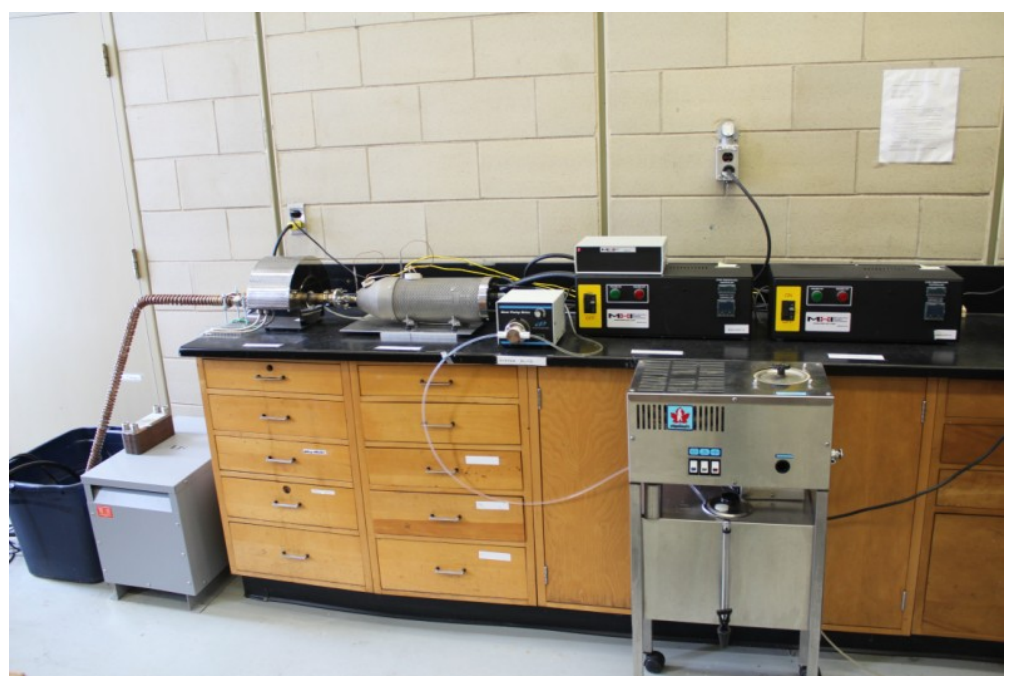

Figure 40. Assembled superheated steam rig.

\subsubsection{Superheated Steam Rig Operation Procedure}

The operation procedure for the superheated steam rig was based on the operating manual from supplier with a number of modifications and added steps to most effectively operate the system. The procedure for assembling the rig is summarized here:

1- Connect all equipment to the AC source, ensure the water supply is connected to the water distiller inlet and that there is a water connection to the pump.

2- After placing the samples in the Inconel 625 stand, position the stand with the samples inside the superheater tube.

3- Close test chamber by fastening the rubber gasket and the inlet of the superheater tube with the steam generator outlet. The graphite gasket and the outlet of the superheater should be fastened together to the cooling tubing. 
4- Start the water distiller by pressing "Power", "Fan" and "Water" switches in the 'ON' position. Important: Before turning the steam generator ' $O N^{\prime}$ ' (step 8) ensure the distilled water reservoir has an appropriate amount of water (half way full at least).

5- Ensure that the outlet flex tubing of the gear pump is disconnected from the steam generator inlet. Turn On the gear pump and prime it by moving the dial to the maximum flow or prime position. Once there is water flowing through the tubing, adjust the flow rate to approximate $0.8 \mathrm{~L} /$ hour (third division of the dial scale).

6- Power On the superheater and steam generator controllers from the panels. Set the desired temperatures in the temperature controllers - for this test they were set-up to $300^{\circ} \mathrm{C}$ for the steam generator and $625^{\circ} \mathrm{C}$ for the superheater.

7- Start the water supply to the cooling assembly of the superheater outlet by using the valve of the cooling tube coil.

8- Press "Heater On" bottom in the steam generator controller panel to start the steam production while simultaneously connect the gear pump outlet tubing to the inlet of the steam generator.

9- Start the superheater by pressing "Heater On" bottom in the superheater controller panel.

10- Wait for the components to reach desired temperature. This process takes approximately one hour. It is important not to leave the system running by itself until it is being checked for leaks or any malfunction. 
The system was checked on a daily basis for leaks or temperature drops for a total of 1000 hours of testing time. No problems were detected. Once the amount of hours has been reached, samples were brought out by following the steps outlined below:

1- Press the "Heater Off" bottom on the steam generator controller panel and simultaneously switch the gear water pump to the off position.

2- Slowly decrease the temperature of the superheater in the controller panel by a interval of $30^{\circ} \mathrm{C}$ every $30 \mathrm{~min}$ to avoid thermal shocking until the ambient temperature is reached.

3- Turn off the superheater in the controller panel by pressing the "Heater Off" bottom.

4- Switch the breaker in the steam generator and the superheater to the Off position.

5- Stop the water flow through the cooling coil using the flow valve.

6- Remove samples from inside the test tubing of the superheater by disconnecting the silica gasket side of the chamber.

\subsection{Analysis of Samples}

After finishing all the tests in the autoclave and the superheated steam rig, samples were cleaned and baked following steps 4 to 6 detailed in section 4.2. Inspection and analysis of the samples were carried out following the steps explained in the following sections.

\subsubsection{Visual Inspection}

After the samples were removed from the autoclave or furnace, they must be handled with tweezers. The first test performed was a visual inspection. During visual inspection, ensure 
there is sufficient lighting to capture adequate detail of the sample. Any visible imperfections, colouring changes, excessive oxidation and corroded areas are recorded with digital camera. White paper with the labelling of the samples is used to obtain a good contrast and make the visual inspection and identification processes easier. A Canon T3i DSLR camera was used to photograph the samples after being inspected. The results from all visual inspections done on each sample can be found in Chapter 5 .

\subsubsection{Weight Change}

The weight change in each sample is an important measure of the presence of oxidation and corrosion and how well can they withstand the conditions to which they were exposed. All samples were weighed three times, using the same Metler Toledo (Figure 41) balance, after samples were cleaned and baked. The changes in weight of all samples were recorded. The results of these changes are further discussed in Chapter 5 where absolute changes and weight change per surface area are presented.

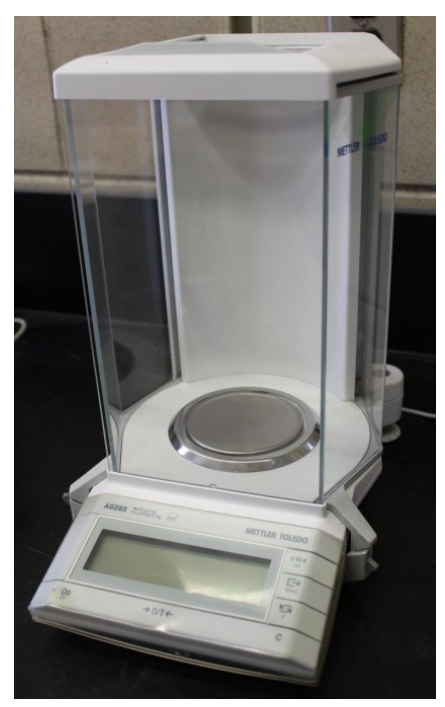

Figure 41. Digital scale Metler Toledo AG285. 


\subsubsection{Scanning Electron Microscope (SEM) and Energy Dispersive X-Ray Spectrometry (EDS)}

Scanning Electron Microscope (SEM) and Energy Dispersive X-Ray Spectrometry (EDS) were used to investigate the samples for surface changes caused by oxidation and corrosion due to the conditions applied in the tests. These analyses were performed with the assistance of Dr. Jianqung Wang in the Carleton University's Nano Imaging Laboratory. The investigation was focussed on changes of the surface microstructure and the compositions. The equipment employed is a Tescan Vega-II XMU SEM equipped with Oxford X-Ray detection systems (INCA EDS).

SEM allows for the acquisitions of very high resolution, magnified images of the surfaces. The use of electrons also allows for a high depth of field. The electrons of varying energy are produced by a filament (thermionic emission), and the electron beam is focussed by a number of electromagnetic lenses before impinging the sample surfaces. Samples are placed in a high vacuum chamber to be examined. SEM uses two methods of electron detection for imaging: Secondary electrons detection (SE) and back-scattered electrons detection (BSE).

SE relies on the detection of electrons of low energy, from the sample surface, after having an inelastic scattering interaction with the beam electrons. These electrons are detected in a secondary detector after being ejected from the k-orbital of the atom. The good quality images produced by this detection method are best suited for material's surface morphology and the brightness of the image depends on the amount of secondary electrons that get to the detector. BSE, on the other hand, consists of the detection of high energy electrons originated in the original electron beam that are reflected or back-scattered by the material after having 
an elastic interaction with the substrate atoms. BSE produces images that are chemical composition dependent since the differences in contrast between areas are based on energy loss; areas with heavier elements on the surface appear brighter. It uses a different detector from SE. The images obtained during the SEM analysis were from general and specific areas, with magnifications from 200X to a maximum of 10000X. All results are presented in Chapter 5. EDS analyze the energy of emitted x-ray to characterize the chemical composition of the material's surface. When the electrons of an inner shell, characterized by a low energy state, are ejected from a given atom/element by electrons of the incident beam, the empty space will be filled by an electron from the outer orbital, which are characterized by a higher energy state. The difference in energy between the outer and the inner shells is released in a form of x-ray. Every element has a different atomic number and unique electron configuration, which allows the determination of chemical composition by measuring the energy of the x-rays emitted. The EDS analysis was carried out on every sample before and after the exposure, overall composition of the surface was determined as well as the composition of areas of interest or any special features. 


\section{Chapter 5. Results and Discussion}

The following chapter will present the results obtained and observations made after the samples were exposed to supercritical water, subcritical water and superheated steam. The results of visual inspection, weight change, SEM and EDS analysis, using procedures explained in the previous chapter, will allow comparisons between the different materials, exposure conditions and testing times. The distilled water used in all tests was characterized by a $\mathrm{pH}$ value of 6 and an oxygen concentration of $8 \mathrm{ppm}$.

\subsection{Visual Inspection}

The visual inspection was performed on all samples and their surface appearance was recorded after being removed from their perspective testing conditions for various durations. Subcritical and supercritical water tested samples had 1000, 2000 and 3000 hours of exposure, while the superheated steam tested samples were exposed for 350, 700 and 1000 hours.

After cutting the samples, a whole was drilled to facilitate hanging before grinding. After grinding, cleaning and baking, all samples of the same type of material had the same surface appearance. Pictures of the samples before any exposure were taken and are shown in Table 8. As expected, all samples had shiny, silvery surface appearance with noticeable grinding lines in the direction that 600 grit step was performed. 
Table 8. Samples' surface appearance before any type of exposure.

\begin{tabular}{|c|c|c|c|}
\hline AISI 304 & AISI 310 & A-286 & IN 625 \\
\hline \multirow{3}{*}{$*$} & & & \\
\hline & & & \\
\hline
\end{tabular}

\subsubsection{Effects of Testing Duration and Pressure in Sub- and Supercritical Samples}

Samples of the same materials, exposed to supercritical water $\left(625^{\circ} \mathrm{C}\right.$ and $\left.29 \mathrm{MPa}\right)$ and subcritical water $\left(625^{\circ} \mathrm{C}\right.$ and $\left.8 \mathrm{MPa}\right)$, were compared for surface conditions. The tables presented below, show in sequence of various materials.

Pictures showing AISI 304 surface conditions after the two tests are included in Table 9. The oxide is more uniformly distributed on the samples exposed to subcritical condition while the SCW tested samples have more patchy appearance. In general, all samples tested in both conditions progress from grey to black with the passing of time. The subcritical water tested samples have a more evident greyish appearance than the SCW tested ones, but they tend to become darker with time. 
Table 9. Images of samples after test (AISI 304).

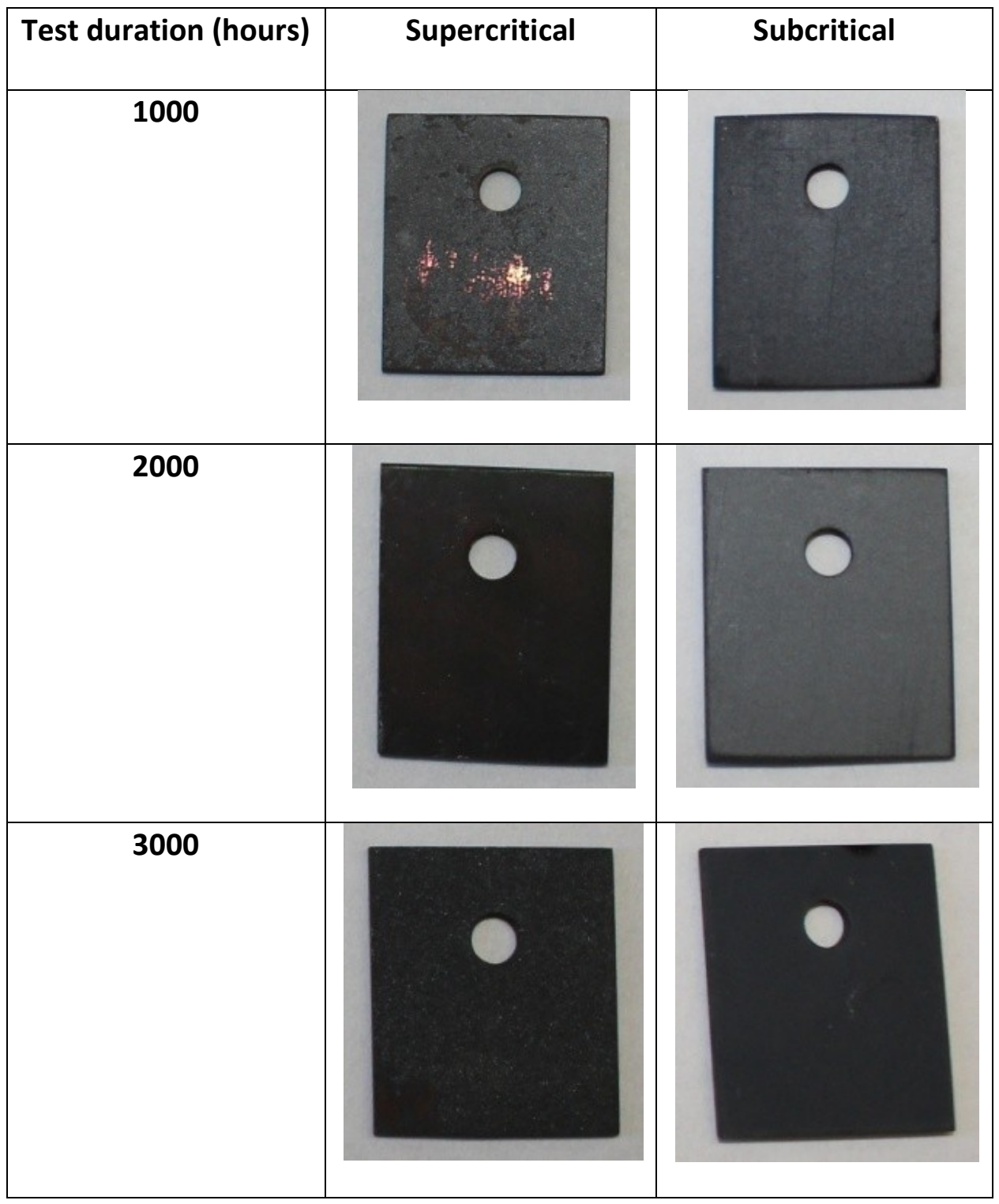

For AISI 310, pictures of samples after both tests are presented in Table 10. All samples have more surface discoloration that other three materials presented in Table 9, Table 11 and Table 12, suggesting an increased corrosion on the surface. The SCW samples all have a black and uniform corrosion surface that doesn't vary with exposure time, at least visually. Under the subcritical test condition, surfaces become more dull grey and darker with the increase of time. 
The difference between the SCW and the subcritical samples is mainly the predominant darker colour on the surface.

Table 10. Images of samples after test (AISI 310).

\begin{tabular}{|c|c|c|}
\hline Test duration (hours) & Supercritical & Subcritical \\
\hline 1000 & & \\
\hline 2000 & & \\
\hline 3000 & & \\
\hline & \\
\hline & \\
\hline & \\
\hline
\end{tabular}

Surface images for A-286, after being tested under both conditions, can be seen in Table 11. The presence of corrosion is noticed in all samples. Samples tested in SCW show changes with exposure time. A dull surface with dark-blue covering and some dispersed grey islands is 
observed in the two samples exposed to lesser time; while in the sample with 3000 hours of exposure, the surface becomes completely dark and dull with noticeable increment of grey spots, evidencing a progressed corrosion. Samples exposed to subcritical water have a more dramatic change of surface appearance with time, changing from dull grey to dark with the maximum exposure time. Samples with the same exposure time but different water condition look different, the subcritical water tested samples look more uniformly grey coloured, except for the last one which looks as dark as the SCW tested one with the absence of gray spots. 
Table 11. Images of samples after test (A-286).

\begin{tabular}{|c|c|c|}
\hline Test duration (hours) & Supercritical & Subcritical \\
\hline 1000 & & \\
\hline 2000 & & \\
\hline 3000 & & \\
\hline & & \\
\hline & & \\
\hline & \\
\hline
\end{tabular}

Surface images of IN 625, under both conditions, are presented in Table 12. Samples exposed to SCW have very similar surface appearance, irrespective of exposure time; they all have a uniform dark, dull surface, evidencing the presence of corrosion/oxidation; some small grey coloured areas are also noticed. Samples exposed to subcritical water show more reflectiveness and different colour from that exposed to supercritical water. They have a grey colour that tends to disappear and become more bronzed with the increase of exposure time; samples with 
3000 hours of exposure show little more surface corrosion than the other two samples of less exposure time. However, when comparing samples with the same exposure time but different water conditions, the supercritical ones evidence higher corrosion; results from weight change measure will further support this observation.

Table 12. Images of samples after test (IN 625).

\begin{tabular}{|c|c|c|}
\hline Test duration (hours) & Supercritical & Subcritical \\
\hline 1000 & & \\
\hline 2000 & & \\
\hline 3000 & & \\
\hline & \\
\hline
\end{tabular}


All the visual inspections suggest the presence of corrosion/oxidation in all samples and it is not possible to determine the nature of oxide changes with time visually. IN 625 was the only material that showed fewer changes in surface appearance and a lesser indication of corrosion under subcritical water conditions. A-286 and AISI 304 had more surface corrosion presence in both conditions and pronounced changes on the surface when being compared to their initial condition.

\subsubsection{Superheated Steam Samples}

Superheated steam tested samples were exposed to less time in comparison to the other samples. The main reason for this was the unstable operation of the steam rig. As a multicomponent system, it was challenging initially to keep the desired operating parameters for extended period of time (than that for the autoclave system). The maximum testing duration in the superheated steam rig was able to reach 1000 hours, same as the first testing duration for the other two types of tests. Table 13 shows the surface appearance of all the samples exposed to superheated steam conditions at $625^{\circ} \mathrm{C}$ and $0.1 \mathrm{MPa}$. 
Table 13. Images of samples after superheated steam test.

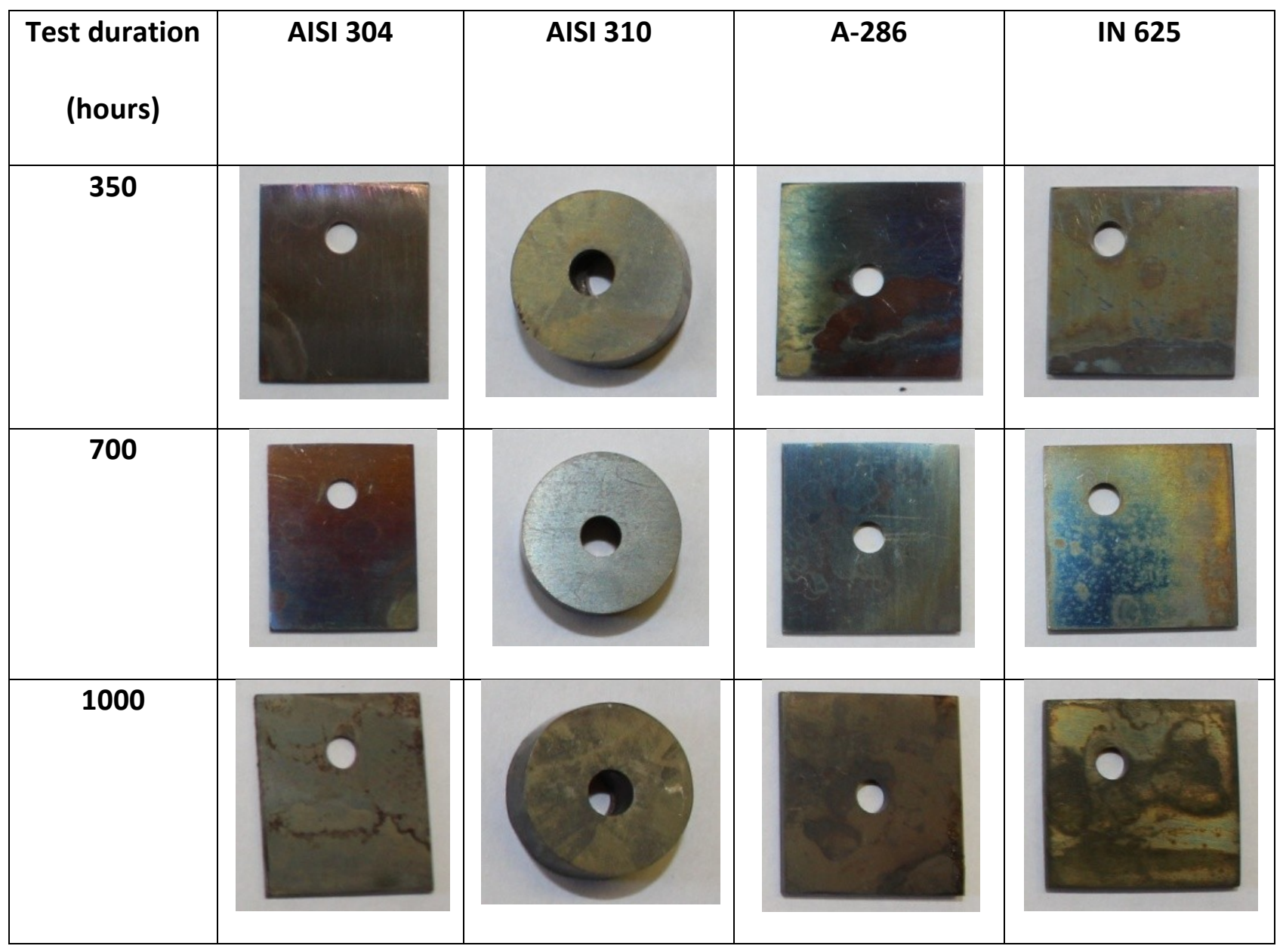

In the steam tested samples, the changes with the increase of time are more noticeable than that in the other two tests. A greater presence of corrosion is present in all fours samples with longer exposure, this corrosion is not severe, rather only small areas can be noticed. IN 625, A286 and AISI 304 all show a blue-golden coloration in the first 700 hours of exposure, changing drastically to a darker appearance at 1000 hours. A-286 has slightly more discolored area. In AISI 310, the first 700 hours produce very minor changes to the surface; the samples even preserve some of its initial silver appearance and reflectiveness. By the time it reaches 1000 hours, the sample has a similar appearance to the other three materials. 


\subsubsection{Effects of Substrate Material}

All samples with the maximum exposure time for the three conditions were further analyzed to establish visual differences in the surface that could be explained by the difference in the composition of each material. All samples tested in SCW for 3000 hours (Table 14) show uniformly corroded/oxidized surface, with A-286 and AISI 304 exhibiting higher corrosion on the surface. The higher corrosion might be a result of a lower $\mathrm{Cr}$ content in these materials in comparison with IN 625 and AISI 310. The lower Cr content prevents the formation of a stable oxide layer on the surface thus enabling more corrosion/oxidation to take place.

Table 14. Images of samples tested in supercritical water for 3000 hours.

\begin{tabular}{|c|c|c|c|}
\hline AISI 304 & AISI 310 & A-286 & IN 625 \\
\hline & & & \\
\hline & & & \\
\hline
\end{tabular}

Samples exposed to subcritical water for 3000 hours (Table 15) evidence a less uniform surface appearance among them. Once again, A-286 and AISI 304 have darker surface (indicating more corrosion/oxidation), followed by AISI 310 with a surface of slightly greyish coloration. In the case of subcritical water test condition, the effects of surface corrosion appear to be more related to alloy composition, especially the combination of $\mathrm{Ni}+\mathrm{Cr}$. The two samples with less $\mathrm{Cr}$ content and moderate Ni content (A-286 and AISI 304) were more corroded, while IN 625, the 
sample with the highest $\mathrm{Cr}$ and $\mathrm{Ni}$ concentration, showed a much lower corrosion based on its surface appearance; lesser change in coloration and some localized corrosion patterns are observed.

Table 15. Images of samples tested in subcritical water for 3000 hours.

\begin{tabular}{|c|c|c|c|}
\hline AISI 304 & AISI 310 & A-286 & IN 625 \\
\hline \multirow{2}{*}{0} & & & \\
\hline & & 0 & \\
\hline
\end{tabular}

Samples tested for 1000 hours in superheated steam (Table 16) show a reduced corrosion on the surface when being compared to the samples exposed for 1000 hours in the other two types of tests. This might be due to either a lower corrosion rate at superheated steam condition or a higher dissolution / spallation processes of the surface oxide in flowing steam. Superheated steam samples in Table 16 show that the presence of discoloration/oxidation on the surfaces is more evident on A-286 and IN 625. As the influence of dissolution/spallation process is not certain at this stage, it is difficult to predict how the substrate material composition has affected the surface characteristics of the samples tested in the superheated steam. 
Table 16. Images of samples tested in superheated steam for 1000 hours.

\begin{tabular}{|c|c|c|c|}
\hline AISI 304 & AISI 310 & A-286 & IN 625 \\
\hline & & & \\
\hline & & & \\
\hline
\end{tabular}

\subsection{Weight Change}

Samples were weighed before and after exposure. The scale used has an accuracy of $\pm 0.1 \mathrm{mg}$. The dissolution of surface oxides in the fluid may cause weight loss while the re-deposition of oxides on the other samples, during cooling in the autoclave, could also taken place leading to weight gain. There are also possibilities of sealant contamination to the samples tested in autoclave. Sample cleaning process may further remove loose oxide particles from the surface. As such, weight change should only be used in the screening stage of material testing. A summary table with all weight measurements and surface area calculations can be seen in Appendices A, B and C.

Table 17 shows a summary of the weight gain/loss of all samples after 1000, 2000 and 3000 hours of exposure under various conditions. All calculations of weight change are with respect to sample's initial weights before testing. 
Table 17. Averaged Weight change $\left(\mathrm{mg} / \mathrm{cm}^{2}\right)$.

\begin{tabular}{|c|c|c|c|c|c|}
\hline Condition & Test Duration (hours) & AISI 304 & AISI 310 & A-286 & IN 625 \\
\hline Supercritical & 1000 & 4.868 & 0.020 & 1.034 & 0.090 \\
\cline { 2 - 6 } & 2000 & 6.301 & 0.173 & 2.646 & 0.245 \\
\cline { 2 - 6 } & 3000 & 6.970 & 0.124 & 4.584 & 0.142 \\
\hline Subcritical & 1000 & 6.332 & 0.668 & 7.350 & -0.120 \\
\cline { 2 - 6 } & 2000 & 5.738 & -0.206 & 7.490 & 0.020 \\
\cline { 2 - 6 } & 3000 & 6.950 & -0.240 & 10.161 & -0.143 \\
\hline Steam & 1000 & 0.067 & 0.049 & 0.055 & 0.032 \\
\hline
\end{tabular}

After analyzing the results plotted in Figure 42 for SCW and SubCW conditions, they are in concordance with some of the observations made in the visual inspection. As shown in the figure, A-286 has continuous weight gain with time, this increased weight gain is about two times higher in subcritical condition with respect to SCW. The other material that experimented a large weight gain is AISI 304; after 1000 hours of exposure the weight gain was higher for the subcritical condition, but with increased time increased this difference becomes less. In the majority of the cases the weight gain tends to increase with exposure time, except for 310 in subcritical test condition where it decreases and moves on to weight loss over time. As mentioned in the visual inspection, the reason for the increment of weight in these materials ( $\mathrm{A}$ 286 and AISI 304) must be associated with the lower $\mathrm{Cr}$ content in relation with the other two materials (IN 625 and AISI 310). This is also the reason for a higher corrosion/oxidation rate where a stable oxide layer is not able to establish.

The materials with lower weight changes are IN 625 and AISI 310 . The IN 625 samples experiments very small weight changes, with weight gain in the supercritical test and weight loss in the supercritical condition. While the limited weight gain signals limited oxide formation 
on the surface, weight loss can be a cause for concern if dissolution or spallation of material affects the working fluid. AISI 310 also shows a slight weight gain for the supercritical test while during the subcritical test, the weight increases in a small amount within the first 1000 hours of test, and after that time, a continuous weight loss ensues. The results obtained for these two materials suggest the formation of a stable oxide layer on the surface, enabled by the higher $\mathrm{Cr}$ concentration in the alloys, preventing surface from further oxidation. However, the surface oxide may be subjected to slight dissolution in subcritical water resulting in weight loss.

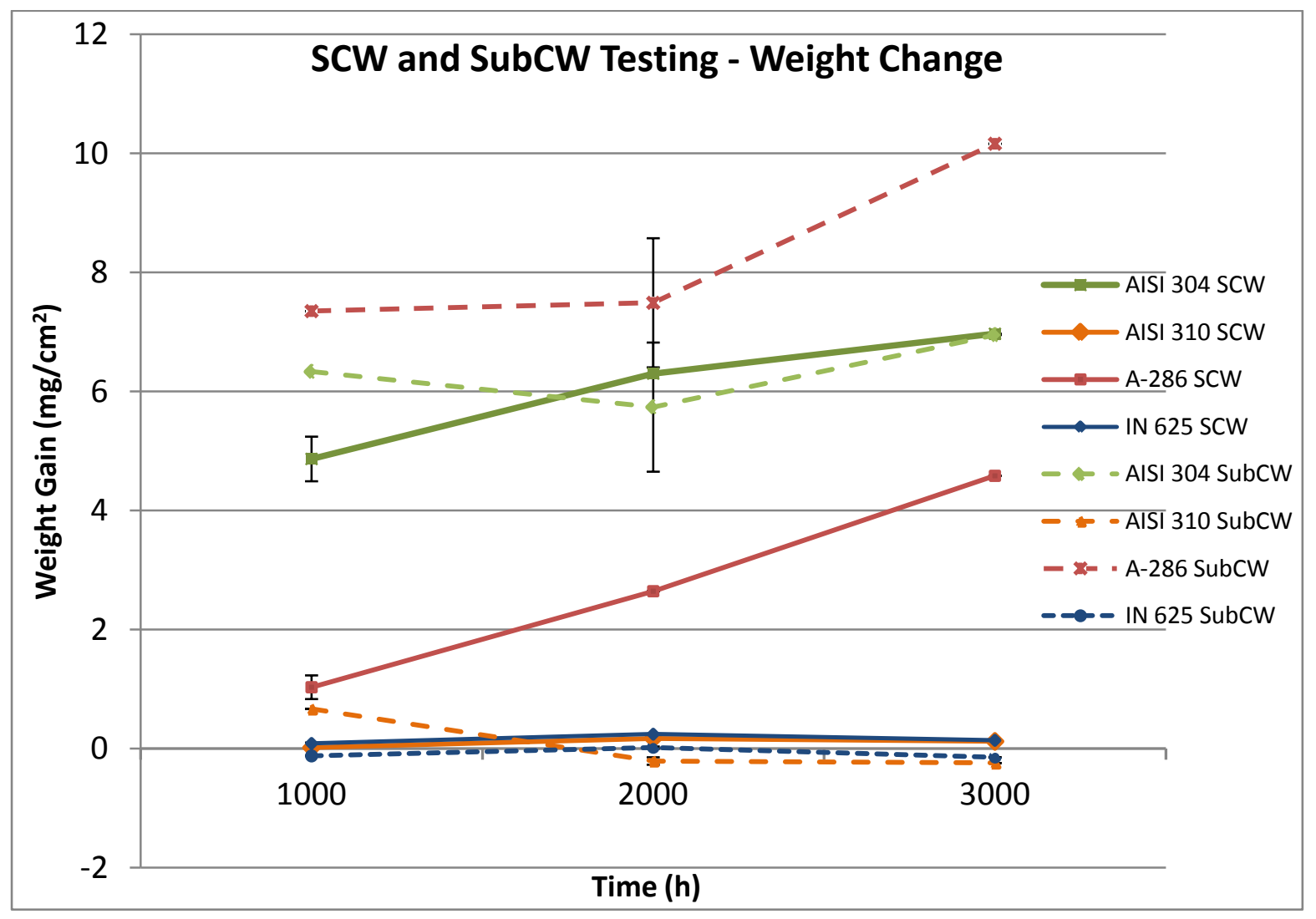

Figure 42. Line graph of $\mathrm{mg} / \mathrm{cm}^{2}$ vs. time for supercritical $\left(625^{\circ} \mathrm{C}, 29 \mathrm{MPa}\right)$ and subcritical $\left(625^{\circ} \mathrm{C}, 8 \mathrm{MPa}\right)$ tested samples. 
To analyze the repeatability of the weight measurement, error bars on several data points were provided in Figure 42. In particular, two different samples of A-286 and AISI 304 were exposed for 1000 hours in SCW condition and two samples of A-286 and AISI 304 exposed for 2000 hours in the SubCW condition. The differences between the two samples tested under the same condition were not significant to influence the observed trends in weight loss/gain.

The weight measurement results for samples tested in the steam rig at $625^{\circ} \mathrm{C}$ can be seen in Table 18. Although they are for lesser exposure time when compared to the samples test in the autoclave, the effects of superheated steam on sample's weight change with increasing times can still be observed clearly.

Table 18. Averaged weight change in superheated steam samples $\left(\mathrm{mg} / \mathrm{cm}^{2}\right)$.

\begin{tabular}{|c|c|c|c|}
\hline $\begin{array}{c}\text { Material/Test duration } \\
\text { (hours) }\end{array}$ & $\mathbf{3 5 0} \mathbf{h}$ & $\mathbf{7 0 0} \mathbf{h}$ & $\mathbf{1 0 0 0} \mathbf{~}$ \\
\hline AISI 304 & 0.011 & 0.015 & 0.067 \\
\hline AISI 310 & 0.027 & 0.058 & 0.049 \\
\hline A-286 & 0.019 & 0.018 & 0.055 \\
\hline IN 625 & 0.012 & 0.028 & 0.032 \\
\hline
\end{tabular}

Figure 43 displays the weight change of these samples with time. As a general trend, the results are in concordance with the visual inspection observations. The increment in weight with time is evident in almost all samples, even though the weight changes are much smaller than that in supercritical and subcritical test condition. There is a competing process corrosion and dissolution that causes the weight to reduce after 700 hours for A-286 and AISI 304 and 1000 hours for IN 625 and AISI 310. Samples of A 286 and AISI 310 show higher increment in weight initially (due possible to oxide formation), followed by weight reduction. The dynamic 
conditions of the flowing steam $(0.8 \mathrm{~kg} / \mathrm{h})$ may be responsible for the surface scale removal on IN 625 and AISI 310. The results obtained here are remarkably important to understand these effects, but real simulations of supercritical reactors using flowing steam at supercritical conditions are needed for design considerations. Error bars were added to the data points in Figure 43; however, the variation between two measurements was too small to be able to display.

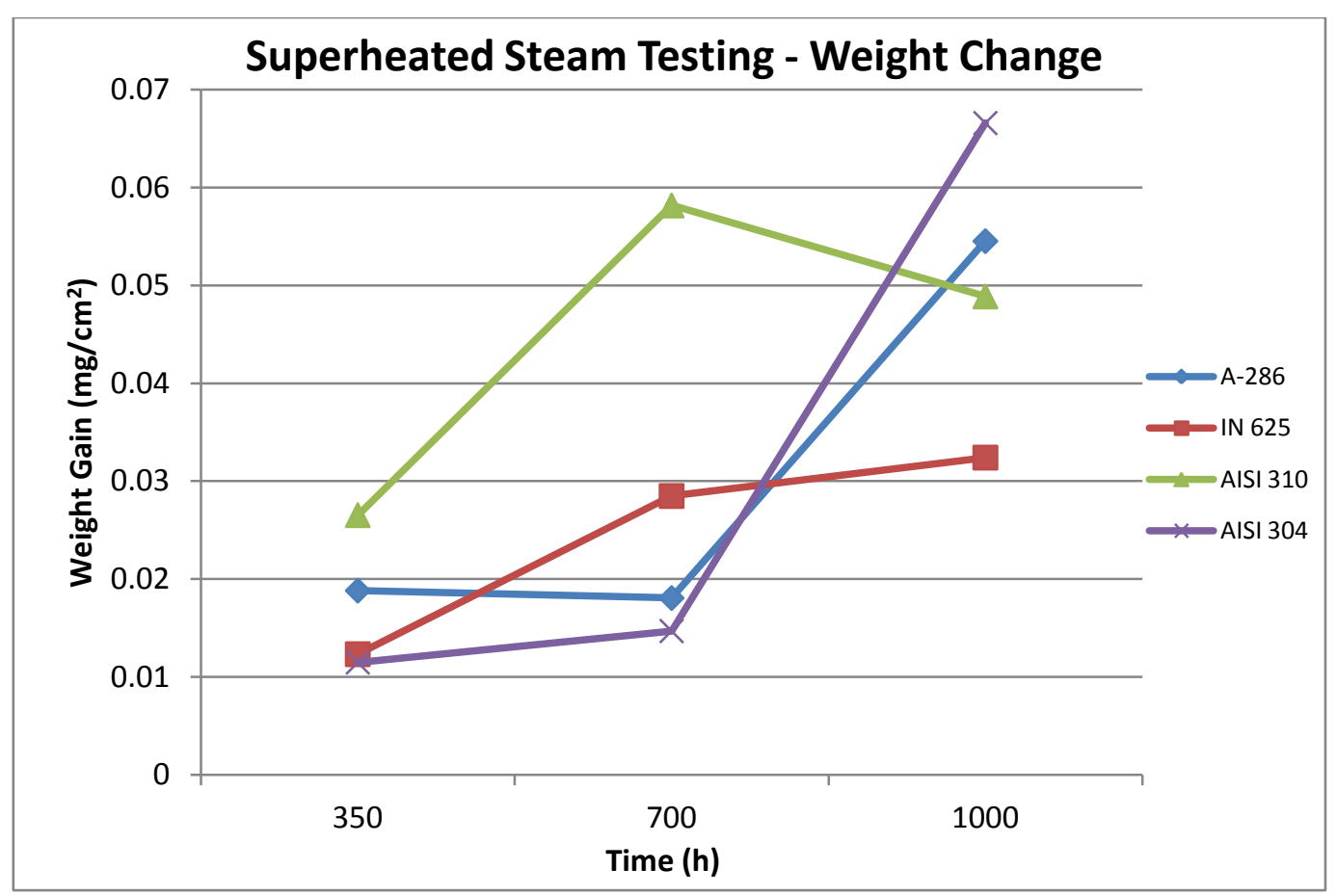

Figure 43. Weight gain of samples exposed to superheated steam $\left(625^{\circ} \mathrm{C}, 0.1 \mathrm{MPa}\right)$.

The bar graph from Figure 44 shows the influence of test conditions on weight change of all samples exposed for 1000 hours. Greater weight gain takes place in the subcritical test condition (the static condition and lower pressure in the autoclave produce an incremented corrosion in comparison to the other two tests). Very minimal weight changes occur in the superheated steam condition. The interesting observation for the subcritical and supercritical 
cases is that A-286, AISI 304 and AISI 310 have much more weight gain under the subcritical condition. Overall, AISI 304 experiences the highest weight changes in SCW and IN 625 has the least weight change under all three test conditions. According to these results, the high $\mathrm{Cr}$ content is effective in the prevention of corrosion in supercritical conditions. While for all three conditions, the higher concentration of $\mathrm{Ni}$ and $\mathrm{Cr}$, results in least weight change to samples of IN 625 and AISI 310.

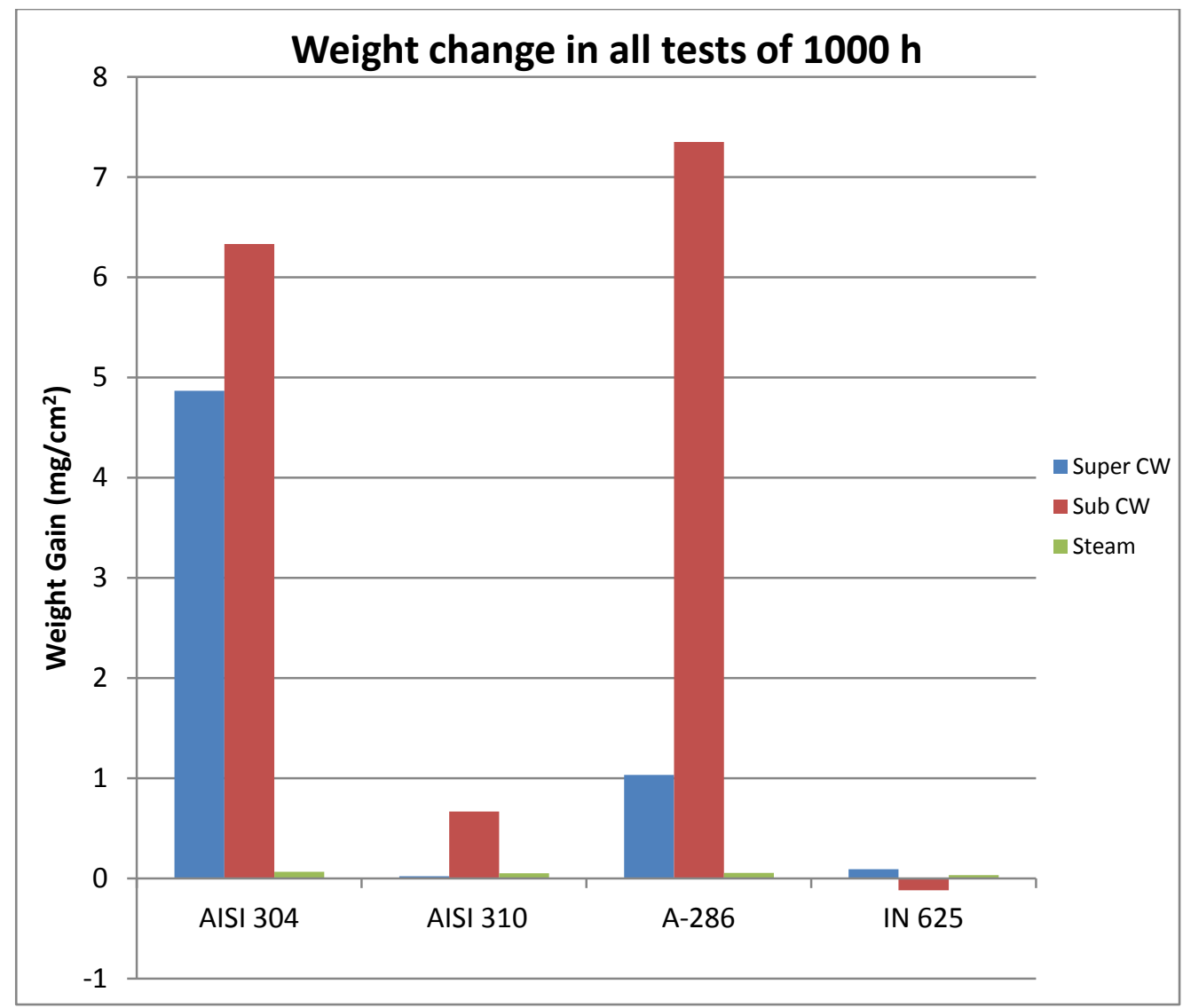

Figure 44. Bar graph of weight change $\mathrm{mg} / \mathrm{cm}^{2}$ vs. test condition for all samples tested for 1000 hours. 


\subsection{SEM and EDS Analysis Results}

Scanning electron microscope and energy dispersive x-ray spectroscopy (EDS) analysis were performed after visual inspection and weighing of samples. First, samples with no exposure to any condition were analyzed to establish a baseline for comparison to the other samples. Then, each material type was analyzed for each condition and testing time.

\subsubsection{Samples with No Exposure}

SEM pictures of all unexposed samples can be seen in the following figures, both SE and BSE SEM pictures are shown. The main feature observed in the materials' surfaces are the grinding lines resulting from the 600 grit SiC abrasive paper used in the grinding process. These regular and silver shiny surfaces will be used as a point of comparison for the exposed samples under different conditions. The apparent pitting or defects visible in the surface of samples A-286 and IN 625 are possibly due to (1) the presence of voids in the as-received material and (2) material pull out during grinding process. 


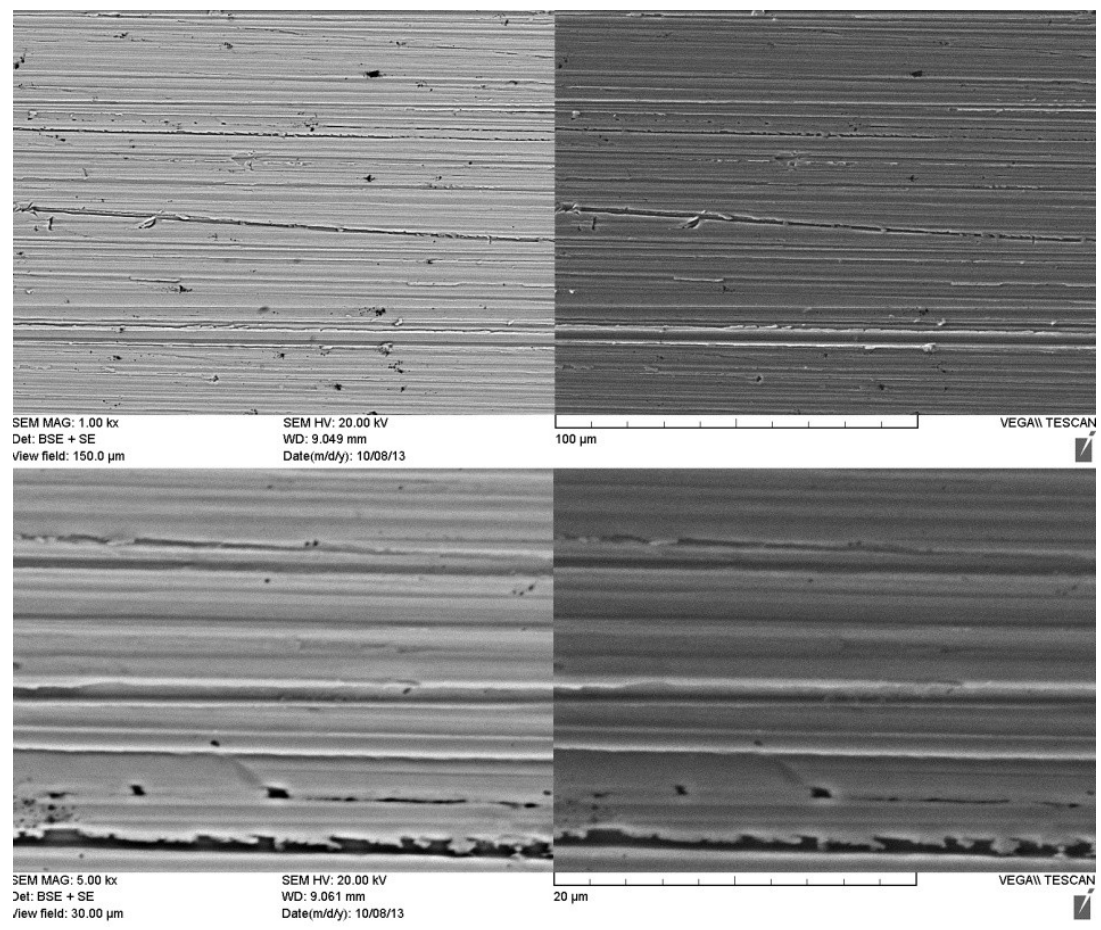

Figure 45. SEM images (BSE left, SE right) of unexposed AISI 304 at 1kx (top) and 5kx (bottom).

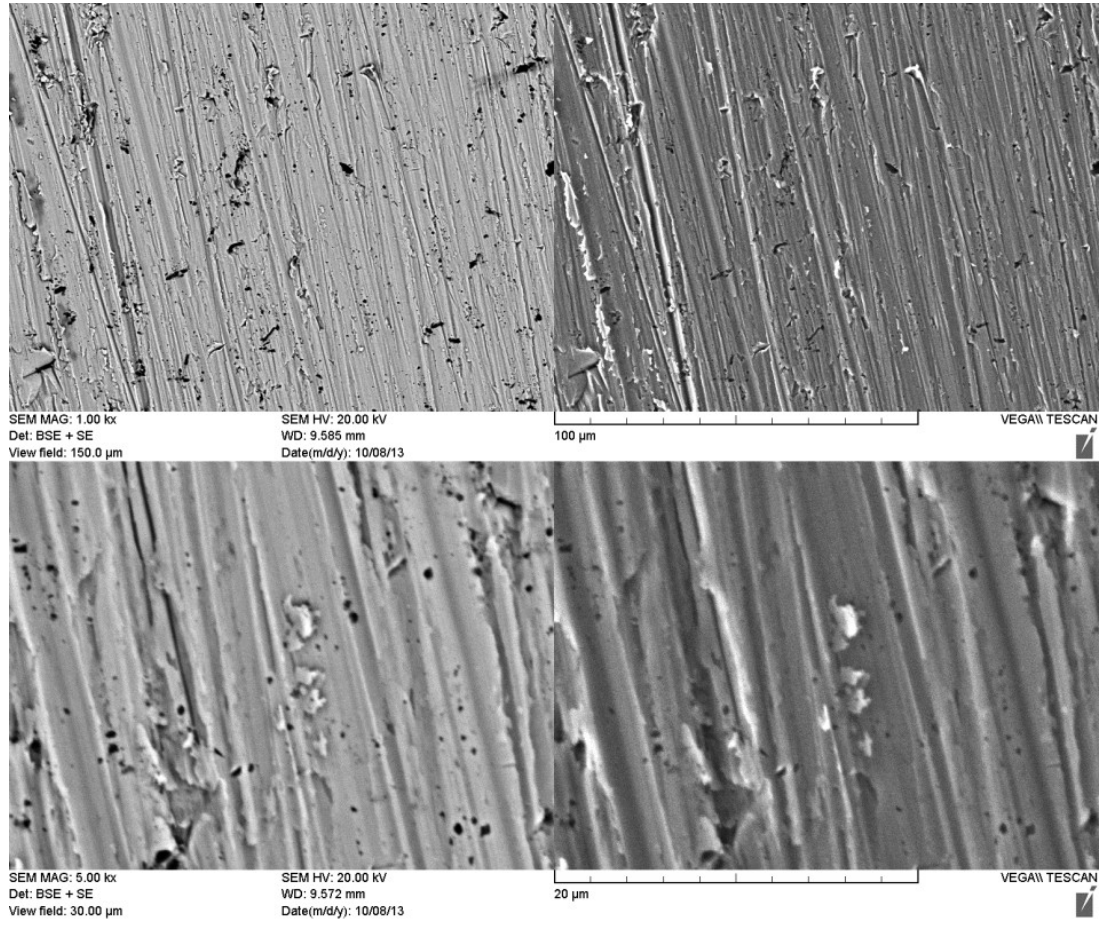

Figure 46. SEM images (BSE left, SE right) of unexposed AISI 310 at $1 \mathrm{kx}$ (top) and 5kx (bottom). 


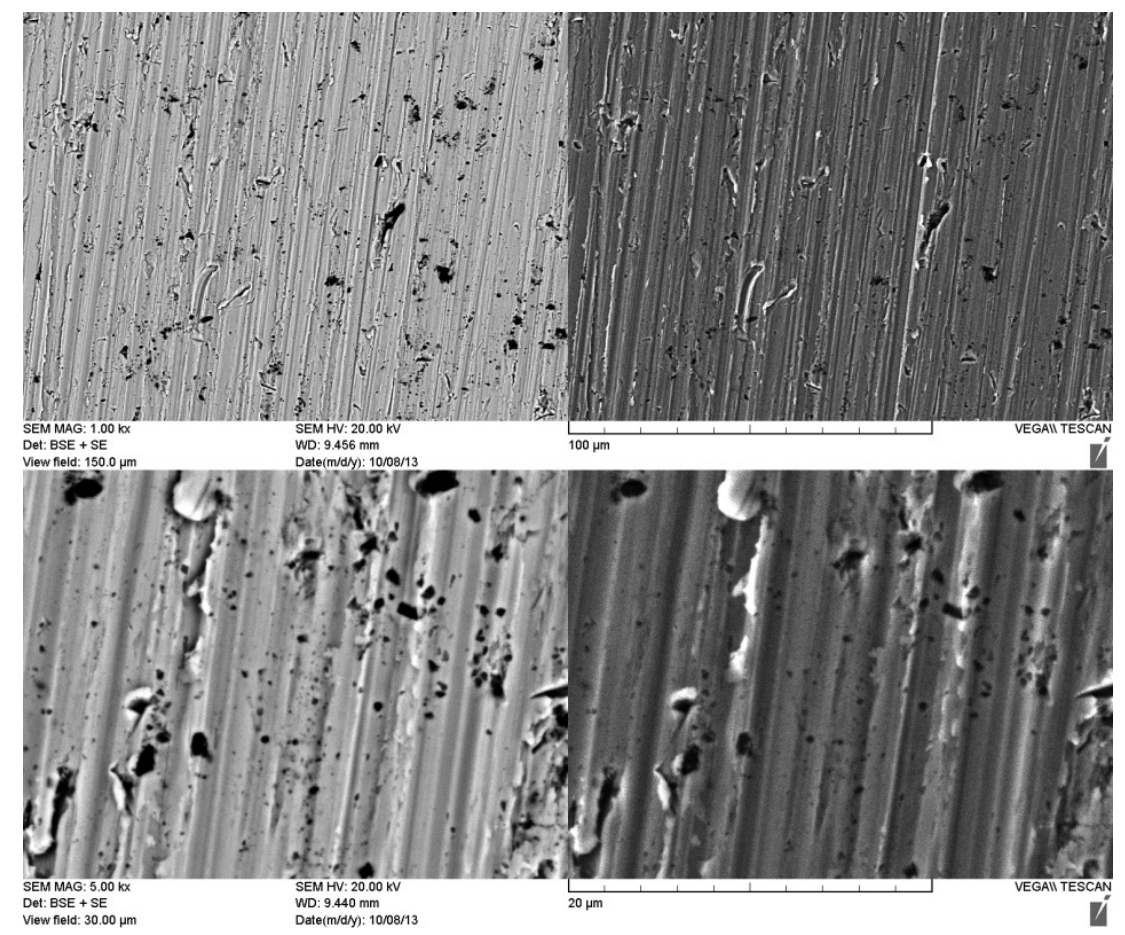

Figure 47. SEM images (BSE left, SE right) of unexposed A-286 at $1 \mathrm{kx}$ (top) and 5kx (bottom).

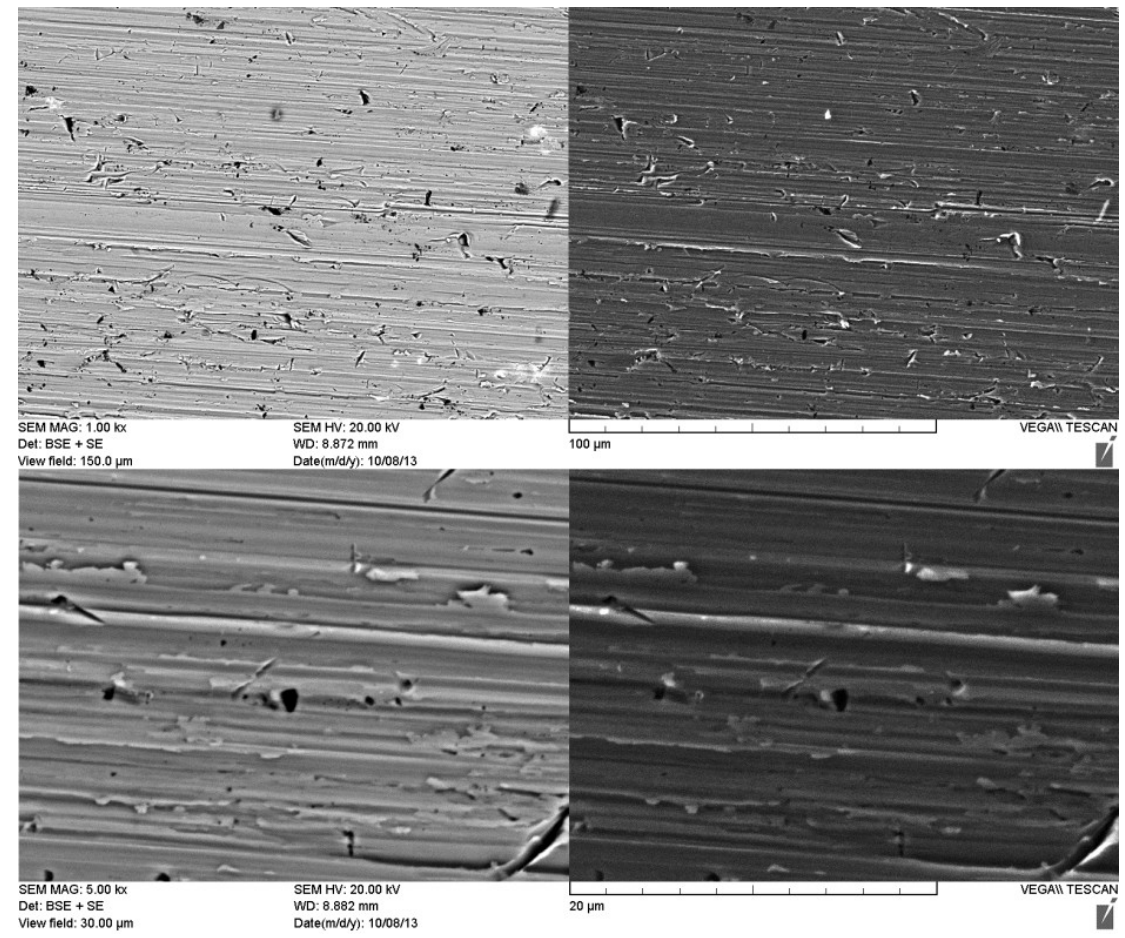

Figure 48. SEM images (BSE left, SE right) of unexposed IN 625 at 1kx (top) and 5kx (bottom). 
EDS analysis was also performed on all these samples, their polished, flat surfaces allow for accurate composition measurements. The results obtained in this analysis, of all four materials, can be seen in Table 19. When comparing the percentages of elements, provided by the manufacturer's specification (labelled as max. in the table), to the results obtained from the EDS analysis, they are fairly similar showing an accuracy of $\pm 2.5 \%$. Some minor elements may have not been detected by EDS accurately due to the semi-quantitative nature of EDS.

Table 19. Maximum specified and EDS chemical compositions for untested materials.

\begin{tabular}{|c|c|c|c|c|c|c|c|c|}
\hline & \multicolumn{2}{|c|}{ AISI 304 } & \multicolumn{2}{c|}{ AISI 310 } & \multicolumn{2}{c|}{ A-286 } & \multicolumn{2}{c|}{ IN 625 } \\
\hline $\begin{array}{c}\text { Element } \\
\text { (wt \%) }\end{array}$ & Max & EDS & Max & EDS & Max & EDS & Max & EDS \\
\hline $\mathrm{Cr}$ & 20 & 19.16 & 26 & 25.26 & 16 & 14.77 & 23 & 22.86 \\
\hline $\mathrm{Ni}$ & 10.5 & 8.75 & 22 & 18.83 & 27 & 23.53 & $\mathrm{R}$ & 59.39 \\
\hline $\mathrm{Fe}$ & $\mathrm{R}$ & 69.83 & $\mathrm{R}$ & 51.18 & $\mathrm{R}$ & 54.69 & 5 & 4.45 \\
\hline $\mathrm{Co}$ & - & - & - & - & 1.0 & 0.37 & 1.0 & 0.30 \\
\hline $\mathrm{Mo}$ & - & - & - & - & 1.5 & 1.28 & 10 & 9.08 \\
\hline $\mathrm{Al}$ & - & - & - & - & 0.35 & 0.20 & 0.40 & 0.27 \\
\hline $\mathrm{Mn}$ & 2.0 & 1.16 & 2.0 & 1.57 & 2.0 & 0.41 & 0.50 & - \\
\hline $\mathrm{B}$ & - & - & - & - & 0.01 & - & - & - \\
\hline $\mathrm{Ti}$ & - & - & - & - & 2.35 & 2.28 & 0.40 & 0.21 \\
\hline $\mathrm{V}$ & - & - & - & - & 0.5 & 0.29 & - & - \\
\hline $\mathrm{C}$ & 0.08 & - & 0.25 & - & 0.08 & - & 0.10 & - \\
\hline $\mathrm{Si}$ & 0.75 & 0.61 & 1.5 & 2.13 & 1.0 & 1.44 & 0.50 & 0.65 \\
\hline $\mathrm{P}$ & 0.045 & - & 0.045 & - & 0.025 & - & 0.015 & - \\
\hline $\mathrm{S}$ & 0.03 & 0.12 & 0.03 & - & 0.025 & - & 0.015 & - \\
\hline $\mathrm{N}$ & 0.10 & - & - & - & - & - & - & - \\
\hline $\mathrm{Nb}$ & - & - & - & - & - & - & 4.15 & 3.72 \\
\hline
\end{tabular}

\subsubsection{AISI 304 Exposed to SCW, SubCW and SHS}

All results obtained in the SEM and ESD analysis of AISI 304 samples, tested in all conditions, are presented and discussed in this section. The SEM images presented were taken at different magnifications using BSE. 


\section{SCW Samples}

Figure 49, Figure 50 and Figure 51 show the SEM images of AISI 304 samples exposed to supercritical water at $625^{\circ} \mathrm{C}$ and $29 \mathrm{MPa}$ for periods of 1000,2000 and 3000 hours, respectively. The magnifications used in the different pictures range from $500 \mathrm{X}$ to $10 \mathrm{kX}$, depending on the morphology of the surface and special features observed in each sample.

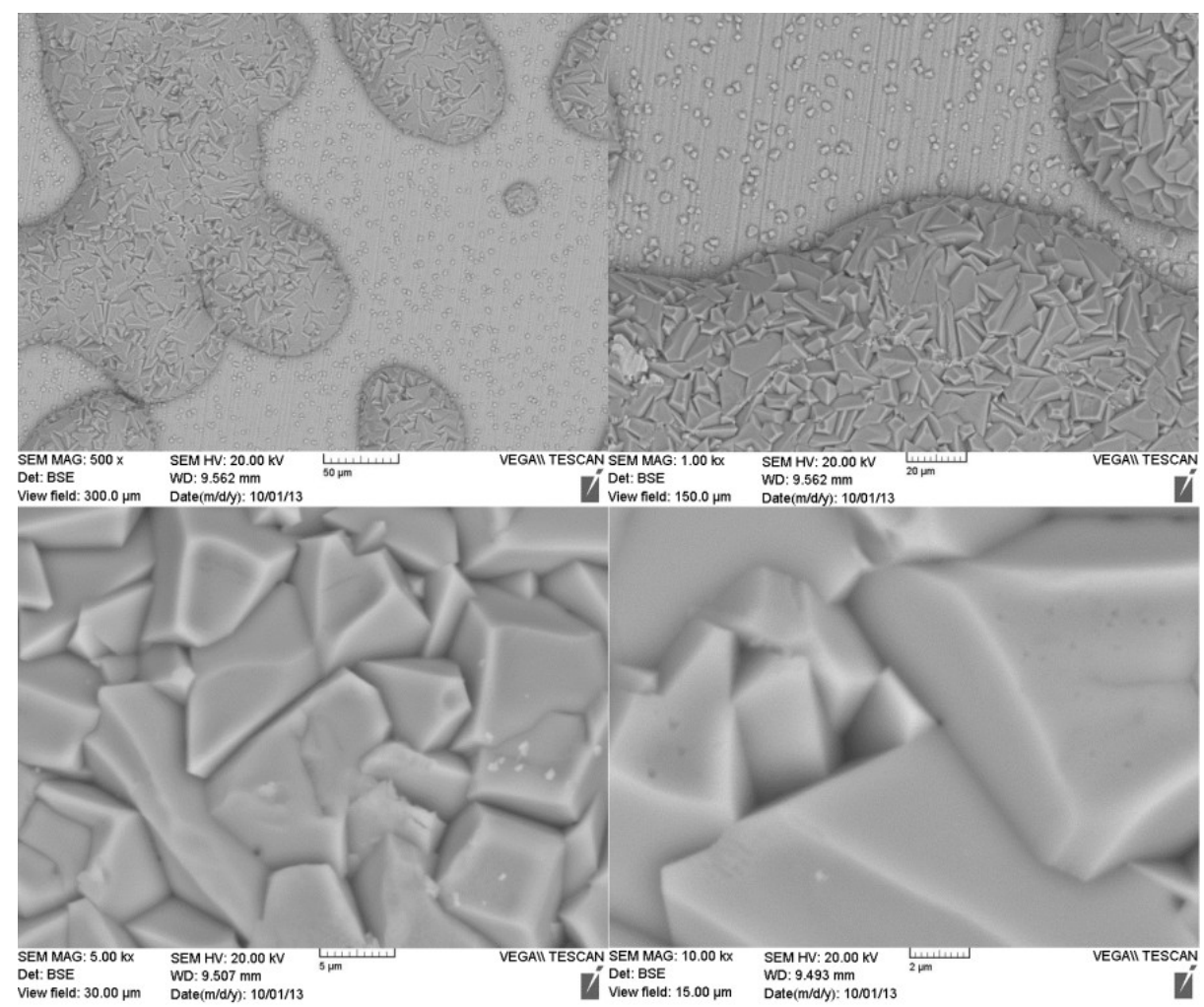

Figure 49. SEM surface images of AISI 304 exposed to SCW $\left(625^{\circ} \mathrm{C}, 29 \mathrm{MPa}\right)$ for $1000 \mathrm{~h}$.

Figure 49 illustrates the appearance and growth of corrosion product(s) (the raised islands) after the first 1000 hours of testing in SCW, which is consistent with the weight gain results obtained in the weight analysis. Oxidized regions of considerable size are observed throughout the surface, separated by areas of pristine substrate material (areas with visible polishing lines). 
The oxide particles that form part of these regions have a variety of geometries and sizes, but they all assume angular features.

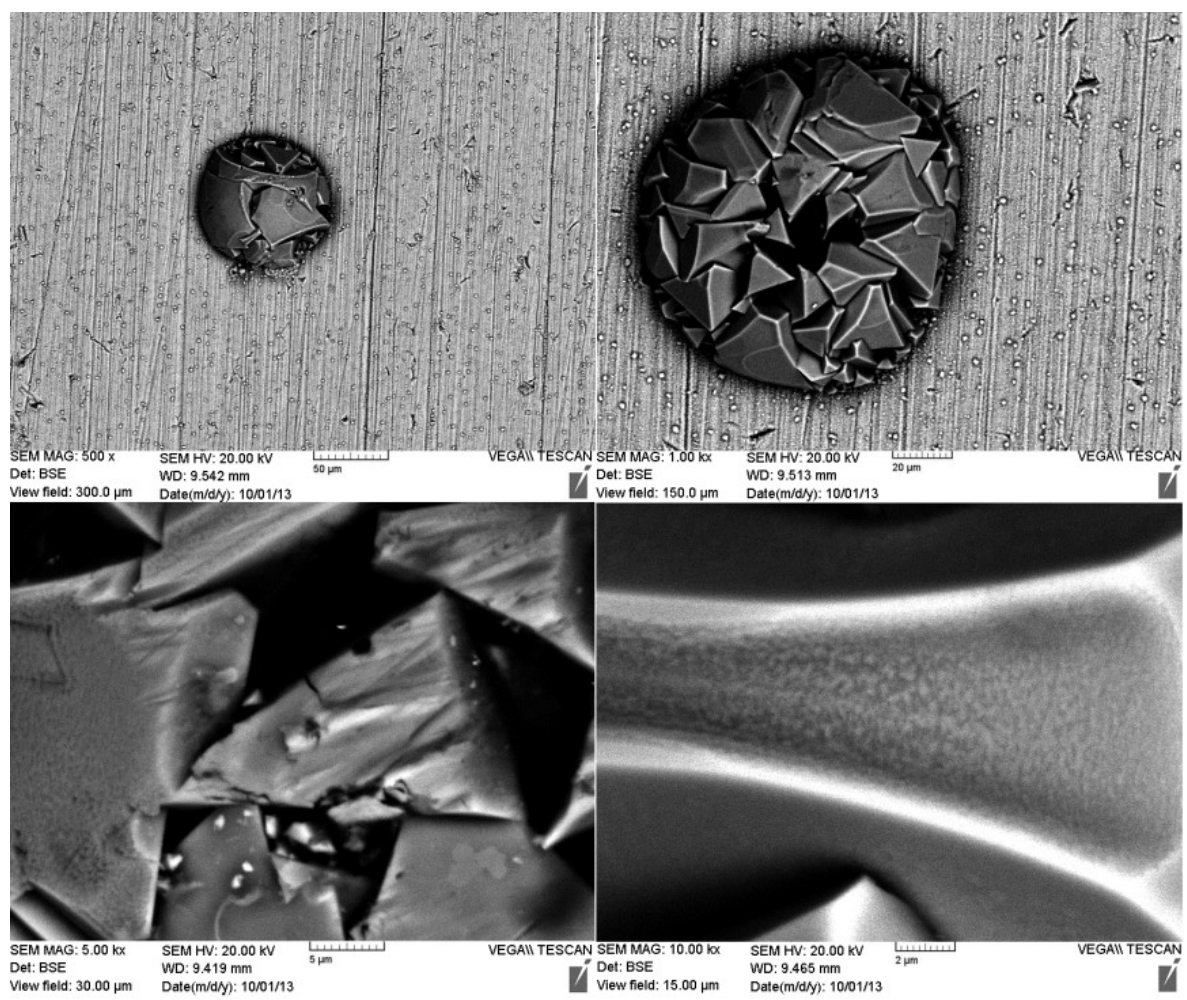

Figure 50. SEM surface images of AISI 304 exposed to SCW (625 $\left.{ }^{\circ} \mathrm{C}, 29 \mathrm{MPa}\right)$ for $2000 \mathrm{~h}$.

After 2000 hours of testing (Figure 50), the presence of oxide (small angular particles) can still be observed. If compared to samples exposed for 1000 hours, the oxide regions seem to be less spaced out, hence increased amount of oxide is present. Oxide particles also have become completely irregular in shape. 


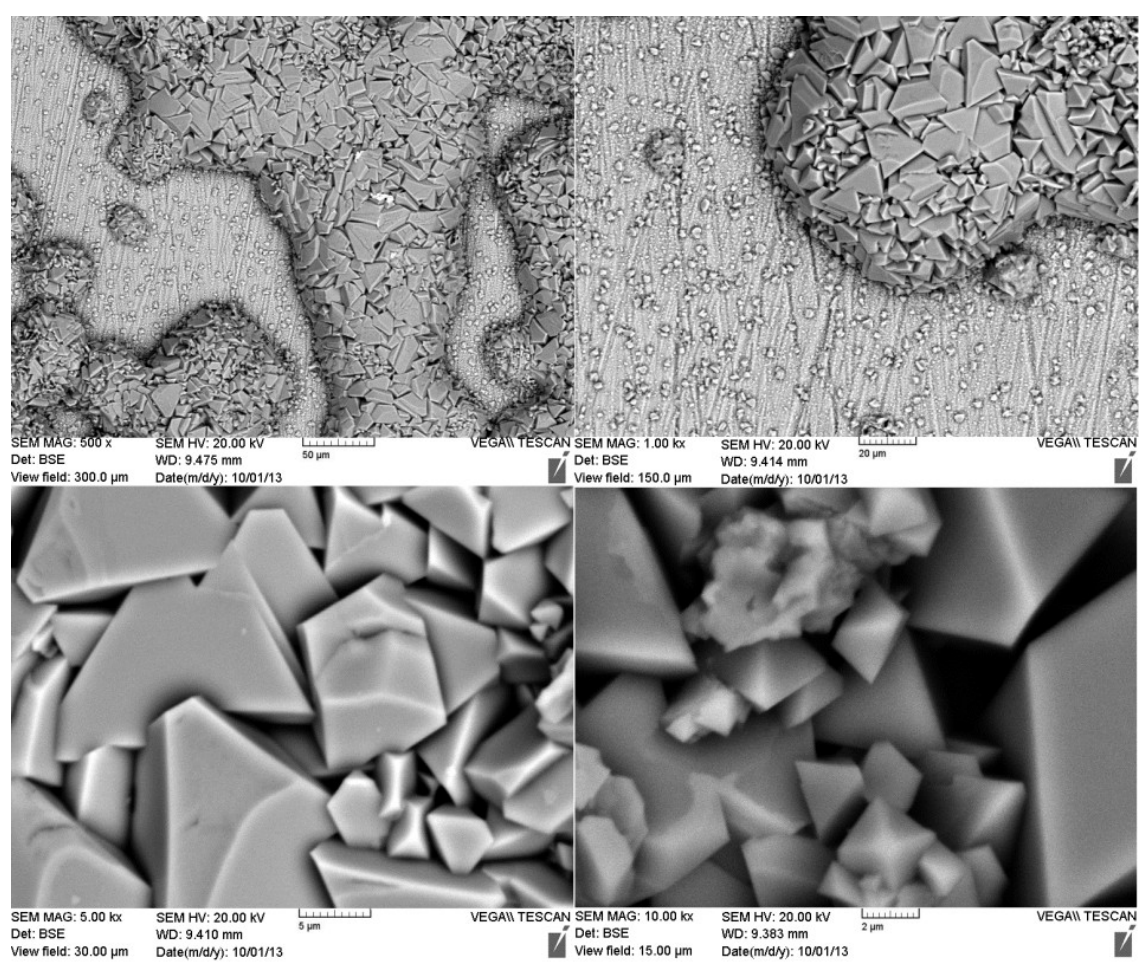

Figure 51. SEM surface images of AISI 304 exposed to SCW $\left(625^{\circ} \mathrm{C}, 29 \mathrm{MPa}\right)$ for $3000 \mathrm{~h}$.

Figure 51 shows sample AISI 304 after being tested for 3000 hours in SCW. The results show that the surface oxide occupies a larger area, hence smaller spacing between the oxidized regions; this is in concordance with the weight gain results shown previously. After 3000 hours of test, approximately $70 \%$ of the material surface is covered by oxidized regions. The oxide particles have similar shape as that displayed in the previous images, but their sizes increase, especially the ones at the center of the oxidized regions. Smaller particles tend to locate closer to the edges. This observation suggests that the oxidized region grows outwards from the center. Oxide particles at the center have longer time to grow (larger) while those smaller ones on the periphery have just started to form.

The elevated concentration of $\mathrm{Fe}$ and $\mathrm{O}$ and lower concentration of $\mathrm{Cr}$ and $\mathrm{Ni}$ in oxidized regions, obtained from the EDS analysis and summarized in Table 20, suggest the presence of 
iron oxide $\left(\mathrm{Fe}_{2} \mathrm{O}_{3}\right)$. The areas with no evidence of corrosion have similar amounts of $\mathrm{Cr}$ and $\mathrm{Ni}$ as the base material and lower presence of oxygen. It can be concluded that the iron oxide layer $\left(\mathrm{Fe}_{2} \mathrm{O}_{3}\right)$ continues to form during SCW test and maintains similar concentrations of iron and oxygen in all cases in the oxidized areas.

Table 20. EDS chemical composition of AISI 304 exposed to SCW.

\begin{tabular}{|c|c|c|c|c|c|c|}
\hline \multirow{2}{*}{ Exposure time (hours) } & \multicolumn{6}{|c|}{ Chemical composition by element (weight percent) } \\
\cline { 2 - 7 } & $\mathrm{Fe}$ & $\mathrm{Cr}$ & $\mathrm{Ni}$ & $\mathrm{O}$ & $\mathrm{Mn}$ & $\mathrm{Si}$ \\
\hline 1000 oxide & 71.69 & 0.76 & 0.29 & 26.91 & 0.35 & 0.00 \\
\hline 1000 substrate & 66.35 & 17.09 & 5.87 & 8.90 & 1.26 & 0.53 \\
\hline 2000 oxide & 70.80 & 0.58 & 0.86 & 26.58 & 0.57 & 0.61 \\
\hline 2000 substrate & 58.15 & 24.21 & 7.16 & 7.43 & 2.18 & 0.87 \\
\hline 3000 oxide & 71.56 & 0.89 & 0.13 & 27.21 & 0.21 & 0.00 \\
\hline 3000 substrate & 51.59 & 23.61 & 5.76 & 16.13 & 2.17 & 0.74 \\
\hline
\end{tabular}

\section{Subcritical Water Samples}

Figure 52, Figure 53 and Figure 54 shows the SEM images of AISI 304 samples exposed to subcritical water at $625^{\circ} \mathrm{C}$ and $8 \mathrm{MPa}$ for periods of 1000,2000 and 3000 hours, respectively. Magnifications used in the different pictures range from 500X to $10 \mathrm{kX}$ depending on the surface morphology and areas considered of interest. 


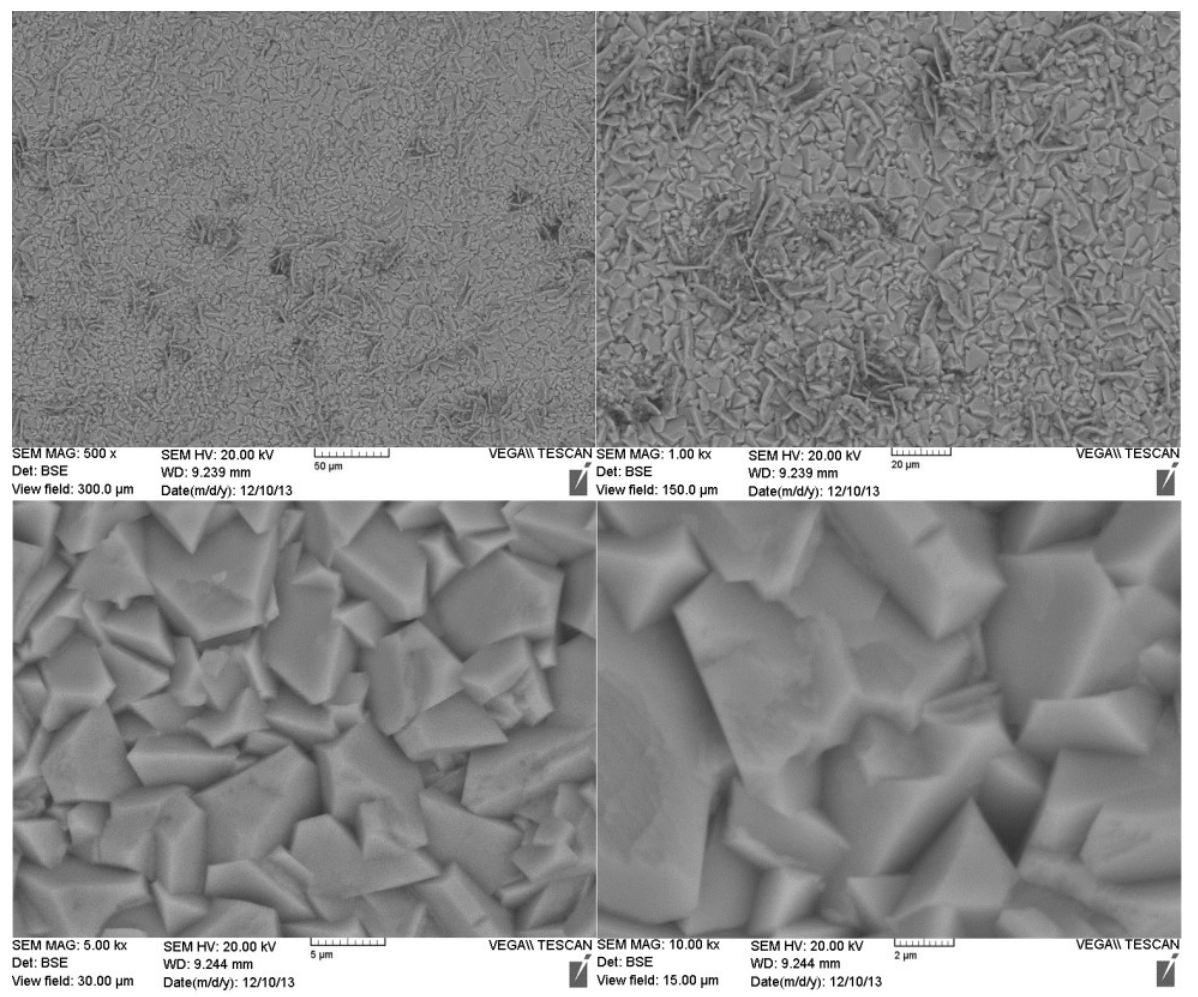

Figure 52. SEM surface images of AISI 304 exposed to SubCW $\left(625^{\circ} \mathrm{C}, 8 \mathrm{MPa}\right)$ for $1000 \mathrm{~h}$.

Figure 52 shows the formation of oxide particles with irregular shape on the surface. These particles are similar to the oxide particles observed in the SCW tested samples, however, the surface is completely covered with oxide. This is consistent with the higher weight gain of the sample after 1000 hours in SubCW (in comparison to that in SCW). 


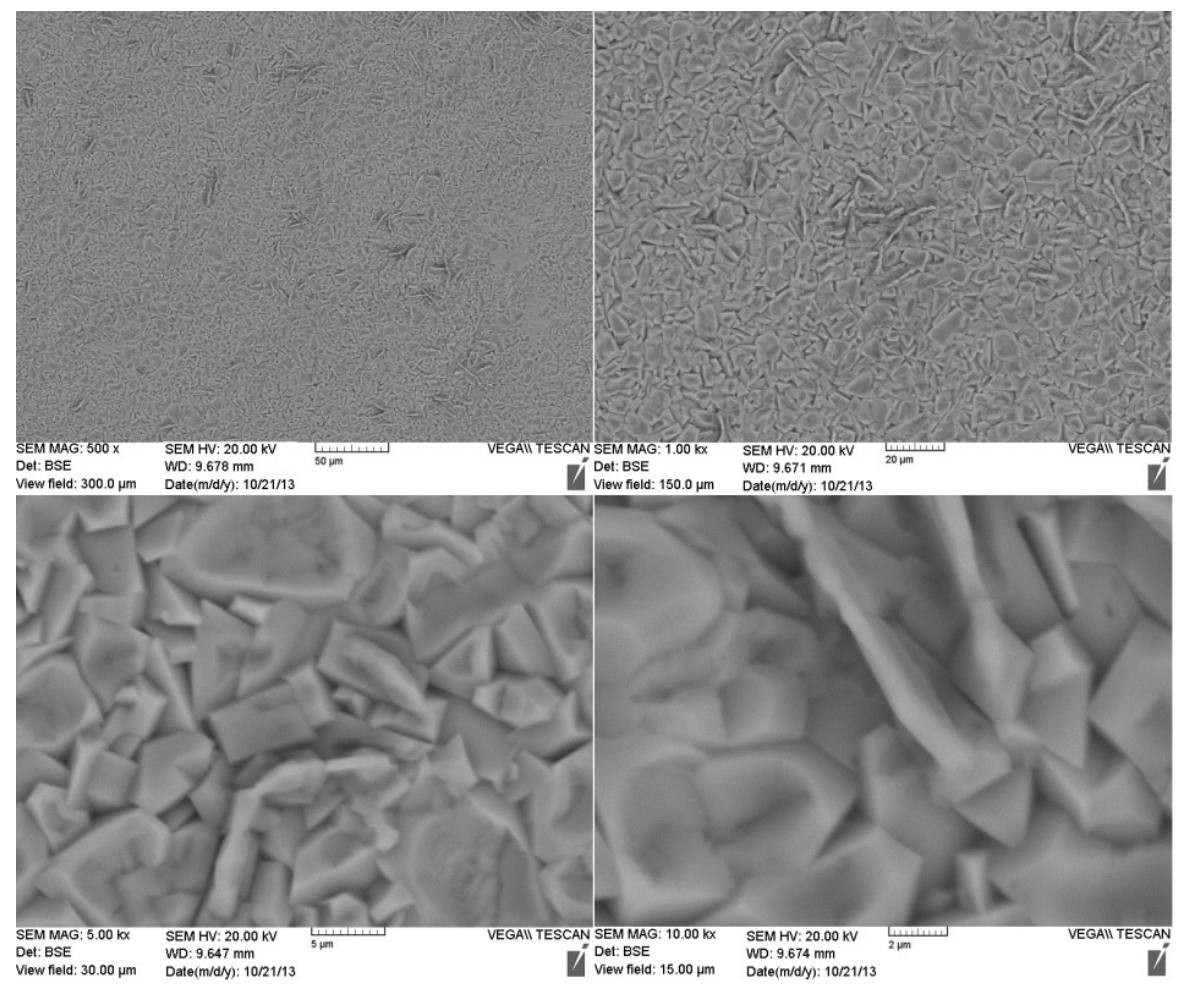

Figure 53. SEM surface images of AISI 304 exposed to SubCW $\left(625^{\circ} \mathrm{C}, 8 \mathrm{MPa}\right)$ for $2000 \mathrm{~h}$.

After 2000 hours of tests (Figure 53), no significant superficial differences are observed with respect to the previous test (1000 hours). The oxide particles again cover almost the entire sample surface, the presence of patches of larger particles surrounded by darker outline is almost the same as the previous one after 1000 hours. The oxide particles have similar shape and average size as that after 1000 hours in SCW, however, the particles seem to be more rounded. The reduced weight gain in this case suggests possible dissolution of oxide. 


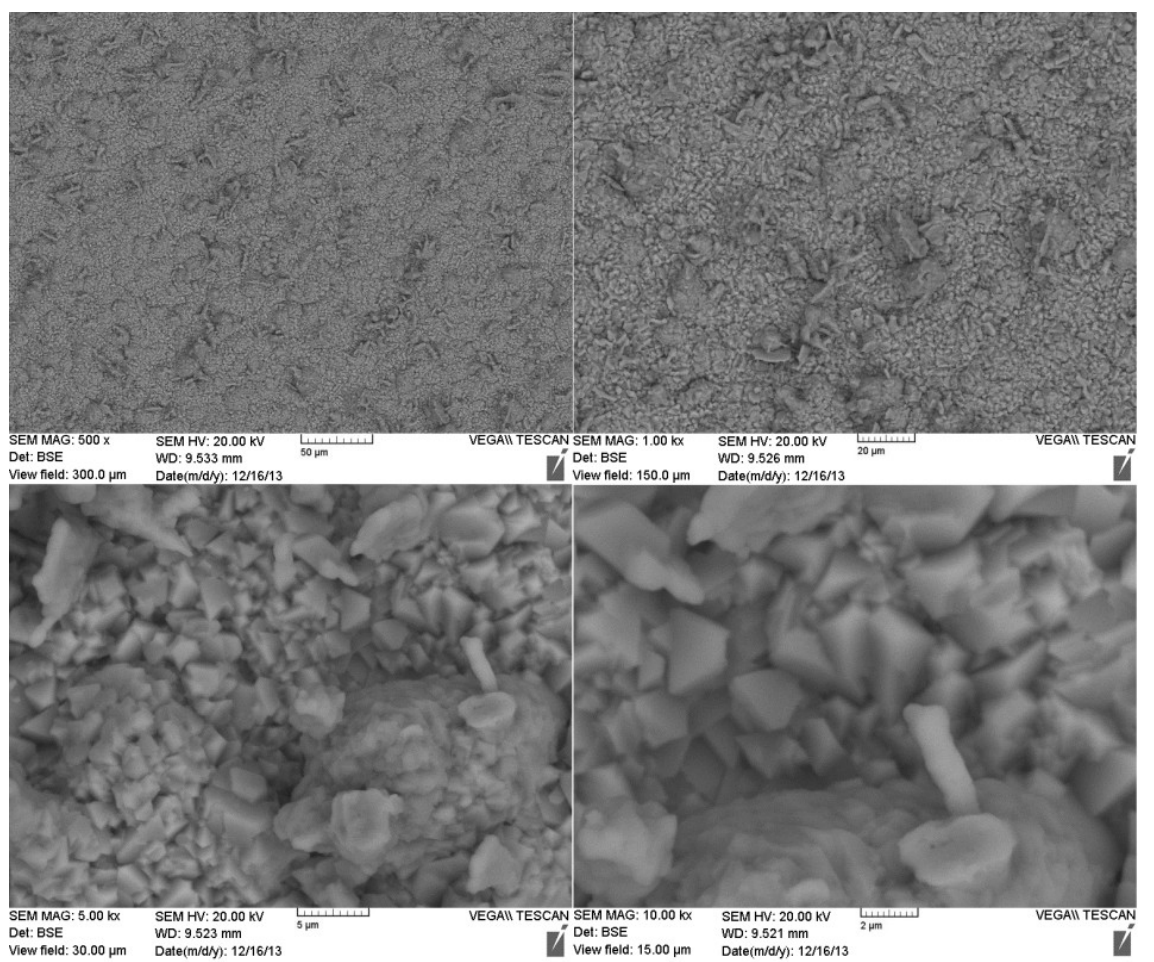

Figure 54. SEM surface images of AISI 304 exposed to SubCW $\left(625^{\circ} \mathrm{C}, 8 \mathrm{MPa}\right)$ for $3000 \mathrm{~h}$.

Figure 54 shows that after 3000 hours, the sample still presents a generalized corrosion on the surface, but the oxide particle morphology changes to smaller sizes and assumes more uniform form; this might be due to the continued oxide growth on the surface or partial dissolution. Formation of other types of oxide is also possible with prolonged exposure.

When analyzing the EDS results in Table 21, the high concentrations of iron and oxygen in the 1000 and 2000 hours samples suggest that the oxide present in the surface is iron oxide $\left(\mathrm{Fe}_{2} \mathrm{O}_{3}\right)$ in nature. Small amounts of $\mathrm{Cr}$ and $\mathrm{Mn}$ are also detected. Oxygen level remains quite constant with exposure time, but the iron level decreases and the chromium levels increase at 3000 hours, which is a sign of chromium oxide $\mathrm{Cr}_{2} \mathrm{O}_{3}$ or mixed oxide $\left(\mathrm{Fe}_{2} \mathrm{CrO}_{4}\right)$ formation on the surface. 
Table 21. EDS chemical composition of AISI 304 exposed to SubCW.

\begin{tabular}{|c|c|c|c|c|c|c|}
\hline \multirow{2}{*}{$\begin{array}{c}\text { Exposure } \\
\text { time (hours) }\end{array}$} & \multicolumn{6}{|c|}{ Chemical composition by element (weight percent) } \\
\cline { 2 - 7 } & $\mathrm{Fe}$ & $\mathrm{Cr}$ & $\mathrm{Ni}$ & $\mathrm{O}$ & $\mathrm{Mn}$ & $\mathrm{Si}$ \\
\hline 1000 oxide & 73.85 & 1.33 & 0.00 & 24.47 & 0.24 & 0.21 \\
\hline 2000 oxide & 71.53 & 0.75 & 0.00 & 26.63 & 1.09 & 0.00 \\
\hline 3000 oxide & 55.79 & 16.40 & 0.00 & 27.27 & 0.38 & 0.16 \\
\hline
\end{tabular}

\section{Superheated Steam Samples}

Figure 55, Figure 56 and Figure 57 are images taken during the SEM analysis of the AISI 304 samples after being tested in superheated steam at $625^{\circ} \mathrm{C}$ and $0.1 \mathrm{MPa}$ for periods of 350,700 and 1000 hours, respectively. Magnifications used range from 500X to $10 \mathrm{kX}$, depending on the surface features and zones considered of interest.

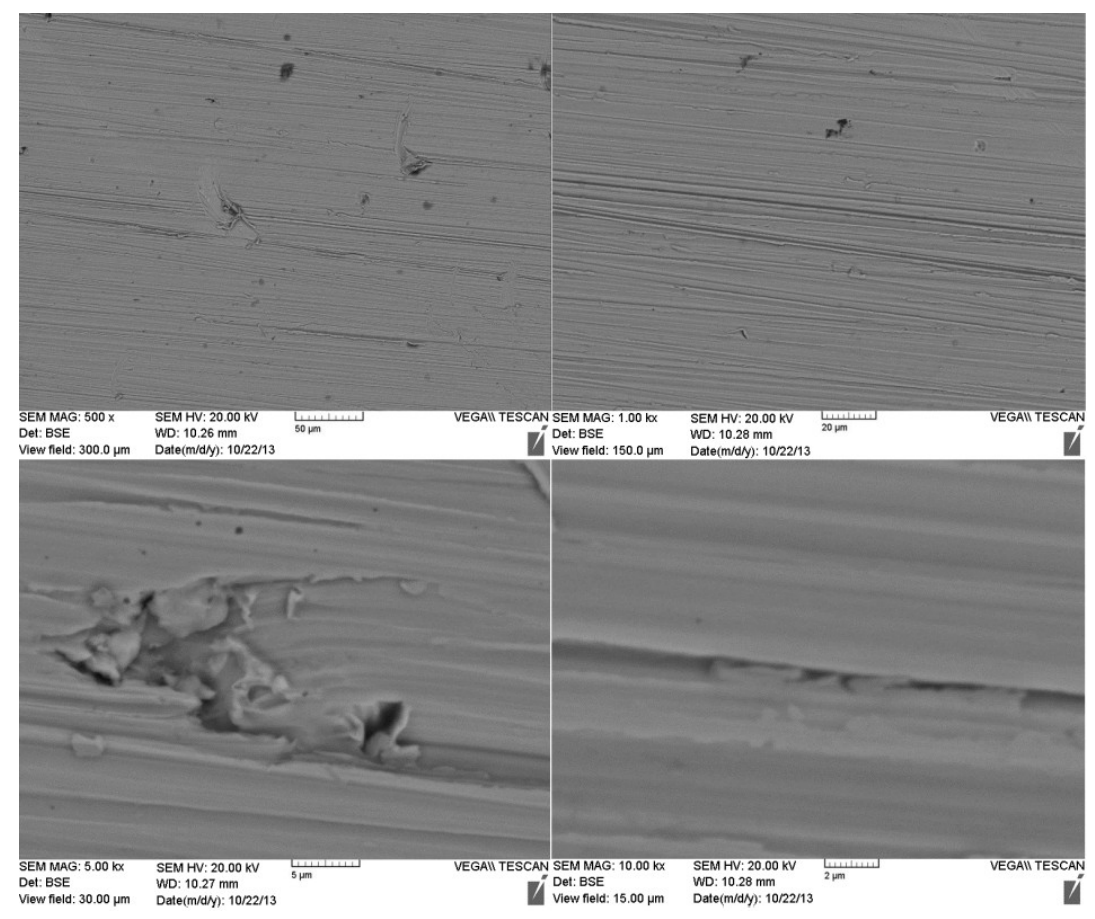

Figure 55. SEM surface images of AISI 304 exposed to superheated steam $\left(625^{\circ} \mathrm{C}, 0.1 \mathrm{MPa}\right)$ for $350 \mathrm{~h}$. 


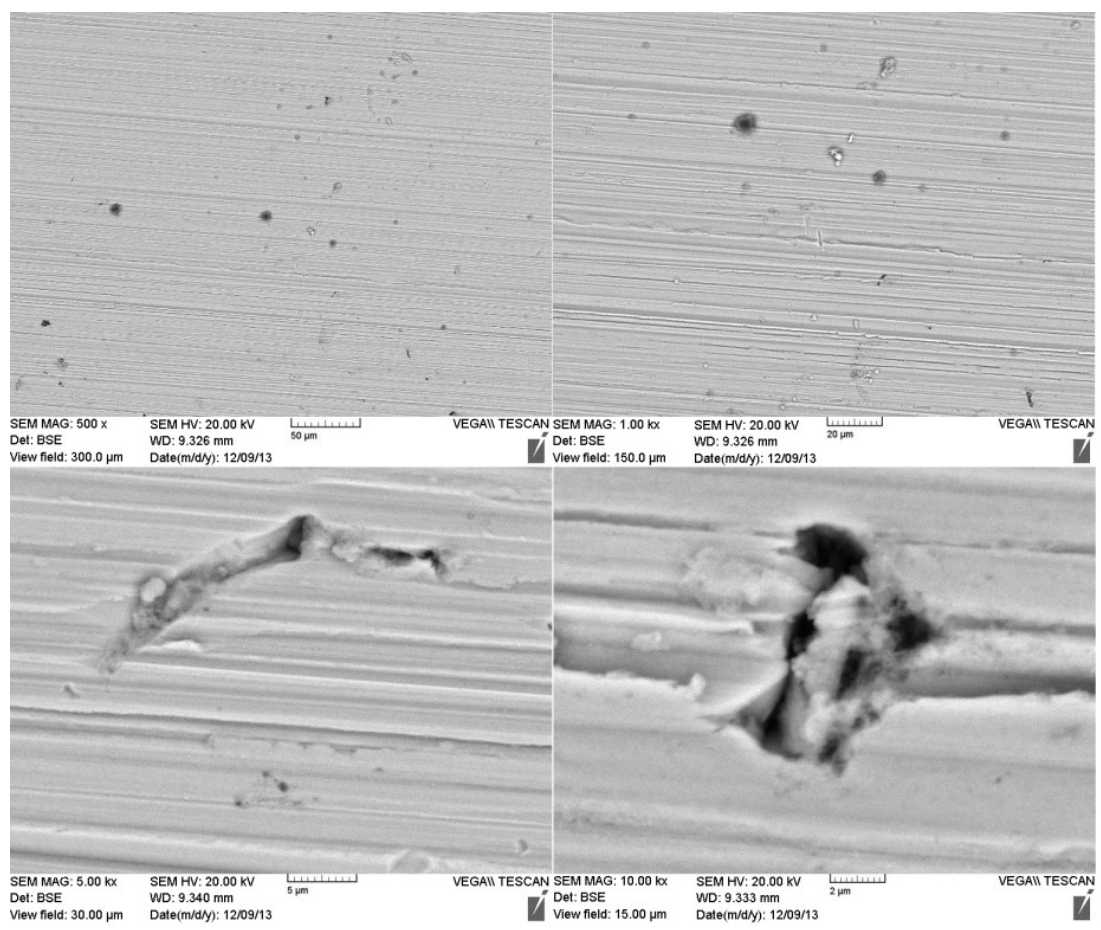

Figure 56. SEM surface images of AISI 304 exposed to superheated steam $\left(625^{\circ} \mathrm{C}, 0.1 \mathrm{MPa}\right)$ for $700 \mathrm{~h}$.

Figure 55 (350 hours sample) shows a clean base material surface with grinding lines and occasional small crack-like features (defects in original sheet metal). The 700 hours sample (Figure 56) shows an almost identical surface, with no evidence of oxide growth.

The third sample (Figure 57) shows a different feature after being exposed for 1000 hours. Signs of oxide formation are clearly present on the surface, covering approximately a $20 \%$ of the total area. This is consistent with the gain weight results.

EDS results, presented in Table 22, indicate that the majority of the areas in all samples is composed of the base material. Small amount of oxygen is present on the surface. Only after 1000 hours in superheated steam, high amount of oxygen and low amounts of $\mathrm{Cr}$ and $\mathrm{Ni}$ suggest that oxide $\left(\mathrm{Fe}_{2} \mathrm{O}_{3}\right)$ has started to form. 


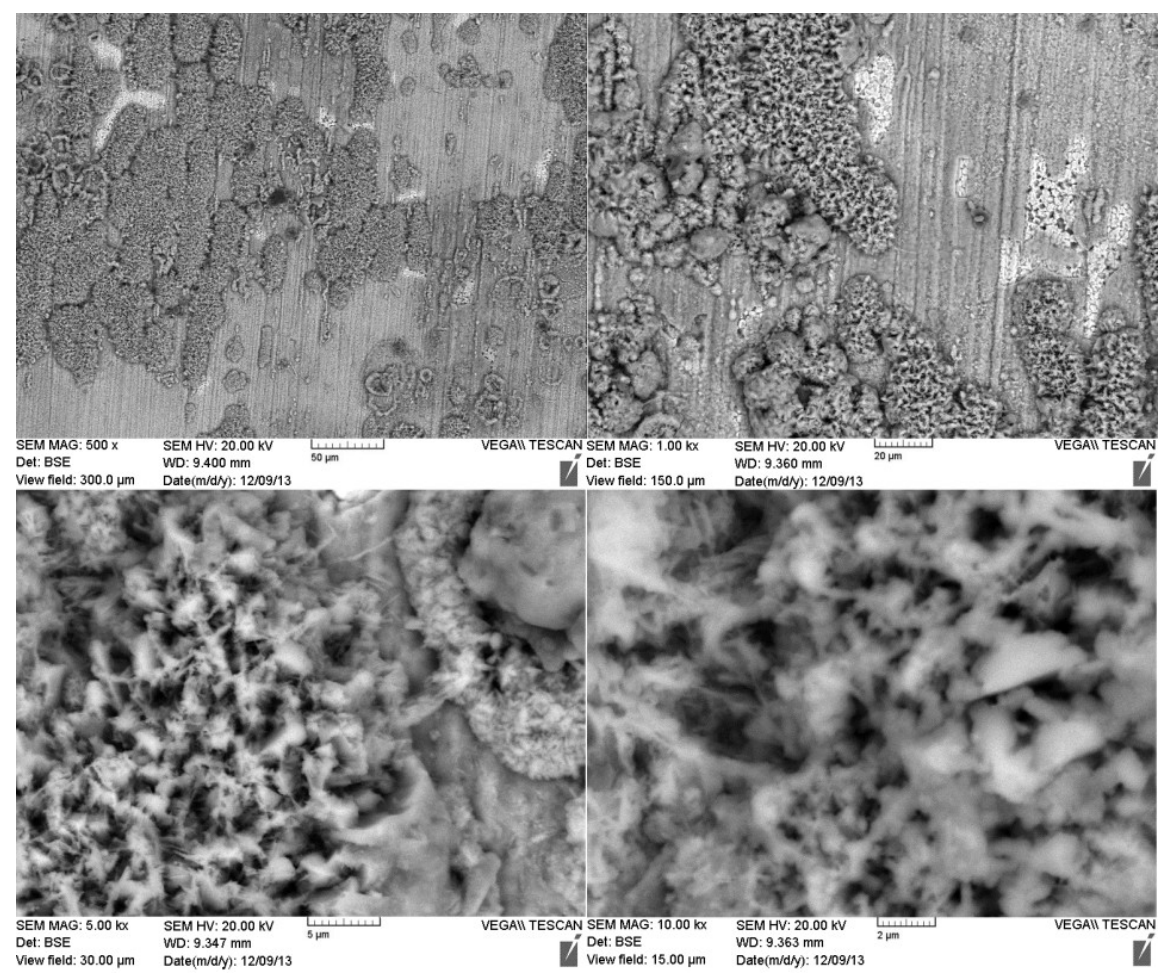

Figure 57. SEM surface images of AISI 304 exposed to superheated steam $\left(625^{\circ} \mathrm{C}, 0.1 \mathrm{MPa}\right)$ for $1000 \mathrm{~h}$.

Table 22. EDS chemical composition of AISI 304 exposed to superheated steam.

\begin{tabular}{|c|c|c|c|c|c|c|}
\hline \multirow{2}{*}{$\begin{array}{c}\text { Exposure time } \\
\text { (hours) }\end{array}$} & \multicolumn{5}{|c|}{ Chemical composition by element (weight percent) } \\
\cline { 2 - 7 } & $\mathrm{Fe}$ & $\mathrm{Cr}$ & $\mathrm{Ni}$ & $\mathrm{O}$ & $\mathrm{Mn}$ & $\mathrm{Si}$ \\
\hline 350 & 67.11 & 19.31 & 7.89 & 3.03 & 1.27 & 1.39 \\
\hline 700 & 67.05 & 19.27 & 7.79 & 4.02 & 0.99 & 0.88 \\
\hline 1000 oxide & 60.76 & 3.19 & 0.00 & 34.47 & 0.33 & 1.25 \\
\hline 1000 substrate & 66.97 & 20.15 & 7.13 & 3.27 & 1.64 & 0.84 \\
\hline
\end{tabular}

\subsubsection{AISI 310 Exposed to SCW, SubCW and SHS}

Samples of AISI 310 were tested in all conditions and analyzed using SEM and EDS. All SEM images were taken at different magnifications and the BSE images are presented and discussed below together with the EDS compositional analysis results. 


\section{SCW Samples}

Figures 58, 59 and 60 show the SEM images of AISI 310 samples exposed to supercritical water at $625^{\circ} \mathrm{C}$ and $29 \mathrm{MPa}$ for periods of 1000,2000 and 3000 hours, respectively. Magnifications used in the different images range from 500X to $10 \mathrm{kX}$ depending on the surface morphology and special features observed in each sample.

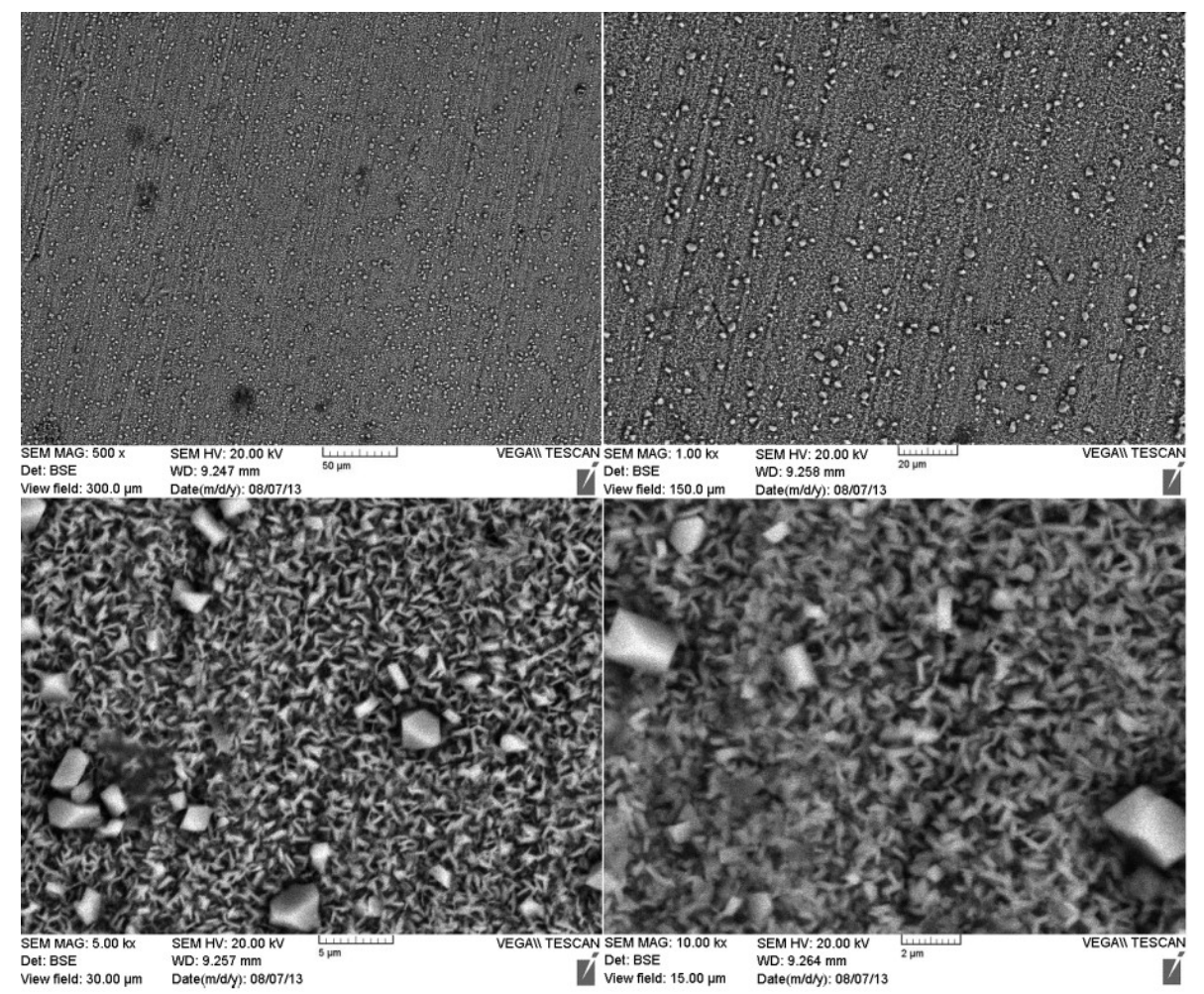

Figure 58. SEM surface images of AISI 310 exposed to SCW $\left(625^{\circ} \mathrm{C}, 29 \mathrm{MPa}\right)$ for $1000 \mathrm{~h}$.

Figure 58 shows the presence of a uniform layer of oxide that covers the whole sample surface.

This is consistent with the visual inspection, which suggested the formation of surface scale after initial exposure. All oxide particles show consistently bright, elongated features. Occasionally larger particles are present on the surface, but in a smaller density. 
No noticeable changes can be seen between the first two samples tested for 1000 and 2000 hours in SCW. Images in Figure 59 are consistent with the visual inspection and weight gain analysis results which show that there is very little weight change from 1000 to 2000 hours, suggesting that the oxide layer that has been formed remains thin and stable. The few bigger sized oxide particles are not present any longer after 2000 hours.

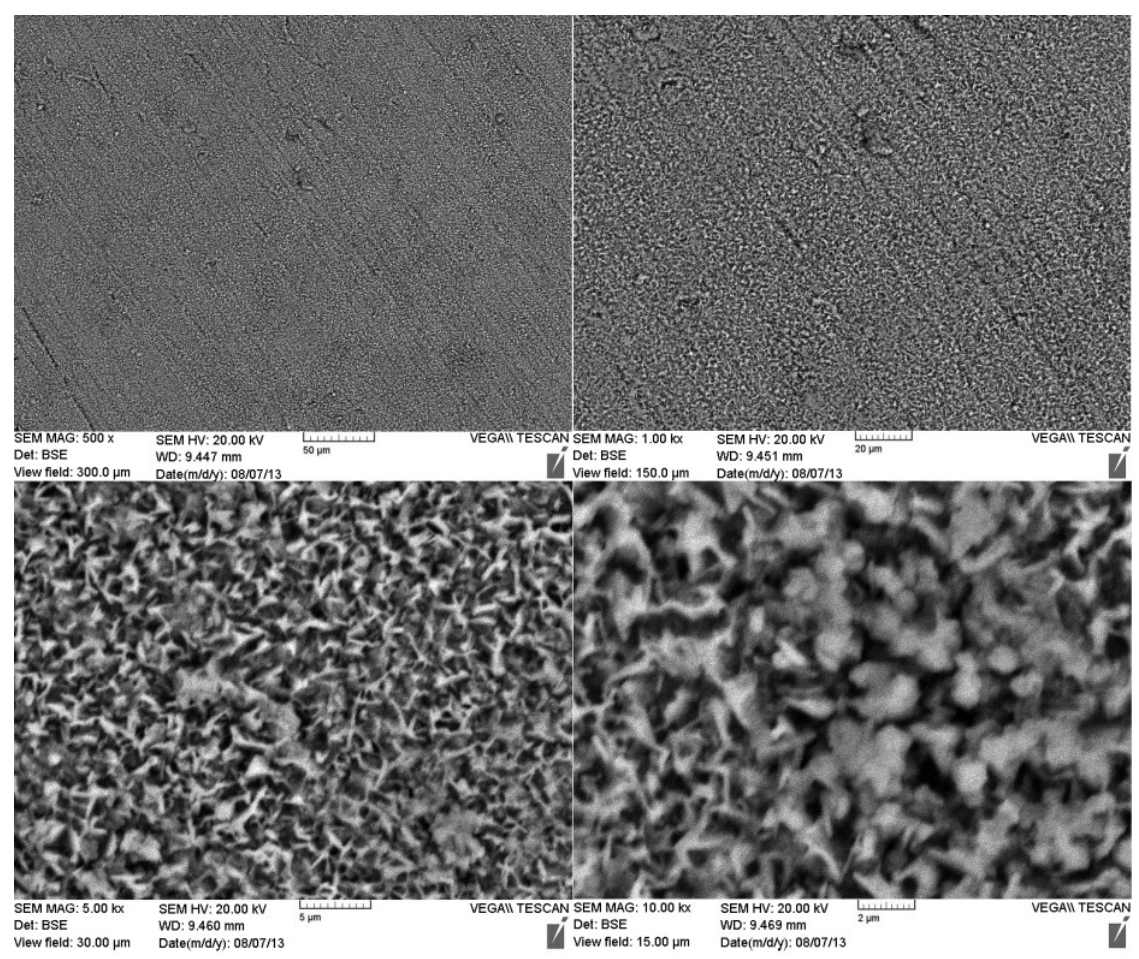

Figure 59. SEM surface images of AISI 310 exposed to SCW $\left(625^{\circ} \mathrm{C}, 29 \mathrm{MPa}\right)$ for $2000 \mathrm{~h}$.

After exposure for 3000 hours (Figure 60) the sample still shows almost no difference from the other samples, consistent with the negligible weight change results. The stable oxide layer continues to cover $100 \%$ of the sample surface. Occasional large sized superficial particles are also observed on the surface. 


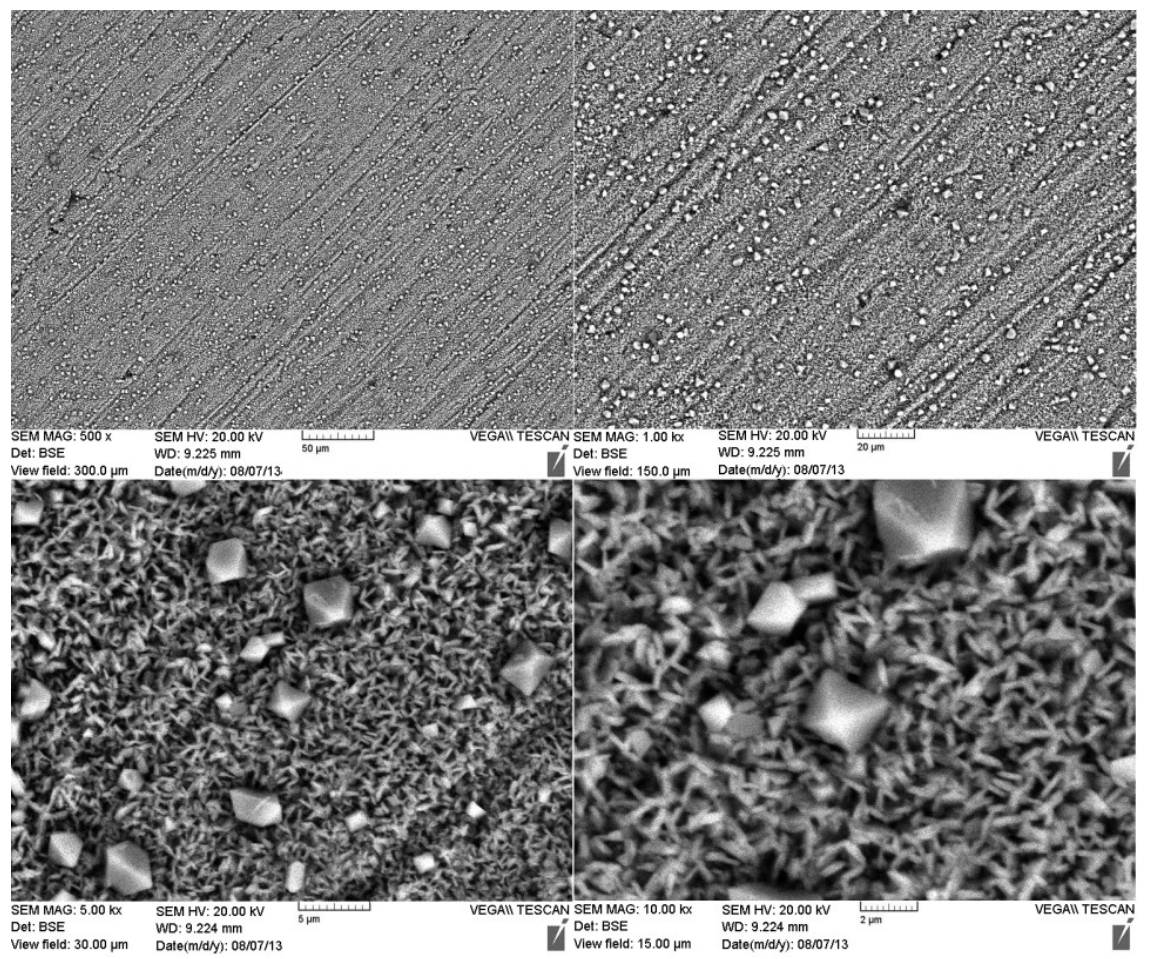

Figure 60. SEM surface images of AISI 310 exposed to SCW $\left(625^{\circ} \mathrm{C}, 29 \mathrm{MPa}\right)$ for $3000 \mathrm{~h}$.

The iron content measured from the surface is much lower in comparison with the base alloy, in contrast, chromium and oxygen levels are high, suggesting the formation of a chromium oxide layer $\left(\mathrm{Cr}_{2} \mathrm{O}_{3}\right)$ or mixed oxide containing $\mathrm{Cr}$. The oxygen concentration shows a small increase with test duration and the chromium level at the surface remains constant. The oxide layer remains stable for the entire 3000 hours of testing time and provides protection to the alloy from further corrosion/oxidation and very low weight variation in AISI 310 samples.

Table 23. EDS chemical composition of AISI 310 exposed to SCW.

\begin{tabular}{|c|c|c|c|c|c|c|}
\hline \multirow{2}{*}{$\begin{array}{c}\text { Exposure } \\
\text { time (hours) }\end{array}$} & \multicolumn{6}{|c|}{ Chemical composition by element (weight percent) } \\
\cline { 2 - 7 } & $\mathrm{Fe}$ & $\mathrm{Cr}$ & $\mathrm{Ni}$ & $\mathrm{O}$ & $\mathrm{Mn}$ & $\mathrm{Si}$ \\
\hline 1000 oxide & 22.73 & 40.66 & 8.11 & 22.34 & 5.59 & 0.57 \\
\hline 2000 oxide & 19.41 & 40.62 & 6.76 & 24.78 & 5.39 & 1.04 \\
\hline 3000 oxide & 18.46 & 41.81 & 7.22 & 25.1 & 6.65 & 0.76 \\
\hline
\end{tabular}




\section{Subcritical Water Samples}

Figure 61, Figure 62 and Figure 63 show SEM images of AISI 310 samples exposed to subcritical water at $625^{\circ} \mathrm{C}$ and $8 \mathrm{MPa}$ for periods of 1000,2000 and 3000 hours, respectively. The magnifications used range from $500 \mathrm{X}$ to $10 \mathrm{kX}$, depending on the surface features and areas of interest.

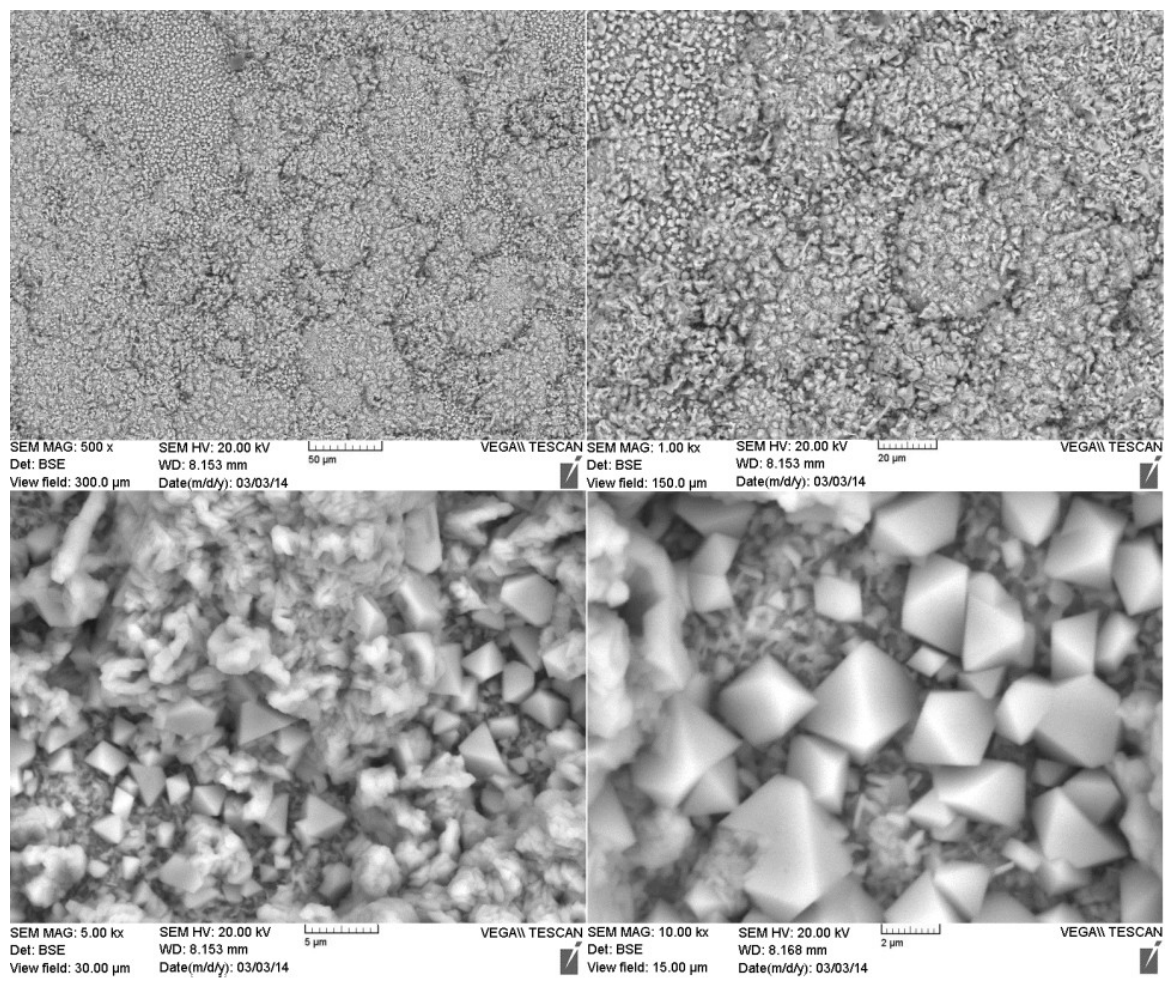

Figure 61. SEM surface images of AISI 310 exposed to SubCW $\left(625^{\circ} \mathrm{C}, 8 \mathrm{MPa}\right)$ for $1000 \mathrm{~h}$.

The sample tested for 1000 hours (Figure 61) it shows a surface entirely covered with corrosion product, in the form of small irregular particles topped with few large diamond shaped particles.

Sample in Figure 62 shows similar features to the sample exposed in SubCW for 1000 hours, with the exception that there is no presence of large surface particles (assuming to be Fe-oxide 
formed at the initial stage of testing). The weight loss observed after 2000 hours (and 3000 hours) could be due to the removal of this type of large particles through dissolution or spallation. The SEM results confirm the visual inspection where $100 \%$ of the surface is believed to be covered by oxide.

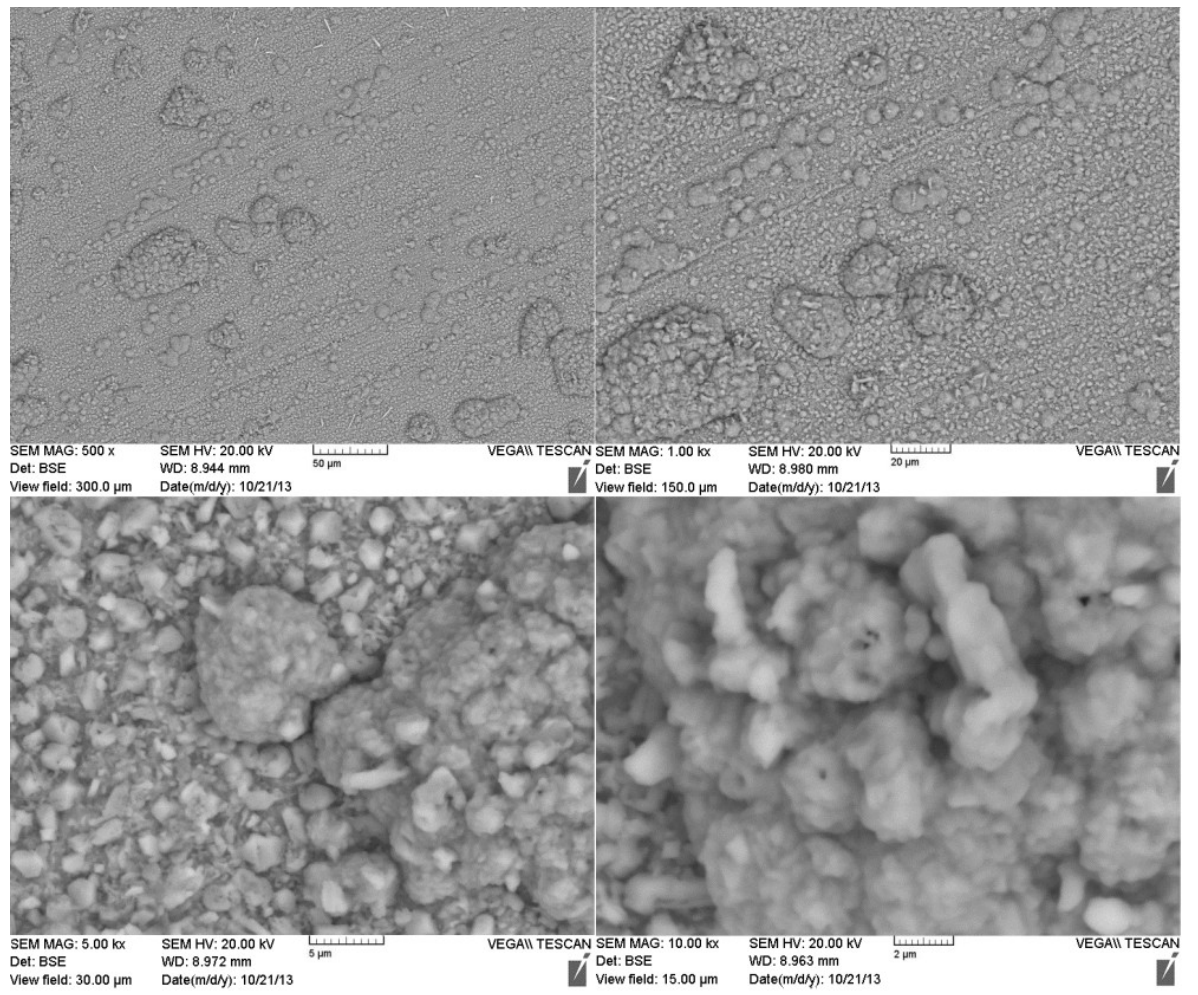

Figure 62. SEM surface images of AISI 310 exposed to SubCW $\left(625^{\circ} \mathrm{C}, 8 \mathrm{MPa}\right)$ for $2000 \mathrm{~h}$. 

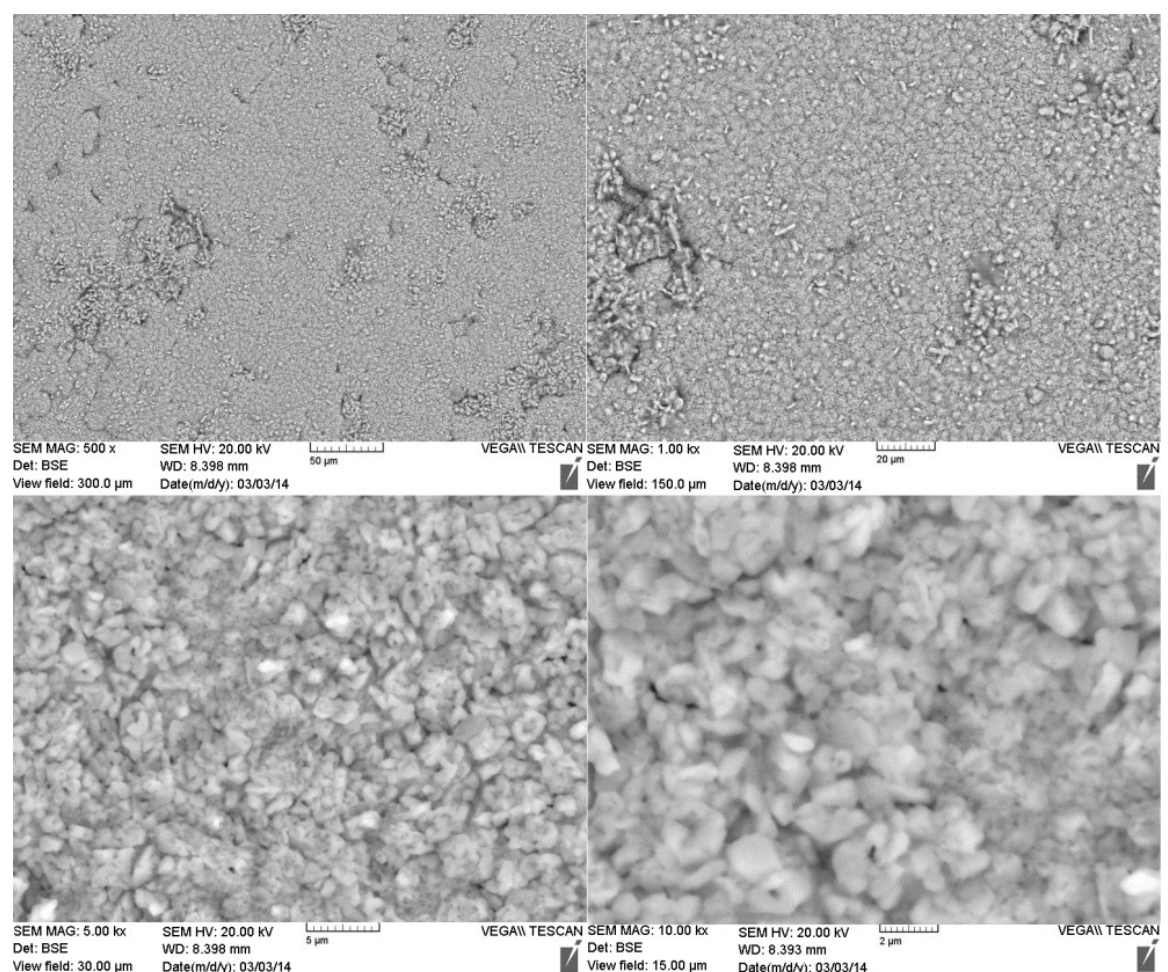

Figure 63. SEM surface images of AISI 310 exposed to SubCW $\left(625^{\circ} \mathrm{C}, 8 \mathrm{MPa}\right)$ for $3000 \mathrm{~h}$.

The oxide layer continues to develop on samples tested for 3000 hours. The oxide particles are more compacted together and have reduced in sizes when compared with the base oxide found in the first 1000 hours test. The surface of this sample can be seen in Figure 63.

The surface compositions of all samples, as determined by EDS analysis, are shown in Table 24. The elevated concentration of chromium and oxygen on the surface of all samples indicates that the oxide formed is chromium oxide $\left(\mathrm{Cr}_{2} \mathrm{O}_{3}\right)$ or mixed oxide $\left((\mathrm{Cr}, \mathrm{Fe})_{2} \mathrm{O}_{3}\right)$ in nature, and the presence of iron in all samples is lower than base metal. There is very little variation in the percentage of all main elements on all three samples, indicating that the oxide on the surface provides a protection for the alloy from further oxidation. 
Table 24. EDS chemical composition of AISI 310 exposed to SubCW.

\begin{tabular}{|c|c|c|c|c|c|c|}
\hline \multirow{2}{*}{$\begin{array}{c}\text { Exposure } \\
\text { time (hours) }\end{array}$} & \multicolumn{6}{|c|}{ Chemical composition by element (weight percent) } \\
\cline { 2 - 7 } & $\mathrm{Fe}$ & $\mathrm{Cr}$ & $\mathrm{Ni}$ & $\mathrm{O}$ & $\mathrm{Mn}$ & $\mathrm{Si}$ \\
\hline 1000 & 33.06 & 31.23 & 1.25 & 28.75 & 5.70 & 0.00 \\
\hline 2000 & 31.99 & 32.12 & 6.46 & 22.03 & 6.47 & 0.93 \\
\hline 3000 & 32.12 & 34.04 & 6.21 & 23.63 & 4.00 & 0.00 \\
\hline
\end{tabular}

\section{Superheated Steam Samples}

Figure 64, Figure 65 and Figure 66 show the SEM images of the AISI 310 samples, exposed to steam at $625^{\circ} \mathrm{C}$ and $0.1 \mathrm{MPa}$ for periods of 350, 700 and 1000 hours, respectively.

After 350 hours of test (Figure 64) the formation of certain amount of surface scale is evidence. The morphology of the observed oxide looks rather featureless, and differs from that resulted from the two conditions seen before. Figure 65 shows the sample after 700 hours; there is no discernable difference between the two samples (350 $\mathrm{h}$ and $700 \mathrm{~h}$ ). This is consistent with the weight gain/loss analysis results and visual inspection observations; all of which show very little to no change between the samples. 


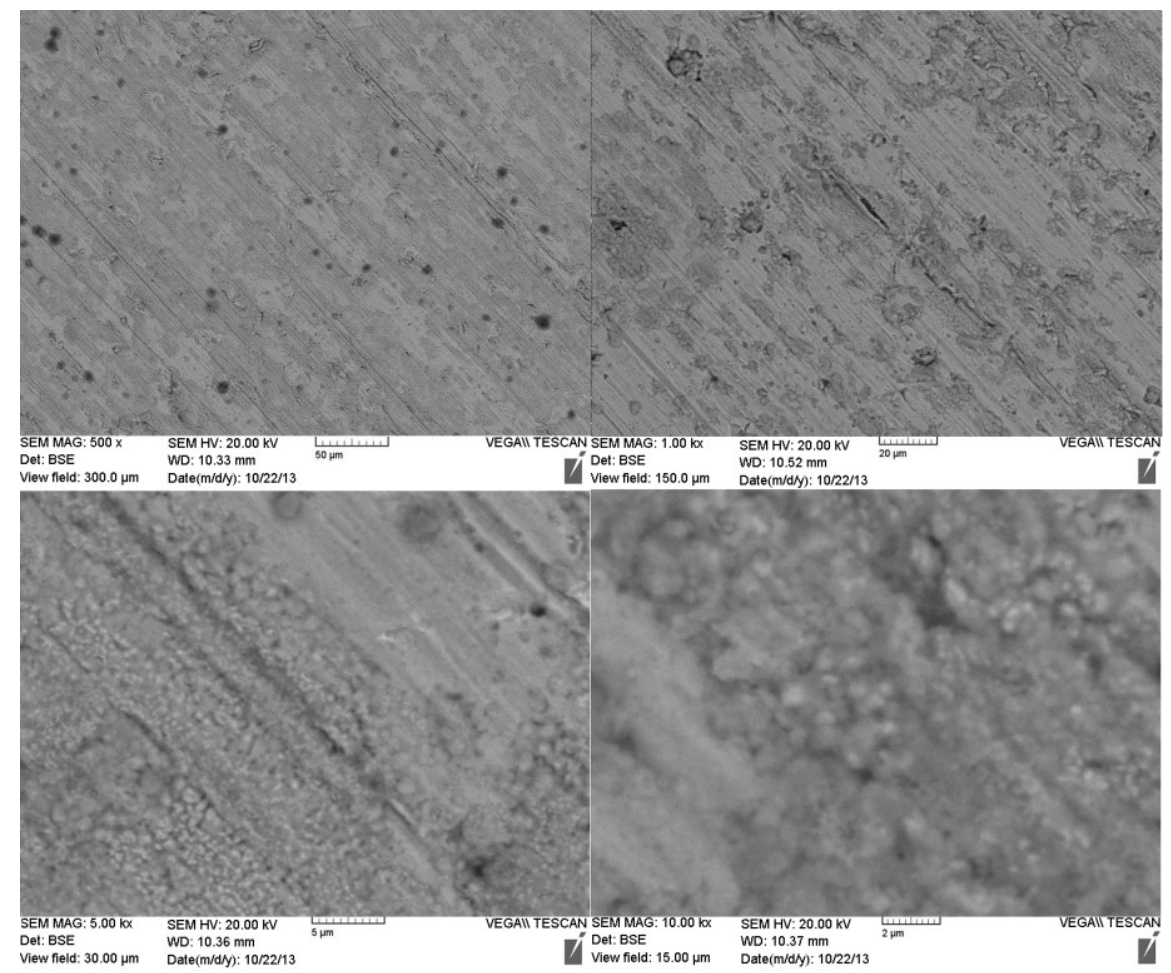

Figure 64. SEM surface images of AISI 310 exposed to superheated steam $\left(625^{\circ} \mathrm{C}, 0.1 \mathrm{MPa}\right)$ for $350 \mathrm{~h}$.

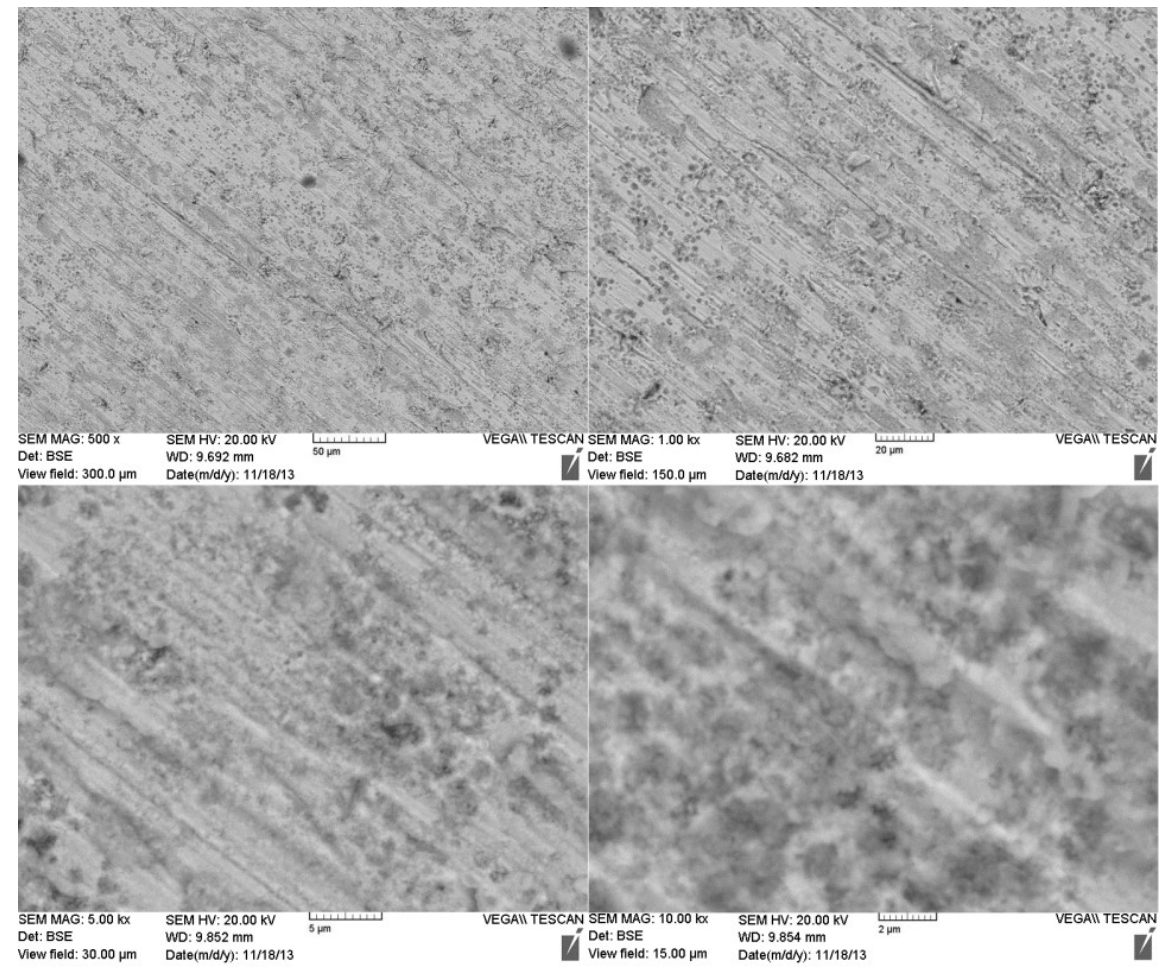

Figure 65. SEM surface images of AISI 310 exposed to superheated steam $\left(625^{\circ} \mathrm{C}, 0.1 \mathrm{MPa}\right)$ for $700 \mathrm{~h}$. 
The 1000 hours tested sample can be seen in Figure 66. These images show a similar distribution and morphology of the surface oxide to the previous two samples (350 and $700 \mathrm{~h})$. The oxide layer does not seem to show any distinct features. The lack of changes to the surface oxide is in accordance with the minimal weight changes for steam tested samples.

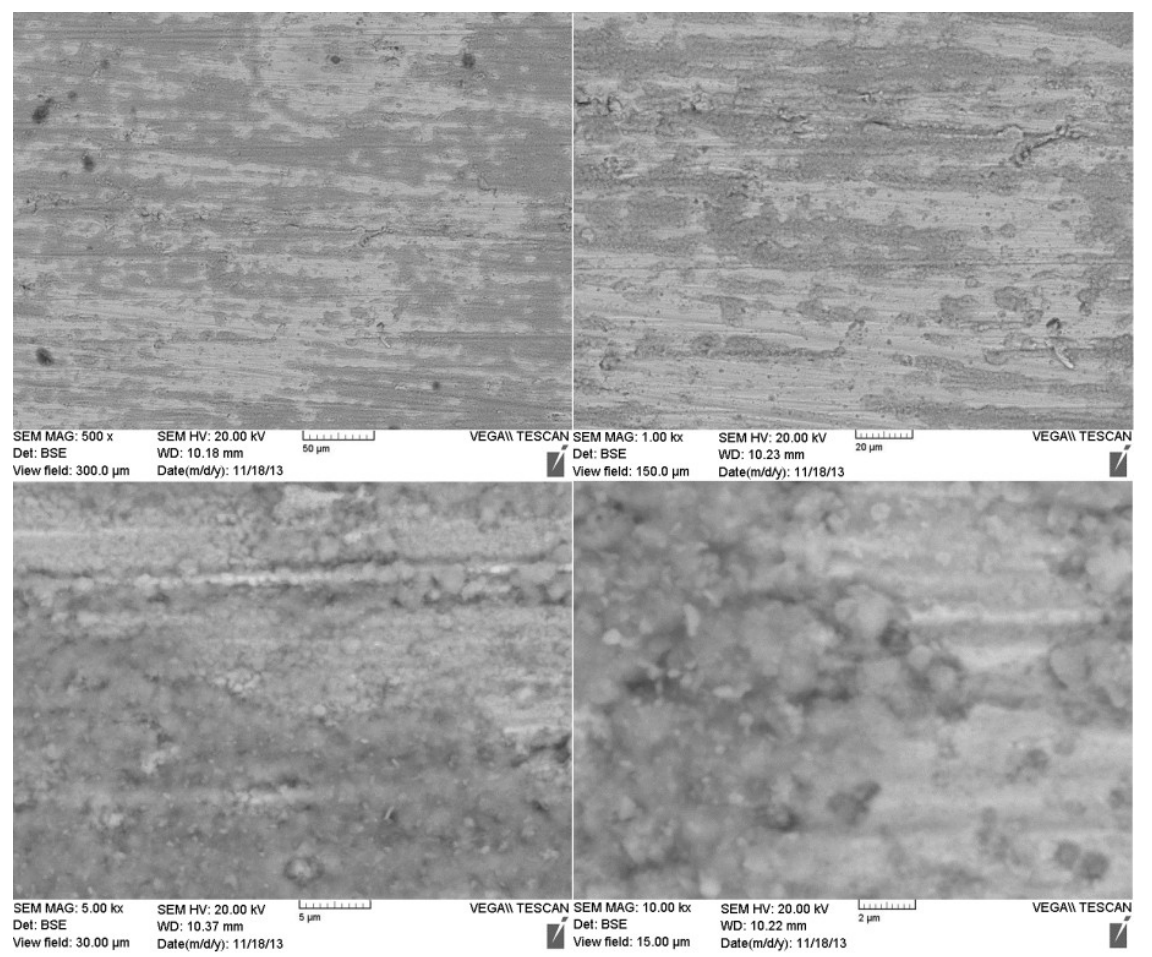

Figure 66. SEM surface images of AISI 310 exposed to superheated steam $\left(625^{\circ} \mathrm{C}, 0.1 \mathrm{MPa}\right)$ for $1000 \mathrm{~h}$.

EDS compositional analysis results in Table 25 suggest that the amount of oxide in fact increases slowly with time, raising measurable oxygen content gradually. Even though SEM and visual observations could not characterize the increase in oxide formation, the increased oxygen and reduced iron and nickel concentrations indicate more oxide formation. The percentage of chromium remains fairly constant, which suggest that the formed oxide layer is mainly composed of chromium oxide $\left(\mathrm{Cr}_{2} \mathrm{O}_{3}\right)$ or mixed oxide. 
Table 25. EDS chemical composition of AISI 310 exposed to superheated steam.

\begin{tabular}{|c|c|c|c|c|c|c|}
\hline \multirow{2}{*}{$\begin{array}{c}\text { Exposure } \\
\text { time (hours) }\end{array}$} & \multicolumn{6}{|c|}{ Chemical composition by element (weight percent) } \\
\cline { 2 - 7 } & $\mathrm{Fe}$ & $\mathrm{Cr}$ & $\mathrm{Ni}$ & $\mathrm{O}$ & $\mathrm{Mn}$ & $\mathrm{Si}$ \\
\hline 350 & 46.34 & 26.26 & 17.93 & 4.79 & 1.96 & 2.72 \\
\hline 700 & 45.60 & 25.74 & 17.06 & 9.72 & 1.88 & 0.00 \\
\hline 1000 & 41.15 & 25.99 & 14.82 & 12.77 & 2.26 & 3.01 \\
\hline
\end{tabular}

\subsubsection{A-286 Exposed to SCW, SubCW and SHS}

Results obtained from SEM and EDS analysis of A-286 samples are presented in the following section. All SEM images were taken using BSE mode and at different magnifications depending on the surface features to be observed.

\section{SCW Samples}

Figure 67, Figure 68 and Figure 69 exhibit the SEM images of A-286 samples exposed to supercritical water at $625^{\circ} \mathrm{C}$ and $29 \mathrm{MPa}$ for periods of 1000,2000 and 3000 hours, respectively.

Figure 67 shows that after 1000 hours in SCW A-286 alloy has developed islands of corrosion produce that covers more than $50 \%$ of the surface area. The morphology of the oxide is similar to iron oxide seen on previous samples (AISI 304). The oxide particles have a similar pattern in all areas where it can be found. They have a random orientation and irregular/angular shapes. The growth of the surface oxide layer is the cause of the weight gain detected in these samples. 


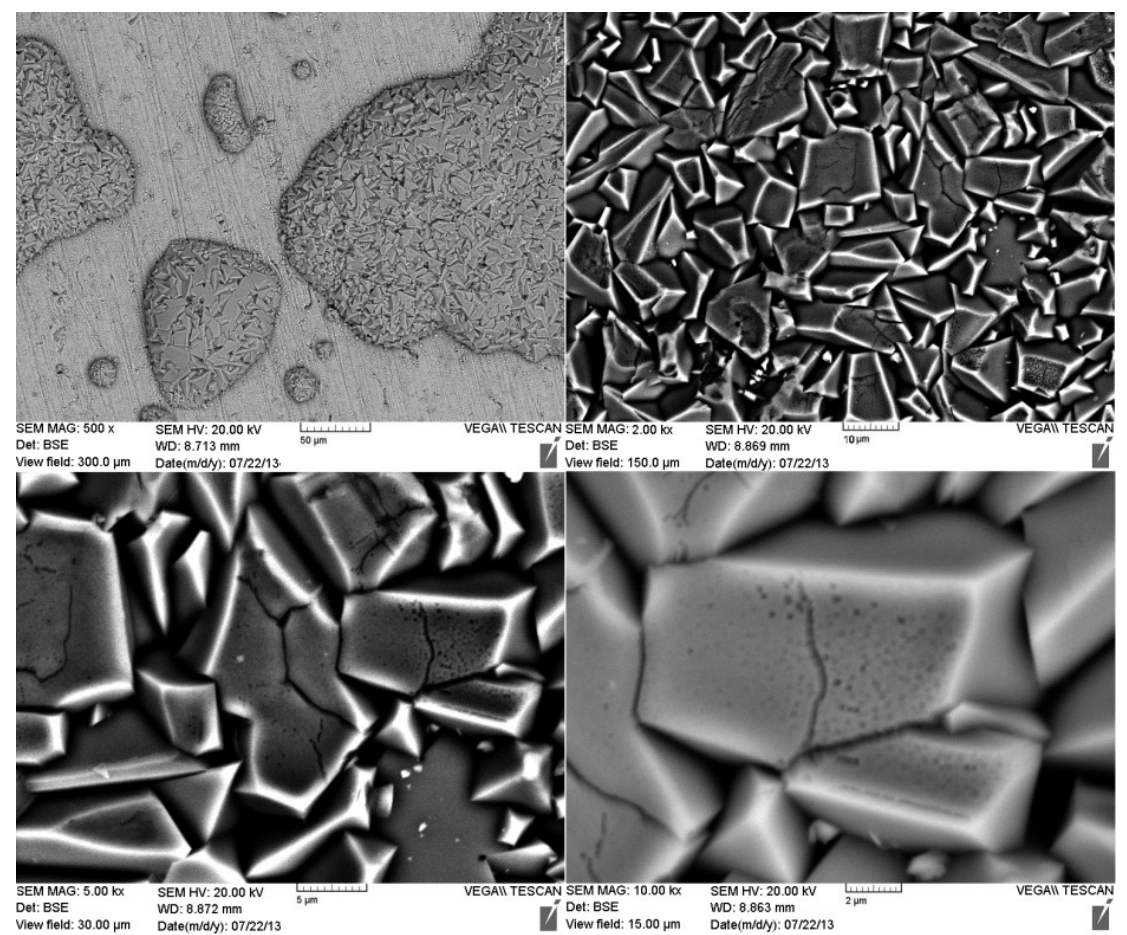

Figure 67. SEM surface images of A-286 exposed to SCW (625 $\left.{ }^{\circ} \mathrm{C}, 29 \mathrm{MPa}\right)$ for $1000 \mathrm{~h}$.
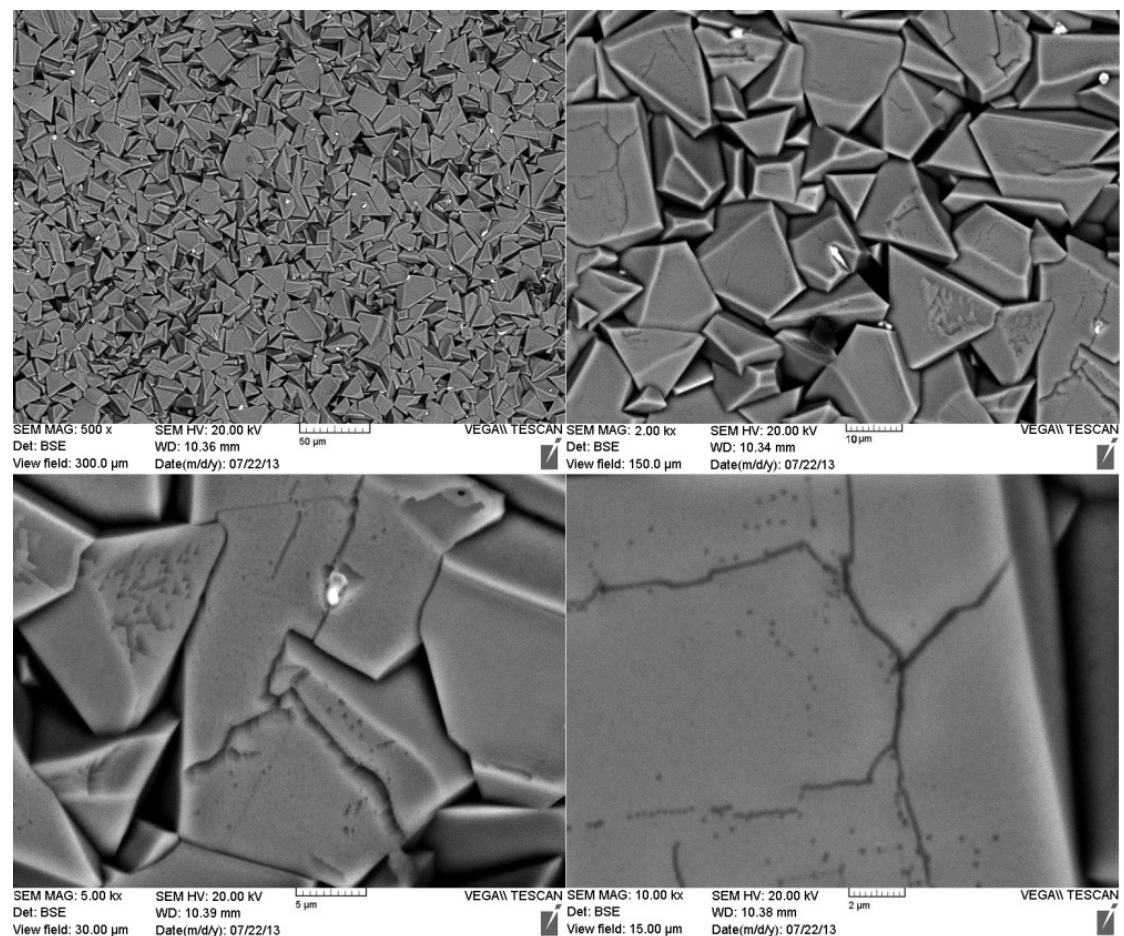

Figure 68. SEM surface images of A-286 exposed to SCW (625 ${ }^{\circ}$ C, $\left.29 \mathrm{MPa}\right)$ for $2000 \mathrm{~h}$. 
Figure 68 illustrates a larger area of surface ( $>60 \%$ ) covered by an oxide layer for A-286 sample after 2000 hours in SCW. The continued exposure in autoclave encouraged further growth of oxide layer during the $2^{\text {nd }} 1000$ hours (for 2000 hour sample). The oxide particles seem to have grown into larger and more regular shape.

The images for sample experienced 3000 hours of test (Figure 69) show slightly different characteristics on the sample's surface. Smaller particles began to form in between the already identified irregular/angular kind of oxide. The density of the surface area covered by oxide(s) continues to increase (>80\%) and becomes densely populated. From the results from SEM analysis are in accordance with the visual inspection and weight gain analysis results, where an increase in oxide formation with exposure time was predicted. 

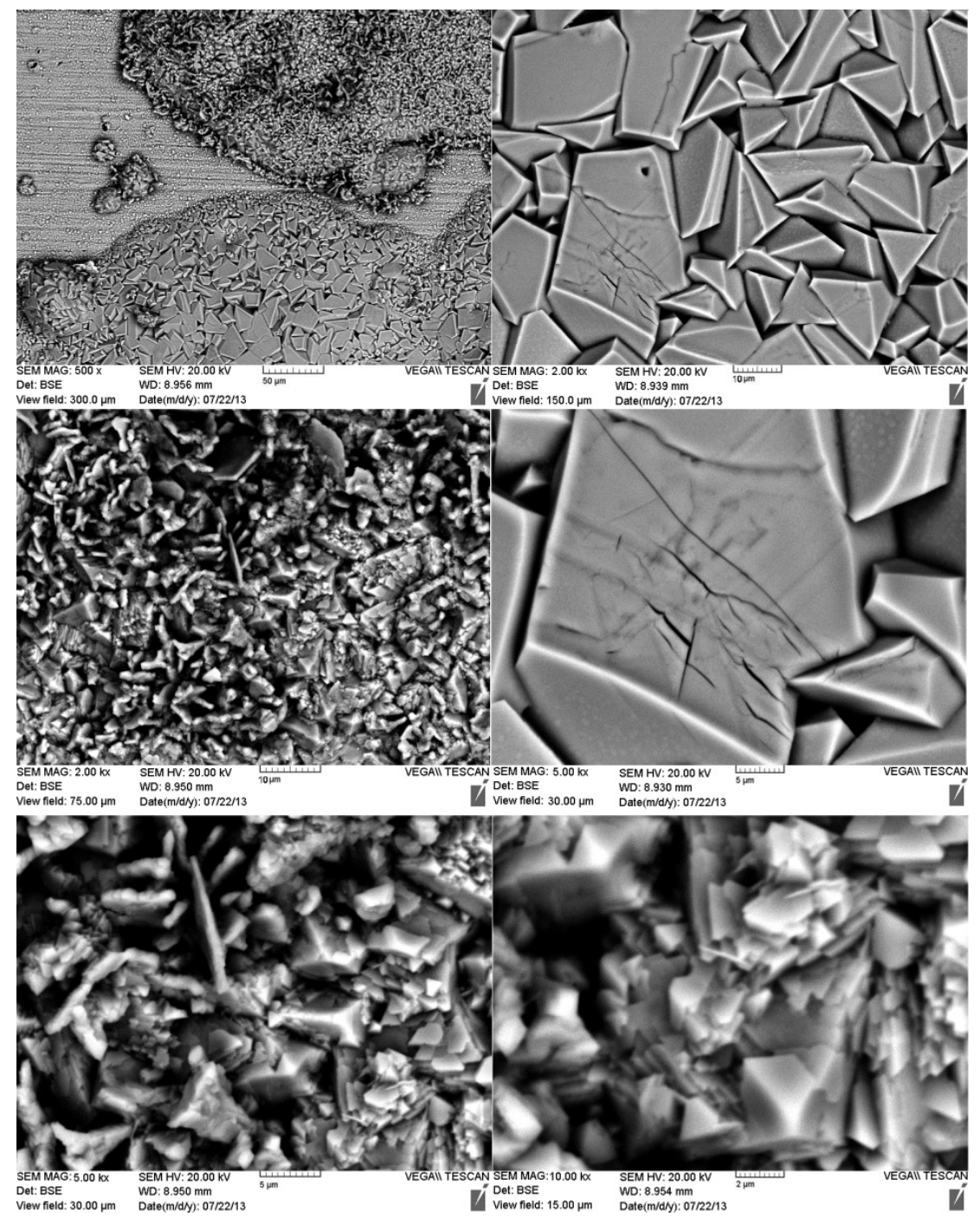

Figure 69. SEM surface images of A-286 exposed to SCW $\left(625^{\circ} \mathrm{C}, 29 \mathrm{MPa}\right)$ for $3000 \mathrm{~h}$.

EDS analysis results summarized in Table 26 show a high concentration of iron and oxygen in the oxidized areas of all three samples. This suggests the presence of iron oxide, most likely magnetite $\left(\mathrm{Fe}_{3} \mathrm{O}_{4}\right)$, on the surface. The concentration of iron shows a slight decrease with time and the oxygen content tends to increase; this suggests that the oxide layer grows continuously due to the inward diffusion of oxygen and the outward diffusion of iron during SCW exposure. Should this alloy be used in SCWR, it is foreseeable that the corrosion process will progress continuously. The other oxide that appears in the sample tested for 3000 hours is believed to 
be chromium oxide $\left(\mathrm{Cr}_{2} \mathrm{O}_{3}\right)$ as higher concentration of chromium was detected (oxide 2 in Table 26). The EDS results obtained in the non oxidized zones are similar to that of the base metal except for a higher concentration of oxygen.

Table 26. EDS chemical composition of A-286 exposed to supercritical water.

\begin{tabular}{|c|c|c|c|c|c|c|c|c|}
\hline $\begin{array}{c}\text { Exposure time } \\
\text { (hours) }\end{array}$ & \multicolumn{8}{|c|}{ Chemical composition by element (weight percent) } \\
\cline { 2 - 9 } & $\mathrm{Fe}$ & $\mathrm{Cr}$ & $\mathrm{Ni}$ & $\mathrm{O}$ & $\mathrm{Ti}$ & $\mathrm{Si}$ & $\mathrm{Al}$ & $\mathrm{Mo} / \mathrm{V}$ \\
\hline 1000 oxide & 70.69 & 0.00 & 0.00 & 28.75 & 0.00 & 0.00 & 0.56 & 0.00 \\
\hline 1000 substrate & 43.92 & 16.78 & 16.08 & 20.48 & 2.17 & 0.57 & 0.00 & 0.00 \\
\hline 2000 oxide & 70.39 & 0.00 & 0.00 & 28.89 & 0.00 & 0.00 & 0.71 & 0.00 \\
\hline 2000 substrate & 28.03 & 23.62 & 15.75 & 25.89 & 3.70 & 0.49 & 0.00 & $2.51 \mathrm{Mo}$ \\
\hline 3000 oxide 1 & 67.07 & 0.40 & 0.00 & 31.89 & 0.00 & 0.00 & 0.65 & 0.00 \\
\hline 3000 oxide 2 & 39.27 & 27.81 & 0.00 & 31.09 & 0.00 & 0.00 & 0.87 & 0.00 \\
\hline 3000 substrate & 37.35 & 21.32 & 10.12 & 26.91 & 2.40 & 0.50 & 0.97 & $0.44 \mathrm{~V}$ \\
\hline
\end{tabular}

\section{Subcritical Water Samples}

The next three SEM images illustrate A-286 samples after exposure to subcritical water at $625^{\circ} \mathrm{C}$ and $8 \mathrm{MPa}$ for periods of 1000, 2000 and 3000 hours, respectively. Images of A-286 tested for 1000 hours can be seen in Figure 70. The entire samples surface is covered with an oxide layer that has a very similar morphology to iron oxide particles observed in the SCW tested samples. Oxide particles also have the same distribution as that seen in the SCW tests. The presence of oxide, on the entire surface, is the reason that the weight gains for A-286 under subcritical condition were much higher than those tested in SCW for the same amount of hours. 

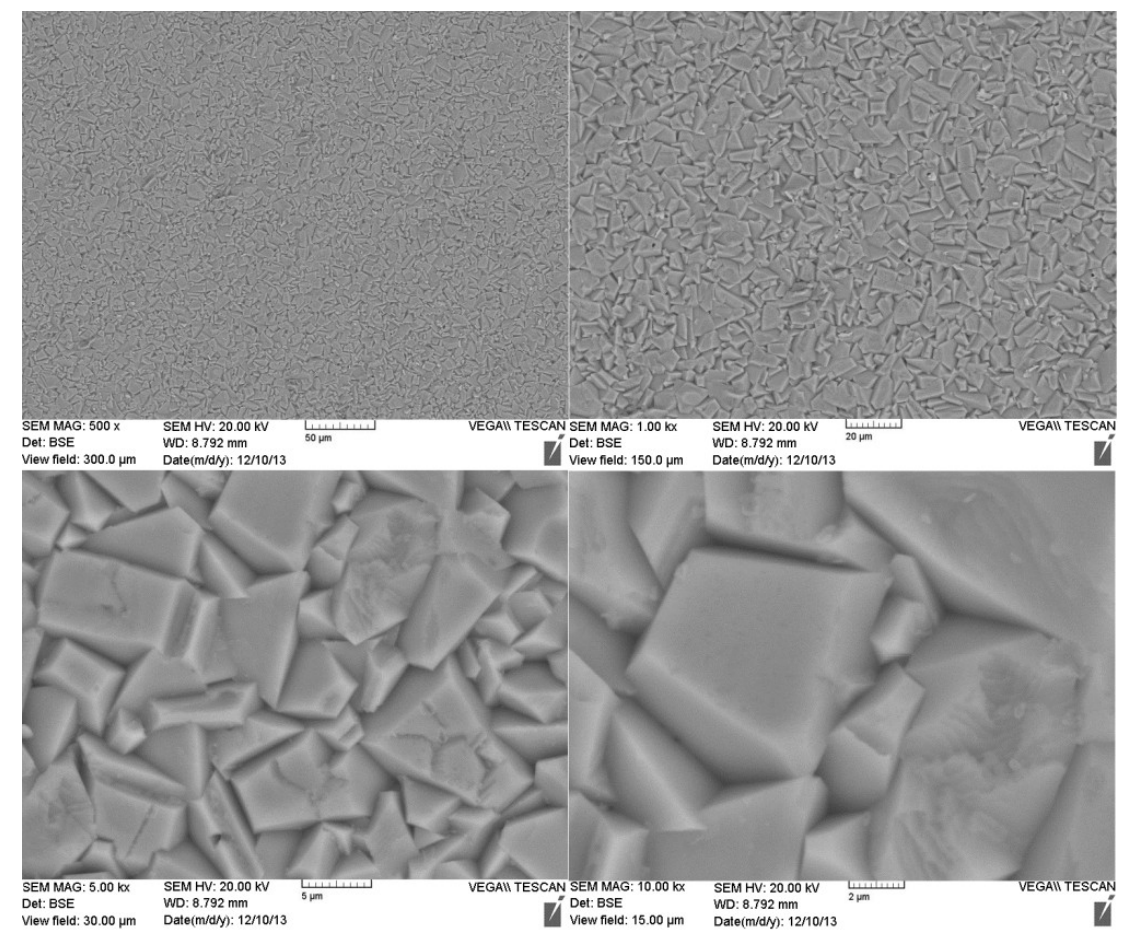

Figure 70. SEM surface images of A-286 exposed to SubCW $\left(625^{\circ} \mathrm{C}, 8 \mathrm{MPa}\right)$ for $1000 \mathrm{~h}$.
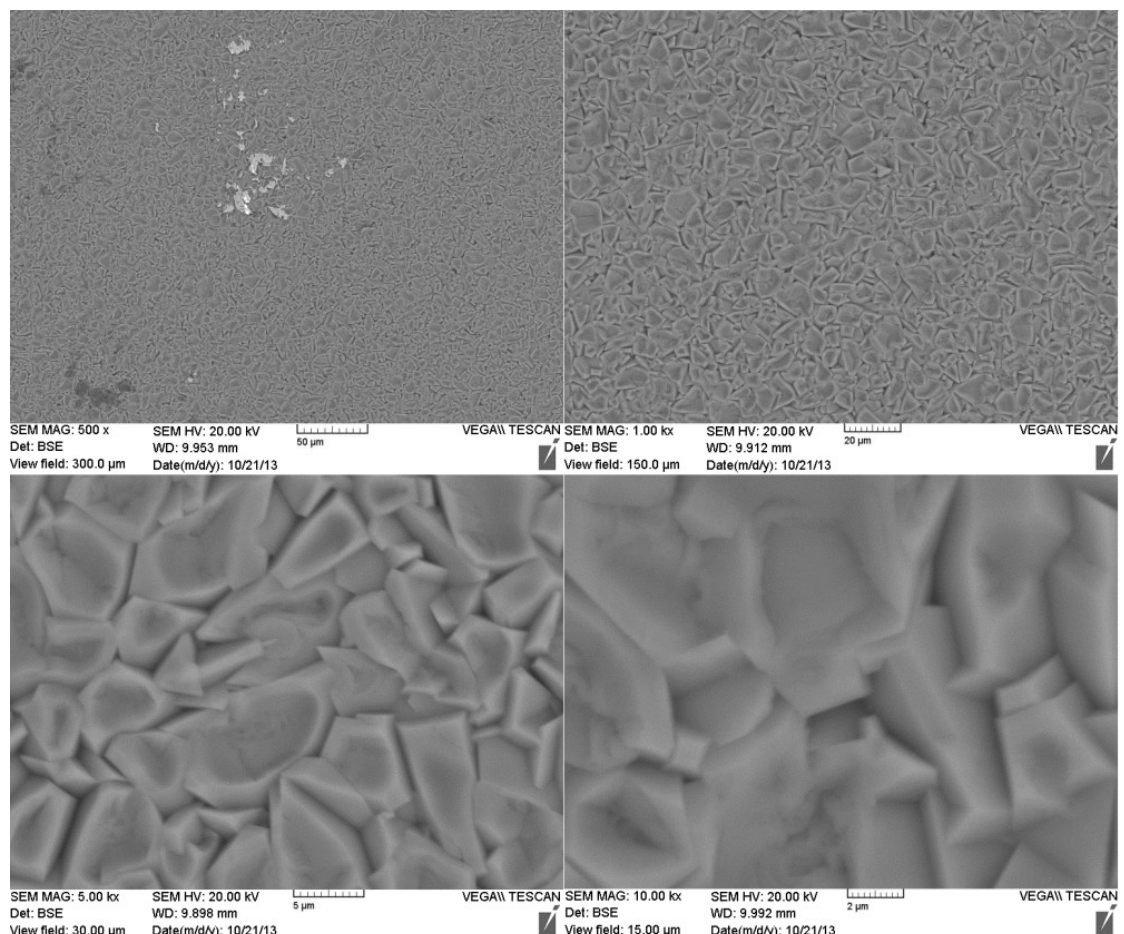

Figure 71. SEM surface images of A-286 exposed to SubCW $\left(625^{\circ} \mathrm{C}, 8 \mathrm{MPa}\right)$ for $2000 \mathrm{~h}$. 
Very similar surface oxide formation is found on A-286 sample tested for 2000 hours (Figure 71): the entire surface is covered by the same type of oxide particles seen before. Occasionally brighter particles are found on the surface, due to copper contamination from the sealant/lubricant used in autoclave. The increased weight gain for this sample can be attributed to the continued oxide growth with time.

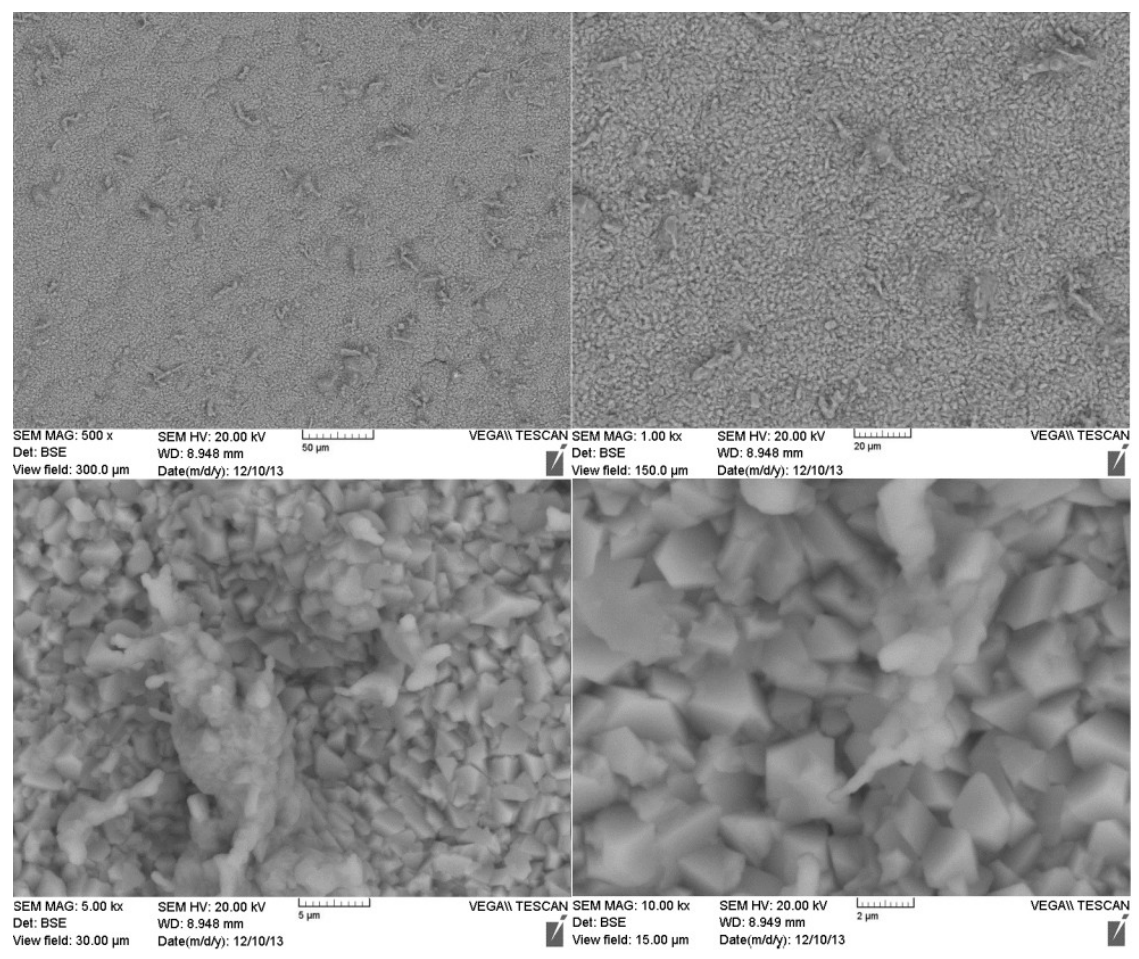

Figure 72. SEM surface images of A-286 exposed to SubCW (625 $\left.{ }^{\circ} \mathrm{C}, 8 \mathrm{MPa}\right)$ for $3000 \mathrm{~h}$.

There is an evidence of appearance change to the oxide layer after 3000 hours of experiment in SubCW. Figure 72 shows oxide particles with a different geometry (than that after 1000 and 2000 hours) but they still cover the entire area of the sample surface. It seems that another type of oxide has formed on the surface; this new type of oxide has smaller particles clustered together. EDS analysis did detect $\mathrm{Cr}$ increase on the surface, suggesting either $\mathrm{Cr}$-rich oxide 
forms at a later stage of the test or the top iron oxide has gone into dissolution, leaving behind inner of Cr-rich oxide.

EDS analysis results, found in Table 27, confirm the existence of iron oxide $\left(\mathrm{Fe}_{3} \mathrm{O}_{4}\right)$ on the surface of samples after 1000 and 2000 hours of SubCW test. The high percentages of iron and oxygen detected suggest the presence of iron oxide. The composition of the oxide in the 3000 hours sample shows a higher content of chromium and oxygen, indicating the presence of chromium oxide on the surface. The results from weight measurement suggest weight loss after 2000 hours of test in SubCW due possibly to the dissolution of iron oxide. SEM analysis confirms the changes of surface oxide as test duration increases.

Table 27. EDS chemical composition of A-286 exposed to subcritical water.

\begin{tabular}{|c|c|c|c|c|c|c|c|c|}
\hline \multirow{2}{*}{$\begin{array}{c}\text { Exposure } \\
\text { time (hours) }\end{array}$} & \multicolumn{10}{|c|}{ Chemical composition by element (weight percent) } \\
\cline { 2 - 9 } & $\mathrm{Fe}$ & $\mathrm{Cr}$ & $\mathrm{Ni}$ & $\mathrm{O}$ & $\mathrm{Ti}$ & $\mathrm{Si}$ & $\mathrm{Co}$ & $\mathrm{Mn}$ \\
\hline 1000 oxide & 74.19 & 0.85 & 0.00 & 24.66 & 0.00 & 0.30 & 0.00 & 0.00 \\
\hline 2000 oxide & 71.92 & 0.26 & 0.00 & 26.86 & 0.00 & 0.00 & 0.40 & 0.56 \\
\hline 3000 oxide & 53.96 & 18.73 & 0.00 & 26.55 & 0.00 & 0.30 & 0.46 & 0.00 \\
\hline
\end{tabular}

\section{Superheated Steam Samples}

Figure 73, Figure 74 and Figure 75 show the SEM images of A-286 samples exposed to superheated steam at $625^{\circ} \mathrm{C}$ and $0.1 \mathrm{MPa}$ for periods of 350,700 and 1000 hours, respectively.

Figure 73 shows very little scale presence after 350 hours. Sample has a clean surface dominated by the appearance of the polishing lines. Occasional discoloration on the surface can be observed around the defects sites. No apparent oxide can be found. The sample exposed to team for 700 hours (Figure 74) shows almost no difference, except limited areas with globular 
oxide presence. The vast majority of the sample has a clean appearance. Figure 75 shows that after 1000 hours a slightly higher quantity and enlarged regions with corrosion indications are observed. The very minimal weight gains for these samples correspond well with the SEM results.
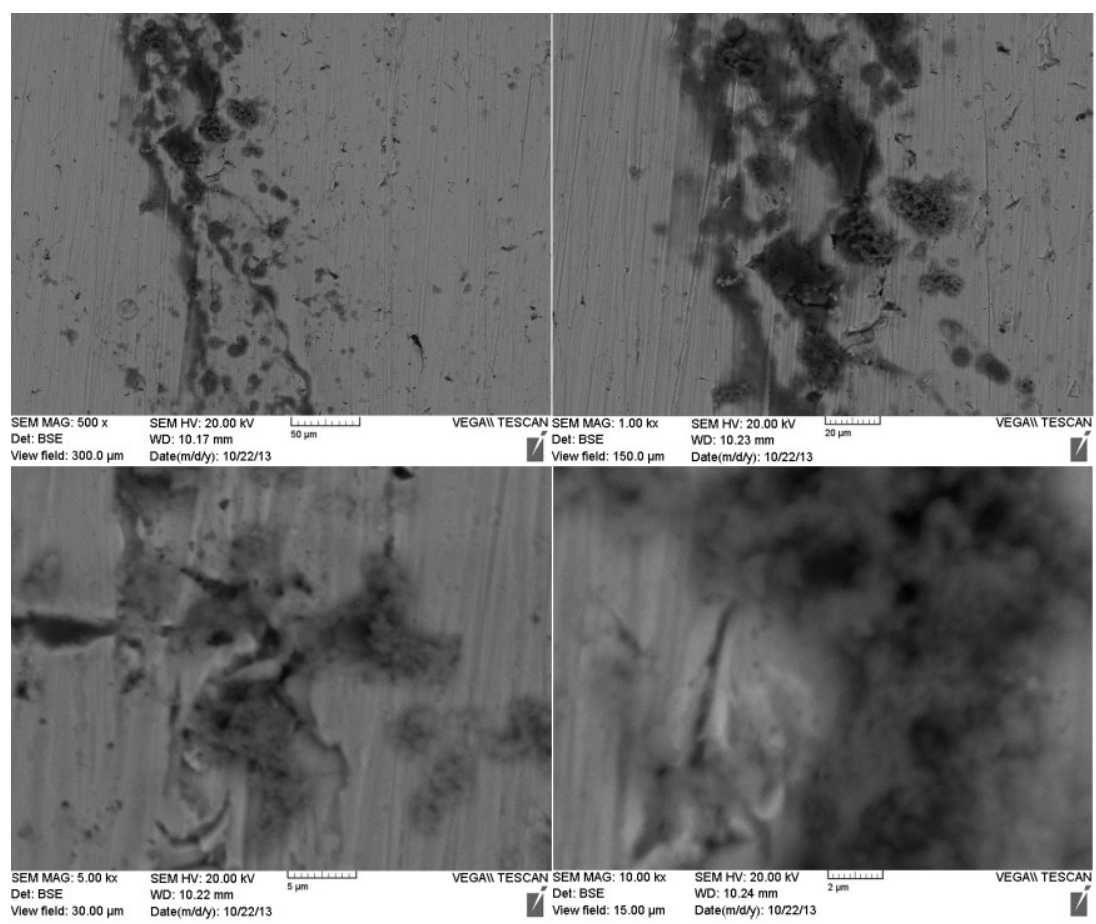

Figure 73. SEM surface images of A-286 exposed to superheated steam (625 $\left.{ }^{\circ} \mathrm{C}, 0.1 \mathrm{MPa}\right)$ for $350 \mathrm{~h}$. 


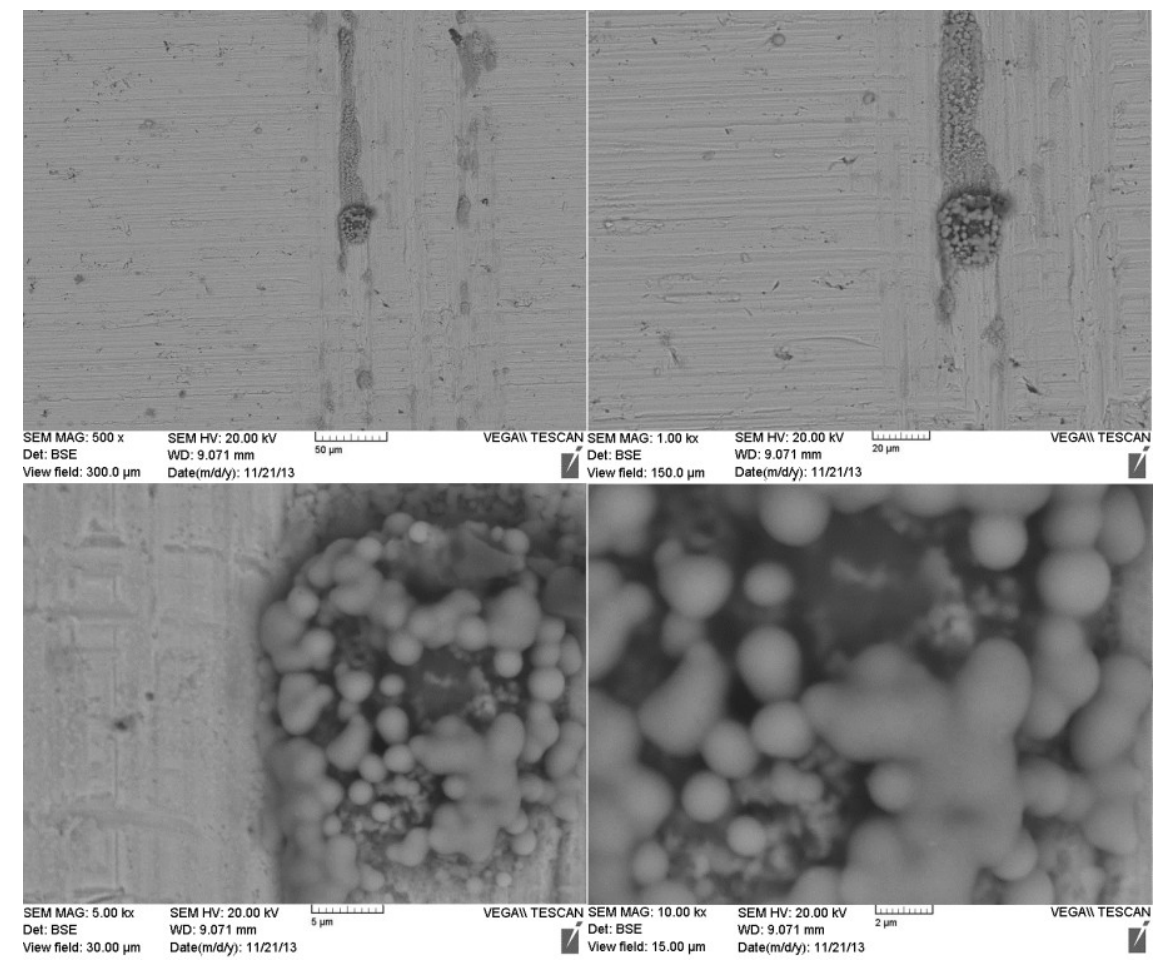

Figure 74. SEM surface images of A-286 exposed to superheated steam $\left(625^{\circ} \mathrm{C}, 0.1 \mathrm{MPa}\right)$ for $700 \mathrm{~h}$.

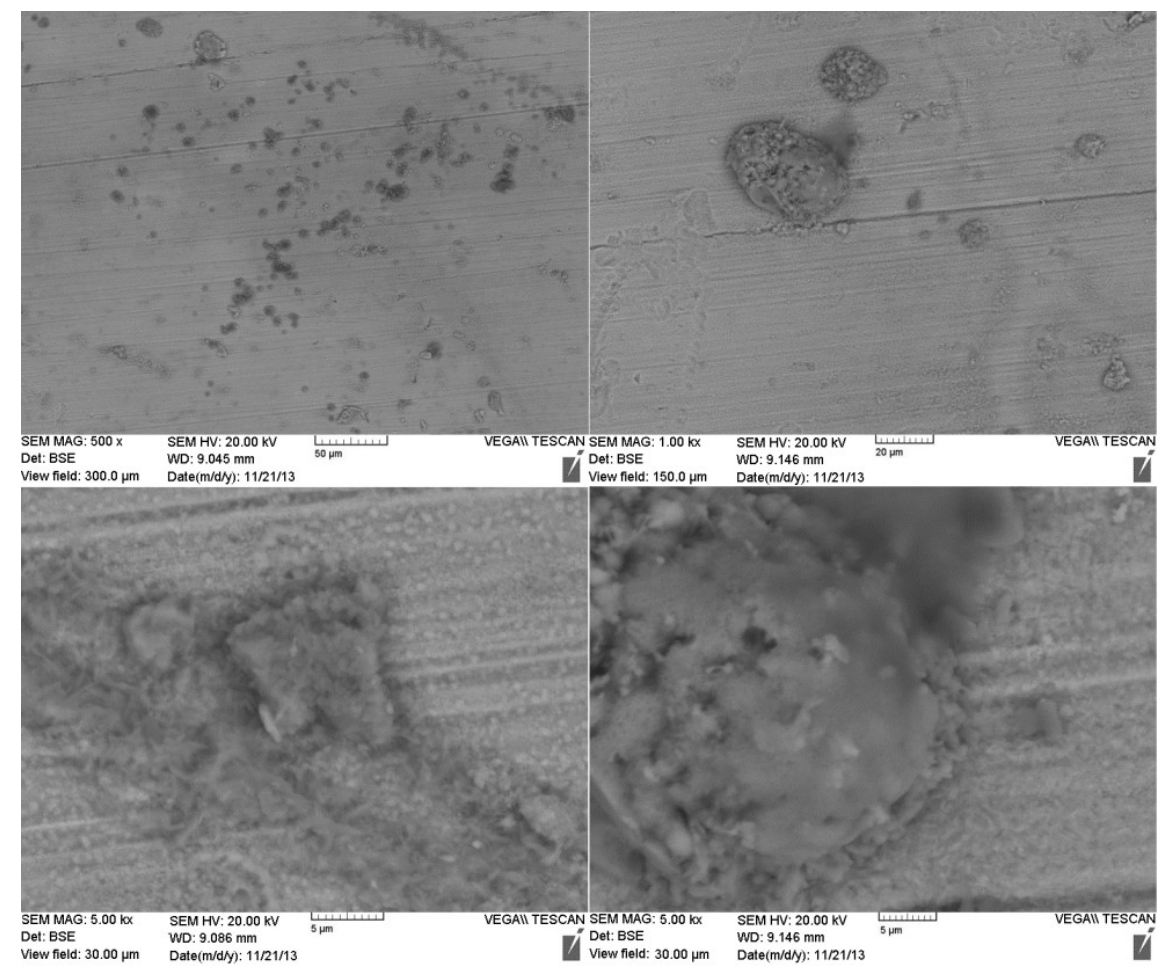

Figure 75. SEM surface images of A-286 exposed to superheated steam $\left(625^{\circ} \mathrm{C}, 0.1 \mathrm{MPa}\right)$ for $1000 \mathrm{~h}$. 
The chemical compositions measured using EDS analysis are shown in Table 28. The sample tested for 350 hours has very little scale and it composition is similar to the base material (very limited oxide formation). The clean areas on the other two samples (700 and 1000 hours) also have a similar composition to the initial alloy. The oxidized regions on the 700 and 1000 hours samples contain high percentages of oxygen and iron and negligible chromium and nickel; this suggests that the oxide present on the surface is primarily iron oxide (likely $\mathrm{Fe}_{2} \mathrm{O}_{3}$ ).

Table 28. EDS chemical composition of A-286 exposed to superheated steam.

\begin{tabular}{|c|c|c|c|c|c|c|c|c|c|}
\hline \multirow{2}{*}{$\begin{array}{c}\text { Exposure time } \\
\text { (hours) }\end{array}$} & \multicolumn{8}{|c|}{ Chemical composition by element (weight percent) } \\
\cline { 2 - 11 } & $\mathrm{Fe}$ & $\mathrm{Cr}$ & $\mathrm{Ni}$ & $\mathrm{O}$ & $\mathrm{Ti}$ & $\mathrm{Si}$ & $\mathrm{V}$ & $\mathrm{Mn}$ & $\mathrm{Mo}$ \\
\hline 350 & 52.39 & 14.38 & 23.29 & 5.41 & 2.11 & 0.60 & 0.26 & 0.43 & 1.13 \\
\hline 700 substrate & 52.40 & 14.73 & 23.34 & 4.52 & 2.06 & 0.82 & 0.21 & 0.40 & 1.52 \\
\hline 700 oxide & 55.86 & 2.57 & 1.02 & 37.66 & 0.00 & 2.89 & 0.00 & 0.00 & 0.00 \\
\hline 1000 substrate & 52.16 & 16.65 & 20.61 & 4.66 & 3.21 & 0.66 & 0.35 & 0.72 & 0.98 \\
\hline 1000 oxide & 53.79 & 3.68 & 0.00 & 40.55 & 0.20 & 1.56 & 0.00 & 0.22 & 0.00 \\
\hline
\end{tabular}

\subsubsection{IN 625 Exposed to SCW, SubCW and SHS}

Results obtained from the SEM and EDS analysis of IN 625 samples tested in all conditions are presented in this section. All SEM pictures were taken using BSE mode at different magnifications depending on features to be examined.

\section{SCW Samples}

Figure 76, Figure 77 and Figure 78 show the SEM images of IN 625 samples exposed to supercritical water at $625^{\circ} \mathrm{C}$ and $29 \mathrm{MPa}$ for periods of 1000,2000 and 3000 hours, respectively. Magnifications used in the different pictures range from 500X to $10 \mathrm{kX}$. 


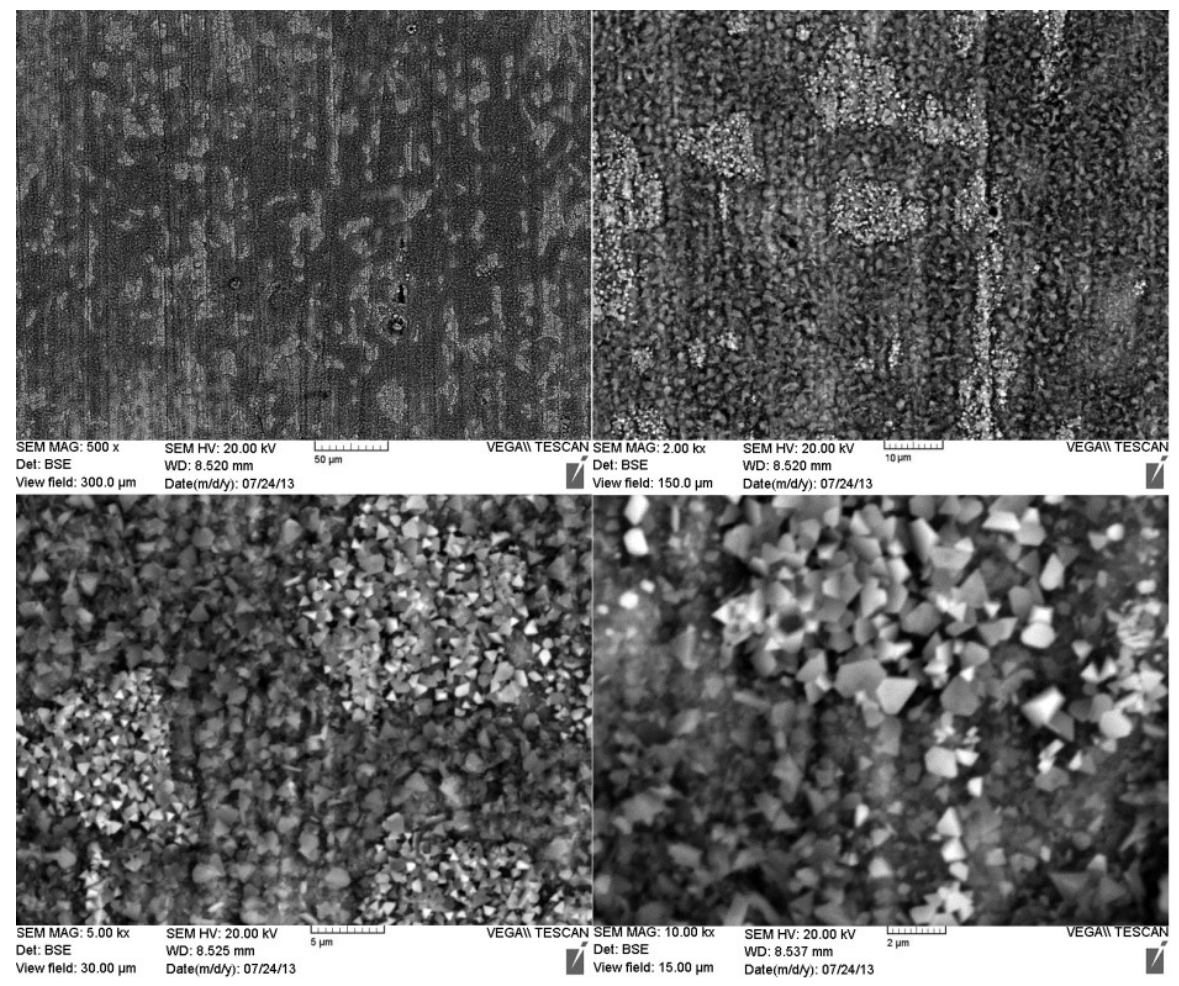

Figure 76. SEM surface images of IN 625 exposed to SCW $\left(625^{\circ} \mathrm{C}, 29 \mathrm{MPa}\right)$ for $1000 \mathrm{~h}$.

Figure 76 shows the surface condition of IN 625 sample after 1000 hours in SCW. Throughout the surface two types of areas with different colorations are observed; the darker oxide occupies approximately $60 \%$ of the total surface area. The morphology of the particles found in both areas is very similar: submicron particles with irregular shape and random orientation. No evidence of cracks is observed but some pitting seems to present. 


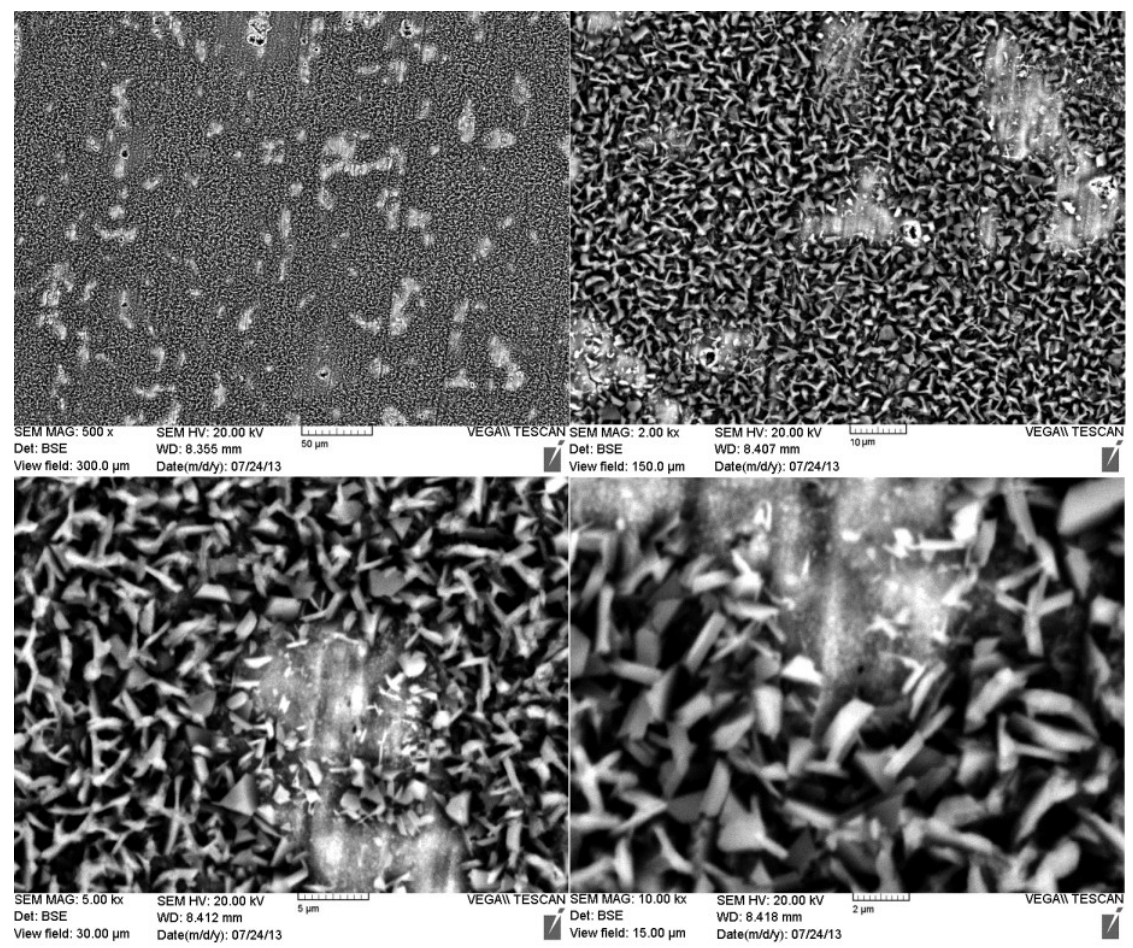

Figure 77. SEM surface images of IN 625 exposed to SCW $\left(625^{\circ} \mathrm{C}, 29 \mathrm{MPa}\right)$ for $2000 \mathrm{~h}$.

Sample after 2000 hours of test (Figure 77) in SCW is different from the one analyzed above.

Two main areas still cover the whole surface, but in this case the darker zone increases its density to approximate $80 \%$ of the total surface area. The morphologies of the particles in both zones are different. Particles in the dark area look elongated with brighter contrast while the lighter patches have minuscule white particles. Some pitted spots are visible and they are observed in approximate the same amount as the previous sample.

The sample after 3000 hours (Figure 78) in SCW also has the two different scale contracts, with approximately $65 \%$ of the entire surface area covered with darker oxide. Again, the oxide in the darker patch has larger particle size than that in lighter patches. 

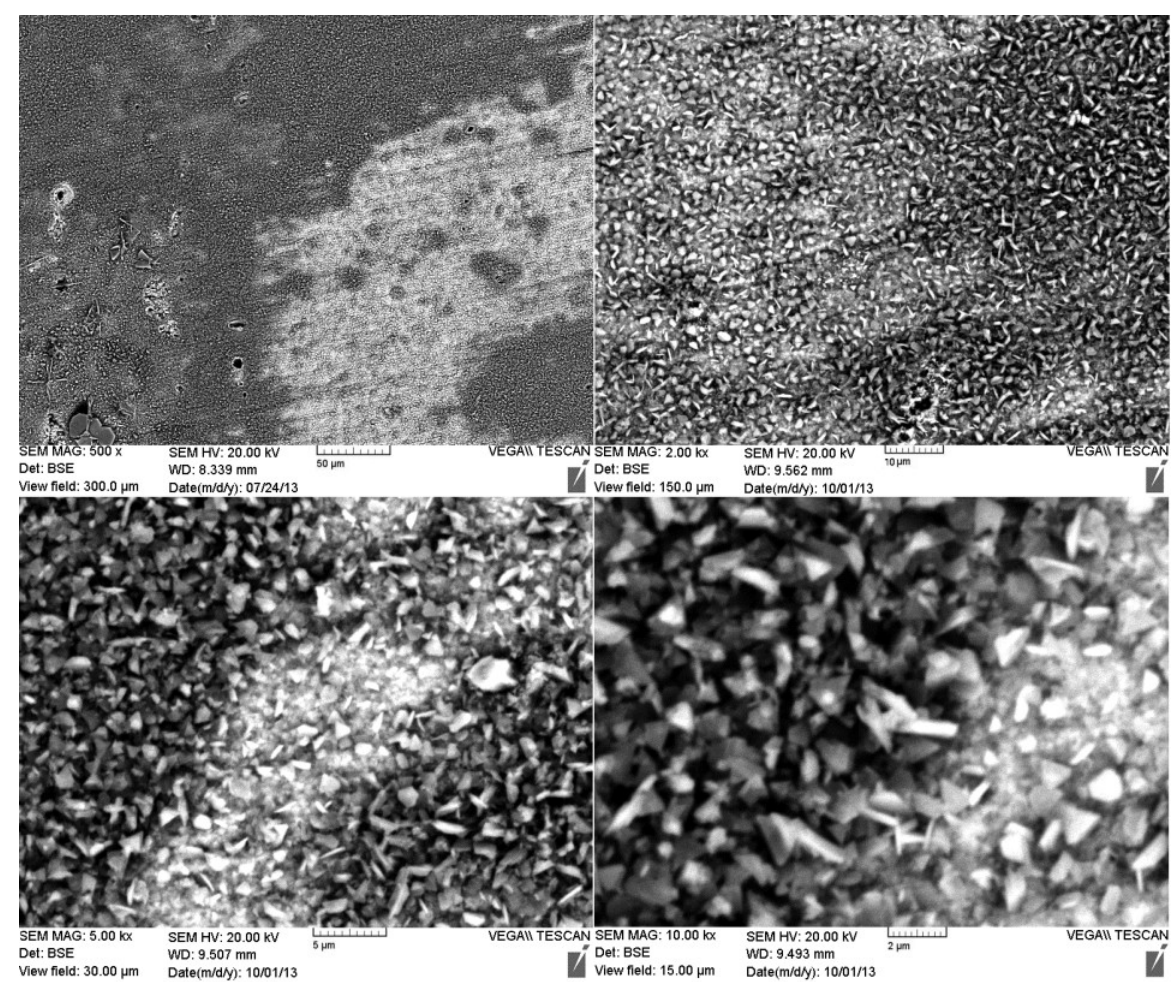

Figure 78. SEM surface images of IN 625 exposed to SCW $\left(625^{\circ} \mathrm{C}, 29 \mathrm{MPa}\right)$ for $3000 \mathrm{~h}$.

EDS compositional analysis results (Table 29) show the difference between the areas. The lighter zones show a higher presence of nickel and oxygen, which suggest the presence of primarily $\mathrm{NiO}$ or spinel. The darker areas contain a higher concentration of chromium and oxygen, which suggests it is chromium oxide (possibly $\mathrm{Cr}_{2} \mathrm{O}_{3}$ with nickel signals from underlying substrate). Both types of oxide are present for the duration of three tests. Based on the SEM results and the minimal weight gain of IN 625 samples during SCW testing is attributed to Nirich and $\mathrm{Cr}$-rich oxide formation on the surface. 
Table 29. EDS chemical composition of IN 625 exposed to supercritical water.

\begin{tabular}{|c|c|c|c|c|c|c|c|c|c|}
\hline $\begin{array}{c}\text { Exposure time } \\
\text { (hours) }\end{array}$ & \multicolumn{10}{|c|}{ Chemical composition by element (weight percent) } \\
\cline { 2 - 10 } & $\mathrm{Fe}$ & $\mathrm{Cr}$ & $\mathrm{Ni}$ & $\mathrm{O}$ & $\mathrm{Nb}$ & $\mathrm{Si}$ & $\mathrm{Al}$ & $\mathrm{Mo}$ & $\mathrm{Ti}$ \\
\hline $\begin{array}{c}1000 \text { oxide } \\
\text { (light) }\end{array}$ & 4.40 & 21.02 & 42.44 & 26.30 & 2.77 & 0.47 & 0.62 & 1.94 & 0.00 \\
\hline $\begin{array}{c}1000 \text { oxide } \\
\text { (dark) }\end{array}$ & 2.91 & 37.15 & 23.95 & 29.95 & 2.48 & 0.00 & 0.55 & 3.01 & 0.00 \\
\hline $\begin{array}{c}\text { 2000 oxide } \\
\text { (light) }\end{array}$ & 5.63 & 18.25 & 45.12 & 25.06 & 3.76 & 0.55 & 1.63 & 0.00 & 0.00 \\
\hline $\begin{array}{c}\text { 2000 oxide } \\
\text { (dark) }\end{array}$ & 3.16 & 33.32 & 18.90 & 38.07 & 3.32 & 0.29 & 1.86 & 1.08 & 0.30 \\
\hline $\begin{array}{c}3000 \text { oxide } \\
\text { (light)w }\end{array}$ & 2.87 & 23.25 & 34.59 & 30.14 & 3.42 & 0.33 & 0.39 & 4.67 & 0.34 \\
\hline $\begin{array}{c}3000 \text { oxide } \\
\text { (dark) }\end{array}$ & 2.96 & 41.04 & 19.03 & 31.33 & 2.72 & 0.00 & 0.79 & 1.80 & 0.33 \\
\hline
\end{tabular}

\section{Subcritical Water Samples}

The following figures present SEM images of IN 625 samples exposed to subcritical water at $625^{\circ} \mathrm{C}$ and $8 \mathrm{MPa}$ for periods of 1000,2000 and 3000 hours. Magnifications used range from $500 \mathrm{X}$ to $10 \mathrm{kX}$, depending on surface features to be analyzed.

Figure 79 shows the formation of a shallow scale (polishing lines can still be observed) on the sample surface after 1000 hours. This scale covers $100 \%$ of the surface, and has a uniform distribution and morphology that is interrupted by areas of pitting corrosion and a few surface cracking. 


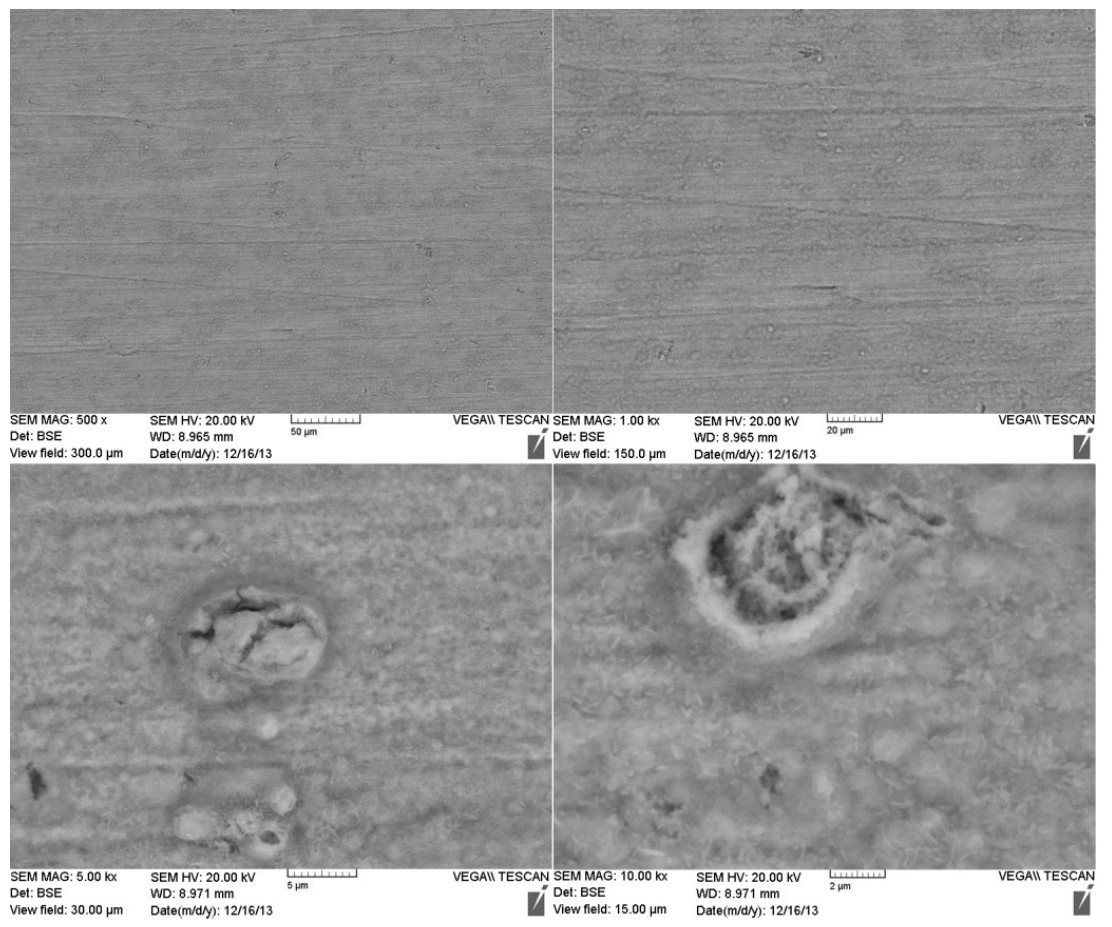

Figure 79. SEM surface images of IN 625 exposed to SubCW $\left(625^{\circ} \mathrm{C}, 8 \mathrm{MPa}\right)$ for $1000 \mathrm{~h}$.
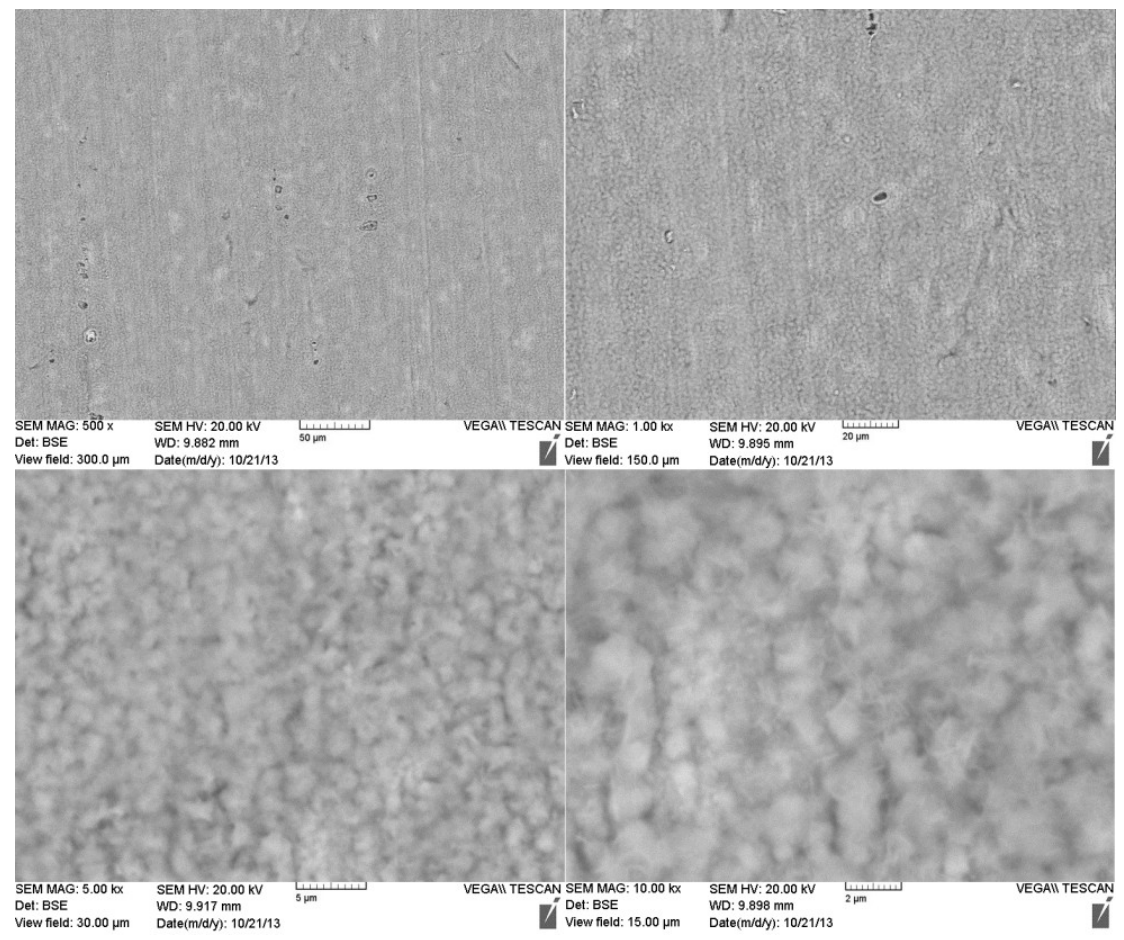

Figure 80. SEM surface images of IN 625 exposed to SubCW $\left(625^{\circ} \mathrm{C}, 8 \mathrm{MPa}\right)$ for $2000 \mathrm{~h}$. 
Figure 80 sample (2000 hours sample) shows an oxide layer very similar to the previous sample, some micro-cracks are still present and the amount of pitting and corrosion areas is slightly higher in comparison with the 1000 hours sample. The oxide morphology remains the same.

The 3000 hours sample (Figure 81) has similar features to the previous two samples, except that the presence of micro-cracks is not observed. The pitting corrosion is still present and the oxide layer still covers the whole surface.

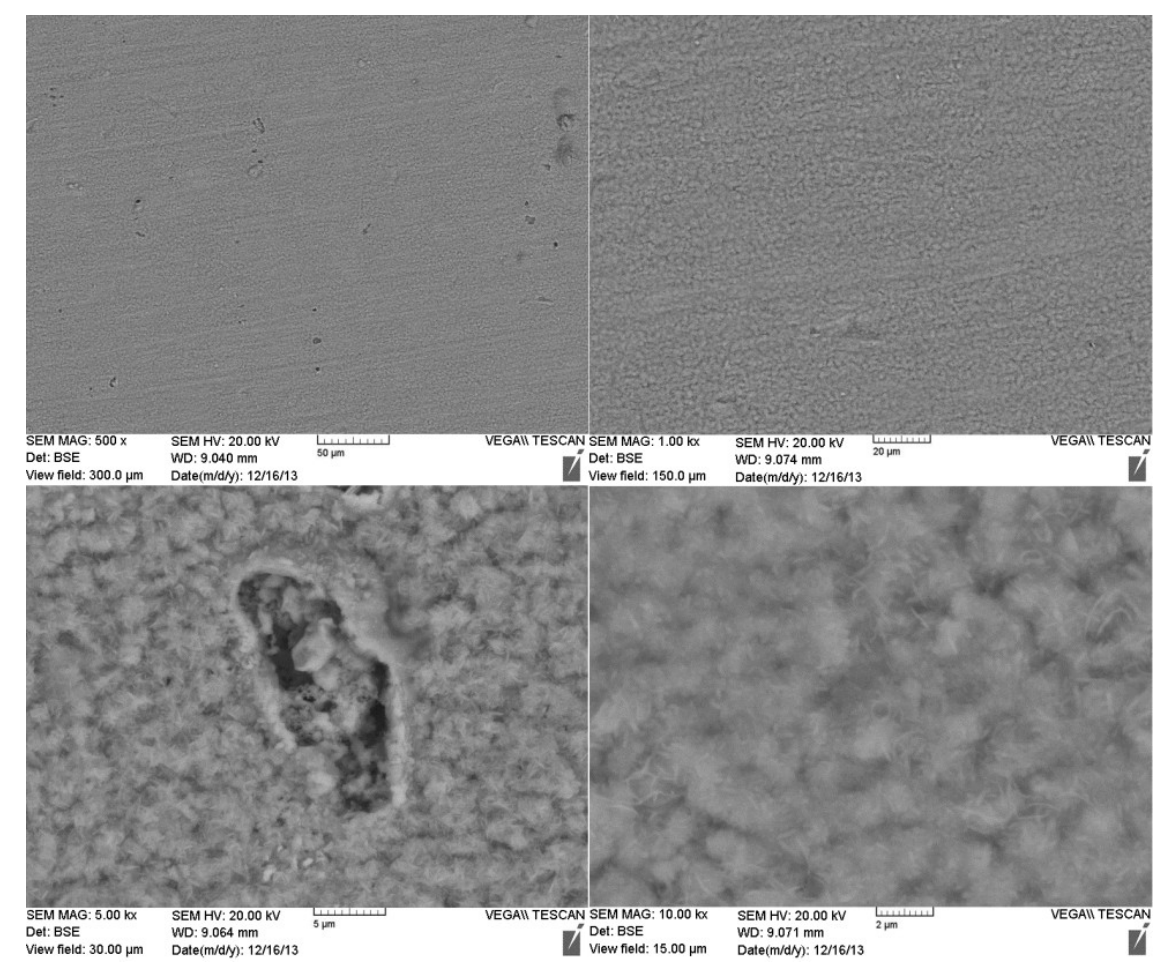

Figure 81. SEM surface images of IN 625 exposed to SubCW $\left(625^{\circ} \mathrm{C}, 8 \mathrm{MPa}\right)$ for $3000 \mathrm{~h}$.

Chemical composition results from EDS analysis are presented in Table 30. The oxide layers in all three samples have similar compositions: high concentrations of chromium and oxygen. The amounts of $\mathrm{Cr}$ and $\mathrm{O}$ increase after 1000 hours of test and then stay constant for 2000 and 3000 hours. This observation suggests that a layer of chromium-rich oxide becomes stable after 
2000 hours. EDS performed in the pitted area points to high amount of niobium, indicating the presence of $\mathrm{Nb}$ containing compound ( $\mathrm{NbC}$ or $\mathrm{NbN})$ is likely the cause for pitting occurrence.

Table 30. EDS chemical composition of IN 625 exposed to subcritical water.

\begin{tabular}{|c|c|c|c|c|c|c|c|c|c|}
\hline \multirow{2}{*}{$\begin{array}{c}\text { Exposure } \\
\text { time (hours) }\end{array}$} & \multicolumn{8}{|c|}{ Chemical composition by element (weight percent) } \\
\cline { 2 - 11 } & $\mathrm{Fe}$ & $\mathrm{Cr}$ & $\mathrm{Ni}$ & $\mathrm{O}$ & $\mathrm{Nb}$ & $\mathrm{Si}$ & $\mathrm{Al}$ & $\mathrm{Mo}$ & $\mathrm{Ti}$ \\
\hline 1000 oxide & 4.08 & 27.39 & 43.11 & 13.47 & 3.71 & 0.80 & 0.72 & 6.20 & 0.52 \\
\hline 1000 pit & 1.18 & 3.80 & 31.92 & 21.37 & 41.07 & 0.00 & 0.00 & 0.00 & 0.66 \\
\hline 2000 oxide & 3.36 & 37.63 & 31.68 & 16.67 & 4.20 & 1.04 & 0.80 & 4.18 & 0.44 \\
\hline 2000 pit & 1.51 & 4.43 & 20.81 & 30.53 & 41.59 & 0.00 & 0.00 & 0.00 & 1.12 \\
\hline 3000 oxide & 3.43 & 37.10 & 29.26 & 19.25 & 4.61 & 0.93 & 0.90 & 4.07 & 0.45 \\
\hline 3000 pit & 7.34 & 27.35 & 28.08 & 28.36 & $6.11^{*}$ & 0.95 & 1.28 & 0.00 & 0.53 \\
\hline
\end{tabular}

* Nb-containing compound mat have fallen out of the pit during test.

\section{Superheated Steam Samples}

The following SEM images (Figure 82, Figure 83 and Figure 84) illustrate the surface morphology of IN 625 samples exposed to superheated steam at $625^{\circ} \mathrm{C}$ and $0.1 \mathrm{MPa}$ for periods of 350, 700 and 1000 hours. Figure 82 shows small islands of oxide formation on the surface. Other than that, the material has a similar appearance to the initial untested condition. After 700 hours, SEM images (Figure 83) show a small increment of scale density on the surface, but the general appearance is very similar to the previous sample. 

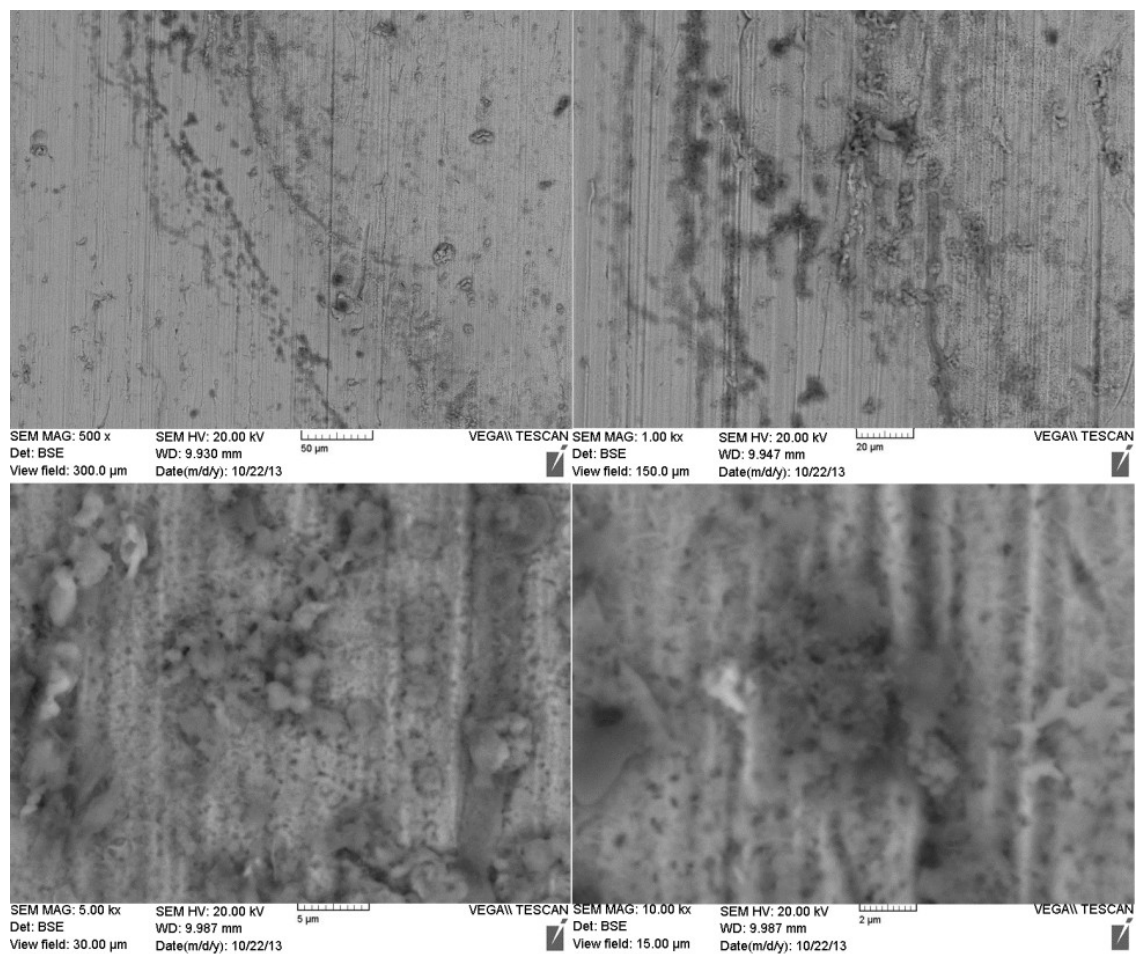

Figure 82. SEM surface images of IN 625 exposed to superheated steam $\left(625^{\circ} \mathrm{C}, 0.1 \mathrm{MPa}\right)$ for $350 \mathrm{~h}$.

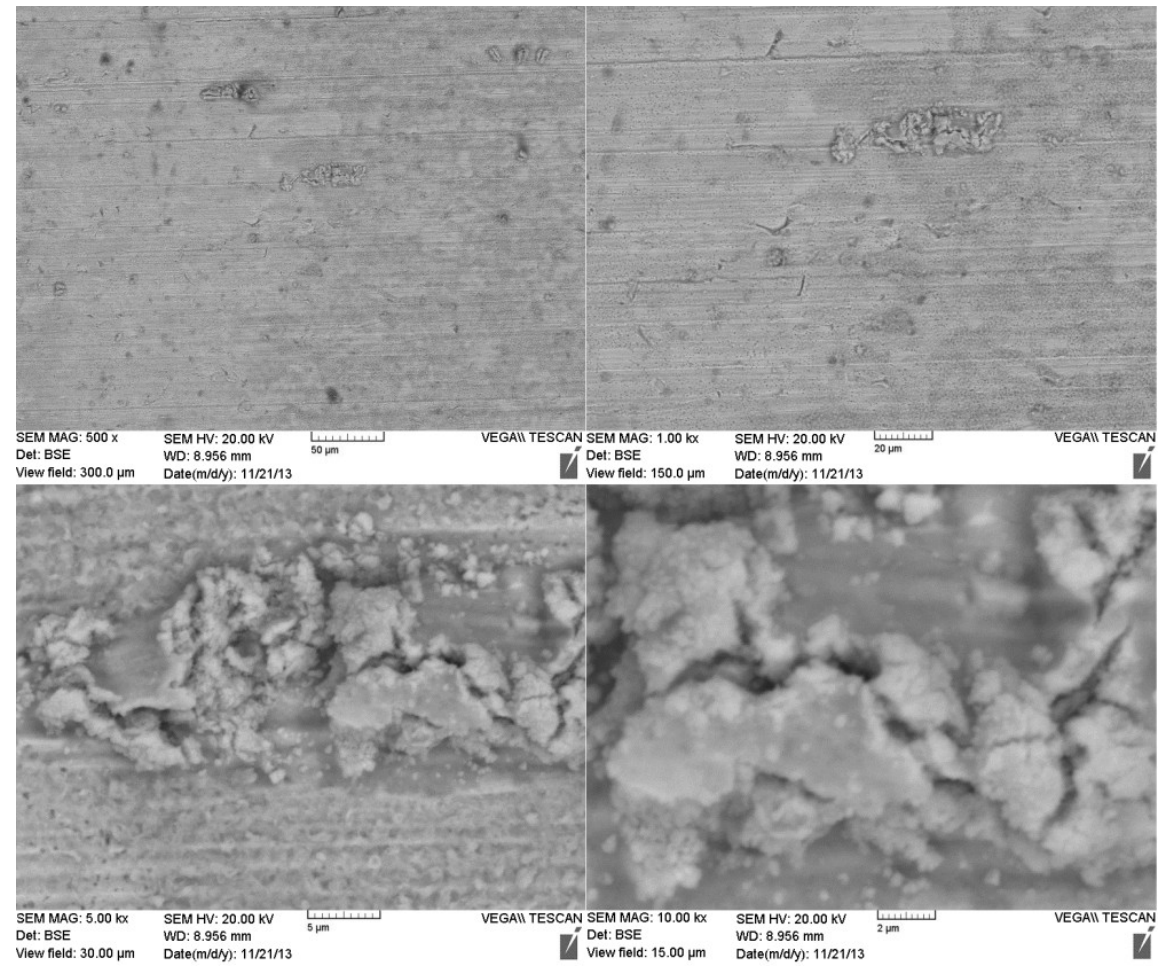

Figure 83. SEM surface images of IN 625 exposed to superheated steam $\left(625^{\circ} \mathrm{C}, 0.1 \mathrm{MPa}\right)$ for $700 \mathrm{~h}$. 
Figure 84 shows that after 1000 hours of test the sample remains almost the same; the surface is still dominated by the appearance of grinding lines. The morphology of the small oxide particles in all three samples is similar. The similar surface condition of all three samples is in accordance with the weight gain results, where a really small change in weight was seen with time.
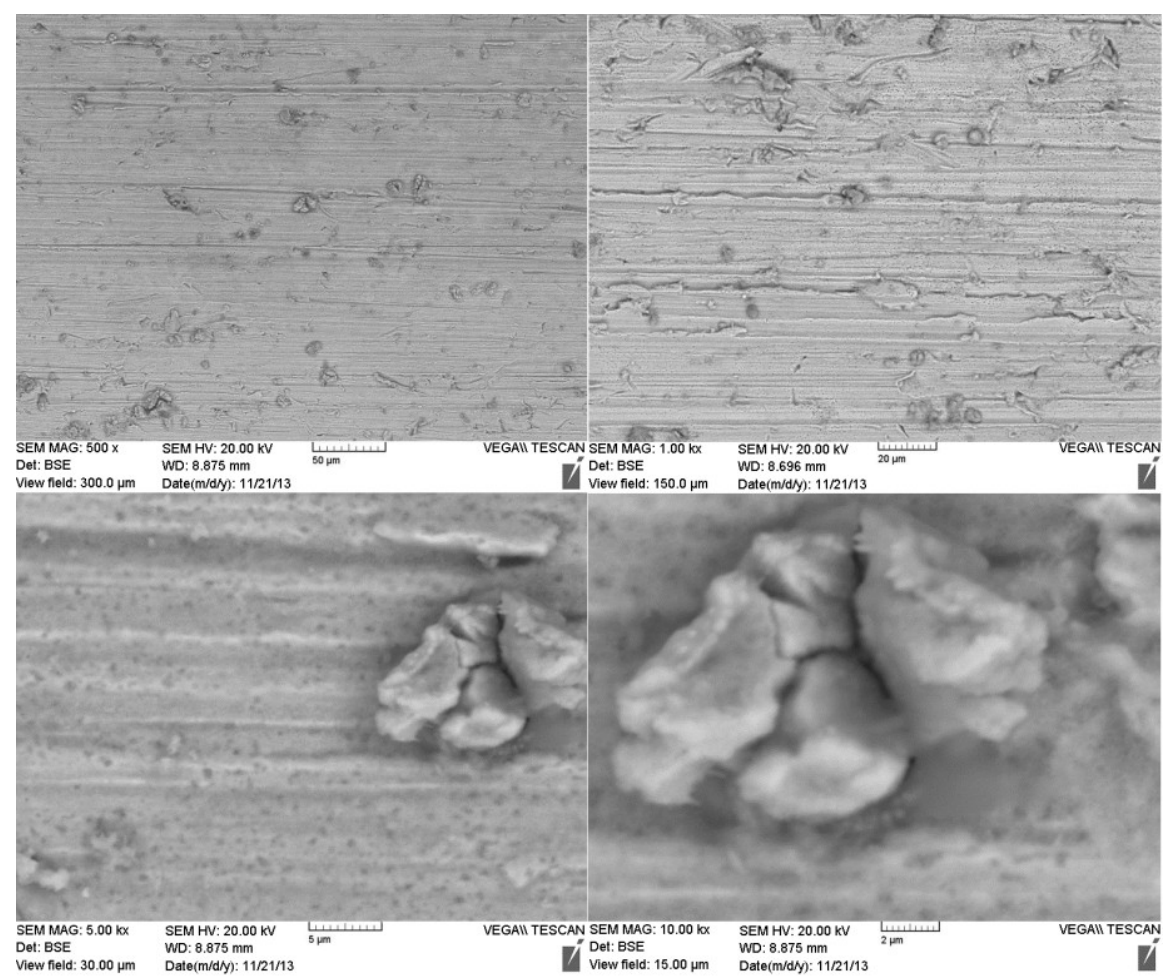

Figure 84. SEM surface images of IN 625 exposed to superheated steam $\left(625^{\circ} \mathrm{C}, 0.1 \mathrm{MPa}\right)$ for $1000 \mathrm{~h}$.

The EDS analysis results in Table 31 illustrate small increments of oxygen and chromium presence in the surface with time, this suggests that small amounts of oxide remain in the material's surface after exposure. 
Table 31. EDS chemical composition of IN 625 exposed to superheated steam.

\begin{tabular}{|c|c|c|c|c|c|c|c|c|c|c|c|}
\hline \multirow{2}{*}{$\begin{array}{c}\text { Exposure } \\
\text { time (hours) }\end{array}$} & \multicolumn{10}{|c|}{ Chemical composition by element (weight percent) } \\
\cline { 2 - 13 } & $\mathrm{Fe}$ & $\mathrm{Cr}$ & $\mathrm{Ni}$ & $\mathrm{O}$ & $\mathrm{Nb}$ & $\mathrm{Si}$ & $\mathrm{Al}$ & $\mathrm{Mo}$ & $\mathrm{Ti}$ & $\mathrm{Co}$ & $\mathrm{Mn}$ \\
\hline 350 & 4.51 & 21.51 & 60.78 & 1.40 & 3.85 & 0.48 & 0.47 & 6.35 & 0.17 & 0.22 & 0.26 \\
\hline 700 & 4.11 & 23.94 & 53.71 & 2.75 & 4.09 & 1.42 & 0.54 & 9.09 & 0.00 & 0.00 & 0.35 \\
\hline 1000 & 3.71 & 24.08 & 48.51 & 8.82 & 3.83 & 1.80 & 0.48 & 8.13 & 0.22 & 0.00 & 0.42 \\
\hline
\end{tabular}

\subsection{Effects of Test Duration}

The effects on material's oxidation/corrosion behaviour caused by the duration of the tests are analyzed in this study for up to 3000 hours. AISI 304 samples showed an increased corrosion (more oxide formation on the surface) with time in the supercritical water tests; this is also confirmed by the results of the weight gain analysis. Subcritical water tested samples showed higher oxidation rates and the oxide formed $\left(\mathrm{Fe}_{2} \mathrm{O}_{3}\right)$ had a much higher density in the surface, and the appearance of chromium oxide after longer duration was also noticed. There is suspected scale dissolution or spallation under subcritical condition as weight loss was observed between 1000 and 2000 hour tests.

Samples of A-286 showed significant changes, in terms of weight gain and surface scale formation, with time in both tests. There is an increase in the extend of the oxide surface coverage with time; this is visible in samples tested under the supercritical condition but not so for the subcritical water tested ones as the sample surfaces are completely covered by oxidation from the beginning. The weight gain analysis supports this conclusion. The iron oxide layer found on A 286 and AISI 304 is not as protective as the chromium oxide layer detected on AISI 310 and IN 625, as such it fails to protect the integrity of the base material with exposure 
time and allows more oxygen to reach the substrate. The composition of iron oxide layer changes with time until chromium oxide is found on the surface after 3000 hours.

AISI 310 did not suffer much change with exposure time in SCW and SubCW conditions; in both cases a stable chromium oxide $\left(\mathrm{Cr}_{2} \mathrm{O}_{3}\right)$ layer was formed that covered the entire surfaces. The main changes observed in the subcritical samples were the presence of smaller oxide particles after 2000 and 3000 hours of test, exposure times where weight loss was also detected.

IN 625 had the less weight change among all the samples tested. A stable layer of chromium oxide and possibly some nickel oxide were present on the surface, providing oxidation protection. However, indications of cracking and pitting were found on samples tested under the subcritical condition.

\subsection{Effects of Test Condition/Pressure}

To compare the effects of the three different test conditions, samples exposed to the same amount of time have to be analyzed. For this comparison, samples from the 1000 hours tests will be analyzed base on SEM and EDS results. The effects of the test conditions on weight gain and visual appearance were described in Sections 5.1 and 5.2.

When comparing the results for all 1000 hours samples of AISI 304, it can be noticed that the subcritical water seems to be the harshest condition for this material. The amount of iron oxide present on the surface of samples tested in subcritical water is higher than the other two; the minimum oxidation is observed during the superheated steam test. In the oxidized areas, the maximum oxygen amount was found on the superheated steam tested sample and the maximum amount of iron on the sample tested under subcritical condition. 
Similarly, sample tested in subcritical water had the highest amount of oxide formation, among all the AISI 310 samples tested for 1000 hours. The percentage of oxygen measured in the oxidized regions is lower on the steam tested sample and reaches maximum on sample tested in subcritical water. All samples are shown to develop a stable chromium oxide layer that protects the base material from further oxidation. The subcritical water condition is again the worst condition for AISI 310 with regard to its corrosion performance.

The largest deviations between tests are observed in the A-286 samples. The subcritical test condition is where the sample had the poorest performance. As presented in the results section, the most iron oxide was found on the surface of the sample tested under subcritical condition; a lower density of oxide formation was observed on the other two samples. Due to the continuous fresh water supply, the oxygen content was highest on samples tested under the superheated steam condition. The oxide morphology is quite similar among the SCW and SubCW tested samples but different for the steam tested samples.

For IN 625 samples, there was not much difference in surface oxide formation between the tests. IN 625 performs in a similar way under all conditions, except having a lower oxidized area on the superheated steam tested sample. Again the worst condition for this material is the subcritical one where the presence of pitting corrosion is most noticeable. The presence of chromium and nickel oxides impacted a stable protective layer preventing the samples from excessive oxidation/corrosion.

Of all conditions, samples tested in the superheated steam seem to have higher material loss; this is likely due to a higher dissolution and/or spallation of the surface oxide than that on 
samples tested in the other two conditions. This observation is consistent with a research performed by Ruther and Greenberg [43], who found material loss was up to $50 \%$ higher in dynamic tests (SHS) than that in static tests (SCW and SubCW).

\subsection{Effects of Substrate}

The composition of the sample substrate material plays a very important role in the properties of the materials, and ultimately their performance in different types of working environment. The main difference in oxidation/corrosion behaviour observed in this study is likely due to the difference in $\mathrm{Cr}$ and $\mathrm{Ni}$ content.

During the supercritical water test the performance of A-286 and AISI 304 was poorer than that of AISI 310 and IN 625. This is possibly due to the different chromium content in these materials. AISI 304 has 10.5 wt\% of $\mathrm{Cr}$ and A-286 has 16 wt\% of Cr, while AISI 310 and IN 625 have 26 wt\% and 23 wt\% of $\mathrm{Cr}$, respectively. Higher Ni content was beneficial for IN 625 ( $\approx 60$ wt\%) and AISI 310 (22 wt\%) but not for A-286 (27 wt\%), clearly indicating the importance of having critical amount of $\mathrm{Cr}$ in the alloy. This is in agreement with the results obtained by Tavast [36], in which an increased concentration of $\mathrm{Cr}$ provided more corrosion resistance. The high percentage of Fe (and low \% of $\mathrm{Cr}$ ) in A-286 and AISI 304 contributed to the formation of a large amount of iron oxide, which is not as protective as the chromium oxide formed in AISI 310 and IN 625 .

In subcritical water test the effects of the composition on the corrosion performance of various alloys are similar to that in the SCW test. Some differences are observed among the samples; however, A-286 exhibited a significantly larger amount of iron oxide on its surface than the 
others. The lower $\mathrm{Cr}$ content could be the reason for the higher oxidation/corrosion and weight change observed in AISI 304 and A-286. The high chromium content in IN 625 and AISI 310 helped in the formation of the stable and protective chromium oxide layer.

In superheated steam test the corrosion behaviour was different in each material. According to the weight gain analysis all samples had a consistent increase in weight, except for AISI 310 which had a weight lost in the last test 1000 hours of test. The effect of flowing steam may have played a role in causing weight loss. Samples with less $\mathrm{Cr}$ content (AISI 304 and A-286) showed a larger change in weight gain and greater presence of oxide. 


\section{Chapter 6. Conclusions}

AISI 304 shows poor corrosion performance in both supercritical and subcritical water due to its low chromium content and Fe based substrate. The corrosion resistance of AISI 304 in superheated steam is better than the ones obtained in supercritical and subcritical water. It loses some of oxide layer during steam exposure, causing weight loss after 700 hours. Overall, this material is not a good candidate to be used in supercritical water cooled reactors due to its high weight gain in supercritical and subcritical water and excessive iron oxide formation on the surface.

AISI 310 performs very well in all tests due to its high chromium content. It shows a good corrosion resistance in both supercritical and subcritical water, enabled by the stable chromium oxide layer formed on the surface. In superheated steam part of the stable oxide layer is lost during test (the mechanism is being analyzed at the moment).

Similar to AISI 304, A-286 also has a very poor performance in the supercritical and subcritical water. For this material the differences between supercritical and subcritical tests are more pronounced than in other materials. In subcritical water environment, the alloy has the highest weight gain, reaching $10 \mathrm{mg} / \mathrm{cm}^{2}$. During superheated steam test, A-286 also showed inferior performance than other samples. The low chromium content is the primary cause for these results. This material is not appropriate for use in supercritical water reactors because of the concerns with excessive corrosion in supercritical water.

IN 625 has a strong resistance to corrosion resistance both supercritical and subcritical water. The similar Cr content in IN 625 and AISI 310 is the reason why both have such a good 
performance in these conditions. The performance in superheated steam is different due to the loss of the protective oxide layer during test. The presence of cracks and pitting corrosion in the supercritical and subcritical water conditions may be a cause for concern and it should be evaluated further.

Based on all the tests performed so far it can be concluded that the most promising materials evaluated in this study, for use in the supercritical water cooled reactors with temperatures of $625^{\circ} \mathrm{C}$ or lower, are AISI 310 and IN 625 . AISI 310 is the most widely used alloy in the industry mainly because of its lower cost than IN 625.

Furthermore, subcritical water seems to be more corrosive than supercritical water, causing either higher weight gain (in A-286) or weight loss (AISI 304 and 310). The alloy's corrosion performance in superheated steam is different from the other two types of test due to the dynamic nature of the superheated steam test (flowing steam and higher dissolved oxygen content). This could cause spallation or dissolution of the protective oxide layer in some materials (more than the others). None of the three tests can be substituted for the other; the results obtained in each type of test are not equivalent to the other. Further test should be conducted in dynamic/flowing supercritical water loop, if possible; this will truly represent the real conditions found in the SCWR.

Future studies to be performed include a detailed analysis of the surface scale to determine its crystal structure and composition in s more accurate way employing FIBS (Focused Ion Beam) and TEM (Transmission Electron Microscopy). The determination of the thickness of the scale present on the surface will also be performed to calculate estimated scale formation per year. 
Also to be investigated is the sample weight loss after descaling in order to obtain assessment of the metal loss due to oxidation/corrosion. This process will give us a better understanding of the amount of metal being consumed per unit time due to corrosion.

Furthermore, the conditions used in the current tests do not take into consideration of the effects of water radiolysis on the corrosion and embrittlement of the materials due to radiation. Also, long term testing shall be done in the future under more simulated condition, i.e., in a SCW loop with representative fluid flow rate, water chemistry, temperature and pressure, to provide accurate lifing input for the design of Canadian SCWR. 


\section{References}

[1] H.-H. Roger, "World Energy Demand and Supply", International Atomic Energy Agency, 2012.

[2] International Energy Agency, "2012 Key World Energy Statistics", International Energy Agency, Paris, 2012.

[3] U.S. DOE Nuclear Energy Research Advisory Committee and Gen IV International Forum, “A Technology Roadmap for Generation IV Nuclear Energy Systems", December 2002.

[4] Gen IV International Forum, "GIF Symposium Proceedings 2012 Annual Report", San Diego, California, USA, 14-15 November 2012, Nuclear Energy Agency, Organisation for Economic CoOperation and Development, 2013.

[5] Gen IV International Forum, “Introduction to Generation IV Nuclear Energy Systems and The International Forum", 2008. [Online]. Available: www.gen-4.org.

[6] M. Naidin, I. Pioro, R. Duffey, S. Mokry, L. Grande, B. Villamere, L. Allison, A. RodriguezPrado, S. Mikhael and K. Chophla, "Super Critical Water-Cooled Nuclear Reactors (SCWRs) Thermodynamic Cycle Options and Thermal Aspects of Pressure-Channel Design", IAEA-CN-164$5 S 03$.

[7] M. Naidin, R. Monichan, U. Zirn, K. Gabriel, and I. Pioro, 2009. Thermodynamic Considerations for a Single-Reheat Cycle SCWR, Proc. ICONE-17, July 12-16, Brussels, Belgium, Paper \#75984, 8 pages. 
[8] CANDU Owners Group Inc., "CANDU Reactors", [Online]. Available: http://www.candu.org/candu_reactors.html\#CANDU.

[9] G.L. Brooks, "A Short History of the CANDU Nuclear Power System", Prepared for the Ontario Hydro Demand/Supply Plan Hearing, January 1993. Revision 2, 2002.

[10] Encyclopaedia Britannica, “Canada Deuterium Uranium Reactor: Schematic Diagram of a Nuclear Power Plant Using a Canada Deuterium Uranium (CANDU) Reactor", [Online]. Available: http://www.britannica.com/EBchecked/media/177378/Schematic-diagram-of-a-nuclearpower-plant-using-a-Canada.

[11] S. Le Caër, "Water Radiolysis: Influence of Oxide Surfaces on $\mathrm{H}_{2}$ Production under Ionizing Radiation", 28 February 2011, [Online]. Available: www.mdpi.com/2073-4441/3/1/235/pdf.

[12] National Research Council, "Radiochemistry in Nuclear Power Reactors", Chapter 6. Washington, DC: The National Academies Press, 1996.

[13] Hilbert Christensen, "Fundamental Aspects of Water Coolant Radiolysis", April 2006, [Online].

Available:

http://www.stralsakerhetsmyndigheten.se/Global/Publikationer/SKI_import/061108/0d904db Ob3198474ea75bcdc9b8b24a5/SKI\%20inlaga\%202006_16_web.pdf.

[14] D. M. Bartels, M. Anderson, P. Wilson, T. Allen, K. Sridharan, "Supercritical Water Radiolysis Chemistry Supercritical Water Corrosion", Executive Summary, [Online]. Available: http://nuclear.inel.gov/deliverables/docs/uwnd_scw_level_ii_sep_2006_v3.pdf. 
[15] J. Bros, A. Ballesteros, A. Lopez, "Radiation Embrittlement of Spanish Nuclear Reactor Pressure Vessels Steels", Radiation Embrittlement of Nuclear Reactor Pressure Vessels Steels; An International Review (Fourth Volume), ASMT STP 1170, Lendell E. Steele, Ed., American Society for Testing and Materials, Philadelphia, 1993, pp. 39-45.

[16] M. Kutz, "Supercritical Water Oxidation", Environmentally Conscious Materials and Chemical Processing", Chapter 13, John Wiley \& Sons, Inc., 2007.

[17] Department of Biochemistry and Molecular Biophysics, "Chemistry Tutorial- The Chemistry of Water", University of Arizona, 2003. Available. [Online]: http://www.biology.arizona.edu/biochemistry/tutorials/chemistry/page3.html.

[18] P. Kritzer, "Corrosion in High-Temperature and Supercritical Water and Aqueous Solution: A Review", Journal of Supercritical Fluids, vol. 29, pp. 1-29, 2004.

[19] P. Kritzer, N. Boukis, E. Dinjus, "Factors Controlling Corrosion In High-Temperature Aqueous Solutions: A Contribution to the Dissociation and Solubility Data Influencing Corrosion Processes", Journal of Supercritical Fluids, vol. 15, pp. 205-227, 1999.

[20] P. Kritzer, E. Dinjus, "An Assessment of Supercritical Water Oxidation (SCWO). Existing Problems, Possible Solutions and New Reactor Concepts", Chemical Engineering Journal, vol. 83, pp. 207-214, 2001.

[21] M. Chaplin, "Water Structure and Science - Water Ionization and pH", 2013. [Online]. Available: http://www1.Isbu.ac.uk/water/ionis.html. 
[22] J. F. Connolly, "Solubility of Hydrocarbons in Water Near The Critical Temperature", J. Chem. Eng. Data 11, 1966.

[23] W. F. Bogaerts, C. Bettendorf, "Electrochemistry and Corrosion of Alloys in HighTemperature Water", EPRIReport NP-4705, Electric Power Research Institute, Palo Alto, CA, 1986.

[24] W. F. Bogaerts, C. Bettendorf, "High-Temperature Electrochemistry and Corrosion", EPRIReport NP-5863, Electric Power Research Institute, Palo Alto, CA, 1988.

[25] P. E. Manning, D. J. Duquette, "The Effect of Temperature $\left(25-289^{\circ} \mathrm{C}\right)$ On Pit Initiation In Single Phase And Duplex 304L Stainless Steels In 100 ppm Cl- Solution”, Corrosion Sci. 20, pp. 597-609, 1980.

[26] G. Okamoto, "Passive Film of 18-8 Stainless Steel Structure and its Function", Corrosion Sci. 13, pp. 471-489, 1973.

[27] S. Abe, M. Kaneko, "Corrosion of Grain Boundaries in Iron-Chromium-Nickel Alloys", in: S.M. Bruemmer, E.I. Meletis, R.H. Jones, W.W. Gerberich, F.P. Ford, R.W. Staehle (Eds.), Parkins Symposium on Fundamental Aspects on Stress Corrosion Cracking, The Minerals, Metals and Materials Society, Warrendale, PA, 1992.

[28] W. D. Callister, David G. Rethwisch, "Materials Science and Engineering: An Introduction, 8th Edition", Wiley and Sons, Inc., 2009. 
[29] W. G. Cook, R. Olive, "Pourbaix Diagrams for Iron, Nickel, and Chromium in Sub-Critical and Supercritical Water", The $2^{\text {nd }}$ Canada-China Joint Workshop on Supercritical Water-Cooled Reactors, Toronto, Canada, April 25-28, 2010.

[30] H. A. Pray, C. E. Schweickert, B.H. Minnich, "Solubility of Hydrogen, Oxygen, Nitrogen, and Helium in Water at Elevated Temperatures", Ind. Eng. Chem. 44, pp. 1146-1151, 1952.

[31] P. Kritzer, N. Boukis, E. Dinjus, “Transpassive Dissolution of Alloy 625, Chromium, Nickel, and Molybdenum in High-Temperature Solutions Containing Hydrochloric Acid and Oxygen", Corrosion 56, pp. 265-272, 2000.

[32] Spirax Sparco, "Superheated Steam," 2012. [Online]. Available: http://www.spiraxsarco.com/resources/steam-engineering-tutorials/steam-engineeringprinciples-and-heat-transfer/superheated-steam.asp.

[33] A. Fry, S. Osgerby, M. Wright, "Oxidation of Alloys in Steam Environments - A Review", National Physical Laboratory Report MATC (A) 90, pp. 1-39, 2002.

[34] H. G. Simms, "Oxidation Behaviour of Austenitic Stainless Steels at High Temperature in Supercritical Plant", Master of Research Thesis, The University of Birmingham, 2011, [Online]. Available: http://etheses.bham.ac.uk/1689/1/Simms11MRes.pdf.

[35] H. L. Solberg, G. A. Hawkins and A. A. Potter. "Corrosion of Unstressed Steel Specimens by High Temperature Steam", Transactions of the American Society of Mechanical Engineers, vol. 64, pp. 303-309, 1942. 
[36] J. Tavast, "Experience of Austenitic Materials in Fossil Fuel Boilers", Stiftelsen Für Värmeteknisk Forskning, SVF-356, 1989.

[37] J. C. Griess, W. A. Maxwell. "The Long-Term Oxidation of Selected Alloys in Superheated Steam at 482 and $538^{\circ} \mathrm{C}^{\prime \prime}$. ORNL-5771, Oak Ridge National Laboratory, 1981.

[38] W. D. Callister, Jr., Materials Science and Engineering an Introduction, $7^{\text {th }}$ Edition, Chapter 11, Jon Wiley \& Sons, Inc, 2007.

[39] Y. Otoguro, M. Sakakibara, T. Saito, H. Ito and Y. Inoue, "Oxidation Behaviour of Austenitic Heat-resisting Steels in a High Temperature and High Pressure Steam Environment", Transactions ISIJ, vol. 28, pp. 761-768, 1988.

[40] G. Was, P. Ampornrat, G. Gupta, S. Teysseyre, E. West, T. Allen, K. Sridharan, L. Tan, Y. Chen, X. Ren and C. Pister, "Corrosion and Stress Corrosion Cracking in Supercritical Water," Journal of Nuclear Materials, vol. 371, p. 176-201, 2007.

[41] L. Zhang, F. Zhu, Y. Bao and R. Tang, "Corrosion Tests of Candidate Fuel Cladding and Reactor Internal Structural Materials", The 2nd Canada-China Joint Workshop on Supercritical Water-Cooled Reactors (CCSC-2010), 2010.

[42] M. Montgomery and A. Karlsson, "Survey of Oxidation in Steamside Conditions", VGB Kraftwerkstechnik, 75, pp. 235-240, 1995.

[43] W. E. Ruther and S. Greenberg, "Corrosion of Steels and Nickel Alloys in Superheated Steam," Journal of the Electrochemical Society, vol. 111, no. 10, pp. 1116-1121, 1964. 
[44] S. Cisse, L. Laffont, B. Tanguy, M.-C. Lafont and E. Andrieu, "Effect of Surface Preparation on the Corrosion of Austenitic Stainless Steel 304L in High Temperature Steam and Simulated PWR Primary Water", Corrosion Science, vol. 56, pp. 209-216, 2012.

[45] INSG Secretariat Briefing Paper, "Nickel-Based Super Alloys", INSG Insight, no. 20, April 2003.

[46] R. Fujisawa, N. Nishimura, T. Nishida, M. Sakaihara, Y. Kurata, Y. Watanabe, “Corrosion Behavior of Nickel-Based Alloys and Type 316 Stainless Steel in Slightly Oxidizing or Reducing Supercritical Water", Corrosion, vol. 62, no. 3, pp. 270-274, 2006.

[47] P. Kritzer, N. Boukis, E. Dinjus, "The Corrosion of Nickel-Base Alloy 625 in Sub- And Supercritical Aqueous Solutions of Oxygen: A Long Time Study", Journal of Material Science Letters 18, pp. 1845-1847, 1999.

[48] M. Warzee, J. Hennaut, M. Maurice, C. Sonnen, J. Waty and P. Berge, "Effect of Surface Treatment on the Corrosion of Stainless Steels in High-Temperature Water and Steam", Journal of the Electrochemical Society, vol. 112, no. 7, pp. 670-674, 1965.

[49] C. Piehl, Z. Toekei, and H. J. Grabke, "Influence of Chromium Diffusion and Different Surface Finishes on the Oxidation Behaviour of Chromium Steels", Materials at High Temperatures 17, pp. 243-246, 2000.

[50] L. Tan, X. Ren, K. Sridharan and T.R. Allen, "Effect Of Shot-Peening on the Oxidation of Alloy $800 \mathrm{H}$ Exposed to Supercritical Water and Cyclic Oxidation". Corrosion Science, vol. 50, no. 7, pp. 2040-2046, 2008. 
[51] "Stainless Steel - Grade 304", AZoM.com, 12 July 2013. [Online]. Available: http://www.azom.com/article.aspx?ArticlelD=965.

[52] "Stainless Steel - Grade 310", AZoM.com, 12 July 2013. [Online]. Available: http://www.azom.com/article.aspx?ArticlelD=966.

[53] “A-286 High Strength Iron-Based Superalloy - Properties, Composition, Heat Treatments and Specifications from Super Alloys", AZoM.com, 11 June 2013. [Online]. Available: http://www.azom.com/article.aspx?ArticlelD=4221\#_Typical_Mechanical_Properties.

[54] "Alloy 625 - Inconel 625 Properties and Applications", AZoM.com, 11 June 2013. [Online]. Available: http://www.azom.com/article.aspx?ArticlelD=5738. 


\section{Appendices}

Appendix A. Supercritical Water Samples Weight Change.

\begin{tabular}{|c|c|c|c|c|c|c|}
\hline Material & $\begin{array}{l}\text { Exposure } \\
\text { Time }\end{array}$ & $\begin{array}{c}\text { Initial } \\
\text { weight (g) }\end{array}$ & $\begin{array}{c}\text { Final } \\
\text { weight (g) }\end{array}$ & $\begin{array}{l}\text { Weight } \\
\text { gain (mg) }\end{array}$ & $\begin{array}{c}\text { Surface } \\
\text { Area }\left(\mathrm{cm}^{2}\right)\end{array}$ & $\begin{array}{c}\text { Weight } \\
\text { gain } \\
\left(\mathrm{mg} / \mathrm{cm}^{2}\right)\end{array}$ \\
\hline \multirow[t]{3}{*}{ AISI 304} & 1000 & 2.52760 & 2.56159 & 33.983 & 6.982 & 4.868 \\
\hline & 2000 & 2.47202 & 2.51368 & 41.660 & 6.612 & 6.301 \\
\hline & 3000 & 1.94681 & 1.99622 & 49.417 & 7.090 & 6.970 \\
\hline \multirow[t]{3}{*}{ AISI 310} & 1000 & 4.15933 & 4.15941 & 0.083 & 4.245 & 0.020 \\
\hline & 2000 & 3.90731 & 3.90800 & 0.697 & 4.022 & 0.173 \\
\hline & 3000 & 4.20651 & 4.20702 & 0.517 & 4.176 & 0.124 \\
\hline \multirow[t]{3}{*}{ A-286 } & 1000 & 2.68612 & 2.69427 & 8.153 & 7.886 & 1.034 \\
\hline & 2000 & 3.65258 & 3.67279 & 20.207 & 7.636 & 2.646 \\
\hline & 3000 & 3.16183 & 3.19667 & 34.840 & 7.600 & 4.584 \\
\hline \multirow[t]{3}{*}{ IN 625} & 1000 & 3.57920 & 3.57989 & 0.690 & 7.669 & 0.090 \\
\hline & 2000 & 3.77926 & 3.78118 & 1.920 & 7.828 & 0.245 \\
\hline & 3000 & 3.89910 & 3.90018 & 1.077 & 7.568 & 0.142 \\
\hline
\end{tabular}


Appendix B. Subcritical Water Samples Weight Change.

\begin{tabular}{|c|c|c|c|c|c|c|}
\hline Material & $\begin{array}{l}\text { Exposure } \\
\text { Time }\end{array}$ & $\begin{array}{c}\text { Initial } \\
\text { weight (g) }\end{array}$ & $\begin{array}{c}\text { Final } \\
\text { weight (g) }\end{array}$ & $\begin{array}{c}\text { Weight } \\
\text { gain }(\mathrm{mg})\end{array}$ & $\begin{array}{c}\text { Surface } \\
\text { Area }\left(\mathrm{cm}^{2}\right)\end{array}$ & $\begin{array}{c}\text { Weight } \\
\text { gain } \\
\left(\mathrm{mg} / \mathrm{cm}^{2}\right)\end{array}$ \\
\hline \multirow[t]{3}{*}{ AISI 304} & 1000 & 2.36408 & 2.41006 & 45.973 & 7.260 & 6.332 \\
\hline & 2000 & 2.44407 & 2.48587 & 41.800 & 7.285 & 5.738 \\
\hline & 3000 & 2.26007 & 2.31069 & 50.627 & 7.285 & 6.950 \\
\hline \multirow[t]{3}{*}{ AISI 310} & 1000 & 3.51671 & 3.51929 & 2.577 & 3.859 & 0.668 \\
\hline & 2000 & 4.14323 & 4.14236 & -0.863 & 4.200 & -0.206 \\
\hline & 3000 & 4.35642 & 4.35538 & -1.040 & 4.334 & -0.240 \\
\hline \multirow[t]{3}{*}{ A-286 } & 1000 & 3.49514 & 3.55457 & 59.427 & 8.085 & 7.350 \\
\hline & 2000 & 3.37530 & 3.43605 & 60.753 & 8.111 & 7.490 \\
\hline & 3000 & 3.32866 & 3.41058 & 81.920 & 8.062 & 10.161 \\
\hline \multirow[t]{3}{*}{ IN 625} & 1000 & 3.84834 & 3.84743 & -0.913 & 7.642 & -0.120 \\
\hline & 2000 & 3.80577 & 3.80592 & 0.153 & 7.702 & 0.020 \\
\hline & 3000 & 3.77937 & 3.77829 & -1.087 & 7.579 & -0.143 \\
\hline
\end{tabular}


Appendix C. Superheated Steam Samples Weight Change.

\begin{tabular}{|c|c|c|c|c|c|c|}
\hline Material & $\begin{array}{l}\text { Exposure } \\
\text { Time }\end{array}$ & $\begin{array}{l}\text { Initial weight } \\
\text { (g) }\end{array}$ & $\begin{array}{c}\text { Final weight } \\
\text { (g) }\end{array}$ & $\begin{array}{l}\text { Weight } \\
\text { gain (mg) }\end{array}$ & $\begin{array}{c}\text { Surface } \\
\text { Area } \\
\left(\mathrm{cm}^{2}\right)\end{array}$ & $\begin{array}{c}\text { Weight } \\
\text { gain } \\
\left(\mathrm{mg} / \mathrm{cm}^{2}\right)\end{array}$ \\
\hline \multirow[t]{3}{*}{ AISI 304} & 350 & 2.52187 & 2.52195 & 0.083 & 7.261 & 0.011 \\
\hline & 700 & 2.33716 & 2.33726 & 0.100 & 6.807 & 0.015 \\
\hline & 1000 & 2.27988 & 2.28039 & 0.507 & 7.608 & 0.067 \\
\hline \multirow[t]{3}{*}{ AISI 310} & 350 & 4.30510 & 4.30521 & 0.113 & 4.272 & 0.027 \\
\hline & 700 & 4.37650 & 4.37675 & 0.247 & 4.240 & 0.058 \\
\hline & 1000 & 3.88659 & 3.88679 & 0.207 & 4.228 & 0.049 \\
\hline \multirow[t]{3}{*}{ A-286 } & 350 & 3.40896 & 3.40911 & 0.150 & 7.972 & 0.019 \\
\hline & 700 & 3.38815 & 3.38829 & 0.140 & 7.749 & 0.018 \\
\hline & 1000 & 3.40858 & 3.40902 & 0.447 & 8.191 & 0.055 \\
\hline \multirow[t]{3}{*}{ IN 625} & 350 & 3.91194 & 3.91203 & 0.093 & 7.573 & 0.012 \\
\hline & 700 & 3.79488 & 3.79510 & 0.227 & 7.956 & 0.028 \\
\hline & 1000 & 3.81655 & 3.81681 & 0.260 & 8.021 & 0.032 \\
\hline
\end{tabular}

